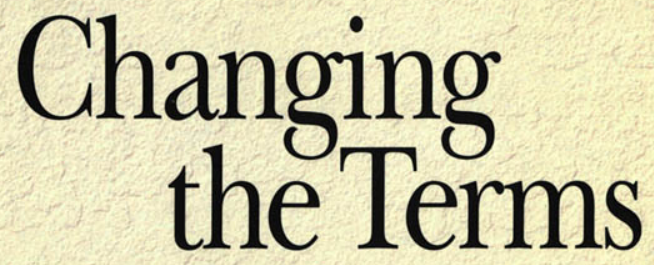

Translating in the Postcolonial Era

Edited by

Sherry Simon and Paul St-Pierre

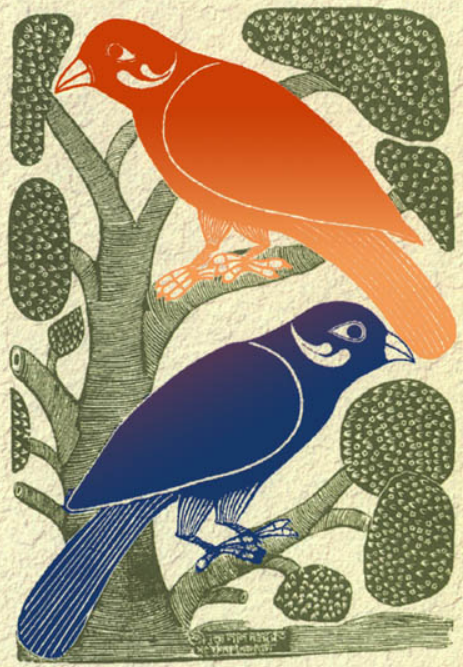




\section{Changing the Terms}

Translating in the Postcolonial Era 
This page intentionally left blank 


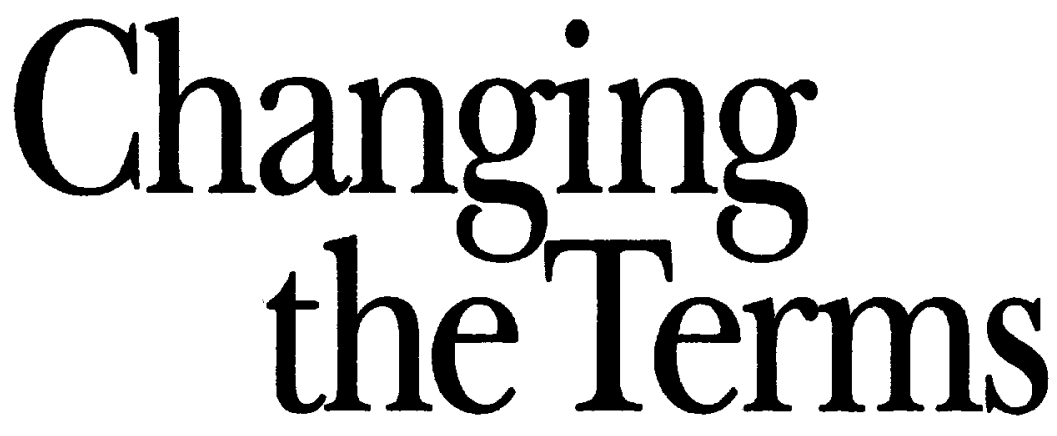

Translating in the Postcolonial Era

Edited by

Sherry Simon and Paul St-Pierre 
University of Ottawa Press gratefully acknowledges the support extended to its publishing programme by the Canada Council and the University of Ottawa.

We acknowledge the financial support of the Government of Canada through the Book Publishing Industry Development Program (BPIDP) for our publishing activities.

\section{Canadian Cataloguing in Publication Data}

Main entry under title:

Changing the terms: translating in the postcolonial era

(Perspectives on translation)

Includes bibliographical references.

ISBN 0-7766-0524-0

1. Translating and Interpreting-Social aspects. 2. Literature and society. 3. Language and culture. 4. Acculturation. 5. Postcolonialism. I. Simon, Sherry II. St-Pierre, Paul III. Series

\section{UNIVERSITY OF OTTAWA \\ UNIVERSITÉ D'OTTAWA}

Cover design: Robert Dolbec

Cover illustration: Two mynahs sitting on the branch of a tree. Woodcut done by Shri Nrityala Datta of Garanhata, Calcutta. From: Woodcut Prints of Nineteenth Century Calcutta, edited by Ashit Paul (Calcutta: Seagull Books, 1983).

\section{ISBN 0-7766-0524-0}

ISSN 1487-6396

(C) University of Ottawa Press, 2000

542 King Edward, Ottawa, Ont., Canada K1N 6 N5

press@uottawa.ca http://www.uopress.uottawa.ca

Printed and bound in Canada 


\section{ACKNOWLEDGMENTS}

The editors would like to acknowledge the contributions of the Fonds pour la formation de chercheurs et l'aide a la recherche in Quebec, of the Social Science and Humanities Research Council, and of the Dean of Arts and Science, Concordia University. We would like to warmly thank Joanne Akai for her help in preparing the manuscript and Jean Delisle for his generous and efficient support. 
This page intentionally left blank 


\section{TABLE OF CONTENTS}

\section{INTRODUCTION}

Sherry Simon, Concordia University (Canada)

\section{PART I}

(POST)COLONIALISM AND THE POWERS OF TRANSLATION

\section{ChAPTER 1}

History, Translation, Postcolonialism

Michael CronIN, Dublin City University (Ireland)

ChAPTER 2

"Colonization," Resistance and the Uses of Postcolonial Translation

Theory in Twentieth-Century China

Leo TAK-HUNG ChaN, Lingnan College (Hong Kong)

ChAPTER 3

The Power of Translation: A Survey of Translation in Orissa

Diptiranjan PatTanaik, Utkal University (India)

Chapter 4

Cultural Transmission Through Translation: An Indian Perspective

Shantha RAMAKRISHNA, Jawaharlal Nehru

University (India)

CHAPTER 5

Legitimacy, Marronnage and the Power of Translation

Jean-Marc GouAnvic, Concordia University (Canada)

ChAPTER 6

Balai Pustaka in the Dutch East Indies: Colonizing a Literature

Elizabeth B. FITZPATRICK, University of Massachusetts, Amherst (USA). 


\section{ChAPTER 7}

The Third Space in Postcolonial Representation

Michaela WoLf, Universität Graz (Austria)

CHAPTER 8

Translations of Themselves: The Contours of Postcolonial Fiction

Maria TYмосzKo, University of Massachusetts,

Amherst (USA)

\section{Part II}

\section{SCENES OF NEGOTIATION}

CHAPTER 9

A Gesture to Indicate a Presence: Translation, Dialect and Field Day

Theatre Company's Quest for an Irish Identity

Maria-Elena DoyLE, West Georgia State

University (USA) .

ChAPTER 10

The Impact of Spanish-American Literature in Translation on

U.S. Latino Literature

Juliana DE ZAVALIA, University of Massachusetts,

Amherst (USA)

Chapter 11

From Other Tongue to Mother Tongue in the Drama of Quebec

and Canada

Louise LADOUCEUR, University of Alberta, Faculté St-Jean

(Canada)

CHAPTER 12

The Changing Face of Translation of Indian Literature

Anita MANNUR, University of Massachusetts,

Amherst (USA)

Chapter 13

Gateway of India: Representing the Nation in English Translation

N. KAMALA, Jawaharlal Nehru University (India)

ChAPTER 14

Translating (into) the Language of the Colonizer

Paul St-Pierre, Université de Montréal (Canada)

ChAPTER 15

The Post-Missionary Condition: Toward Perceptual Reciprocity

Probal DASGUPTA, University of Hyderabad (India) 


\title{
INTRODUCTION
}

\author{
Sherry Simon \\ Concordia University (Canada)
}

When the novelist Amitav Ghosh gave a lecture in Montreal a few years ago, he began by describing, as writers often do, the early influences on his writing career. In the course of his talk, he conjured up two very different images of the cultural impact of translation, images that will serve as useful reference points for the issues in this book.

Ghosh spoke first about his grandfather's library, recalling the look and smell of the books lined up on the shelf, and remembering their titles and origins. These books were almost all translations into Bengali, he noted. They were works by European authors, many of whom had been Nobel Prize winners. It was a collection of books which could be found, he supposed, in much the same form in all the corners of the Empire, either in English or, as here, translated into local languages. These translations represented, for him and for his grandfather, entrance into the world of European letters. They also imposed a certain canon of recognized works into a foreign setting, satisfying a certain display function, identifying middleclass tastes in genteel settings. They made up a somewhat artificial and heterogeneous export culture, which arrived in alien climes as a ready-made unit, detached from its separate contexts of origin, signifying the power of European print culture as the horizon of colonialism.

Later in his talk, Ghosh referred to another kind of translation. He spoke of the powerful tradition of Indian storytelling, and I quote here from similar remarks he made in the introduction to an anthology of Indian stories: 
It has been said, with good reason, that nothing that India has given the world outside is more important that its stories. Indeed, so pervasive is the influence of the Indian story that one particular collection, The Panchatantra (The Five Chapters) is reckoned by some to be second only to the Bible in the extent of its global diffusion. Compiled early in the first millennium, The Panchatantra passed into Arabic through a sixth century Persian translation, engendering some of the best known of middle eastern fables, including parts of The Thousand and One Nights. The stories were handed on to the Slavic languages through Greek, from Hebrew to Latin (1270), and thence to German and Italian. From the Italian version came the famous Elizabethan rendition of Sir Henry North, The Morall Philosophy of Doni (1570). These stories left their mark on collections as different as those of La Fontaine and the brothers Grimm, and today they are inseparably part of a global heritage of folklore. $(1994,35)$

Ghosh also referred to the tradition of rewriting, which is so central to the diffusion of the Puranas, the Ramayana and the Mahabharatha within the Indian cultures and abroad.

The two images of translation which Ghosh evokes conjure up two very different understandings of cultural diffusion. The first kind comes from outside Indian culture, involves written texts and serves the imperialist, Orientalizing cause. The second kind emanates from within India, is essentially oral, involves a much looser notion of the text, interacts intensely with local forms of narrative and is a revigorating and positive global influence. The first kind of translation, from Ghosh's point of view, results in a static and potentially oppressive array of cultural goods; the second is a continuous life-giving and creative process.

These two examples can perhaps help us to understand the kinds of questions we are asking in this volume. What are the roles that translations play within the colonial and postcolonial contexts? Do they serve only to impose an alien and oppressive presence on a foreign culture, or are they part of a process of exchange which involves an active chain of response, a vivifying interaction?

Translations during the colonial period, we know, were an expression of the cultural power of the colonizer. Missionaries, anthropologists, learned Orientalists chose to translate the texts which corresponded to the image of the subjugated world which they wished to construct. Translations materialized modes of interpretation whose terms were rarely questioned. The title of the volume in honour of the celebrated British social anthropologist Evans-Pritchard, Translating Culture (1962), comes to represent a 
whole range of interpretive activities whose final meaning rested exclusively within the colonizers' language. Colonized cultures were texts whose vast spaces were contained within the hermeneutic frames of Western knowledge. "Translation" refers not only to the transfer of specific texts into European languages, but to all the practices whose aim was to compact and reduce an alien reality into the terms imposed by a triumphant Western culture.

Translation was part of the violence, then, through which the colonial subject was constructed. But this version of events does not tell the whole story of the processes through which the culture of the colonized and of the colonizers came to interact. As Robert Young reminds us, the vocabulary which has been available to describe cultural contact has been drastically limited.

It is only recently that cultural critics have begun to develop accounts of the commerce between cultures that map and shadow the complexities of its generative and destructive processes. Historically, however, comparatively little attention has been given to the mechanics of the intricate processes of cultural contact, intrusion, fusion and disjunction. $(1995,5)$

Young points to language itself as providing the most revealing traces of cultural contact. Hybrid languages, like pidgins and creoles, show patterns of interpenetration and overlay which reflect the actual processes of contact.

Pidgin and creolized languages constitute powerful models because they preserve the real historical forms of cultural contact. The structure of pidgin - crudely, the vocabulary of one language superimposed on the grammar of another-suggests a different model from that of a straightforward power relation of dominance of colonizer over colonized. (5)

It is surprising that Young does not look to translation as a site for investigating intercultural contact. Even more than pidgin languages, which came to exist in only a limited number of settings, translations would seem to be the terrain Young is looking for, the impressionable surface which preserves the intricate tracings of contact. Translations materialize exactly the sort of overlay which Young sees as operating in pidgin, preserving the "real historical forms" of cultural contact. They report on areas of interchange between colonizer and colonized; they also reveal the nature of the interaction.

It is the aim of this volume to engage precisely in the kind of work which Young was pointing to: the detailed work of revealing "the intricate 
processes of cultural contact, intrusion, fusion and disjunction." The series of studies presented here, analyzing specific translating situations, provides a rigorous basis upon which we can more fully understand the dynamics of postcolonial transactions. Our aim in preparing this collection was to emphasize critical work which studied relations between individual translation projects and the institutional pressures promoting or hindering them. All of the articles are framed by an understanding of postcolonial cultural dynamics, and use the specific situations of language exchange to test out categories of analysis and comparison.

The strength of these articles speaks well of the current moment of research in translation studies, and the very fertile links which are being created between literary and cultural theory. The internationalization of networks of translation studies has led to new conversations among scholars from a wide variety of countries. This sudden diversification and true globalization of the field is exciting. But it leads to the obvious need for careful explication of specific contexts, for thorough understanding of the historical situations which have given rise to present-day cultural dynamics. It also implies that theory itself must be understood as being positioned, both ideologically and culturally. This does not mean that any specific researcher is obliged to speak "for" or "out of" the circumstances of geography or history, but that we must recognize that entire discourses are shaped by the contexts from which they emerge, and that our use of them is influenced by this history. Transnational culture studies has tended to operate entirely in English, at the expense of a concern for the diversity of languages in the world. The focus on translation within the global context is necessary to draw attention to language issues in cultural exchange.

The studies in this volume cover a wide variety of geographical and linguistic contexts, but all use translation as a lens through which to define and assess the dynamics of postcolonialism. India seems to be a particularly welcome site for such studies but investigations into the cultural histories of Ireland, China, Canada, the United States and Latin America are equally suggestive in questioning the terms of cultural exchange. What unites this work is attention to unequal power relations and the voices of marginality within literary commerce.

\section{II}

It is not surprising that much of the work on power and ideology in translation has come out of postcolonial contexts, like India, Canada, Ireland or Brazil, and has been sustained by theoretical currents like feminism and poststructuralism. Translators, as cultural and economic intermediaries, are often members of marginalized groups. Historically, they occupy socially 
fragile positions, on the fringes of power. When they are, in addition, members of colonial or neocolonial societies, their work is saturated with the knowledge which comes from daily exposure to the conflictual aspects of language exchange. They are attentive to the fact that cultural traffic does not circulate freely about the globe, that its flow is regulated by the existence and condition of trade routes, the availability of willing vehicles and the needs and pleasures which cultural commerce caters to. In other words, they know that the circulation of translations is not to be equated with the logic of the gift but with the rules of commodity exchange (Frow 1996). Postcolonial contexts heighten awareness that translations are solicited and exchanged according to rules of trade and ownership, which are both commercial and ideological.

Nevertheless, every writer using the concept of "postcolonialism" today is surely aware that this term has become increasingly ambiguous and contested. A rich body of writing has grown up in an attempt to identify the confusing and misleading implications of the term for cultural and political analysis. Why continue to use the term in this anthology? Anne McClintock, in the conclusion to her forceful critique of the term, reminds us that there cannot be the imposition of any new "single term" to replace postcolonialism. There is no one term which will allow "rethinking the global situation as a multiplicity of powers and histories..." She calls for a proliferation of historically nuanced theories and strategies, which will more adequately account for the "currently calamitous dispensations of power" $(1995,302)$.

In the context of translation studies, the term "postcolonalism" remains useful in suggesting two essential ideas. The first is the global dimension of research in translation studies; the second is the necessary attention to the framework through which we understand power relations and relations of alterity.

If there is one central image which postcolonialism conjures up, it is the image of the map. To enter into the postcolonial world is to see cultural relations at a global level, to understand the complexities of the histories and power relations which operate across continents. For translation studies and literary study in general, adopting a postcolonial frame means enlarging the map which has traditionally bound literary and cultural studies. It means moving beyond the boundaries of Europe and North America, and following more expansive itineraries, moving into new territories. But this excursion into new domains of culture-India, Africa, South America, Asia-must take into account the profound scars of colonialism and its sequels, scars which have shaped not only its victims but also its perpetrators. And so "we" must understand our own place on this map. Where do 
"we" belong, where are "we" speaking from, and on the basis of what particular kinds of knowledge?

These questions bring with them a renewed consciousness of the power adhering to particular sites of research. Nevertheless, our remapping of power relationships does not have to consist of single, one-way vectors. If "postcolonial criticism bears witness to the unequal and uneven forces of cultural representation involved in the contest for political and social authority within the modern world order" (Bhabha 1992, 437), it also reveals the complexity of the workings of this authority. The overwhelming concern of postcolonial critique has been to carve out a space of reflection which avoids simplistic characterizations of power. Ania Loomba makes clear that this investigation must include both the ways in which colonial modes of thinking were introduced and the ways in which they exist today:

[T]he spread of English literature teaching cannot be explained away as the simple effectiveness of British policies; neither can its persistence in contemporary institutions be understood as a straightforward indication of Indians' continued subjection, a neocolonial conspiracy or a simple nostalgia for the West. Both kinds of inquiry - into nineteenth-century or modern Indian interaction with English literaturecannot be usefully conducted within the parameters of either a theory which insists on the starkness of the colonial encounter, or another where native recipients are entirely conditioned or devastated by the master culture. $(1995,311)$

She emphasizes the interactive aspects of colonial educational practicesdespite the asymmetry of the interaction. Such demonstrations make clear that "postcolonial" stands today as a term that problematizes relations of alterity:

The term post-colonial is not merely descriptive of this society rather than that, or of then and now. It re-reads colonization as part of an essentially transnational transcultural global process-and it produces a decentred, diasporic or global rewriting of earlier, nation-centred imperial grand narratives... It obliges us to re-read the binaries as forms of transculturation, of cultural translation, destined to trouble the here/there binaries forever. (Hall 1996, 247)

Stuart Hall's reformulation of the binaries of postcolonialism is especially pertinent for translation. By announcing the necessity of troubling the "here/there" binaries forever, he rescues translation from the threat of incommensurabilities lodged in certain polarized positions. Adopting a postcolonial framework would not necessarily imply, as Vijay Mishra and Bob Hodge suggest, a focus on the untranslatable authenticity of local 
realities. Referring to Rushdie's novel Midnight's Children, they establish a hypothetical opposition between a postmodern reading, which would emphasize "play and deferral," and a postcolonial one, which

will locate the meaning of the untranslated words and the special, culture-specific resonances of the text. It might even offer a radical reshaping or rethinking of what Habermas has called our "communicative rationality". The post-colonial text persuades us to think through logical categories which may be quite alien to our own. For a text to suggest even as much is to start the long overdue process of dismantling classical orientalism. (Mishra and Hodge 1991, 382)

For Mishra and Hodge, a postcolonial reading would insist on untranslatability and the affirmation of radical difference. Such an understanding of cultural relations and of Rushdie's text neglects the alterities which compose Midnight's Children, the processes of translation which are internal to the novel. While Mishra and Hodge are right to ask the question "Does the postcolonial exist only in "english'?" (287), and to remind readers of the unequal exchange values of language, the differential circuits through which language intersects with market trends, political pressures, historical traditions and literary values, they also oversimplify the relation between the postmodern (West) and the postcolonial (East). In fact the postcolonial condition implies an unceasing flow of cultural traffic, but this flow operates according to different time schemes and achieves differing degrees of equivalence.

Detailed studies of specific translating situations provide crucial sites through which to view relations of alterity and to understand their complexity. The example of the Bengali Renaissance in the nineteenth century is particularly rich. It demonstrates the ways in which translations, though undertaken as acts of colonial mimicry, though undertaken under the aegis of colonial power, can have unpredictable effects and can become stimulants to the development of national languages. It was at the initiative of the East India Company and the European missionaries, explains Partha Chatterjee,

that the first printed books are produced in Bengali at the end of the eighteenth century and the first narrative prose compositions commissioned at the beginning of the nineteenth. $(1993,7)$

During the first half of the nineteenth century, English emerges as the most powerful vehicle of intellectual influence on a new Bengali elite.

The crucial moment in the development of the modern Bengali language comes, however, in midcentury, when this bilingual elite makes 
it a cultural project to provide its mother tongue with the necessary linguistic equipment to enable it to become an adequate language for "modern" culture. (Chatterjee 1993, 7)

This equipment involves printing presses, publishing houses, newspapers, magazines, literary societies ... and the production of translations into Bengali. Chatterjee suggests that this new national culture, though created through interaction with European influences, remained separate and distant from the "colonial intruder" (7). For instance, though the novel was the principal form through which the bilingual elite in Bengal fashioned a new narrative prose, the frequency of the "direct recording of living speech" in the Bengali popular novel (which often makes it look like a play) suggests, according to Chatterjee, that "the literati, in its search for artistic truthfulness, apparently found it necessary to escape as often as possible the rigidities of that prose" (8).

The example of Bengali literature provides rich material for exploration and theoretical debate. While most analysts would agree that the Bengali Renaissance of the nineteenth century was indeed a "translational" phenomenon, they would not necessarily agree on the value of its effects. Are these translational processes to be understood simply as the effects of cultural imperialism, or rather as transaction, as "an interactive, dialogic, two-way process involving complex negotiation and exchange" (Trivedi 1993 ) and therefore as a salutary mode of aesthetic renewal? Today's processes of globalization raise similar questions regarding cultural exchange. The flow of translations continues to actively promote the power of First World cultures. How can the trade imbalance in translations be rectified so that the voices of the silenced might be heard?

The postcolonial frame in translation studies allows exploration of such questions by drawing useful parallels among a large number of disparate contexts. The language struggles in Ireland at the turn of this century, which used translation as a "catalyst for renewal and invention" (Cronin 1996, 126) and which made English into the literary language of Ireland, resonate richly with the contemporary situation in India. Michael Cronin draws a portrait of Ireland as traversed "from the beginning" by intense activities of translation. Nationalism, paradoxically, served as a vehicle for the promotion of English (92).

The [nationalist and republican movements'] faith in translation is strong because of an implied belief that an Irish nation can express its own distinctness in the English language. Learning and literature in the Irish language can be carried across the language divide and used as building materials for a new Irish identity. (116-17) 
And today, adds Cronin, "translation is our condition" (199). Surely, the same could be said of many other national and protonational situations in the world today whose ongoing struggle with the English language originated in colonial domination. At the same time, the postcolonial frame obliges us to adopt a critical attitude toward the relation between nation and culture, rather than to use these terms uncritically as the basis for our understanding of literary exchange.

The "map" of postcolonialism is not, then, just a trace of the oneway movements of power. Nor is it just a geographical map. It exposes the marks of history and the continuing tensions of power relations. Ethical relations are also to be plotted onto this map. What postcolonialism means, for literary and cultural studies, for translation studies, then, is briefly this: that we understand all exchange within the context of global power relations. That we see cultural traffic, the movement of books, plays, ideas, languages, as involved in the dynamics of exchange dictated by colonialism and its consequences.

This means that translations become part of a larger picture, which includes the economic and political frameworks through which ideas are circulated and received. In other words, postcolonialism is about rethinking the ways in which cultures relate to one another, recognizing their internal differences and also questioning the poles from which and to which cultural products travel. It makes us increasingly aware of the ways in which hybridity has come to complicate relations of exchange and trouble categories of alterity. The poles of Otherness which supported relations of oppression and contestation have been weakened by the fragmentary nature of contemporary cultural identities.

\section{III}

The first block of readings in the volume take a critical look at the implications of postcolonial theory for translation studies. The essays question the intellectual and ethical underpinnings of the postcolonial model, and its applicability to specific national situations. In one of the three papers in the volume focussing on Ireland, Michael Cronin identifies translation as an essential part of the normative process which brings colonies into the "Imperial Archive," reducing the unruly expanses of conquered territory into bits of information which can be stored and accessed. Through his analysis of Brian Friel's emblematic play Translations, and the enterprise of the British Ordnance Survey of Ireland, which is its pretext, Cronin highlights the links between translation, information gathering and falsification. Friel's play is a precise and evocative demonstration of the ways in which British 
power uses translation to "cover" the Irish landscape with the Imperial grid. Translation is seen as a form of violence which redefines the terms of legitimacy.

Like other theorists working within the postcolonial paradigm, Cronin balances his exposition of the oppressive functions of translation with a view of its potential for resistance. He suggests that translation-in its alliance with falsification - has had powerful creative capacities within Irish literary history, where translations without originals seem to proliferate. He also points to outlaws and marginal groups as exemplary translators. Marginalized groups, he suggests, often as a result of nomadic displacement or territorial dispossession, are generally much more implicated in the practice of translation than dominant, settled communities.

What is the relevance of a "postcolonial" translation theory for China, a country which has never, strictly speaking, experienced colonialism? What is to be lost or gained by adopting the postcolonial stance? This is the question Leo Chan develops with a great deal of pertinence in his article. Like other Western wares now available on the market in China, Western theory is now available to Chinese scholars, who must decide how it will be used. Can postcolonial theory help explain China's ongoing negotiation with Western influences, as well as its role as an aggressive purveyor of its own cultural models within Asia? Chan suggests that "postcolonialism" as a term can be used very broadly to refer to the question of positionality-where one places oneself in relation to existing modes of interpreting reality.

Chan's article considers two positions taken by Chinese translation theorists and translators as a response to the cultural influences of the West. A strong tradition opposes the introduction of Europeanized structures and expressions into the Chinese language, fearing that they will result in the inevitable contamination of the language. More recently, however, counterarguments have highlighted the resilience of the language. Chan shows how these various positions are situated within translation practice, translation theory and cultural theory. He also shows how these debates take up issues very similar to those involved in postcolonialism. The relationship between language theory, cultural theory and the historical and political context of the changing relations of China with the West has to be understood within the body of Chinese cultural history. Chan remains wary, however, of using postcolonial theory as a template. The uniqueness of the Chinese case forces us to revise the parameters within which postcolonial theorizing functions.

Diptiranjan Pattanaik and Shantha Ramakrishna both present strong models of the ways in which translation can be used as a tool of cultural affirmation. For Pattanaik, it is the strength of endotropric translation that has contributed to the growth of Oriya nationhood. Ramakrishna points, 
rather, to what she calls "counter-translation" as a strategy for using translation as an anti-hegemonic tool. Both ground their analyses in different spaces of India: Pattanaik in the cultural life of the state of Orissa (situated on the Eastern coast below Bengal), Ramakrishna more broadly referring to the Indian nation as a whole.

Pattanaik begins his essay with an amusing and telling anecdote. Friends who were critical of a short story he had written in the Oriya language for a local journal were quite thrilled with it when they saw it published in English translation. They were genuinely impressed by the novelty of its theme, its dramatic presentation and its message, whereas they had found the Oriya original to be trite. They had not recognized the English story as a translation of the Oriya. Pattanaik uses the story to stand as an emblem of the prestige of the English language in India today and the "aura" which translations can confer.

In Oriya, in particular, he adds, translation has traditionally been held in high esteem. Like other regional literary languages in India, Oriya was nourished through translation, specifically translations from Sanskrit texts. This process of "endotropic" translation, in contrast to the translations toward English, have historically served to build the distinct cultural identity of Oriya-speaking people and acted, as well, as an instrument of democratization. This can be seen, in particular, in the translations of Sarala Das in the fifteenth century. His "transcreations" of Sanskrit classics were decisive in developing an Oriya literary language. At this time, when the Oriya kingdom was undergoing a period of expansion, as well as in the nineteenth century, when a movement sought to form a separate Oriya province in colonial India, endotropic translations were associated with the consolidation of Oriya nationhood. The difference is that under colonial administration it was no longer Sanskrit texts but Western novels which became originals for endotropic translations. Pattanaik points to the heroic efforts of Prafulla Das, whose small publishing house produced more than seventy world classics in Oriya translation.

And what about exotropic translation? Translation into English has had none of the democratizing zeal of endotropic translation, according to Pattanaik, and feeds the needs of Western educated audiences at home and abroad. Translation into English may bring some international attention to a literature which would otherwise not be known at all, but has none of the powerful nourishing effects which come from translating into Oriya. These must be maintained if the Oriya literary culture is to prevail and to generate new works for a national and an international audience.

Ramakrishna identifies the cultural authority of what she calls "counter-translations," translations which by their choice of object and manner of 
translation shift attention away from the British colonial legacy. The British introduced little European literature to India. Whether they were conventionally "faithful" or not, Vidyarthi's adaptation of a novel by Victor Hugo or Premchand's translations of Anatole France are contributions to a more diversified literary culture, Ramakrishna argues. These translations from the French were a deliberate effort to turn attention away from British models. Contemporary efforts at such "counter-translation" activity are the translation of Sri Aurobindo's work Savitri into Urdu (as a gesture of anticommunalism) or Suman Venkatesh's translations from French into English of documents of the period 1781-1796, on the history of Mysore. Critics and reviewers, she adds, must be sensitive to the cultural projects of translators as well as the variety of practices of "fidelity" which they might choose.

In parallel to Michael Cronin's evocation of translators as marginal beings, Jean-Marc Gouanvic focusses on resistance in translation by looking at marginalized groups as exemplary translator figures. While Cronin mentions nomads, traders and outlaws, or such communities as the Huguenots and Irish Catholics, who were forced to accept restrictions in their access to power, Gouanvic considers the "maroon," the runaway slave who succeeds in living outside of the control of the white man. Gouanvic develops his analysis through the ideas of Pierre Bourdieu, insisting on the directionality of translation, its strategic use in imposing social values by the source culture on a target culture. Attempting not to idealize the space of the "maroon," which though it represents a breaking away from the structures of white power nevertheless remains subject to it in many ways, Gouanvic offers this figure as a potent evocation of marginality - as do a number of contemporary Francophone writers in the Caribbean. "Maroon" translators do not play according to the laws of the market; they are heretics. As such, they are associated with the subversive power of pseudotranslations. They transgress borders and defy systems of classification. The evocation of this conflictual space seems to Gouanvic to offer a more satisfying paradigm than that of hybridity, which he suggests is simply a mask for the reinforced power of the dominator.

Gouanvic's critique of hybridity as a kind of "mystical fusion" is a serious challenge to the current popularity of the term (as evidenced in the essays of Wolf and Tymoczko). He joins here an important debate on the political implications of hybridity within postcolonial studies and specifically the understanding of the colonial enactment of cultural power (see, for instance, Loomba 1995).

Elizabeth Fitzpatrick's essay on Balai Pustaka in the Dutch East Indies provides valuable information on a colonial enterprise which had an indisputable, though paradoxical, effect on the development of modern 
Indonesian literature. Balai Pustaka was an agency of the Dutch colonial government, active from about 1905 to World War II, whose purpose was to provide books for the native population of the East Indies colonies. Fitzpatrick's paper is devoted to correcting the perception that Balai Pustaka was the decisive factor in the emergence of modern Indonesian literature. She shows how the cultural agency's political and social agenda brought only a limited, ideological influence to bear, and that the interactions between creation and translation which worked to create Indonesian literature were more complex. Balai Pustaka worked to promote European values and to maintain Dutch power, at the same time adding to the rich mix of influences which have contributed to Indonesian culture. Balai Pustaka is an example of how a "small" colonial power invested in scholarship to provide the leverage necessary to implement policy. The agency conducted a wide range of language and cultural policies, including an aggressive translation policy into Malay of the European classics. Fitzpatrick shows that Dutch efforts were aimed toward diverting attention from discussions of nationalism and independence in an attempt to control the cultural discourse of emerging Indonesia.

Both Michaela Wolf's and Maria Tymoczko's contributions insist on hybridity as a central marker of postcolonial practices. Wolf uses hybridity to develop an understanding of cultural relations that goes beyond limited conceptions of alterity in order to include the ongoing differences within and among cultures. Postcolonialism can be understood as a reading and writing practice which questions the production of knowledge concerning the other. Translation, like ethnography, is faced with issues of asymmetrical authority and legitimacy in the production of cultural knowledge. Wolf uses Homi Bhabha's definition of the hybrid as an "active moment of challenge and resistance to the dominant cultural power" which transforms the cultural from the source of conflict to an element of production, opening onto a "Third Space" which accommodates a whole fund of syncretisms, recombinations and mechanisms of acculturation. The Third Space is a space of cultural creation, where translation is a "grounds for intervention," creating texts that resist categorization and renaturalization. Translation no longer bridges a gap between two different cultures, but becomes a strategy of intervention through which newness comes into the world, where cultures are remixed. To speak of culture as translation is to stress the fact that cultures develop by negotiating and mixing, and that difference and incommensurability predominate over identities.

The existence of large diasporic and migrant communities in movement across the globe makes any fixed definition of communities difficult. The congruence between nation and language can no longer be taken as the basis for defining a literary community. Consider, for example, the 
introduction to a recently published introduction to comparative literature written in French. The author begins by defining a "foreign" work of literature as one which is not "addressed to me." He seems to assume that all works of literature originally written in French are addressed to a single French-language community (Chevrel 1989). Such an assumption takes no account of the internal fragmentation of the population of France, whether along class, gender or ethnic lines. The author is postulating the existence of a single, French-language literary community. The introduction of Francophone studies as a new framework for studying literature has done much to disturb the collusion between language and culture; yet the consequences of these shifts have not always been transferred to translation studies.

Gayatri Spivak's work as theoretician and translator exposes the complexities of cultural exchange within a disposition where "metropolitans," "colonials" and "migrants" compete for subject positions. Her work troubles the easy identifications of "foreign" and "home" culture, introducing the figure of the translator whose identity is subsumed neither by the host nor the receiving culture, who has no single "home" to offer to the translated work. Translations, like the original works of diasporic writers, become caught up in networks of readership which involve audiences which are not defined by one national frame. New market trends arise which solicit some kinds of voices and suppress others. By foregrounding her own identity problems as a translator, Spivak draws attention to the kinds of forces at play in today's global literary commerce. Providing a preface and a postface to her translations of Mahasweta Devi, she ensures that the reader has a contextualized and informed understanding of the difficult text she is reading. In insisting on her own pivotal role as critic and translator, Spivak (in Devi 1995) replaces the "international" itineraries of translation with more specific and devious cultural routes.

In a phrase which has been widely echoed, Salman Rushdie claimed that migrants are "translated beings." We can understand this expression to highlight the fact that individuals who move from one culture to another are transformed by the many cultural references they collect and reposition. Their selfhood and identity are destabilized and refashioned as they negotiate new realities. But migrants are also active agents of cultural exchange; they "translate" as they are "translated." The texts of those authors who are poised between communities, who are in the process of creating new literary identities, such as Rushdie, Édouard Glissant and Derek Walcott, stand on the border between writing and translation, infusing both of these activities with new meanings.

Maria Tymoczko's essay pursues the investigation of hybrid practices by investigating the areas where postcolonial writing and translation 
overlap. Can it be said that a novel like Amos Tutuola's The Palm-Wine Drinkard is "like" a translation or, even, "is" a translation? The entire text, suggests a critic, is "bent and twisted into the service of a different language." These texts no longer "mediate" between one culture and the other, but show in what ways they come together as new, hybrid cultural realities. Postcolonial writing is different from translation, Tymoczko acknowledges, and yet both involve similar representations and transpositions of language and culture. She chooses to focus on the ability of such texts to evoke two languages simultaneously. This radical bilingualism and polyphony typically give both translations and postcolonial texts much of their evocative appeal and subversive power. The example provided here is that of James Joyce and his "covert" use of the Irish language, through the use of proper names, in particular. Tymoczko links Joyce's uses of Irish with similar textual phenomena to be found in twentieth-century North African postcolonial Francophone literary works. The bilingual reader has a different experience of the text than the monolingual one. Tymoczko insists particularly on the way in which "conventional translation equivalents" are used as a vehicle of inserting meanings from a colonized people's native language into a postcolonial text in the colonizers' language. The hybrid text creates a "crisis of authority," contesting forms of domination. Concluding that translations and postcolonial literary works are not to be treated as the same, she nevertheless points to their functional and formal similarities as manifestations of "double consciousness" and "cultural recuperation." Both Wolf and Tymoczko show, then, how notions of hybridity are essential today to investigate not the collapse of differences but the ever-moving lines against which they take shape. Michaela Wolf, like Leo Chan, reminds us of the very diverse linkages between colonialism and empire. Wolf draws together imperialism and colonialism, showing how the disintegration of empires like the Austro-Hungarian Empire can be compared to a process of decolonization, leading to "fragmentary, dismembered, exhausted" remnants. Both "postimperial" and "postcolonial" countries remain determined from the outside, while "the empty spaces inside are filled with nationalism, fundamentalism and essentialism." She draws attention to the continuous nature of the process, the violence of "aftershocks" like the breakup of Czechoslovakia and Yugoslavia so many years after the initial defeat of the empire.

The second block of essays is devoted to detailed analyses of specific cultural practices situated at the border between colonialism and postcolonialism. Brian Friel's important play Translations, briefly discussed by Michael Cronin, is the subject of sensitive and detailed analysis by MariaElena Doyle. Doyle relates the use of dialect in this play to the political ideology and aesthetic practice of the Field Day Theatre Company, of which Friel is a director. In particular, Doyle takes as her central focus the use of dialect in the play, as well as the use of dialect in plays translated for the 
company. What is the political valence of dialect in the polarized English/ Gaelic context of Northern Ireland? Promoting a form of cultural hybridity which speaks of the fusion of identities that embodies Northern Ireland, dialect also instills a sense of community in the public. Within the play Translations, the choice of language and accent point to the complex layerings of meaning in the play and to the rich and conflictual history to which it contributes. Doyle notes the fact that three of Field Day's first six plays were translations of foreign works, a "strange" fact considering that the company is devoted to creating an Irish sense of identity. But in translating some of the central canonical texts of Western drama, Doyle argues, Field Day's writers took the opportunity to "place their stamp on these texts," a form of dramatic appropriation characteristic of postcolonial theatre in general. Theatre thus becomes a particularly effective mode of counterdiscourse. The attempt to skirt English texts recalls similar attempts in India to circumvent what Ashis Nandy has called the "unbreakable dyadic relationships" between colonizer and colonized. Two of these plays are translated into dialect. This practice in many ways echos that of the retranslation into "Québécois" during the same period, analyzed by Annie Brisset and by Louise Ladouceur, constituting a symbolic act of rupture. Providing a highly nuanced and complex reading of the values of dialect within the play Translations as well as within the translated plays, Doyle is obliged to conclude that the ultimate valence of dialect is as unsure as the "we" to which it refers. But for Doyle what will remain is the appeal to the importance of language in these theatre works. Language itself, the escape from silence, becomes the ultimate nexus of meaning.

Louise Ladouceur's essay on the "double coloniality" at work in the translation of Canadian theatre also draws attention to the historical basis for specific translation strategies. She shows how the very different statuses of the receiving languages - the dominance of English and Anglo-Saxon culture in North America, the fragile minority status of French-shape the overarching patterns of translation. When Quebec theatre is translated into English, very often the marks of the original context are transported with it. The titles of the plays, often left in French, point to "an untranslatable reality to which an anglophone public can hardly identify." They also point to an idealized reality, a "quaintness" which seems to evoke a Quebec of the past. This is not the case in the other direction, where adaptation and "dialectization" seemed to be the rule. Ladouceur's findings here echo those of Annie Brisset, whose Sociocritique of Translation also stresses the naturalizing tendencies of Quebec theatre translation during the sixties and seventies. However, as Ladouceur shows, this pattern becomes much less rigid once the eighties set in, and there is a diversification of the kinds of plays translated. 
Juliana de Zavalia examines the new visage of the Latino writer "within" the borders of the U.S. She uses polysystem theory to show how translation is part of a network of activities, including reading, rewriting and reviewing practices, which Andre Lefevere called "refraction." The emergence of Spanish-American writers prepared the way for the discovery of local Latinos. De Zavalia shows as well how translation is at the heart of the writing strategies of many of the new "hyphenated" writers. Her paper charts the flow of cultural traffic in the Americas since the 1960s, a flow that seems to partake more of an economy of neocolonialism than of postcolonialism.

That India should be a privileged site for translation studies today is not surprising. The wealth of India's "civilizational complexity" is such that it will not fit into facile, preconceived frameworks of analysis. Both the historical and the current multingualism of India direct us to new conceptualizations of literary and cultural dynamics. Certainly India seems to offer a particularly fertile terrain for examination of translation questions. India is one the most intense versions of a "translation area" in the world today, with its many official languages, with its partially proprietary attitude toward English, with the tension generated between Indian literature written in English and Indian literature in English translation.

Salman Rushdie was surely conscious of launching a polemic when he declared in the introduction to The Vintage Book of Indian Writing, 19471997 that there is a lack of "first-rate writing in translation." India's "best writing," he suggests, has been done in the English. He condemns at once vernacular-language writing and its poor translation into English. "There need not be an adversarial relationship between English-language literature and the other literatures of India," says Rushdie (1997, xvi), and yet he fires this adversity by making the outrageous claim that there is really nothing good written in the vernacular tongues.

The articles by Anita Mannur and N. Kamala provide the historical and contemporary context for Rushdie's remarks, though their authors would surely not endorse his conclusions. Both deal with India's intimate and conflictual relationship with English as the language of the ex-colonizer, as the link language of a linguistically fragmented territory and as the presentday vehicle of international commerce and culture. They agree with Rushdie that translated literature today has become marginalized with respect to Indian literature written in English, but question the conditions which have created this imbalance and insist on the power of translation to revitalize regional literary cultures.

Anita Mannur's essay is an informative study of a controversial topic: the non-visibility of translated Indian literature in relation to the 
prominence of English-language (Anglo-Indian) literature. Why, despite the steady production of such translations, are they so absent from the national consciousness? Why is it so difficult for knowledge about Indian regional-language writers to transcend state boundaries? Mannur's explanation deals with both ideological and infrastructural factors, such as the sometimes ineffectual policies of the Sahitya Akademi, the rivalry between Hindi and other regional languages, the low status of Indian literature within the academic establishment, the problem of publishing and availability of books. Mannur points, however, to the promising emergence of new publishing ventures which emphasize Indian literature in translation.

These publishing ventures are precisely the subject of N. Kamala's article, and in particular the Macmillan series devoted to Indian literature in translation. Emphasizing many of the same concerns as Mannur regarding the lack of communication among regional literatures, Kamala greets the Macmillan series of translations with enthusiasm, only to confront some of the weaknesses of its presentation and format. In particular, Kamala examines the ways in which the series constructs an idealized image of India and Indian literature. Sensitive to the political dimensions of intra-Indian rivalries, Kamala identifies the Macmillan project as a reflection of the newly effervescent South Indian leadership in Indian politics and popular culture. The most serious critique which the first eleven books of the series seem to have inspired among its reviewers is neither the choice of novels nor the style of their translations but the practice of footnoting, encouraged by the series editor. The footnotes are a particular source of irritation to Indian readers, because they relentlessly explain realities familiar to all Indians. Who is the ideal reader of these translations meant to be, then? The tourist, the Indian reader, the North American student? Kamala argues for a series whose first and primary reader would be Indian. Translation, she argues, ought to be an "intra-national" activity. Her conclusions reinforce the thesis of several of the previous articles: that translation remains a powerful means for generating literary identities in India. Whether the translations are endocentric or exocentric, in reaction to or promoting the cause of English, the interplay between regional and cosmopolitan identities in India today provides for intense creative tensions.

Paul St-Pierre's article demonstrates in fine detail the ways in which the tensions of postcoloniality are played out on the scene of translation. In terms which recall the colonial occupation of Ireland, St-Pierre chooses to focus on the ways in which "law" and "language," two of the colonizers" principal instruments, are evoked in an Oriya novel-and how they are variously translated. Chha Mana Atha Guntha (Six Acres and Thirty-Two Decimals) is a novel written by the celebrated Oriya author Fakir Mohan Senapati and serialized between 1897 and 1899. Three translations, pub- 
lished between 1967 and 1969, show remarkably different translation strategies which reflect different attitudes toward the colonial legacy - in particular with regard to the implied readership (regional, national or international?) and to the authority of the English language. Paradoxically, it is the translation which most explicitly sets itself within the British literary context which also best highlights the satirical, ironic mood of the text. The continued pertinence of the novel in Oriya society, its questioning of colonial power and the ideological power of translation is reinforced through St-Pierre's references to a forthcoming, collective translation which will propose yet another version of the text.

In the final essay, Probal Dasgupta uses the political and linguistic aspects of postcoloniality as a starting point to take on the very broadest questions of knowledge creation and transfer - as well as the moral issue he refers to as "courage." His essay, which takes the form of a kind of manifesto, is in fact a call for translation as a guarantee of modernity for the postcolonial world. Modernity demands that knowledge be translatable, that it be reformulatable within different languages, and therefore given body, rather than the abstract voice of universality. Translation becomes, therefore, a necessary means through which knowledge is tested, recontextualized, submitted to critical scrutiny. Cognitive accountability is a condition for modernity. The stories of "initiating cultures" must be retold by the receiving culture, unlocking its essential rather than contingent features. Dasgupta refers specifically to the retelling of scientific stories, a process he claims should not be confided to bureaucrats (who will produce official terminology) but to thinkers who make it a part of scientific practice and of the critique of science. The "hijack" of scientific work by the English language works against culturally healthy communities, the rethinking of terms and concepts, and the revitalization of the sense of wonder which accompanies this "radical respecification." He argues that postcolonialism means formulating and practising a "post-missionary" attitude to knowledge, which includes an active traffic in translation.

Dasgupta talks of two waves of translating: the missionary enterprise, motivated by bureaucratic imperatives, and the new wave of "careful" translators, which creates a care-induced distance, "somewhat akin to speaking loudly to overcome the barrier of physical distance." Dasgupta rejects both these approaches, arguing for "the cause of Reperception." He is arguing for redress in the balance of trade, for more translation into Less Equipped Languages rather than toward More Equipped Languages. And this not in the name of narrow nationalism but of community: "A politics of Reperception has to work at the level of discourse, a flow of spoken and written activity where the performers are explicitly each other's guests, taking and giving space and aware that this is the fundamental act of culture." 
There is a strain of idealism in Dasgupta's call for courage in the construction of the postcolonial living space. His critique of science and of authoritarian discourse is also an appeal for more responsible and creative uses of language. His own essay contributes to this goal, to the extent that it mixes vocabularies and knowledge categories generally kept separate. Here the political aims of postcolonialism are blended with cognitive and moral critiques of scientific and authoritarian discourse. Dasgupta wants to disrupt the bureaucratic rationality that organizes thought for us. What are we to pay attention to? How are we to welcome distractions not provided by the purveyors of knowledge? Translators play a vital part in dealing with these questions, as they "are on the job of modifying the objects and patterns of people's attention." Translation theory, following Dasgupta, joins communications and cultural theory in criticizing the scientific enterprise and the political order which guarantees its credibility.

\section{IV}

Is it possible to conclude in favour of one or the other of the images that Amitav Ghosh provided to account for the power of translations? Surely such a single conclusion, whether it be in favour of the repressive force of translation, or, on the contrary, its liberating power, would be contrary to the aims of this volume. As a practice of mediation deeply embedded in patterns of domination and yet permitting newness to exist, translation both "separates and joins" (Venuti 1998). The effects of translation are best described in the mixed vocabulary used today to characterize the dynamics of globalization. On the one hand, the spread of international cliché produces effects of homogenization; on the other, meaningful engagements across cultures, in increasingly diverse modes, produce increased particularization. Relations of intercultural exchange perform on a continuum whose one extreme carries the force of non-translation ("translating out of, away from, against, a culture") and whose opposite pole mobilizes the energy of cultural specificity ("translating for, into, with"). The tension between these poles is characteristic of the dialogue between cultural nationalism and postnational heterogeneity which is characteristic of the present moment.

We increasingly understand cultural interaction not merely as a form of exchange but as production. Translation then is not simply a mode of linguistic transfer but a translingual practice, a writing across languages. The economy of exchange gives way to a circulation governed by a "complex, decentered interactiveness" (Buell 1994, 337), which permits new kinds of conversations and new speaking positions. Borders do not simply divide and exclude, but allow the possibility to "interact and construct" (341). The double vision of translators is continuously redefining creative practices - and changing the terms of cultural transmission. 


\section{Works Cited}

BHABHA, Homi K. 1992. "Postcolonial Criticism." In Redrawing the Boundaries: The Transformation of English and American Literary Studies, ed. Stephen Greenblatt and Giles Gunn. New York: MLA.

BRISSET, Annie. 1996. A Sociocritique of Translation: Theatre and Alterity in Quebec, 1968-1988. Trans. Rosalind Gilland and Roger Gannon. Toronto: U of Toronto P.

BUELL, Frederick. 1994. National Culture and the New Global System. Baltimore/London: John Hopkins UP.

CHATTERJEE, Partha. 1993. The Nation and Its Fragments: Colonial and Postcolonial Histories. Princeton, NJ: Princeton UP.

CHEVREL, Yves. 1989. La littérature comparée. Paris: PUF (Que sais-je?).

CRONIN, Michael. 1996. Translating Ireland: Translation, Languages, Cultures. Cork: Cork UP.

DEVI, Mahasweta. 1995. Imaginary Maps. Trans. Gayatri Spivak. London/New York: Routledge.

FROW, John. 1996. "The Commodification of Culture." New Left Review: 89-108.

GHOSH, Amitav. 1994. "The Indian Story." Civil Lines 1, 35-49. Delhi: Ravi Dayal Publisher.

HALL, Stuart. 1996. "When Was "The Post-Colonial"? Thinking at the Limit." In The Post-Colonial Question: Common Skies, Divided Horizons, ed. Iain Chambers and Lidia Curti, 242-60. London/New York: Routledge.

LOOMBA, Ania. 1995. "Overworlding the 'Third World."' In Colonial Discourse and Post-Colonial Theory, ed. Patrick Williams and Laura Chrisman, 305-23. New York: Columbia UP.

MCCLINTOCK, Anne. 1995. "The Angel of Progress: Pitfalls of the Term 'Post-Colonialism."' In Colonial Discourse and Post-Colonial Theory, ed. Patrick Williams and Laura Chrisman, 291-304. New York: Columbia UP.

MISHRA, Vijay, and Bob HODGE. 1991. "What Is Post(-)Colonialism?" Textual Practice 5, no. 3: 399-414.

MUKHERJEE, Meenakshi. 1985. Realism and Reality: The Novel and Society in India. Delhi: Oxford UP.

PADIKKAL, Shivarama. 1993. "Inventing Modernity: The Emergence of the Novel in India." In Interrogating Modernity, Culture and Colonialism in India, ed. T. Niranjana, P. Sudhir and V. Dhareshwar, 220-41. Calcutta: Seagull Press.

RUSHDIE, Salman. 1991. Imaginary Homelands. London: Granta.

1997. Introduction. The Vintage Book of Indian Writing, 1947-1997. Ed. Salman Rushdie and Elizabeth West. London: Vintage.

SPIVAK, Gayatri. 1993. "The Politics of Translation." Outside in the Teaching Machine, 179-200. London/New York: Routledge.

TRIVEDI, Harish. 1993. Colonial Transactions: English Literature and India. Calcutta: Papyrus.

VENUTI, Lawrence. 1998. The Scandals of Translation: Towards an Ethics of Difference. London/New York: Routledge.

YOUNG, Robert J.C. 1995. Colonial Desire: Hybridity in Theory, Culture and Race. London/New York: Routledge. 
This page intentionally left blank 


\section{I}

\section{(POST)COLONIALISM AND THE POWERS OF TRANSLATION}


This page intentionally left blank 


\section{Chapter 1}

\section{HISTORY, TRANSLATION, POSTCOLONIALISM}

Michael Cronin

Dublin City University (Ireland)

Having some time at my disposal when in London, I had visited the British Museum, and made search among the books and maps of the library regarding Transylvania; it had struck me that some foreknowledge of the country could hardly fail to have some importance in dealing with a noble of that country. I find that the district he named is in the extreme east of the country, just on the borders of three states, Transylvania, Moldavia, and Bukovina, in the midst of the Carpathian mountains; one of the wildest and least known portions of Europe. I was not able to light on any map or work giving the exact locality of the Castle Dracula, as there are no maps of this country as yet to compare with our own Ordnance Survey maps... (Stoker 1993, 1-2)

The above is an extract from Jonathan Harker's journal dated May 3. Jonathan Harker, a hapless solicitor and diligent child of the Empire, is one of the central characters in Dracula, a novel by Irish novelist Bram Stoker, that appeared over 100 years ago.

\section{Translation and the Imperial Archive}

Jonathan Harker's enquiries take as two initial points of reference the British Museum and the Ordnance Survey, the essential constituents of what Thomas Richards calls the "Imperial Archive." The British Empire in the 
nineteenth century covered a vast geographical area. Since it was clearly impossible to control this empire by force, information became the dominant means of control. The Baconian equation of knowledge with power gradually became the guiding dictate of imperial policy. Knowledge in this sense did not supplement power, knowledge was power. As such, the Ordnance Survey was at the heart of the imperial project of territorial expansion, surveillance and control. Colonel Thomas Holdich, Superintendent of Frontier Surveys in India (1892-1898), stated quite explicitly that "geographical surveys are functions of both civil and military operations" (Richards 1993, 14): the India Survey proceeded "square mile by square mile, gradually taking cadastral possession of the entire country, stopping just at its borders" (14). Ireland, as for many imperial experiments, was used as the laboratory for the geographical mapping of Empire when the British Army, in the 1830s, carried out there the first comprehensive Ordnance Survey outside of England. ${ }^{1}$ This Survey is the subject of Brian Friel's play Translations, where the impact of the survey on the language and culture of the people of Baile Beag/Ballybeg is explored by the playwright. The Survey involves the Anglicization of the locality through languageEnglish transliterations of the Irish names reflecting the wider translation of a people from one language and culture to another. Crucial to the operation of this enterprise is the use of local knowledge, and a striking feature of British imperial policy was its ability to co-opt local, dominated knowledge(s) in a strategy for retaining power. The fact that able scholars such as George Petrie and John O'Donovan, who were deeply sympathetic to the Irish language and culture, were employed on the Survey enhanced rather than diminished its effectiveness as an archival tool. ${ }^{2}$

In Friel's play, Owen is employed by the Army to act as translator and interpreter, due to his knowledge of Irish. After translating for Captain Lancey, who describes the purposes of the Survey, Owen is taken to task by his brother Manus:

MANUS: What sort of a translation was that, Owen?

OWEN: Did I make a mess of it?

MANUS: You weren't saying what Lancey was saying!

OWEN: "Uncertainty in meaning is incipient poetry"-who said that?

MANUS: There was nothing uncertain about what Lancey said: it's a bloody military operation, Owen! and what's Yolland's function? What's "incorrect" about the placenames we have here?

OWEN: Nothing at all. They're just going to be standardised.

MANUS: You mean changed into English. 
Manus's main accusation is that Owen, in his translation, is falsifying the original as part of a covert operation by the Survey to expropriate the local Irish-speaking community of their sense of place. The notion of falsification of the original can be linked to a more general concern with origins in the nineteenth century that helps to explain both the fascination of Bram Stoker's novel and its significance for translation studies.

A strategic shift occurred in nineteenth-century morphology from the Linnaean concept of forma formata, or fixed form, to the Darwinian notion of forma formans, the diachronic notion of changing form. This evolutionary preoccupation with dynamic lineage had widespread disciplinary impact. In the area of language, philology took on a major importance because the desire to study living languages led to a preoccupation with dead languages: the forms of the dead could be perceived in the forms of the living, and vice versa. In a similar way, the desire to study living matter led to an obsession with fossil records. In both instances, the scholar-scientist traces the morphological evolution of form through time. Forms do not exist in a static, timeless space, but are rather infinitely susceptible to change. Underlying the Darwinian system is the notion of consonance: that missing links will restore continuity where there is discontinuity. ${ }^{3}$ What is truly monstrous about Dracula's vampires is that they lie outside the purview of Darwinian morphology. They are mutants who can change form at an alarming rate. They have no past, no lineage, no progenitors. They are a species without origin-or whose origin is obscure-located in the liminal zone of Dracula's castle. This castle, Harker tells us, is "just on the borders of three states, Transylvania, Moldavia, and Bukovina." Monsters have, of course, long been an European figure representing external (Empire) and internal (female) alterity, and the figure of the vampire can be seen as a recasting of alterity in a post-Darwinian mould. ${ }^{4}$ The vampires, which threaten the Empire from the East, are a fictional creation of an Irishman, the threat from the West.

\section{Uncertain Origins}

The status of the original has, of course, been a vexed issue for translation through the centuries and what I wish to suggest here is that the threat of translation in colonial and postcolonial contexts is bound up with the question of origin. Translation is frequently presented in colonial contexts as either a predatory, exploitative activity or as the True Path to reconciliation, understanding and the withering away of prejudice. Less account has been taken of translation as resistance-the ways in which originals can be manipulated, invented or substituted, or the status of the original subverted in order to frustrate the intelligence-gathering activities of the Imperial Agent. This perspective is unpopular, as it frustrates the unspoken desire in 
Translation Studies for consonant wholeness, a notion that saturates the metaphorical language of bridge-building that is frequently employed in the discipline. It is therefore instructive to look at the status of the original in colonial situations, and see what implications this status has for translation practice and reception.

Nineteenth-century Irish-verse translation is replete with examples of lost or missing originals. Not one single original copy survives of Charles Henry Wilson's Poems Translated from the Irish Language into the English, the first volume of translations of Irish verse into English, which appeared in 1782. No Irish originals can be found for the influential English translations of J.J. Callanan, of which "Outlaw of Loch Lene" was a huge success. No original has been established for "Bumpers, Squire Jones," which first appeared in Joseph Cooper Walker's Historical Memoirs of the Irish Bards (1786), translated by the "facetious Baron Arthur Dawson" (Welch 1988, 32). In other instances, translators have translated from a language that they scarcely knew. James Clarence Mangan, whose translations left an indelible mark on Irish translation activity in the nineteenth century and beyond, had little or no knowledge of Irish and therefore had no direct access to the originals. He was totally reliant on cribs from Eugene O'Curry and John O'Donovan, both of whom worked for the Ordnance Survey. The translations of J.J. Callanan and others became, in a sense, the originators of their own species, and led the way for countless imitations or, more properly, as no one translation is ever wholly like any other, countless mutations. This mutability has a political dimension in that both Callanan and Mangan were sympathetic to Irish nationalism. Indeed, Mangan claimed, "When I translate from the Irish my heart has no pulse except for the wrongs and sorrows of my native land" (qtd. in Welch 1988, 110). Mangan's most successful political translation, "My Dark Rosaleen," is based on his poetic reworking of Samuel Ferguson's earlier prose-translation of the same poem, which appeared in the Dublin University Magazine in 1834. Mangan's translation appeared in the newspaper The Nation on May 30,1846, at the height of the Great Famine, and had a lasting impact as an iconic poem of Irish opposition to imperial rule. The peripheral threat to the centre comes then not from unmediated access to the original but from obliquity, indirectness, a complicated relationship with origin. This is perhaps particularly the case when target audiences do not have access to the original texts or language. When origins are unknown, uncertain, translations have the potential, in a sense, to become truly terrifying. This observation counters essentialist assumptions that only direct, unobstructed contact with origins can produce the shock of othemess. But the danger, on the contrary, is that such a conception of origin leads to a cult of purity, a purity that is always, of course, imperilled by others, who must be eliminated in order to restore the fantasmatic original state. 


\section{Double Agents}

One of the longest, if least dramatic, scenes in Neil Jordan's recent film Michael Collins, about a leading figure in the Irish War of Independence, is set in a room containing box upon box of dusty files. Through the services of a detective sympathetic to the nationalist cause, Collins gains access to all the files on nationalist activists, in Dublin Castle. There, he is in the Irish heart of the Imperial Archive. After spending an entire night looking through the files, Collins comes to realize that the empire is a construct of information, and that a strategy of opposition must be based not on the heroic stasis of the shelled building, but on the mobile control of information. Lord Deputy Sidney, a veteran of Tudor military campaigns in Ireland, had understood this centuries earlier, in 1580, when while in retirement he wrote to his successor, Grey de Wilton:

And since it is marciallie that you must proceede, and considering your experience and judgemente, I seasse to treate any more of that, lest, as I wright in the beginning of my lettre, I might power more follie out of myself then put wisdome into you; only this, that you spare for no coste to gette spies. (qtd. in Egerton 1847, 71)

Sixteenth-century Ireland was overwhelmingly Irish-speaking, so that spies also had to be translators. Críostóir Nuinseann, also known as Christopher Nugent, is one such example. Later to become Lord Delvin, Nugent is primarily known for an Irish primer he was asked to prepare for Queen Elizabeth I (see Williams 1986, 10-11). Irish-born of English origins, Nugent sent the following report that explicitly links espionage and translation to Lord Deputy Mountjoy, in 1600:

The intelligencer, with whom I formerly acquainted your Lordship is returned with a packet containing thirteen letters written in Irish from Tyrone, all directed to the Munster and Leinster rebels, saving one to the Earl of Ormonde, the copy whereof, and of Desmond and Onie Mac Rory his letters translated verbatim, I send your Lorship. The other ten, containing the general news, and persuasions to guard down the Earl of Ormonde, I could not translate verbatim by reason of the messenger's haste, and fear to be discovered but have sent your Lordship a brief of their differences and to whom they were directed. (qtd. in Jackson 1973, 27)

Nugent was a Crown supporter, an Irish landowner and fully bilingual in both Irish and English. He was in all respects in the classic position of the entre-deux.

In Sidney's letter to Wilton in 1580, the spies referred to-Thomas Masterson, Robert Pipho and Robert Harpole--were Englishmen who had 
married local Irish-speaking women, and who had no qualms using their partners' linguistic competence for their intelligence-gathering activities. These spies/translators were, in a sense, living double lives. And indeed, it is the necessary doubleness/duplicity of translation in this colonial context that points to the inherent entropy of the system-the disorder that threatens order not from outside, as Matthew Arnold thought, but from the inside, as Ruskin (1884) more correctly observed. Captain Thomas Lee, an English soldier who dreamed of establishing a "principality" for himself during the Elizabethan period on the borders of Kildare and Wicklow, married an Irish-speaking Irishwoman. He also employed his wife as translator/interpreter in a plot to eliminate one of his most dangerous native-Irish rivals. Her political sympathies were, however, with the Irish rebels to whom she betrayed Lee's military plans (see Jackson 1973, 24).

The invisibility of the translator in colonial contexts is more often than not a pious fiction that is structurally programmed to implode. The relationship between local knowledge, information and control is crucial here. Effective agents of empire and state must operate as part of a community, but proximity can of course shade into complicity. State nomadology draws its strength from decentred instability, but this process of decentring also exposes the vulnerability of the State. It is noticeable that of the five major texts discussed by Richards in The Imperial Archive, two are by Irishmen-Bram Stoker's Dracula and Erskine Childers's The Riddle of the Sands - and one, Rudyard Kipling's Kim, features an Irishman as a main character. While it is not mentioned anywhere in Richards's book, it can be argued that it was precisely the doubleness of the Irish in the imperial context that made them such valuable allies of Empire in an archival consolidation of territory. Yet, this duality prefigures the disintegration of Empire. Richards does, however, make much of the use of local knowledge as part of the reworking of imperial information strategies in Childers's The Riddle of the Sands; Childers would use this local knowledge in 1914 to supply arms to Irish nationalists and to contribute to the incipient breakup of Empire.

When James Clerk Maxwell, a contemporary of Darwin, presented his unified field theory in 1854 , he addressed not only Newtonian preoccupations with the movement of bodies, but also the thermal and electromagnetic conditions separating them. Maxwell's field theory was above all an exploration of the phenomena impeding the unmediated movement of bodies through space (see Harman 1982, esp. 72-119). Translation is one of these phenomena that potentially impedes the movement of imperial bodies through the colonial space, despite the Newtonian rhetoric of unmediated universality. If one were to map a "subversive" theory of translation, what then might it look like? What are the different forms of "translation resist- 
ance," or a dissident relationship to origin? Two forms that merit mention here are resistance at the level of positionality and resistance at the level of text.

\section{Resistance at the Level of Positionality}

Translators working from the perspective of positionality are defined by their class, race, gender - their general position in networks of power and influence. However, depending on the configurations of power, translators can shift allegiances. They are, therefore, not to be trusted. Their inferior status is traditionally explained by ignorance or a lack of wider understanding of the difficulties of the translation process. But the subjection can equally plausibly be the fear of the divided (often female) translation subject. This divided subject haunts imperial exchanges. William Jones, in the preface to his Grammar of the Persian Language (1777), claims, "It was found dangerous to employ natives as interpreters upon whose fidelity they [the British] could not depend" (qtd. in Niranjana 1992, 16). The linguistic and cultural instability that results in the effectiveness of the translator as imperial subject (informer/informant) also maximizes the potential for entropy. It is for this reason that the study of the lives of individual translators is so important, as the complex inversions and reversions that characterize the actions of translators in situations of conflict can often be lost sight of in more systematic or programmatic approaches to translation history. Indeed, Edwin Gentzler, in a recent essay, uses the work of Michel de Certeau to point up the shortcomings of these approaches. He claims that "most systemic or structuralist methodologies fail at the task of linking human agency to historical change" $(1996,122)$ and that de Certeau's emphasis on the creative, inventive subversion of the everyday allows translation theorists to "explore the poiesis on the part of the user/translator, that which is often hidden, silent, invisible, but according to de Certeau, insinuated every where" (123). Linking this poiesis to positionality enables us to explore strategies of resistance to, and complicity in, cultural subjection in situations of colonial conflict.

\section{Resistance at the Level of Text}

While there are many forms of textual resistance, I wish to mention two forms here. The first is what might be termed "macaronic subversion." An example taken from Irish literary history is the tradition of political macaronic verse in eighteenth-century Ireland, where the lines of the poem in English appeared blameless or conciliatory, while the lines in Irish carry a very 
different political message-a message that was considerably more hostile to the authorities. The political effectiveness of the macaronic poetry lay in the opaqueness of the Irish to an English-speaking audience. The macaronic verse was doubly subversive of translation in that the alternate lines suggested the interlinear. The unsuspecting English speaker might think that the Irish was a literal translation of the English or vice versa, so that what one had, in effect, was a form that imitated the practice of translation, but subverted its alleged purpose..$^{5}$

The second form of textual resistance could be termed "attributive subversion." In this case, translation is a form of insubordination that exploits the deferred responsibility of translation. Je est un autre so I cannot be held accountable for the sentiments expressed. An example of attributive subversion can be found in the February 1799 issue of Dublin Magazine and Irish Monthly Register, which published a satirical anti-Union poem entitled "Sheelagh Bull." The poem appeared in the extremely fraught political context after the bloody suppression of the 1798 rebellion. However, it was presented as being "translated from German of the celebrated Bürger, author of Leonora" (O'Neill 1976, 129). Ironically, Bürger is the author quoted by one of Jonathan Harker's coach companions in the first chapter of Dracula: "Denn die Todten reiten schnell" (For the dead travel fast) (10).

Attributive subversion is related to the larger question of translation and forgery. Is there a sense in which the activity of translation is intrinsically fraudulent? Examples of fictitious translations abound in the history of translation. Macpherson's eighteenth-century Ossianic translations are certainly the most famous examples, but there are many others. James Clarence Mangan, the Irish poet mentioned earlier, produced translations of two German poets-“Selber" and "Drechsler"-who did not exist, who were entirely of his invention (see Mangan 1836). Anikó Sohár (1998) has looked at the widespread practice of fictitious translation in contemporary Hungary, where translations of English-language science-fiction novels that never existed are published. In fact, one could argue that translators are akin to master forgers.

A common enough definition of translation is that it saves us from having to read the original (Ladmiral 1995, 418). Students of pragmatic translation or translators working in localization companies are told that the end-users of technical documentation must not know that they are reading a translation. The text must read like an original. In other words, it must be a successful forgery. The ethical opprobrium attached to forgery may make translators reluctant to acknowledge the affinity, but both activities involve considerable ingenuity; poor translations resemble nothing more than sloppy reproductions. The question I have asked elsewhere (see Cronin 1997-1998) 
is whether it is possible to make a distinction between "translation as reproduction" and "translation as transformation." The polyglot narrator in Héctor Biancotti's Sans la miséricorde du Christ (1985) makes explicit the proximity of translation and falsehood:

Moi, qui n'ai plus de langue, mais que tourmentent plusieurs ou qui, parfois bénéficie de plusieurs, $j$ 'ai des sentiments qui varient selon les mots que j'emploie. Il m'arrive d'être désespéré dans une langue et à peine triste dans une autre. Chaque langue nous fait mentir, exclut une partie des faits, de nous-mêmes; mais dans le mensonge, il y a une affirmation, et c'est une façon d'être à un moment donné; plusieurs langues à la fois nous désavouent, nous morcellent, nous éparpillent en nous-mêmes. (8)

In the context of colonialism-and it is interesting that Macpherson, Mangan and the Hungarians are all translating from a periphery-political truths can be articulated through translation falsehoods, as in the "Sheelagh Bull" example, or, perhaps more correctly, the duplicitous nature of translation can be a strategy that both obstructs and promotes communication. ${ }^{6}$ The political circumstances of translation affect the strategy adopted, as is clear from the obstructionist strategy adopted in Jacobite macaronic verse in eighteenth-century Ireland.

\section{The Translator-Nomad}

In Franz Kafka's short story "Ein altes Blatt" (An old manuscript), Chinese functionaries await destruction at the hands of nomadic tribes who have breached their defences. One of the functionaries claims despairingly, "Sprechen kann man mit den Nomaden nicht. Unsere Sprache kennen sie nicht, ja sie haben kaum eine eigene" (It is impossible to speak to the nomads. They do not know our language; indeed, they hardly have a language of their own) (130). In fact, Kafka's nomads refuse to be translated; they play a deadly zero-sum game of non-equivalence with their Chinese enemies. While all nomads may not be translators, all translators might be defined as nomads. Indeed, the translator-nomad is a recurring figure in translation history. In the preface to his Latin translation of St. John Chrysostom's Homilies on the Gospel of John, the great twelfth-century translator Burgundio of Pisa declared:

I, Burgundio, in fear that, if I wrote in my own idiom when translating this holy father's commentary, I would be changing the meaning of one or more propositions of these two very wise men, and would be incurring the risk of altering so great an original (for these are 
words of faith) through my own error, I resolved to take a more difficult journey and preserve in my translation not only words with the same meaning as in the original Greek but also the same style and order of words. $(1997,41)$

Translation as a difficult journey had been anticipated by St. Jerome's remarks in his famous letter to Pammachius in AD 395, where the translator of the Vulgate quotes from the preface to his translation of Eusebius of Caeserae's Chronicle: "Possibly, I have no equivalent by which to express some word, and if I then must go out of my way to reach the goal, miles are spent to cover what is in reality a short distance" $(1997,26)$.

As Hardy suggests in The Return of the Native, travellers arriving in a foreign country are often objects of suspicion, but so also are travellers returning to their native country. As we saw earlier in the case of translatorsas-informers, they are both remote (politically) from their compatriots and near (linguistically, culturally). For the German thinker Georg Simmel, the tension between distance and proximity is most dramatically evident in the case of the "stranger." In his 1908 essay "Der Fremde," Simmel describes the stranger not as the wanderer who comes today and is gone tomorrow, but rather the person who comes today and stays tomorrow-"the potential wanderer so to speak, who, although he has gone no further, has not quite got over the freedom of coming and going" $(1971,143)$. And this is frequently the position of the translator. He or she eventually settles down, but never gets over the freedom of coming and going. This is even more evident with the shift from translation of classical languages to that of vernacular languages as the main form of translation, and the consequent need to remain in contact with changes in living languages. Simmel points out that in economic activity, the stranger is omnipresent as trader. As long as people produce goods for their own needs or goods are circulated within a small group, there is no need for a middleman:

A trader is required only for goods produced outside the group. Unless there are people who wander out into foreign lands to buy these necessities, in which case they are themselves "strange" merchants in this other region, the trader must be a stranger; there is no opportunity for anyone else to make a living at it. (144)

Johann Wolfgang von Goethe in an 1828 article on Thomas Carlyle's German Romances draws an explicit parallel between the trader and translator. He claims that anyone who studies German finds himself in the marketplace where all nations peddle their wares:

And that is how we should see the translator, as one who strives to be a mediator in this universal, intellectual trade, and makes it his business to promote exchange. For whatever one may say about the 
shortcomings of translations, they are and will remain most important and worthy undertakings in world communication. $(1997,225)$

Mobility is central to Simmel's notion of the trader. The trader is a stranger on the move. When we look at translation theory, we tend to find the following division: translation theory and history deal with literature and religion; translation pedagogy and practice deal with economic, technical and scientific translation. Commercial translation is seen as the vocational application of translation principles. However, commercial translation can also be seen as a nomadic practice that has long involved translators-strangers trading not only in goods, but also in words. A significant motive for translation in the colonial and postcolonial period has been trade in one form or the other. If we conceive of commerce in Simmel's conception of the stranger, then it becomes possible to link commerce and translation as nomadic practices and to argue that translation history in the postcolonial period must not confine itself to the sacred texts of religious and profane literature, but must examine in detail the whole practice of commercial translation and how the translation relationships expressed in this practice are related to the question of power. This, in turn, means that "pragmatic" translation (i.e., technical, scientific, commercial translation) must not become the sole domain of CAT (computer-assisted translation) experts and translation pedagogues. Pragmatic translation is as much in need of a "cultural turn," a political reading, as the high-culture forms of translation practice that have, up until now, monopolized our attention. No full understanding of the impact of translation on colonial and postcolonial societies can be arrived at if we do not investigate, for example, how the relationship between commerce and translation evolved in different colonial situations. Who were translators? Colonizers, traders or both? Were translators and traders separate categories or were traders also translators (interpreters) and vice versa? What impact does translation have on the economic dependency - or otherwise —of postcolonial states in globalized relations of trade ? $^{7}$ These and many other questions point to the significant research potential of pragmatic translation in the context of debates on language, colonization and power.

Goethe was eager to point out that the translator/trader can play "the role of interpreter while enriching himself' (225). The connection between money and translation is not a fortuitous one, and the link has been established by many commentators over the centuries. The French aesthetician Charles Batteux, for example, brings money, trade and translation together in his Principes de littérature (1747-1748). He recommends the use of what we would now call "transposition" in translation practice:

Let him [the translator] take the scales, weigh the expressions on either side, poise them every way, he will be allowed alterations, 
provided he preserve to the thought the same substance and the same life. He will act only like a traveller, who, for his conveniency, exchanges sometimes one piece of gold for several of silver, sometimes several pieces of silver for one of gold.

And the psychology of money is the topic of Georg Simmel's essay "Zur Psychologie des Geldes." He notes that many oppressed and marginalized groups throughout history have sought refuge in activities connected with money. The unspecific character of money meant that its channels ran in many different directions and thus offered possibilities of influence where direct access to power was denied: "Those classes, to whom many goals of personal aspiration were denied from the very outset on the grounds of their civic position, turned to the acquisition of money with particular success"' $(1997,241)$.

The classes or groups referred to by Simmel were the freed slaves of Ancient Rome, the Huguenots and the Jewish community in different cultures. He might also have included the Catholics in eighteenth-century Ireland, who, because of the penal laws that prevented them from entering the professions and owning large amounts of land, turned to trade and money as alternative outlets for economic survival and social mobility. It is striking that the Huguenots in eighteenth-century England and Ireland, the Jewish community throughout history and the Catholic Irish from the sixteenth to the nineteenth century were also extensively involved in translation activity.

As George Steiner argues in an essay on comparative literature in the collection No Passion Spent: Essays, 1978-1996, Jewish scholars or scholars of Jewish origin have played a preponderant role in the development of comparative literature as a critical pursuit.

Endowed, it would appear, with an unusual facility for languages, compelled to be a frontalier (the grim Swiss word for those who, materially and psychologically, dwell near or astride borders), the twentieth-century Jew would be drawn naturally to a comparative view of the secular literatures which he treasured but in none of which he was natively or "by right of natural inheritance" altogether at home. $(1996,148)$

Steiner might have made a similar case for the enormous contribution Jewish scholars have made to translation studies in the twentieth century - from Walter Benjamin to Steiner himself, to contemporary figures like Gideon Toury. Goethe's contention that he "who studies German finds himself in the marketplace where all nations offer their wares" $(1997,225)$ has a truth that he himself may not have anticipated. Many of those offering their wares may indeed have no other choice, just as the sole source of 
patronage for Irish-language translators in the eighteenth century was a new colonial class, a minority of whose members had antiquarian interests. Therefore, the relationship between the marginalized and translation is not a supplemental afterthought to translation history, prompted by twentieth-century soul-searching, but is increasingly emerging as a central feature of translation practice down through the centuries. In the same way that minority languages have far more exposure to the fact of translation than majority languages, marginalized groups, often as a result of nomadic displacement or territorial dispossession, are generally much more implicated in the practice of translation than dominant, settled communities. However, it is precisely these minority languages and marginalized groups that are largely absent as a focus of inquiry from translation theories and histories.

In Entre-Deux: L'origine en partage, Daniel Sibony describes the situation of the "entre-deux-langues," a space frequently occupied by translators in their endless journeying between one language/culture and another:

Comme franchissement, il consiste à inhiber dans une langue son collage à l'origine, sa prétention à être La langue-origine. Il s'agit de se dégager de ce qui, dans la langue où l'on baigne, fait qu'elle se pose comme l'Origine du langage; et de pouvoir donc la traduire, la trahir dans d'autres langues qui la "déforment." Alors on peut passer à d'autres langues; d'autres langues ... deviennent vivables et sont appelées à "vivre." L'origine comme parlante éclate alors dans l'entredeux-langues qu'elle nourrit sans l'envahir. Faute de cela, le sujet ne peut parler et inventer dans d'autres langues; la première lui tient lieu de toute l'origine. $(1991,166)$

[As a crossing over, it consists of preventing a language from clinging to its origin, to its claim to be The language-origin. It involves freeing ourselves from that which makes the language in which we are immersed set itself up as the Origin of language. Therefore, we must be able to translate it, betray it to other languages that "distort" it. Only then can we move on to other languages; other languages become viable and are called upon to "live." The speaking origin erupts then in the space between-two-languages which it nourishes without invading. Failing this, the subject cannot speak or invent in other languages; the first language is the only origin that exists for her. $]^{8}$

Sibony describes his work as beginning with the "entre-deux-langues" and finishing with travel. Travel allows one to reconstruct oneself, to produce something that is other than the self, but where the self can be recognized, 
and where the self acquires a certain consistency. The inability to travel brings us once again back to the question of origins:

... l'impuissance à voyager, c'est-à-dire à intégrer de nouveaux "lieux" non reconnus, à intégrer l'inconnu, voire l'inconnaissable, est la même que l'impuissance à faire alliance et partage, ou à supporter l'origine multiple. Il ne s'agit pas d'aller vers l'origine mais de voyager avec l'idée de l'origine, de faire voyager l'origine. (315, his emphasis)

[... the inability to travel, that is to say, to integrate new, unrecognizable "places," to integrate the unknown, the unknowable even, is also the inability to form alliances and to share, or to tolerate a multiple origin. It is not a question of going toward the origin but of travelling with the idea of origin, of making the origin travel.] ${ }^{9}$

The issue of origin, as we saw earlier, exercised the imperial mind and explained the particular potency of the Transylvanian vampires with their unstable, multiple origins. In recent debates on postmodernism, postcolonialism and feminism, much attention has been focussed on the notion of the nomadic subject, in particular in the work of two feminist scholars, Rosi Braidotti and Caren Kaplan. Braidotti defines the polyglot as being "nomad in between languages":

The nomadic polyglot practices an aesthetic style based on compassion for the incongruities, the repetitions, the arbitrariness of the languages $\mathrm{s} / \mathrm{he}$ deals with. Writing is for the polyglot, a process of undoing the illusory stability of fixed identities, bursting open the bubble of ontological security that comes from familiarity with one linguistic site. The polyglot exposes this false security. $(1994,15)$

Globalization, mass tourism, expanded federal systems, internal and external migration, all foreground the nomadic, and Braidotti offers a euphoric, liberatory vision of the translator-nomad at the end of this millennium. Elements of this nomadic aesthetics certainly point to the potential of translation as an instrument of emancipation in colonial and postcolonial contexts: the emphasis on challenging fixed identities, the sensitivity to arbitrariness, the interrogation of ontological securities that we have already seen with respect to the status of the original in translation. But to invoke Maxwell's field theory once more, movement is not unmediated. There are real obstacles to the triumphant progression of the postcolonial translator. Bruce Chatwin, another theoretician of the nomadic, claimed in his essay "Nomad Invasions":

Nomads never roam aimlessly from place to place, as one dictionary would have it. A nomadic migration is a guided tour of animals around a predictable sequence of pastures. It has the same inflexible charac- 
ter as the migrations of wild game, since the same ecological factors determine it. $(1990,219)$

In our contemporary cultural ecosystem, then, what factors determine the nomadic migration of postcolonial translation? Three factors might be mentioned: lack of historical awareness, infrastructural dependency and high-risk translation environment.

\section{Lack of Historical Awareness}

It is of paramount importance that the work of postcolonial translators be situated in both their own history and the history of others who find themselves in similar political, linguistic and historical predicaments. Anthropologist $\mathrm{M}$. Crick, in an article on the representations of international tourism in the social sciences, noted the absence of the "local voice" in the description of the effects of international tourism. He went on to argue that "without close attention to the local voice, our social scientific work risks being descriptively poor and ethnocentric" $(1989,314)$. Local voices are increasingly being heard in translation studies, but the number of published monographs on translation history by "local" scholars from postcolonial countries is still pitifully small.

There is an added danger for postcolonial scholars, however, in that specificity of origin should not be allowed to overdetermine their contribution to wider debates. What I mean by this is that, whereas scholars from powerful ex-colonial nations can write about whatever they like, the tendency can be to only invite postcolonial scholars to write about their own specific cultural, linguistic or political experience. But nationality is not destiny, and all areas of translation theory, not just translation history, need to be informed by the theoretical perspectives of translators working in postcolonial contexts.

\section{Infrastructural Dependency}

This relates primarily to the production and distribution of translations. There are two levels of dependency that correspond more or less to the shift from a colonial to a postcolonial situation. The first level involves importing or reprinting translations that are produced by the imperial centre: for example, separate editions of fifteen of August von Kotzebue's plays were published in Dublin in 1799, but only one of these translations was by an Irish translator. The production of one's own translations is indeed often seen as a primary mark of cultural independence - hence, the indigenous publishing boom that often accompanies movements of national emancipation. The second level of dependency is more complex and relates to the market 
restriction of translation possibilities for postcolonial translators and to their linguistic position. In postcolonial cultures where one of the languages of translation is a dominant world-language, translators can produce inward translations of lesser-known authors working in commercially less-successful genres, but much more rarely do they find themselves producing inward translations of major world figures. The result is that the bookshops of Dublin (and Montreal) are stocked with titles translated by British, American and French translators for British, American and French publishers. In Ireland, indigenous English-language translation in the last two decades has been almost exclusively dominated by poetic translation with small print runs and inadequate remuneration. This infrastructural dependency is not necessarily a negative development as it is possible to argue that the periphery can afford to be more aesthetically adventurous than the centre in its choice of authors and texts to be translated.$^{10}$ However, even if such experiment is possible, publishers from postcolonial states often find themselves victims of international distribution and marketing arrangements that favour large publishers from powerful nations, so that it is difficult to get these translations to other markets.

\section{High-Risk Translation Environment}

Postcolonial peoples who have been translated (linguistically) or who translate themselves (both physically and linguistically) are acutely sensitive to the affective cost of displacement. ${ }^{11}$ The experience of estrangement, loss, disorientation is involved in these translations. For this reason, translation must not become invisible once again, this time as an emotional and cognitive transaction cost in the elaboration of a nomadic aesthetics. This is not to claim that translation is a secondary distortion that blights the Eden of monoglot cultures. Such a position is absurd in that cultures are, at some level, always already translated. On the other hand, cultural hybridity is often invoked by critics of postcolonial readings of translation less to champion historical scrupulousness than to discredit the whole postcolonial enterprise by dire reference to the twin evils of nativism and essentialism. Translation does have a profound effect on culture, and the associated traumas are complex in their effects. ${ }^{12}$ The traumas exist and cannot be wished away in a glorious celebration of cultural and linguistic plurality, however edifying the celebration. Making the origin travel, sharing, fragmenting and multiplying the space of origin is continually shadowed by the lingering guilt of duplicity, treason and betrayal.

In an essay entitled "Looking at Obstacles," British psychoanalyst Adam Phillips argues that children find out what an object is by constructing obstacles to its access or availability. He claims: 
The search for obstacles - the need to impose them in their familiar guise of time and space-is part of the endless, baffled inquiry into the nature of the object. I know what something or someone is by finding out what comes between us. $(1993,96)$

In my view, exploring the historical and contemporary obstacles to translation in colonial and postcolonial contexts can help us to find out what this object called "translation" is. In one sense, Walter Benjamin's notion of translation as überleben may indeed be the unsettling, protean state of the Undead.

\section{Notes}

1. For a detailed history of the Ordnance Survey in Ireland, see Andrews (1975).

2. For an account of the life and scholarship of O'Donovan, one of the most active members of the topographical department of the Ordnance Survey, see Boyne (1987). The limits to local knowledge in subverting an imperial project are graphically illustrated by the fate of the topographical department of the Ordnance Survey. One of the primary activities of the department was to draw up Memoirs that would include a systematic description of the social, economic and cultural aspects of life in each Irish county. The Memoirs project embodied the epistemic ambition of Empire in its desire to produce a total knowledge of the lives of its subjects. However, only one of the Memoirs was produced-Memoir of the County of Londonderry (1837). There was increasing hostility to the project on the grounds of cost and, more importantly, political unsafeness. Boyne writes, "In some quarters it was stated that the historical and social sections of the memoirs would revive political animosities, provoke intense patriotic feeling, and make much more bitter the deep divisions between members of different religions, between the governing classes and those governed, between former and present holders of land," 22 . She adds in a footnote that this was believed to be the main reason for the suppression of the Memoirs project. A formal Order was sent on July 1,1840 by the Master of Ordnance in England to the Survey in Ireland instructing members of the Survey to revert to strictly cartographical functions for the purposes of valuation. Despite the recommendation by the Commission of Inquiry established in June 1843 by Sir Robert Peel that the Memoirs continue to be published, the project was abandoned.

3. For a discussion of the cultural implications of the notion of the "missing link," see Beer (1996).

4. For an interesting discussion of the notion of the "monstrous," particularly in relation to representations of women, see Braidotti (1994), ch. 3.

5. For examples of such verse, see Breandản Ó Buachalla (1996).

6. The relationship between translation, forgery and cultural resonance is also discussed in Welch (1997).

7. I have attempted to examine this question in the context of Ireland and the software localization industry in Cronin, "The Broadest Way Immarginable"" (forthcoming). 
8. My translation.

9. Ibid.

10. I am grateful to Ubaldo Stecconi for his observations on this point.

11. For a discussion of some of the issues involved, see the essays in King, Connell and White (1995).

12. For a psychoanalytic perspective on the nature of trauma in language and cultural transfer, see Amati Mehler, Argentieri and Canestri (1994).

\section{Works Cited}

AMATI MEHLER, Jacqueline, Simona ARGENTIERI and Jorge CANESTRI. 1994. La Babel de l'inconscient: Langue maternelle, langues étrangères et psychanalyse. Trans. Maya Garbuoa. Paris: PUF.

ANDREWS, John. 1975. A Paper Landscape: The Ordnance Survey in 19th Century Ireland. Oxford: Oxford UP.

BEER, Gillian, ed. 1996. Open Fields: Science in Cultural Encounter. Oxford: Clarendon P.

BIANCOTTI, Héctor. 1985. Sans la miséricorde du Christ. Paris: Gallimard.

BOYNE, Patricia. 1987. John O'Donovan (1806-1861): A Biography. Kilkenny: Boethius.

BRAIDOTTI, Rosi. 1994. Nomadic Subjects: Embodiment and Sexual Difference in Contemporary Feminist Theory. New York: Columbia UP.

BURGUNDIO OF PISA. 1997. "The Risk of Altering So Great an Original." In Western Translation Theory, ed. Robinson, 41-43.

CHATWIN, Bruce. 1990. "Nomad Invasions." What Am I Doing Here? London: Picador. 216-19.

CRICK, M. 1989. "Representations of International Tourism in the Social Sciences: Sun, Sex, Sights, Saving and Servility." Annual Review of Anthropology 18: 307-44.

CRONIN, Michael. 1997-1998. "After Bellsybabble: Transformation, Invention and Resistance in Translation." Parallèles 19: 48-59.

."'The Broadest Way Immarginable': Peripherality, Localization and Polyglossia." In Translation and Globalization, ed. Annie Brisset and Paul St. Pierre. Forthcoming.

EGERTON, P., ed. 1847. Life of Lord Grey of Wilton. London: Camden Society.

FRIEL, Brian. 1981. Translations. New York: Samuel French.

GENTZLER, Edwin. 1996. "Translation, Counter-Culture and The Fifties in the USA." In Translation Power Subversion, ed. Román Álvarez and M. Carmen-África Vidal, 11637. Clevedon: Multilingual Matters.

GOETHE, Johann Wolfgang von. 1997. "On Carlyle's German Romances." In Western Translation Theory, ed. Robinson, 224-25. 
HARMAN, P.M. 1982. Energy, Fonce and Matter: The Conceptual Development of Nineteenth-Century Physics. Cambridge: Cambridge UP.

JACKSON, Donald. 1973. "The Irish Language and the Tudor Government." Eire-Ireland 8, no. 1: 21-28.

KAFKA, Franz. 1971. “Ein altes Blatt.” Sämtliche Erzählungen, 129-34. Frankfurt: Fischer Verlag.

KAPLAN, Caren. 1996. Questions of Travel: Postmodern Discourses of Displacement. Durham: Duke UP.

KING, Russell, John CONNELL and Paul WHITE, eds. 1995. Writing Across Worlds: Literature and Migration. London/New York: Routledge.

LADMIRAL, Jean-René. 1995. 'Traduire, c'est-à-dire... Phénoménologies d'un concept pluriel." Meta 40, no. 3: 415-20.

MANGAN, James Clarence. 1836. "Anthologia Germanica." Dublin University Magazine (Mar.): 278-302.

NIRANJANA, Tejaswini. 1992. Siting Translation: History, Post-Structuralism and the Colonial Context. Berkeley: U of California P.

Ó BUACHALLA, Breandán. 1996. Aisling Ghéar. Baile Átha Cliath: An Clóchomhar.

O'NEILL, Patrick. 1976. "The Reception of German Literature in Ireland, 1750-1850." Studia Hibernica 16: 122-39.

PHILLIPS, Adam. 1993. "Looking at Obstacles." Kissing, Tickling and Being Bored, 8398. London: Faber and Faber.

RICHARDS, Thomas. 1993. The Imperial Archive: Knowledge and the Fantasy of Empire. London: Verso.

ROBINSON, Douglas, ed. 1997. Western Translation Theory: From Herodotus to Nietzsche. Manchester: St. Jerome Publishing.

RUSKIN, John. 1979. "The Storm-Cloud of the Nineteenth Century." In Norton Anthology of English Literature, 4th ed., M.H. Abrams et al., vol. 2, 1341-42. New York: Norton.

SIBONY, Daniel. 1991. Entre-Deux: L'origine en partage. Paris: Seuil.

SIMMEL, Georg. 1971. "The Stranger." In On Individuality and Social Forms, trans. and ed. Donald N. Levine, 143-49. Chicago: Chicago UP.

. 1997. Simmel on Culture. Ed. David Frisby and Mike Featherstone. London: Sage.

SOHÁR, Anikó. 1998. "“Genuine' and 'Fictitious' Translations of Science Fiction and Fantasy in Hungary." Unity in Diversity? Current Trends in Translation Studies, ed. Lynne Bowker, Michael Cronin, Dorothy Kenny and Jennifer Pearson, 39-46. Manchester: St. Jerome Publishing.

ST. JEROME. 1997. “Letter to Pammachius, no. 57." In Western Translation Theory, ed. Robinson, 23-30.

STEINER, George. 1996. "What Is Comparative Literature?" No Passion Spent: Essays, 1978-1996, 142-59. London: Faber and Faber. 
STOKER, Bram. 1993. Dracula. London: Everyman.

WELCH, Robert. 1988. A History of Verse Translation from the Irish, 1789-1897. Gerrards Cross: Colin Smythe.

1997. "A Ghostly Paradigm: Translation and the Source." Translation Ireland 11, no. 2: 13-15.

WILLIAMS, Nicholas. 1986. I bPrionta i Leabhar: Na Protastúin agus Prós na Gaeilge 1567-1724. Baile Átha Cliath: An Clóchomhar. 


\title{
Chapter 2
}

\section{"COLONIZATION," RESISTANCE AND THE USES OF POSTCOLONIAL TRANSLATION THEORY IN TWENTIETH-CENTURY CHINA}

\author{
Leo Tak-hung Chan \\ Lingnan College (Hong Kong)
}

Discussions of postcolonial translations have come into vogue in recent years. Originally a term used extensively in literary theory, "postcoloniality" seems suddenly to have been given a prominent part to play in research on translation in Third World countries, particularly India. Undoubtedly, postcolonial theory should have some relevance to all countries that were colonized in one way or another. That being the case, much thought ought to be given to the relevance of postcolonial translation to China. To be sure, China has not been formally occupied by a foreign power in the past century, so she has not experienced a "colonial" period as did her Southeast Asian neighbours, India and most African countries. Indeed, extraterritorial rights over certain parts of the country (like Shanghai and the Yangtze River) were claimed at certain times by foreign powers: Hong Kong was ceded to Britain (though she entered her postcolonial period with the 1997 Chinese takeover); and Taiwan was colonized by the Dutch and by the Japanese (from the end of the nineteenth century to the end of World War II). However, for mainland China, where the majority of translations are still carried out and published, the term "postcoloniality" may not mean much. What use do we have for postcolonial theories of translation in the Chinese context?

In hindsight, the influx of contemporary Western critical theory into China is among the most phenomenal intellectual events of the eighties and 
nineties. The chain of events connected with the introduction of deconstructionism, feminism and postcolonialism (not postcolonial translation theory, though) into China can be briefly recounted. Other than the proliferation of translated texts on "new theory," one can cite a sequence of academic events sponsored by China, but attended by major Western theorists. Fredric Jameson toured the major Chinese universities in 1985, and two conferences at which postcolonialism became a hot subject were held in 1995. At the International Conference on Cultural Studies held in Dalian (August 1995), scholars such as Terry Eagleton and Ralph Cohen were invited to give lectures; at the International Conference on Cultural Dialogue and Cultural Misreading (October 1995), which took place in Beijing, Douwe Fokkema, Gerald Gillespie and Mario Valdes were the principal speakers. Another international conference that served as a forum for debating the applicability of Western critical theories, including postcolonial theories, was the Conference on Critical Theories: China and the West, sponsored by the Chinese Academy of Social Sciences and held in the summer of 1997 in Changsha, Hunan. Jameson was again one of the keynote speakers at the conference. Thus, before the century draws to a close, postcolonial theory from the West will have been well planted in Chinese intellectual soil; this is not dissimilar to the way in which sundry kinds of commodities have successfully found a place (at roughly the same time) on the Chinese market.

That postcolonial theory has become a reality in both the fields of literature and linguistics is evidenced by the spate of articles and books on the subject by Chinese scholars in the past decade. ${ }^{1}$ If this trend continues, translation studies in China will eventually have to face the postcolonial challenge. This article attempts to show how the new critical discourse on postcoloniality can become significant and meaningful in the Chinese context. I will consider the two "positions" that Chinese translation theorists, cultural theorists and translators have taken as a response to "colonization." Additionally, my discussion will be guided by the following insight: though the concepts of postcoloniality in translation throw new light on the Chinese situation, the uniqueness of the Chinese case forces us to revise the parameters within which postcolonial theorizing functions. To begin with, it must be noted that the terms "postcolonial" and "colonization" are used here in their broader sense, being restricted neither geographically nor temporally. This qualification is important in view of the fact that there has never been any form of territorial colonialism to speak of in the Chinese context; rather, the Chinese have experienced, since the beginning of the century, a partly self-imposed kind of cultural and linguistic colonization. The difference between the Chinese situation and the Indian model, on which most recent postcolonial translation theorizing has been based, ${ }^{2}$ is probably as wide as can be imagined. 
More specifically, to explicate the Chinese case I will use the elements that are the focus of analysis by postcolonial critics: the production of (Western) forms of discourse during periods of colonial expansion, the use of universalist discourses to subjugate colonized and marginalized peoples, and the resistance to the apparently well-meaning imperialist projects. Among these, the idea of native (or nativist) resistance will engage the greater part of my attention, especially as many texts, when examined from a postcolonial perspective, reveal the degree to which the "colonized" can react, and are not simply acted upon. The discussion below will centre around the different forms of resistance over a wide historical span, beginning with the 1920 s and ending in the present. I will first detail the arguments, made prior to the nineties, against translators contaminating the Chinese language through the introduction of Europeanized structures and expressions. Then a reversal is shown to have occurred in the nineties, the counter-argument being that the language itself, carrying a unique "cultural cargo," simply cannot be contaminated. It can be said that the resistance prior to the nineties was very much an unconscious one, and by reading the statements of theorists with the benefit of postcolonial theory, we will see issues and approaches not obvious even to the writers of those statements. Subsequent to the work of those theorists, a conscious effort was made to combat "colonization" by European languages, but the still-ongoing resistance was forged in the main by cultural critics for whom translation theorizing was nevertheless of little interest.

\section{Keeping the Language "Pure"}

A clear contribution of postcolonial theory to our understanding of Chinese translations is the new light it sheds on existing translated texts. This comes about in an act of rereading: the theory is retroactively applied to a colonial, or even precolonial, period. The body of ideas associated with postcolonial translation theory, when shorn of its temporal-historical dimension, becomes applicable to earlier eras in which postcolonial translation practices, as we know them now, were only nascent. Thus, we can look at the first position, taken by translators and translation theorists in an earlier period, which we could designate as an act of resistance: the call for using a "pure" Chinese language when translating. A dominant trend since 1919 (the year the May Fourth Movement broke out in protest against the unjust treatment given China by the Western powers and Japan in the aftermath of World War I) was to adhere closely to the formal features of source texts and to import, on a huge scale, foreign terms and expressions. For many, this was a means whereby the sterile Chinese language could be rejuvenated. There is no need at this point to pursue at length the continued (and still continuing) debate on the merits and drawbacks of using imported structures and expressions. ${ }^{3}$ Suffice it to say that the opponents of linguistic Europeanization 
were in fact fighting against a form of colonization; they were attacking a new language emerging primarily out of translations into Chinese, with the following features:

(1) the insertion of subjects where none was needed;

(2) the increased use of conjunctions and other linking devices;

(3) the proliferation of passive structures;

(4) the appearance of affix-like morphemes like hua ("-ize") and fei ("non-"); and

(5) the widespread use of lengthy modifiers.

From our present-day perspective, it seems clear that the linguistic purists were fighting a losing battle. Lydia Liu has recently proven, with ample documentary evidence, that modern Chinese is a heteroglossic construction, incorporating elements from many languages - though predominantly, we must say, resulting from the aggressive cultural influence of Japanese, English and Russian. ${ }^{4}$ Nevertheless, the resistance efforts merit closer examination, and I will refer specifically to two of these, one in the thirties and another in the sixties.

In the "Language of the Masses Movement" (dazhongyu yundong) of the thirties, the target of attack was Europeanized Chinese; spoken Chinese as it was used in people's daily lives was considered superior because, crude as it was, it was at least more "alive." There are, however, deeper implications to the debate, for the question of the kind of language fit for use also engaged issues of ethnic and national identity. The leaders of the movement, such as Chen Wangdao (1890-1977) and Ye Shengtao (18941988), held that "language, being the supreme symbol of ethnic character," would be defiled if foreign elements were admitted into it (Fang 1992, 34348). Like these leaders, Zhao Shuli (1906-1970), a leading novelist of the era, advocated using a new language with Chinese characteristics. He was most adamant about avoiding Europeanizations; for him, every nation and every race has its own special linguistic habits, and it is precisely these habits that distinguish one language from another-and by analogy, one national or ethnic group from another. Zhao believed that Chinese is as fully capable of fulfilling its mission as other languages are of theirs. In fact, he was of the opinion that, of the two archrivals, Europeanized Chinese and classical Chinese (a language comparable to Latin of the Middle Ages, and a language which the vernacular has been trying to replace), the former is much more to be feared.

Translators and translation theorists resisted the Europeanizations as strongly as creative authors (such as Zhao and Ye) did, and as a group, they sought to launch an attack from another front. In a way, Frederick Tsai 
(1918-1996) and Yu Kwang-chung's (1928-) call to "purify" Chinese in the sixties must also be understood as a continuation of the fight against "linguistic colonization" by the West (and Japan). But this time, the alternative suggested was not the spoken language or the language of everybody; rather, it was the traditional vernacular used before the twentieth century. This vernacular was a written language first developed near the end of the ninth century. Unlike classical Chinese, which remained the standard written language through the centuries, the traditional vernacular more nearly resembled the spoken language of the past and was used to serve "low-culture functions"; it was used in popular writings, such as plays and novels, of the late imperial era. ${ }^{5}$ Although the modern vernacular, having matured slowly since the beginning of the twentieth century, was developed in part from the traditional vernacular, they remain different in significant ways. Primarily, the modern vernacular has incorporated to a substantial degree European structures and expressions. For over a decade, Tsai and Yu issued repeated calls to free the Chinese language from the superimposed foreign influences; put simply, for them the modern vernacular needs to be replaced with the traditional vernacular. By so doing, they opened a new chapter in the history of resistance against Europeanizations.

Tsai and Yu followed nearly parallel careers: both lived in Hong Kong and Taiwan for extended periods of time; both achieved fame as creative writers (the former an essayist, the latter a poet) as well as translators; and both not only translated prodigiously, but also-as translation teachers-raised an entire generation of translators in Hong Kong and Taiwan. Most significantly, both sought to resurrect classic vernacular Chinese novels, such as Dream of the Red Chamber (eighteenth century), as models of language used in traditional times that ought to be emulated by translators (see Tsai 1972, 94-95). Though their views did have a lasting impact, they were not without their detractors. For instance, Frederick Tsai's stand was criticized as impossible to maintain consistently by one of the most influential translation scholars from Taiwan (see Huang 1974). Citing copious examples from Tsai, he shows why the existence of a plural form for "it" (tamen) is indispensable, and denounces as impracticable all of Tsai's suggested alternatives (like repeating the antecedent or not making a distinction between the singular and plural forms of pronouns). For him, all efforts to counter Europeanizations can be half-hearted at best. All in all, it did not seem as if the purists of the sixties were able to go very far in their attack on Europeanizations.

\section{The Nineties: Foregrounding Chineseness}

While efforts at defending the Chinese language against the onslaught of Europeanized translations have continued into the present, since the 
eighties the signs of an alternative mode of resistance have become more and more conspicuous. This second "position" came into existence as a consequence of the recent introduction into Chinese critical and academic circles of new theories dubbed "post-isms": postmodernism, postcolonialism, post-Enlightenment ideas, postcolonialism and so on. If Chinese culture in the May Fourth period (from 1919 to roughly the end of the twenties) can be said to have been "colonized" for the first time, then Deng Xiaoping's era from the late seventies to 1997 -divided by the 1989 Tiananmen Incident into the "New Era" (prior to 1989) and the "Post-New Era" (after 1989 till his death) - has witnessed a "second colonization." Wang Jing has called this period China's "second renaissance"; the similarities that it bears to the late 1910s and 1920s are unmistakable, for both of these eras saw a massive importation of Western ideas. In the late eighties and early nineties, in particular, large-scale translation projects were carried out on key works of Western theory; what modernity meant for China was intensely discussed, and interest in comparative studies of Chinese and Western cultures flourished. ${ }^{6}$ The spirit of the age was such that culture, native as well as foreign, figured prominently in any discourse of contemporary relevance. It is in this context that linguists and cultural theorists have directly and indirectly brought a postcolonial perspective to issues of translation.

What we have referred to as a second position in the reaction against Western linguistic imperialism was taken largely by linguists and cultural theorists, but not translation scholars and practitioners. It is apparent that, the current situation in China being what it is, theorizing about the cultural role that translation is to play will originate with those who grapple with Western theory, rather than those who are primarily translators. In what follows, I will discuss the views of a linguist, a cultural critic and a translation theorist. All three provide perspectives on translation (indirectly, in the case of the first two) that can be appropriately termed "postcolonialist."

Shen Xiaolong (1952-), currently Professor of Chinese at Fudan University, Shanghai, is a staunch exponent of a new approach to analyzing the Chinese language that discards Western linguistic models (see Shen $1992 ; 1995 a)$. He set out to tackle the failure of Western linguistic theory to explain adequately the peculiarities of the Chinese language in his epochmaking study Interpreting Language (1992). For him, the time had come to revamp the entire Chinese linguistic tradition of the twentieth century, which began with the misguided attempt by Ma Jianzhong (1845-1900) in the late nineteenth century to borrow wholesale the Western model, and impose it on the Chinese language. The experience of the last ninety years-especially the insuperable difficulties in analyzing Chinese syntax-has shown that it is futile to try to account for features in the Chinese language simply 
by theories that were developed in the West with reference to Indo-European languages.

The reception of Shen Xiaolong's ideas, however, has been extremely mixed. Considered currently as the leader of one of the three main schools of "cultural linguistics," a new field of study born of the mid-eighties, Shen is sharply differentiated from those cultural linguists whose focus is on the synchronic and diachronic study of how culture influences language and vice versa, and from those who seek to unravel the "cultural content" of a language (Chinese in this case) through an examination of how language adapts to social and communicative needs. Best known for the way in which he highlights language as a system of signs peculiar only to the culture in which it finds itself, a system understandable only by those using the language, Shen has been praised as the "hope of Chinese linguistics." Yet at the same time, others have openly derided him, saying that he is not worthy of serious attention. The debate on Shen's true significance (or lack thereof) reflects, in fact, an atmosphere where linguists are eager to revoke Western linguistic methods that have been applied indiscriminately over the past century, and to establish cultural linguistics as the avenue for "rejuvenating" linguistic study in China. Whether they choose to agree or disagree with Shen, there is little doubt that Shen's system has arisen out of a unique historical—shall we say, postcolonial—situation. ${ }^{7}$

Yet in stressing the need to sinicize the study of Chinese grammar, Shen is in fact furthering the cause of linguists of the thirties, like Fu Donghua (1893-1971) and Chen Wangdao, though he gives a new twist to the model being constructed (see Shen 1992, 416-17). Freely adopting terms from traditional Chinese aesthetics, ${ }^{8}$ he notes the following peculiarities of the Chinese language:

(1) the preference for economy of expression (jian);

(2) the aspiration toward achieving phonological harmony;

(3) the close attention to balance between empty ( $x u$ ) and concrete (shi) words; and

(4) the tendency to use the various parts of speech freely, so long as what is said makes sense.

He concludes in Interpreting Language that such peculiarities reveal the extent to which Chinese can be said to favour "associative thinking," allow the speaker's intentions to shape the language and generally privilege content (or "spirit") over form. This partly explains why the language does not fare well when Western linguistic models, with their strength in formal analysis, are applied. He argues (elsewhere) that the model of "subject-verbobject" ought to be abandoned in the analysis of Chinese sentences, since 
the clue to understanding Chinese syntax lies in explicating the use of "phrases" (jududuan), the fundamental unit of the Chinese sentence (see Shen 1995b, 37-39). ${ }^{9}$ The essence of Shen's argument, which evinces a strong cultural and ethnic bias, adumbrated repeatedly in the dozens of articles and books that he has written, is that a language is inseparable from the culture in which it is nourished and that "when [Chinese] linguistics is severed from Chinese culture, the maternal source of its being, it becomes stale and lifeless" (1990, 75). At one point in Interpreting Language, Shen talks about Europeanizations imported through translations, but curiously, he considers them to be present mainly in non-literary writings such as those of a technical or political nature; Chinese literature has not been much affected $(1992,451-52)$. While Shen seems to be only tangentially interested in translation, he puts forth a theory with serious implications for translation studies.

A similar statement could be made about Zhang Yiwu (1962-), presently Associate Professor of Chinese at Beijing University, and foremost among scholars who have applied a postcolonialist approach to literary studies in China. Zhang was one of the most powerful voices in the early nineties against the Western presence in Chinese intellectual life, which, after all, has been pervasive since the May Fourth era. In contrast to the earlier opponents of Europeanizations in translations, he fights as much against cultural as against linguistic "colonization." In the first two chapters of his book Exploring the Margins (1993), he describes his resistance strategy: to fight back against Western ideological encroachment on its own terms. He points out that while Derrida advocates breaking down binary oppositions, the opposition between the First World and the Third World is one that has yet to be broken down and that China can be a test-case of how a new kind of cultural theory and discourse, pertinent to a Third World country, can be fruitfully developed (Zhang 1993, 14).

In chapter three, in many ways the central chapter of the book, Zhang Yiwu elaborates on a key point that Shen Xiaolong had already made: a language must not be seen as a mere sign system, divorced from the culture in which it is embedded. Reiterated time and again by Zhang is the idea of the mother tongue (note the maternal metaphor, used also by Shen) and the ever-present, ever-powerful "collective memory" that it invokes for every Chinese. For the Chinese language carries a cultural residue, accumulated over a historical span of 5,000 years, that can never be erased in spite of overwhelming Western influence and violence done to the language through the importation of foreign words, structures and modes of expression. Like his predecessors who opposed Europeanizations in translation, Zhang sourly notes the irreparable damage done to the native tongue; for him, the impact is seen clearly in the realm of literature, for the language of literature is after 
all "the distilled essence of the mother-tongue, the agent for the spread of culture" (66). Thus Chinese literature becomes relegated to a subordinate and marginalized position, and pales beside Western literatures.

Unlike his anti-Europeanization predecessors, however, Zhang does not propose ways of further moulding the vernacular to serve as a medium of expression as effectively as Europeanized Chinese does. The attempt to enrich the Chinese language through the incorporation of elements from "real" spoken language is, for him, as ill-advised as the belief-first voiced by scholars like Hu Shi (1891-1962)-that this same language can be improved through the incorporation of translated foreign models. As a method of resistance, Zhang advocates using a new kind of written Chinese, for which he coins the term "post-vernacular" (haobaihua). Drawing upon examples from works by major authors on the Mainland and in Taiwan since the eighties, he discusses the possibility of re-introducing elements of the classical language, denigrated since the May Fourth period, into contemporary written Chinese. It is his opinion that the classical language, the more refined, terse and compact language of the traditional literati that served high-culture functions for two millennia (from the second century $\mathrm{BC}$ to the end of the nineteenth century), should be given a greater role to play. Zhang sums up the postmodern view of language (with a Derridean touch) embodied by the postvernacular thus:

[It] recognizes the fissure, the cleavage between the signifier and the signified, between language and reality. Language is no longer subordinate to the object of signification; it does not connect with reality; it is simply a moving and free-floating signifying system. (71)

Zhang takes pains to point out that his advocacy of the postvernacular does not amount to a rediscovery of (or a retum to) the classical language, or the defeat of the vernacular language in the competition for ascendancy. What he stresses is the potency of the classical language as a carrier of cultural residue and its possible contribution to the emergence of a new mode of expression. Furthermore, Europeanizations are accepted, if only because it is no longer possible, in these fin de siècle times, to talk of completely purging them from the Chinese language. But Zhang is far from arguing for Europeanizations, as a wave of translation theorists in the twenties and thirties, such as Lu Xun (1881-1936) and Zhou Zuoren (18851968), did. The latter two did not think that the Chinese language was adequate for its purposes, whereas Zhang holds the opposite view and revalorizes the classical language, saying that it is more than adequate. Zhang's position is also different from those who suggested that the Chinese language should be completely romanized (see Qu 1989, 3: 280-309) 
or replaced with Esperanto, the "World-language." 10 He restores dignity to the Chinese language while recognizing the difficulty of keeping it pure.

The postvernacular, then, is to be a hybrid language that admits elements of diverse sorts. It is reminiscent of the "in-between" language that Samia Mehrez describes in her study of Francophone North African texts in the postcolonial period-a "newly forged language" that is capable of "exploding and confounding different symbolic worlds and separate systems of signification in order to create a mutual interdependence and intersignification" (1992, 121-22). Seen from this perspective, a postcolonial critic (or a "nativist semiotician," as he has been called in China) such as Zhang Yiwu can be said to have moved to the other end of the spectrum on the issue of the proper language to be used for translations; as opposed to linguistic purity, he favours hybridity. In fact, the position that Zhang assumes is postcolonial in two senses: his recognition of hybridity ${ }^{11}$ and his refusal to accept the modern vernacular - very much a "colonial product"as a replacement language for classical Chinese.

The views of Shen Xiaolong and Zhang Yiwu furnish a context for better understanding the recent work of Liu Miqing (1939-), our third perspective. A graduate of Beijing University and currently Associate Professor of Translation at the Chinese University of Hong Kong, Liu has written prodigiously on Chinese-English translation and to date has authored five books, which, taken together, present a systematic and coherent body of ideas on translation unmatched by any other theorist in this century. His earlier full-length studies deal variously with the translation of different genres, skills for translating from English into Chinese, and contrastive study of the two languages. ${ }^{12}$ However, Present-Day Translation Studies (1993) (a Taiwan reprint of a mainland version published in 1990) is by common consent the most representative of Liu's works; it proffers a comprehensive re-examination of issues pertinent to translation theory and summarizes Liu's positions on certain aspects of translation theory, such as the basic operating mechanisms in translating, translation as a mode of thinking, the stages in the translation process, translatability and untranslatability, and the translation of style. This work was followed in 1995 by the publication of Aesthetic Studies of Translation, in which the aesthetics of translation (already touched upon in one chapter of Present-Day Translation Studies) are singled out for separate and detailed treatment.

As Liu Miqing himself has noted, his complete oeuvre forms a closely knit system that attempts to formulate a translation theory for modern China. ${ }^{13}$ As early as 1987, at the first Conference on Translation Theory in China, he expressed the need for "a Chinese translation theory," and this issue is brought up again in his Present-Day Translation Studies. Stating at 
the outset that there are no global translation theories and that all theorizing can only proceed from knowledge of a pair —or a very limited number - of languages, Liu advocates developing translation theory from the actual experience of translating from or into the Chinese language:

Undoubtedly, the basic model for translation theory in China should begin and end with our mother-tongue... We neglect at our own peril the distribution of lexical meanings and functions of the Chinese language. With this consideration in mind, we can summarily call this basic model a "descriptive semantic-functional model." (my emphasis) $(1993,30)$

The maternal metaphor may or may not have been intended, but we already have here the basic ingredients of a counter-discourse. To be sure, Liu proceeds to expatiate on the specificity of the Chinese experience of translation by discussing the special features of the Chinese language in terms similar to those used by Shen Xiaolong.

Most notably, Liu stresses the idea that the Chinese language, unlike Indo-European languages, is composed of "sentence sections," which are the primary building blocks (bankuai) for clauses, sentences and even paragraphs. These sections are strung together rather loosely, as aggregates or conglomerates, and cohere around the "topic" or the thought to be expressed. It is in this sense that "spirit controls form" (to borrow Chinese terminology). By contrast, in Indo-European languages formal features play a significant role in sentence making, and instead of building blocks, a language like English is structured by means of "chain connections" (Liu 1993, 3335). While clearly an oversimplification, this mode of describing the difference of the "language of the colonized" from the "colonizer's language" is gaining popularity in the discourse of societies emerging from the colonial yoke. Basil Hatim has noted how the Arabs-like the Chinese, perhapshave been described as tending "to fit the thought to the word... rather than the word to the thought"; for them, "the words become the substitutes of thought, and not their representative" $(1997,161)$. One may add that, besides this, the vagueness of thought that linguists have identified in Arabic is almost comparable to the so-called "expressive" nature of the Chinese language, which is prone to present ideas in a cinematographic manner. Elsewhere in the same book, Liu also opposes the form-oriented and analytical features typical of the English language against the thought-oriented and synthetic power of Chinese. Such overgeneralizations about languages are, of course, quite dangerous, but one notices readily the "strategic" function they can serve in postcolonial discourse. Indeed, Liu's presentation of the Chinese language as different, but distinct, from other languages contrasts remarkably with the denigration of the language as inferior and inadequate by men of letters in the twenties, such as Lu Xun. 
Seen in a broader context, Liu Miqing's desire to theorize about translation on the basis of an assumed "equality" between Chinese and Western languages can be understood as the cumulative result of decades of thinking "positively" about their mother tongue on the part of translators. On the question of the perniciousness of Europeanizations also, Liu stands closer to his postcolonial contemporaries (such as Zhang Yiwu) than to the harsh critics of Europeanized Chinese (such as Frederick Tsai) of earlier decades. In a brief section on translationese in Present-Day Translation Studies, he calls the introduction of foreign terms and structures through translation an "alienation" process through which languages can reach even higher planes of perfection. This seems to point toward the more radical position that he takes in Aesthetic Studies of Translation. In this, his most recent book, Liu initiates a completely new view of translation as an activity, developing a discourse on translation that can be seen as almost counter-hegemonic. He blends traditional Chinese aesthetics with Western approaches to translation in order to rewrite translation theory from a Chinese perspective.

In striking contrast to his earlier works, which testify to his familiarity with Western translation theory, Aesthetic Studies of Translation is sprinkled everywhere with references to seminal texts by Chinese aestheticians, from Laozi and Liu Xie (c. 465-522), Zhong Rong (c. 465-518), Sikong Tu (837-809) to Wang Guowei (1877-1927). Among these figures, Laozi is raised to an eminent position. His dictum, from Daode jing [The Classic of the Dao], that "beautiful words are not truthful; truthful words are not beautiful" is cited time and again to clarify the debate between fidelity to the original and artistry in translating. Concepts corresponding to modern Western reception/semiotic theory are sought from Liu Xie and The Book of Rites - the latter, it is said, addressed two millennia ago the methods by which the translator "decodes the feelings" expressed in a literary text (Liu 1995, 200). In a lengthy section on the rendition of the source-text style, ten different styles of writing-reserved, bold, refined, natural, adorned, diluted, light-hearted, forceful, solid, humorous - are expounded with reference to at least one example of Chinese-English or English-Chinese translation in each case (see Liu 1995, 213-38). In line with the sinicizing approach adopted throughout the book, the "Chinese" origins of each style are documented with quotations from traditional Chinese aesthetics texts.

If we understand postcolonial discourse broadly and see it as essentially a question of positionality - that is, where one places oneself in relation to existing modes of interpreting reality--then Liu can be seen as standing alongside Shen and Zhang in denying hegemonic narratives of what the Chinese language is like, and how translation should be understood. 
The basic strategy of resistance deployed by all three is to foreground Chineseness; by pointing out alternative (read "nativist") modes of understanding and contesting prevailing (read "Western") paradigms, they have effectively intervened into and altered perceptions of what the language of translation should be. Insofar as they have voiced similar oppositions to the epistemic violence done to the Chinese language, the earlier theorists can be regarded as postcolonialist, though they may have worked in the "colonial" period. One phenomenon worth pondering is that the resistance efforts were strongest at precisely those times when "colonization" proceeded most ferociously - first in the twenties, immediately after the May Movement, then in the eighties and nineties, when China was again opened to the outside world in the era of Deng Xiaoping's reforms. Though the occurrence of resistance is surely determined by many factors, the history of cultural resistance in China suggests that feelings for sinicization are most intense where Westernization poses the greatest threat (in the first case) and the impact of postcolonial thought is seen most powerfully not in the place of its origin, but in its place of destination, at which it arrives with all its colonial appendages (in the second case). Or there might even be a paradoxical love-hate relationship between the colonizers and the colonized, rendering it necessary to rethink the myth of the inevitable confrontationor opposition-between the two.

\section{Conclusion: A Third Position?}

It may be worth our while, in our concluding remarks, to consider the possibility of a third position of resistance that we have not examined because it, paradoxically, is tantamount to a position of non-resistance. The proponents of Europeanized Chinese came close to endorsing this position, though none said so explicitly, and I will call this the "culturalist" argument for Europeanization/colonization. In her brilliant essay on postcoloniality in Hong Kong in the run-up to 1997, Rey Chow denounces the tendency on the part of some scholars to dilute the specificity of the term "postcolonialism" by allowing it to be construed as synonymous with "postmodernism." She stresses that postcolonialism as a body of ideas has its special value in cultural analysis, a value which is revealed through postcolonialism's application in individual cases (see Chow 1992). If Hong Kong is one such case, then China must be another. The uniqueness of the Chinese situation needs to be taken into consideration if one is to talk about postcoloniality in the Chinese context.

In the first place, with the exception of Hong Kong, China hasstrictly speaking - never been territorially occupied by a foreign power. As a consequence, though Western imperialism did indeed have an impact on 
Chinese life for the greater part of the twentieth century, colonization can only be conceived in cultural terms. Unlike India and most Southeast Asian countries (e.g., Vietnam, Cambodia, Thailand, Laos, Malaysia and the Philippines), mainland China has never come under French, British or American domination; thus, postcolonial theory may seem to furnish a less-thanperfect "tool" when extended to the Chinese case. Second, it must be admitted that China was (and still is) a cultural colonizer herself. Through the centuries Chinese culture has penetrated deeply into Southeast Asian countries such as Vietnam, Thailand, Malaysia and Indonesia; this is borne out by the huge amount of translation of the Chinese classics as well as popular Chinese literature into Vietnamese, Thai, Malay, Makassarese and Madurese. ${ }^{14}$ How does one apply postcolonial theory to a colonized country that is at the same time a colonizer?

The actual situation seems to be that the majority of Chinese translators today use Europeanized structures and expressions almost unthinkingly; this goes against what the translation theorists and cultural critics mentioned above have proposed as "proper." Of course it is true that in China as elsewhere, nations are losing their battle against the "linguistic colonization" by English (already on its way to becoming our lingua franca) and against the cultural dominance of the West. But the complicity of Chinese translators with Western colonizers can be looked at from a different angle. Among the Chinese there has always been an acute consciousness of China's positional superiority vis-à-vis the West. It is well known that, through the centuries of China's history, loanwords (from Mongolian, Pali, Sanskrit and Tibetan, to name just a few) have been ceaselessly absorbed into the Chinese language--just as non-Chinese ethnic groups were assimilated by the Chinese-and linguists have demonstrated that lexical items from diverse languages (such as Hindi) entered the Chinese lexicographical stock via translations. What is linguistic is also cultural. The culturalist viewpoint is precisely that Chinese culture is all-inclusive, and other cultures contribute to it like tributaries to the mainstream. (Similar arguments have been advanced by countries other than China. Of India it has been said that "the amazing capacity to assimilate alien cultural, linguistic, and literary elements is a unique and essential feature of Indian history" [Devy 1997, 400].)

Following this line of thinking, Europeanizations need not be feared. The language, as much as the culture, is powerful enough to absorb alien influences. The recent arguments for the superiority of the Chinese language must be read against this background of linguistic confidence, asserted in the face of the irreversible trend toward incorporating Europeanizations. The paramount concern for many linguistic researchers since the eighties has been to prove that the Chinese tonal system is better 
(than the non-tonal system of Western languages); monosyllabic characters lend themselves more readily to computerization; the flexibility in Chinese word-formation is an advantage; the absence of inflections is a positive feature, as is the presence of words serving as more than one part of speech; and the use of ideograms is preferred to that of phonetic or alphabetic writing. Not unexpectedly, against such arguments, the "colonizers" have fought back: recently Wm. C. Hannas debunked the myth of the usefulness of the character-based Chinese writing system, along with much fallacious reasoning accrued around Chinese as a language. ${ }^{15}$ In spite of that, however, such rediscovered confidence has continued to grow in China, reflecting what for one critic is a "giant consciousness"- "a deeply seated superiority complex... that dictated the sovereignty of China's cultural subjectivity even when it was conscious of its debt to the Western discourse" (Wang 1996, 169).

This is, then, the "colonizer's position," never explicitly presented as such, but perhaps always lurking somewhere in the Chinese subconscious as a viable position to be taken. The unspoken faith in the power of the Chinese language is reminiscent of what Goethe said in regard to German: "The force of a language is not to reject the foreign, but to devour it" (qtd. in Berman 1992, 1). This is also tantamount to a third position of resistance. Diametrically opposed to the first, it is similar in certain ways to the second. It is founded on an unshaken belief in the superiority of Chinese culture, and in China's ability to emerge as the host of the cultural exchange process that we call translation.

\section{Notes}

1. See Wang (1995) for a summary of these trends.

2. See, in particular, Niranjana (1992).

3. See Chan (1996) for a survey of the Europeanization debate.

4. For examples of Japanese, English, French, German and Russian terms that have entered the Chinese language in the past two centuries, see Lydia Liu (1995), 284301, 343-78.

5. For a description in English of the differences between classical Chinese, the traditional vernacular and the modern vernacular, see Chen (1993).

6. Wang (1996), 48-52, depicts at some length the intellectual atmosphere of the eighties, calling it a "culture fever." The impact of the West is clearly observable in this "second colonization."

7. This is an aspect of "culture fever" that Wang (1996) has not considered; her emphasis is on the literary scene. In the main, the reaction against Western linguistics takes the form of a refusal to continue using the analytical methods of the structuralists and an attempt to highlight the "humanistic" study of the Chinese language. 
8. Shen makes abundant reference to Liu Xie's Wenxin diaolong [The Literary Mind and the Carving of Dragons], but other masters of Chinese aesthetics from traditional times are also called upon-among them the ancient philosopher Laozi and the Song dynasty poetry critic Yan Yu (fl. 1180-1235).

9. Shen ends this article by stressing the need "to develop a linguistic theory with Chinese characteristics," 41 .

10. The promotion of Esperanto was most fervent during the early twentieth century; among the better known advocates were Ba Jin and Cai Yuanpei. For some time there was a craze for learning Esperanto among Chinese intellectuals in Shanghai. An abundance of literary works were translated from Esperanto by Zhou Zuoren and others, and an exchange of views concerning the use of this "World-language" that lasted for two years was documented in the 1917-1919 issues of the journal Xin gingnian [New Youth]. See Hou (1926) for a contemporary account.

11. The leading spokesman for the link between postcoloniality and hybridity is Homi Bhabha. See Bhabha (1994), 212-35.

12. These are Wenti yu fanyi [Genre and Translation] (1985), Ying Han fanyi jineng xunlian shouce [Training Handbook for English-Chinese Translation] (1987) and Han Ying duibi yanjiu yu fanyi [CE-EC Contrastive Studies and Translation] (1991).

13. Liu Miqing (1989), 12-15, also stresses the importance of building a Chinese translation theory. Another theorist making the same point is Luo Xinzhang; see Luo (1984), 1-19. For a recent discussion of Liu's research, see Lei (1993).

14. For an indispensable reference work on translations of Chinese works in East Asian and Southeast Asian countries, see Salmon (1987).

15. For arguments in defence of Chinese superiority, see Xu (1992), 26-41. For the Westem response, see Hannas (1997), 174-204.

\section{Works Cited}

BERMAN, Antoine. 1992. The Experience of the Foreign: Culture and Tradition in Romantic Germany. Trans. S. Heyvaert. Albany: State U of New York P.

BHABHA, Homi. 1994. "How Newness Enters the World: Postmodern Space, Postcolonial Times and the Trials of Cultural Translation." The Location of Culture. London/New York: Routledge.

CHAN, Leo Tak-hung. 1996. "Europeanizations Reconsidered: The Deconstructionist Turn in Chinese Translation Theory." In Translation and Meaning: Volume Four, ed. Barbara Lewandowska-Tomaszczyk and Marcel Thelen. Maastricht: Rijkshogeschool.

CHEN, Ping. 1993. "Modern Written Chinese in Development." Language in Society 22: 505-37.

CHOW, Rey. 1992. "Between Colonizers: Hong Kong's Postcolonial Self-Writing in the 1990s." Diaspora: A Journal of Transnational Studies 2, no. 2: 151-70.

DEVY, G.N. 1997. "Literary History and Translation: An Indian View.” Meta 42, no. 2: $395-406$. 
FANG Xide. 1992. Zhongguo xiandai xiaoshuo yu wenxue chuantong [The Modern Chinese Novel and Literary Tradition]. Beijing: Beijing daxue chubanshe.

HANNAS, Wm. C. 1997. Asia's Orthographic Dilemma. Honolulu: U of Hawaii P.

HATIM, Basil. 1997. Communication Across Cultures: Translation Theory and Contrastive Text Linguistics. London/New York: Routledge.

HOU Jue. 1926. Shïieyu gailun [A General Introduction to Esperanto]. Shanghai: Shangwu yinshuguan.

HUANG Xuanfan. 1974. "Ping Xi Guo zhu Fanyi yanjiu" ["A Critique of Frederick Tsai's Studies on Translation']. Zhongwai wenxue 2, no. 2: 48-49.

LEI Wei. 1993. "Kaituo yu chuangshen: Liu Miqing de fanyi lilun yanjiu shuping" ["Expanding Boundaries and Creating Newness: A Survey of Liu Miqing's Studies of Translation Theory"]. Zhongguo fanyi 3: 46-50.

LIU, Lydia. 1995. Translingual Practice: Literature, National Culture, and Translated Modernity - China, 1900-1937. Stanford: Stanford UP.

LIU Miqing. 1989. "Lun Zhongguo fanyi jiben moshi" ["On the Basic Model for a Chinese Translation Theory"]. Zhongguo fanyi 1: 12-15.

1993. Dangdai fanyi lilun [Present-Day Translation Studies]. Taibei: Shulin chubanshe. Rpt. of Xiandai fanyi lilun [Modern Translation Studies]. Nanchang: Jiangxi jiaoyu chubanshe, 1990.

1995. Fanyi meixue daolun [Aesthetic Studies of Translation]. Taibei: Shulin chubanshe.

LUO Xinzhang. 1984. "Woguo zicheng tixi de fanyi lilun" ["China's Own System of Translation Theory"]. Fanyi lunji [Essays on Translation]. Beijing: Shangwu yinshuguan.

MEHREZ, Samia. 1992. "Translation and the Postcolonial Experience: The Francophone North African Text." In Rethinking Translation: Discourse, Subjectivity, Ideology, ed. Lawrence Venuti, 120-38. New York: Routledge.

NIRANJANA, Tejaswini. 1992. Siting Translation: History, Post-Structuralism and the Colonial Context. Berkeley: $\mathrm{U}$ of California $\mathrm{P}$.

QU Qiubai. 1989. "Xin Zhongguo de wenzi geming” ["A Linguistic Revolution in New China"]. In Qu Qiubai wenji: wenxue bian [Essays by Qu Qiubai: Literary Essays]. Beijing: Renmin wenxue chubanshe.

SALMON, Claudine. 1987. Literary Migrations: Traditional Chinese Fiction in Asia. Beijing: International Culture Publishing Corp.

SHEN Xiaolong. 1990. Zhongguo wenhua yuyanxue [Chinese Cultural Linguistics]. Jilin: Jilin jiaoyu chubanshe.

1992. Yuwen de chanshi: Zhongguo yuwen chuantong de xiandai yiyi [Interpreting Language: The Modern Meaning of Chinese Linguistic Traditions]. Shenyang: Liaoning jiaoyu chubanshe.

1995a. Dangdai Zhongguo yufaxue [A Study of Contemporary Chinese Syntax]. Guangzhou: Guangdong jiaoyu chubanshe. 
1995b. "Lishixing de fanbo: Zhongguo wenhua yuyanxue" ["Reversing Historicity: Chinese Cultural Linguistics"]. In Wenhua yuyanxue Zhongguochao [The Chinese Wave of Cultural Linguistics], ed. Shao Jingmin. Beijing: Yuwen chubanshe.

TSAI, Frederick. 1972. Fanyi yanjiu [Studies on Translation]. Taibei: Dadi chubanshe.

WANG Jing. 1996. High Culture Fever: Politics, Aesthetics, and Ideology in Deng's China. Berkeley: U of California P.

WANG Ning. 1995. "Dongfang zhuyi, houzhimin zhuyi he wenhua baquan zhuyi pipan: Aidehua Saiyide de houzhimin zhuyi lilun pouxi" ["Orientalism, Postcolonialism and the Critique of Cultural Hegemonism: A Theoretical Anatomy of Edward Said's Postcolonial Theory"]. Beijing daxue xuebao 2: 54-62.

XU Dejiang. 1992. Dangdai yuyan wenji lilun de xingouxiang [Rethinking Linguistic Theories in the Contemporary Era]. Beijing: Kexue chubanshe.

ZHANG Yiwu. 1993. Zai bianyuan chu zuisuo: Disan shijie wenhua yu dangdai Zhongguo wenxue [Exploring the Margins: Third World Culture and Contemporary Chinese Literature]. Changchun: Shidai wenyi chubanshe. 
Chapter 3

\title{
THE POWER OF TRANSLATION: A SURVEY OF TRANSLATION IN ORISSA ${ }^{1}$
}

\author{
Diptiranjan Pattanaik \\ Utkal University (India)
}

Taking advantage of the recent importance accorded to narratives, I shall begin this paper with an anecdote. I sometimes write Oriya short stories for local journals. My regular audience, a close circle of friends, do not think that these stories are anything special. However, it so happened that one of them was translated into English and published in Katha Prize Stories. Friends who read the English version were genuinely impressed by the novelty of the theme, its dramatic presentation and its message. When I pointed out that this was the same story they had earlier dismissed as trite in both subject and treatment, they were surprised; they suggested that the translator had modified, upgraded, the text. Theoretically, this is within the realm of possibility. Alexander Tytler proposes that translation is a contest between the geniuses of the author and the translator, in which the translator "strives to exalt a worthy original by expunging or altering low images, puerile allusions and obvious defects which detract from the overall effect" $(1978,54)$. But in the case of my story, though the name of a venerable Oriya literary personage appeared as the translator, as far as I was concerned, the real work - the telling of the story-was done by me. And I had this perverse Nabokovian insistence on literal renderings to such an extent that sophisticated renderings in the target language were excluded. How then did an Oriya short story, initially dismissed by a well-read and knowledgeable audience, not only retain, but surpass what Walter Benjamin has called its "aura" in translation? 
Eugene Chen Eoyang has an interesting insight to offer about such a phenomenon:

It may be that translation is the ultimate form of literary evaluation-for only seeing it from the outside can one see a work for what it is. Knowing can be differentiated into native command and abstract understanding: the first embodies what is known, and knowledge becomes familiarity (like knowing something like "the back of one's own hand"); the second defamiliarizes what is known, and knowledge becomes analytical insight (like knowing how to operate on someone else's hand). Translation involves the second kind of knowing: the native, even if he understands and appreciates the translation in the target language, will encounter it as something strange, often to be deplored, occasionally to be relished (like contemporary Japanese preferring The Tale of Genji in English translation, even to the many modern Japanese versions). (1993, 278)

It is apparent that both Tytler and Eoyang, while theorizing on translation, refer to exalted texts which have been canonized in the original version prior to being translated. In contrast, the case of my story involves a work which becomes canonized only after, and seemingly because of the fact that, it has been translated into another language, and especially into English. The very fact that a text is considered worthy of translation somehow elevates its canonical worth. There is an assumption that the text has the capacity to speak beyond the boundaries of the specific cultural-linguistic context of its origin. This phenomenon is specially true of the contemporary literary situation in Orissa. For the purposes of this paper, I will offer two possible explanations for this state of affairs: the first refers to the traditionally high esteem in which the act of translation is held in the Oriya canon; and the second refers to the unprecedented significance accorded to English, a language under postcolonial dispensation. This shift in linguistic authority is accompanied by a decay of the Oriya literature readership.

The act of translation is central to the formation of an Oriya literary canon. With the exception of valiant attempts by saint-poets such as Luippa and Kanhuppa to record their spiritual realizations in the symbolist minimalist poetry of Charya $\bar{a}$ Gitikā, which were written in the people's language, the earliest Oriya texts were translations from Sanskrit. This translation phenomenon is not limited to either the Oriya or Indian context, in fact it is true of most of the literatures of the world. According to Alastaire Fowler, "Many of the most original works are based on the creative reinterpretation of predecessors in a genre" (1982, 31-32). What is so significant about endotropic translation into Oriya is that it has always aligned itself with the attempt to formulate a distinct cultural identity of the Oriya-speaking people. Endotropic 
translation has also acted as an instrument of democratization, consistently subverting the power bases of elite religious and political groups.

Long after the emergence of several spoken languages from Sanskrit (around the tenth century $\mathrm{AD}$ ), the mother language continued to be the language of the scriptures, art and knowledge. Since it was in the hands of the elite priestly class, they were able to control the spiritual as well as secular domains of the people's lives. The lower castes were forbidden to learn Sanskrit or to read the scriptures. Thus, the hegemonic designs of the elite were perpetuated. In the fifteenth century, the foundations of what we know today as written literature in Orissa were laid by Sarala Das, who translated into the popular language Oriya the Mahäbhärata, the great Sanskrit epic by Vyasa concerning the war between Bharata's descendants; the Vilankā Rāmàyana, a Sanskrit epic, ascribed to Valmiki, recounting the exploits of Rama; and Chandi Purāna, an epic poem based on the Sanskrit Durgasaptasati, containing 5,500 verses. By so doing, he not only violated the norms laid down by the elite class - for he belonged to a lower castebut dared to show easy acquaintance with the texts he translated, and also other important Sanskrit manuscripts. He was translating holy texts from deba bhasa - the language of the Gods - into Oriya, the language of humans. Moreover, his translations were subversive in numerous ways: the text of the Mahābhärata was re-articulated to better suit the nature of the Oriya people; the Vilanka Rāmāyana subverted the patriarchal male order by attributing Rama's victory over the thousand-headed Ravana of Vilanka, not to the help of an entire army, but to the aid of his wife Sita, the incarnation of Shakti, the eternal feminine principle. Sarala Das himself was a worshipper of Shakti.

The revolutionary zeal of a translator can usually be gauged from the depth of his or her social commitment and eagerness to share a truth articulated in another language with his or her own people through translation. Sarala's translations, or rather his transcreations, are ample proof of the culturally revolutionizing nature of his inspiration. His literary efforts coincided with the rise in the Oriya people's military and political fortunes under Kapilendra Dev, ${ }^{2}$ who, like Sarala Das, was of very humble origins. Kapilendra Dev unseated his predecessor, a king of the Ganga dynasty (498 to 1435), during whose rule decadence had set in in all walks of Oriya life, and ascended the throne of Orissa. He extended the political territory of Orissa from the Ganges in the north to the Godavari in the south; and he made a significant contribution to stabilizing the internal administration of his kingdom. As a major sponsor of art and architecture, Kapilendra Dev enriched the cultural life of the Oriya people. At the same time, Sarala assumed the cultural leadership of Orissa, and sought to forge a distinct lin- 
Sanskrit still found favour among the elites: kings and noblemen continued to sponsor Sanskrit poets and scholars; and Brahmins were still very influential in matters of administration. For these reasons, though the importance of Sanskrit was waning throughout northern India, it still commanded enormous respect in Orissa. In the twelfth century, Sanskrit was the chosen language for Jayadev's Geeta Govinda, as it was in the fifteenth century for, among others, Biswanath Kaviraj's Sähitya Darpana, a famous treatise on literary aesthetics; Murari Mishra's Anargha Rāghaba Nätakam; Bhattanarayana's Benisanhāram Nätakam; Krushna Mishra's Prabodha Chandrodaya Nätakam; and Sriharsa's Naisadhiya Caritam. Despite the prestige that Sanskrit enjoyed among scholars and in the courts, Oriya, which was derived from Purva Magadhi around the ninth and tenth centuries, became established among the common people, around Sarala Das's time. The elites, however, looked down on the language, branding it prakrit ${ }^{3}$ language, or bibhasa. Indeed, references of such hostility toward the language of the common people can be found in the famous prose-poem by Avadhuta Narayana Swami (thirteenth century), Rudra Sudhanidhi, the earliest complete prose work in Oriya. Despite opposition from the establishment, Sarala's translation of the Mahābhärata into the people's language employed the Dandi rhyme-a popular composition technique in which each line of each couplet contains eighteen letters. Sarala must be considered a true revolutionary who was able to bring Indian philosophy and literature to the common people, freeing them from the monopoly of Sanskrit scholars and Brahmins, and to establish the Oriya language and literature.

The Sanskrit Mahäbhärata largely conveys the worldview of the Vedic Brahminical culture, and dramatizes the conflict between good and evil as it is perceived therein. According to the Vedic Brahminical worldview, the true purpose of human life is to acquire the four bargas, or goalsdharma, artha, kama and moksa, that is, duty, material goods, love and the final liberation of the soul-through the discipline of the four ashramas, or stages of life-brahmacharya, garhastya, banaprastha and sanyasa, that is, celibacy, the married state of the householder, the state of retirement to life in the forest and the final renunciation of all worldly interests. In the course of delineating this worldview the Sanskrit Mahābhārata postulates the ultimate triumph of good over evil. The good characters in the Sanskrit epic exemplify the dharmic life. Sri Krishna, the hero of the epic, and the five Pandava brothers, who are representatives of the dharmic ideal, appear to be very divine in their conception (Biardeau 1982, 75-97).

Indeed, the Mahäbhärata was written against the background of Aryan culture in contemporary northern and central India of the time. However, since Sarala Das wanted to use contemporary Orissa of his time as the backdrop for his transcreation, he had to initiate several changes in the original 
plot, characterization and episodes. Unlike the Sanskrit characters therefore, Sarala's Oriya characters are not overtly divine; in fact, they resemble the average Oriya: Sri Krishna is a village tout trying to accomplish his ulterior motives through good means and bad, as it suits him: several of his actions-such as placating an ass when it threatens to sabotage his mission; killing Belalasena through deception; seducing Radha's maid, Sahaja Sundari-serve to indicate his Machiavallian shrewdness. Similarly, Bhima is a simpleton with the very human weakness for food and wrestling, yet, despite his foolhardiness, his unwavering devotion to his elder brother makes him an adorable character. Draupadi, though she has given birth miraculously in the pit of a sacrificial pyre, is unable to refrain from a verbal duel with her co-wife, Hidimbika, like any other ordinary Odiya countrywoman. Despite having five husbands, she openly confesses her lust for Karna, and expresses her reluctance to spend the first night of marriage on the ashes of a smithy. In order to produce a truly Odiya national epic, Sarala Das took several liberties with the original Sanskrit epic, sometimes omitting episodes and occasionally expanding others or adding new ones to his Odiya narrative. Thus, he was not only able to humanize its appeal, but also to locate it in the very soil of Odissa. A good illustration of this point is the episode of Kokua with which Sarala replaces the Sanskrit Mahsbhārata's narration of how Kala, the force of destruction, appeared in every house of Dwaraka around the time of the annihilation of the Yadus race. Despite all their might, the marauding Yadus warriors could do nothing to prevent Kala. The Oriya episode of Kokua enabled the common people to grasp the complexity of the cosmic force of destruction. Other episodes that were invented to suit Oriya culture include Gandhari's marriage with a Sahada tree, Bhima's stealing of rice (indicative of the abject poverty of an Oriya peasant family) and Duryodhana's swim across the river of blood.

In the sixteenth century Jagannath Dash translated the Bhägabata, Hindu sacred literature known as the Puranas-another important text of the Oriya literary canon. Though a Brahmin himself, Jagannath Dash faced similar opposition from the Puri Mukti Mandap, the Brahmin orthodoxy which controlled the Hindu faith. It is believed that Jagannath Dash's main purpose in translating this sacred text was to enable his mother-women not being allowed to read Sanskrit-to read it for herself. During this period, Bhakti movements, movements based on devotional poetry, which sought to undermine the priestly mediation between man and God, were spreading all over the country, and many more translations of Sanskrit texts into popular languages were produced. In sixteenth-century Odissa, in addition to Jagannath Dash's work, many other works were translated, including Balarama Das's translation of Valmiki's Rāmāyana another milestone in Oriya canonical literature-and various translations by Brindavan Das 
and Badri Das. Translation activity also flourished in seventeenth-century Orissa: Mukul Das translated Betāla Panchavinsati, and a portion of Rupa Goswami's Bidagdha Mädhaba was translated by the poet Gopalakrishna Patnaik. Other notable translations of that period include Krishna Singh's Mahābhārata, Haladhara Das's Ādhyatma Bhãgabata, Balabhadra Mangaraj's Kshetra Mahātmya and Balaram Das's Gita. In addition, many Vaishnavite ${ }^{4}$ Oriya poets drew inspiration from earlier Vaishnavite Sanskrit poets, in their writings. The translations of the time all aimed at demystifying the sacred texts by rendering them in the language of the ordinary people, in the same way as the various religious movements were seeking to free religion from the stranglehold of Brahminical orthodoxy. Translations into Oriya maintained their ideological imperative of subversion of the dominant discourse by democratizing knowledge, by making it available to all sections of society, including women, and challenging the hegemony of the power elite.

It is not purely coincidental that most of the endotropic translation activity was undertaken at a time when the Ganga and Gajapati kings of Orissa had built a powerful empire that stretched from the Ganges in the north to the Kaveri in the south, and the Jagannath Temple at Puri had become a very important seat of the Hindu faith. Endotropic translations became associated with the consolidation of Oriya nationhood. The same flurry of endotropic translation was witnessed again in the late nineteenth/early twentieth century, when a movement to form a separate province of Oriyaspeaking people in colonial India was underway. Threatened by the attempts of the neighbouring Bengali-speaking people to undermine the status of Oriya as a language, littérateurs used translation as a tool for consolidating and strengthening Oriya language and literature. This was also the time when Oriya literature adopted a strategy to wean itself from its Sanskrit base, toward a more colloquial mode. This is seen especially in the writings of Fakirmohan Senapati..$^{5}$

The sphere of translation increased in the nineteenth century with the widespread use of the printing press. Fakirmohan, who was at the forefront of the movement to protect the identity of Oriya as a separate Indian language, was also involved in establishing the first printing press in Orissa. In addition to his original writings, he devoted a great deal of energy to the activity of translation: he not only translated Sanskrit texts such as the Rāmāyana, the Mahäbhārata and the Chhāndogya Upanisad, but also Bengali texts such as Iswarchandra Vidyasagar's Jivan Carita. Sitā Banabāsa, another text by Vidyasagar, was translated by Bichhanda Charan Patnaik, and Jaganmohan Lala translated the parts of Toynbee's history that were especially relevant to Orissa. Contemporaries of Fakirmohan who took an active part in the movement to maintain the separate identity of the Oriya 
language and literature were also aware of the importance of translation in such an enterprise. Poets Radhanath Ray and Madhusudan Rao translated Meghadutam, Tulasi Stabaka and Bhababhuti's Uttara Rāma Carita respectively, and Madhusudan Rao also transcreated William Cowper's famous poem "The Solitude of Alexander Selkirk." Other notable translations around that period were Meghaduta by Kalidasa; Chaura Panchäsika by Gopinath Nandasharma; Naishadha by Biramitra Singhdeo; Bhagbad Gitā by Acharya Harihar; Rāmäyan by Lingaraj Mishra; and Bikromorbashi, Mudrārākshāsa, Benisamhāra, Kumār Sambhaba and Mālati Mādhaba by Mrityunjaya Rath.

It is evident that the litterateurs of the Satyabadi group, the cultural centre of Orissa in the early twentieth century, maintained the revolutionary zeal which was associated with Fakirmohan's and Radhanath's efforts to assert the importance of Oriya language and literature. It is significant that they were also aware of the role of endotropic translation in enriching the Oriya literature: Nilakanth modelled his Pranayini and Dāsa Nāyaka on Tennyson's The Princess and Enoch Arden respectively. Godavarisha's Abhägini is modelled on Hugo's Les Misérables. Contemporaries of the Satyabadi group also excelled in endotropic translation: Ajaya Chandra Das translated Scott's The Lady of the Last Minstrel, Chandramani Das translated Goldsmith's The Deserted Village and Govinda Tripathy translated Cervantes's Don Quixote.

Under colonial administration, an important change took place: Western texts gradually became more esteemed than Sanskrit texts as originals for endotropic translation. The tone was already set by Christian missionaries who had translated into Oriya the major Christian religious texts, including the New Testament, as well as Bunyan's Pilgrim's Progress. While there were rare instances of texts such as Kautilya's Arthasashtra and Bhratrihari's Niti Sataka and Sringara Sataka being translated into Oriya, after India's independence from colonial rule toward the mid-twentieth century, more and more texts of the Western canon were rendered into Oriya. Akshaya Kumar Chakravarti and Mayadhar Mansingh introduced the works of Shakespeare to Oriya audiences; indeed, Chakravarti's Hamlet and Mansingh's Othello stand out as brilliant pieces of translation. During this period, Basant Kumar Satpathy translated Charles and Mary Lamb's Tales from Shakespeare and Amar Ballav Dey rendered Carlyle's The Hero and Hero Worship into Oriya. Also worth noting are Lala Nagendra Ray's translation of Melville's Moby Dick, Krushna Mohan Mohanty's translation of The Prisoner of Zenda and Subodh Chatterjee's translation of Richardson's Pamela. Popular literary texts and children's books were also translated into Oriya during this period, including Conan Doyle's Valley of Fears by Udayanath Sarangi, Bram Stoker's Dracula by Panchanan Pati, Rider 
Haggard's works by Ghanashyam Samal, Stevenson's Treasure Island and some of Jules Verne's works by Bansidhar Das. ${ }^{6}$ During the same time, Udayanath Sarangi's translation of Stowe's Uncle Tom's Cabin-the American classic set during the time of slavery-was a roaring success among Oriya audiences, especially children, but also adults, probably because it dramatized the tension between master and slave, between colonizer and colonized, and brought out the latent divinity in the downtrodden--a sentiment so dear to the Oriya heart, which has been conditioned by endemic adversity to glorify a fatalistic spiritualism. Gopinath Mohanty, a prominent Oriya creative writer of the post-independence era, whose work valorized the underprivileged and marginal groups in Orissa, undertook to translate Tolstoy's magnum opus War and Peace, while Gyanindra Verma presented Eliot's The Waste Land in Oriya and Pravash Satpathy translated Russian classics, including Dostoevsky's masterpiece Crime and Punishment. In the same vein, Ananta Patnaik, one of Orissa's pioneering leftist poets, translated Gorky's The Mother. This translation was significant in the sense that it sought to articulate the theme of the original novel against the background of an entirely Oriya ambience.

However, it is the translation efforts of Chittaranjan Das and Prafulla Das that stand out, not only by the sheer volume of their work, but by the ideological nature of their enterprise. Jorge Klor de Alva, in his essay "Language, Politics and Translation," argues that "the politics of a translation (or interpretation) are more likely to be configured by the unspoken and usually unperceived assumptions making up the reigning ideas and exegetical rules that guide the translator" $(1989,143)$. But these two translators almost consciously sought to open up windows through which Oriya literature could benefit from and Oriya people could experience the broader world outside. Chittaranjan's Oriya translation of The Pilgrim Kamanita from the Danish original, Saint-Exupéry's The Little Prince, Gibran's The Prophet, Pasternak's Doctor Zhivago, as well as the works of Sri Aurobindo, Ashapurna Devi, Albert Schweitzer, François Mauriac, Verrier Alwyn, Mahatma Gandhi, Radhakrishnan and Martin Luther, were all exercises in expanding the capacity of colloquial Oriya to convey the insights of great literatures from all over the world.

Prafulla Das spent his time and fortune trying to make the major classics of world literature available to Oriya audiences through his own abridged Oriya versions. His efforts were pioneering in the spheres of both publishing and translation. His father, Mohan Charan Das, rose from the position of compositor in a printing press in Calcutta to become a smalltime publisher of limericks and religious books, which he sold, along with country-made paste, in a shop in Calcutta to a clientele made up of a sizable number of Oriya migrant labourers. During World War II, he returned to 
Cuttack to start the Manmohan Press, which eventually became Orissa's leading publishing house. Prafulla Das, who had an early exposure to translation into Bengali during his childhood in Calcutta, inaugurated a new phase of publishing in Orissa. Breaking away from his father's publishing venture, which specialized in the publication of Oriya religious texts, he set about bringing world classics to Oriya audiences through his translations, and often at great financial loss.

While many international publishers imposed a condition whereby a minimum of 2,000 copies had to be printed before the copyright could be extended, in Orissa during that time, the average first print run was 1,100 copies; the remaining books would be trashed, causing a great deal of financial loss to the company. But Prafulla Das's early idealism-inspired by his tutor, Panchanan Chakravarti, and stoked by his reading of Romain Rolland's Jean Christophe, which inspired him to share his joys with Oriya readersremained intact, even after he had been reduced to a state of penury. The credit of introducing the Nobel laureates of literature to Oriya goes primarily to him: not only did he translate the works of Pearl S. Buck, Romain Rolland, André Gide, Knut Hamsun, Herman Hesse, Ernest Hemingway and others, sometimes under the pen name Subhadra Nandan, he also published more than seventy world classics in translation. He was ably assisted in his venture by Chittaranjan Das, whose commitment to Oriya language and literature not only made him a renowned translator, but also a versatile prose writer of more than a hundred original works, which introduced a new critical idiom into the Oriya language.

Both as a translator and an essayist, Chittaranjan Das has proven possible what saint-poets such as Achyutananda and Jagannath Dash, from the Middle Ages, and Fakirmohan Senapati and Gopinath Mohanty, in more recent times, had already attempted to prove before him: that the most esoteric and complex philosophical, literary and critical theories can be articulated in colloquial Oriya. The contributions of Prafulla Das and Chittaranjan Das are all the more remarkable because not only was their enterprise not viable financially, but it was carried out at a time when even the regional literary establishment sneered at their efforts. Prafulla Das was accused of being the enemy of original Oriya creative writing: writers and publishers were apprehensive that if the reading public got a taste of the depth and complexity of great world classics, they would stop patronizing original Oriya literature, considering it not of the same calibre as the foreign literature. Subsequently, however, the major publishing houses joined the translation bandwagon as soon as the market became more favourable.

I earlier noted that major endotropic translation coincided with moments in Oriya history when Oriyas either commanded an extensive 
political, economic and cultural power base or were busy fending off the hegemonic aspirations of other languages seeking to undermine their literature or were motivated by the patriotic desire to strengthen the cultural base of the Oriya-speaking people. Eoyang offers another insight on this phenomenon:

Might there be a relationship between the rise and fall of a culture and its exotropic and endotropic phases. Exotropic civilizations may be short-lived at the height of their cultural imperialism but incipiently in decline; endotropic civilizations may be still in their gestation phase and may enjoy an extended life. $(1993,59)$

If his diagnosis holds for endotropic translation into Oriya, it certainly sounds ominous when one considers the state of exotropic translation of contemporary Oriya literature.

The Odiya language policy in postcolonial India has always been rife with contradictions. While governmental rhetoric on the adoption of Oriya as an official language has been shrill right from the days of Nabakrishna Choudhury's government in the late 1950s, for all practical purposes the social reward system continues to favour the learning and mastery of English and, in some rare cases, Hindi. ${ }^{7}$ Speaking about the case of classic Nahuatl in New Spain, Klor de Alva comments that dominant language groups, and those in political control, perpetuate their hegemonic assumptions through language policy $(1989,143)$. Indeed, the ruling class in Orissa - as well as that of India- - which was co-opted into the colonial administration, continues to hold the political reins, and the position of English, like the erstwhile position of Sanskrit, is one of political and economic power. Moreover, instead of remaining a language of higher learning, it has gradually infiltrated secondary and primary levels of schooling. Since social advancement is usually dependent on one's mastery of English, there is hardly any motivation to consolidate literature in the regional language. The almost total decline of endotropic translation into Oriya is proof of this state of affairs.

In the rare instances that endotropic translation into Oriya is undertaken, publishers and their commissioned translators are often not motivated by the kind of idealism and commitment to the Oriya language as were witnessed in a Prafulla Das or a Chittaranjan Das. Often the works to be translated are chosen not for their literary merit, but purely for their saleability: for example, several publishers and translators jumped on the Tasleema Nasreen bandwagon when the Bangladeshi author became an international celebrity for her political stance. But, there are worse instances of publishers and translators catering to the prurient interests of the reading 
public by producing translated versions-often grossly distorted ones-of works like the Kama Sutra, Pramilla Kapur's survey of the life of Indian prostitutes and books that were objects of legal battles in the courts of law for reason of obscenity, such as Budhadev Basu's Rain Through the Night and the works of Samaresh Basu.

Such translations often do not serve the cause of Oriya literature; rather, they present a very distorted picture of literature to the Oriya reading public. Similarly, contemporary exotropic translations from Oriya also present a very distorted view of Oriya literature. For obvious reasons (usually marketing), instead of works that are truly representative of the Oriya literary canon being translated into English, it is usually works by more contemporary creative writers that are translated. This may be due to the fact that most contemporary Oriya writers are exposed to Western education, and the cultural ambience of their work tends to be less ethnocentric, therefore more translation-friendly and posing fewer problems to the prospective exotropic translator, whereas the ethnicity of older texts of the Oriya literary canon is very pronounced. In an essay entitled "Translating from the Oriya: An Approach," Jayanta Mahapatra, a translator whose commitment to exotropic translation from Oriya can be compared to Chittaranjan Das's commitment to endotropic translations, opines:

How can one portray to a western reader the vertebrae of a culture he probably has learnt to shun through the decades? For instance, the interior of a village house, like the inside of a shell with its cramped space; the physical belongings of a rural family such as a sackful of paddy, dried-up cowdung for fuel, some dry gourd seeds - all this adds up to a picture of acceptance and contentment which is difficult to convey to a Western reader. $(1981,28)$

Apart from the cultural aspects that are so intrinsic to a particular language, Mahapatra also cites the difficulties that particular Oriya authors present:

Neither Upendra Bhanja nor Gangadhar Meher used free verse and their poems literally sag with the weight of ornamentation and alliterative sounds... Even the later poets of the Oriya language, poets like Radhanath Ray resorted to strict, musical verse forms, something that fed the poetry with a feeling of mysteriousness. Oriya diction is slow and formal, the sounds of words seem to dig into the mind and meander in the deeper layers of the imagination. Let us consider the first four lines of the poem "Chilika" by Radhanath Ray:

Utkala-Kamala bilasa-dirghika marala malini nilambu chilika Utkalara tuhi charu alankara Utkala bhubane sobhara bhandara 
How very clever, how concise is the construction of this verse form! With what perfection has the poet woven the sounds of each line: How very much does each line convey, with its sensual, archaic flavour! Into the four words of each line is compressed the deep passion of the poet; and how does one translate a compact verse form of this type into a foreign medium such as English? (27-28)

Despite such difficulties, Jayanta Mahapatra, through his translations of ancient medieval texts such as Rudra Sudhanidhi, the love lyrics of Banamali, Gopal Krishna, Padana, Gangadhar Meher's Tapaswini (unpublished), the poetry of Sachi Routray and Fakirmohan Senapati's stories, has made a genuine effort to represent true Oriya literature to an outside audience. But, in the same essay, he alludes to extraliterary reasons behind some of his translations: "If I have, for example, chosen to translate the poetry of Sitakanta Mahapatra, Soubhagya Kumar Mishra and Devdas Chhotray, doesn't it smack of a selective behaviour? Why not other, equally significant poets of the Oriya language?" (29) In a recent conversation with me, he was more forthright and explained that as a teacher with the Orissa Government, he had occasionally succumbed to pressure from ministers and bureaucrats wishing to have their poems translated from Oriya, thereby contributing to a distorted representation of the Oriya literary canon.

Jatindra Nayak, a professor and translator engaged actively in exotropic translation activity, commenting upon the eagerness of contemporary Oriya writers, especially writers with the power and position to get their work translated into English, proposed in a recent interview with me:

The need to get one's work translated into English was not felt until recently by Odissa writers. Most of our creative writers occasionally took to translating/adapting classics of European literatures in their search for models, new techniques and sometimes with a subversive intent. But translation into English was not a priority with them. What they primarily sought was an enthusiastic response from their readership and a warm and intimate relationship with their audience. The growing alienation of modem Odissa writers from their reading public may have contributed to the tendency to look for a readership in other language communities. The role [that the] translation of Gitanjali into English played in establishing Rabindranath Tagore in the West was another important incentive for vernacular authors to get their works translated into English. There seems to be a feeling in the air that a work has not fulfilled its destiny, has not completed its journey, unless it is available in English translation... The eagerness of the author to see his works in English translation is a recent phenomenon. 
And this is occurring at a time when more and more Oriyas are renouncing loyalty to their language and harbouring a sense of hatred toward their own mother tongue, due, most likely, to their early education in English, which has become a status symbol in India.

Simultaneously, there has been a substantial decline in the number of readers of canonical Oriya literature in Oriya. Along with a faulty education policy, the failure of modern Oriya literature, especially Oriya poetry, to address the concerns of the larger body of Oriya-speaking people gradually served to wean readers from canonical literature. Canonical literature became the domain of a very closed, elite circle of readers and writers, making the Oriya publishing business a very risky affair. Publishers were only willing to publish the works of writers who could influence the Raja Rammohan Library Trust Fund and the bulk purchase of their books for various government libraries. This perpetuated the nexus between publishers, bureaucrats and academicians who were not at all interested in creating a regional readership, but rather in gaining a wider public through exotropic translations. This may be a natural progression if, as Eoyang argues, "certain cultures that have become preoccupied with their own importance will either sanction or promote exotropic translation, that is disseminating their own native reaches to the rest of the world" $(1993,54)$. In a postcolonial society such as Orissa, exotropic translation into English may also be interpreted as a sign of profound insecurity; for translation into English not only ensures the work a place in the canon of its original language--as in the case of my story - but it also ensures a fairly wide audience. In fact, to twist Benjaminian logic a little, translation into English gives Oriya works "life" as opposed to "afterlife." The authors most translated into English are usually those who have translated their work themselves or who have gotten them translated through friends, on their own personal initiative: witness Manoj Das and Kishori Charan Das, two contemporary Oriya writers whose works have often been available in English, and who are their own translators. When I asked about his motives for translating his work into English, Kishori Charan Das, in a recent letter, admitted that "self-interest" was his main motivation in undertaking these translation projects. And in a personal letter to me, K.K. Mohapatra, a noted contemporary translator in Orissa, whose motivation for such an exercise is the patriotic desire to assert the importance of Oriya literature among a larger audience, said that most of his early translations into English were not done because of any commitment to the works' literary worthiness, but because of his "enthusiasm for the writers and their personal relationship." A lack of concern for literary worth is also borne out by the fact that today there are many more instances of living writers being translated than earlier writers who contributed to forming the Oriya literary canon. 
Clearly then, exotropic translation from Oriya has no other guiding principle but the writers' desire - which K.K. Mohapatra calls "everyone fending for oneself" - to reach the elite Western educated audience at home and abroad, rather than cultivate a readership among the masses. As I have mentioned earlier, sometimes this attitude ends up projecting a distorted image of the Oriya literary canon to the outsider who has no knowledge or understanding of the Oriya literary scene. Indeed, in the recent $O x f o r d A n-$ thology of Modern Indian Poetry, Paresh Chandra Raut, who is hardly known as a poet in Orissa, is presented in English translation as a representative of modern Oriya poetry. Contemporary exotropic translations lack the progressive character of early endotropic translations, which challenged the dominant discourse by identifying with disempowered and marginal sections of the society. Today's exotropic translations are co-opted into the realm of highly educated Indians and Westerners-a tendency that has been criticized by Ngũgi wa Thiong'o of Kenya in Homecoming and Decolonising the Mind. Ngũgi himself no longer writes in English. In Orissa, the situation has turned full circle: Oriya literature, which started out as an effort to free sacred texts from the hands of the elites, and the elite language of Sanskrit, is gradually, almost gleefully, becoming museumized in another elite language, this time, English. To illustrate my point, I will use as an example the translation of one of Gopinath Mohanty's novels, Paraja , which relates the lives of villagers living in underdeveloped parts of Orissa. Now, due to the lack of an imaginative literacy program in Orissa, the very people whose lives the novel relates have no access to the text, which portrays-often quite effectively - their colloquial speech rhythms, idioms and worldview. But thanks to the English translation-which, as Paul St. Pierre puts it, "has somewhat sanitized the ethnic dimension of the text"8 - an elite international readership has easy access to the texts. This sanitization or "homogenization," as Tejaswini Niranjana describes, "to simplify a text in a predictable direction, towards English and the Judeo-Christian tradition and away from the multiplicity of indigenous languages and religions, which have to be homogenized before they can be translated" $(1992,180)$, misrepresents the traditional culture and constitutes a new type of colonialism, one now practised by dominant groups in Orissa, in the same way that the British misrepresented Hindu India through translation.

Unless tribal groups, who are often the subject of these literary works, have access to both the original and the translated texts, such misrepresentation through translation cannot be challenged. This raises the issue of literacy at the local level, for without the diffusion of mass literacy, such a state of affairs is not nearly in sight. Nonetheless, despite the misrepresentation of a culture, exotropic translation, ironically, heightens the value of a literature by putting it on the world scene. As Eoyang rightly points out, in our world of transparent barriers, 
Moderns bent on everlasting fame may have to consider not only how well they write, but also how well their works translate. Contemporary writers, from Gombrowicz to Lem to Milan Kundera to Nabokov to García Márquez to Simone de Beauvoir to Yukio Mishima and Yasunari Kawabata, have depended crucially on their translators for international recognition. $(1993,52)$

International recognition will definitely enhance the status of Oriya literature, not only in India, but worldwide. But there must first be something to translate. Without a strong, ongoing literary culture, the Oriya language will soon wither away from disuse, and there will not be much - nor quality-Oriya literature to translate. What is urgently needed is a widespread literacy program, accompanied by endotropic translation into Oriya and popularization of literature, as well as some guiding principle regarding the choice of texts to be translated. Such a policy, in the name of literacy in Oriya, will also act as the rudder for accurate representations of Oriya literature through exotropic translation.

\section{Notes}

1. I am grateful to Mr. Ernest Bond, GTA (Department of Children's Literature, School of Education, Ohio State University, Columbus), and Mr. Braja Kishore Maharana, Lecturer in Oriya (Anlabereni College, Dhenkanal, Orissa), for their valuable comments and suggestions.

2. A native Oriya, he captured the throne in 1435 and founded the Gajapati dynasty, which lasted until about the mid-sixteenth century.

3. A general term for vernaculars that existed alongside, or evolved from, Sanskrit.

4. A worshipper of Vishnu in one or other of his incarnations.

5. Fakirmohan Senapati (1843/7-1918) is the leading Oriya literary figure of his age; he began producing serious literature only after fifty-five years of age.

6. For more details, see the bibliography by Gyanindra Kumar Pradhan in Istāhāra 14 (Apr.-June 1981): 96-106.

7. For a detailed analysis of India's language politics, specifically with regard to Orissa, see Golok Behari Dhal's Odiya Kebe (1963).

8. In a conversation.

\section{Works Cited}

BENJAMIN, Walter. 1955. "The Task of the Translator." Illuminations. Trans. Harry Zohn. New York: Harcourt Brace and World Inc.

BIARDEAU, Madeleine. 1982. "The Salvation of the King in the Mahäbhārata." In Way of Life: King, Householder, Renouncer, ed. T.N. Madan, 75-97. New Delhi: Vikas Publishing House. 
DHAL, Golok Behari. 1963. Odiya Kebe. Cuttack: Friends' Publishers.

EOYANG, Eugene Chen. 1993. The Transparent Eye. Honolulu: SHAPS Library of Translations, $\mathrm{U}$ of Hawaii $\mathrm{P}$.

FOWLER, Alastaire. 1982. Kinds of Literature. Oxford: Oxford UP.

KAR, Bauri Bandhu. 1989. Odiya Sahityar Itihasa. Cuttack: Kitab Mahal.

KLOR DE ALVA, Jorge. 1989. "Language, Politics and Translation." In The Art of Translation: Voices from the Field, ed. Rosanna Warren, 143-63. Boston: Northeastern UP.

MAHAPATRA, Jayanta. 1981. "Translating from the Oriya: An Approach." Cygnus Journal of Research in English 2, no. 2. Lucknow: Centre for Commonwealth Literature.

MOHANTY, Surendra. 1992. Odiyā Sähityar Ādiparva. Cuttack: Cuttack Students' Store.

NGÜGI wa Thiong'o. 1972. Homecoming: Essays on African and Caribbean Literature, Culture and Politics. London: Heinemann.

1986. Decolonising the Mind: The Politics of Language in African Literature. London: James Currey.

NIRANJANA, Tejaswini. 1992. Siting Translation: History, Post-Structuralism and the Colonial Context. Berkeley: U of California P.

Oxford Anthology of Modern Indian Poetry. 1994. Ed. Vinay Dharwadker and A.K. Ramanujan. Delhi: Oxford UP.

PATTANAIK, Diptiranjan. 1994-1995. "A Few Sunrises in the Night." Trans. Chittaranjan Das. Short Story Collection, ed. Geeta Dharmarajan. Kathä Prize Stories, vol. 5: 16572. New Delhi: Katha.

PRADHAN, Gyanindra Kumar. 1981. "Bibliography.” Ed. Nityananda Satpathy, 96-106. Istāhära 14 (Apr--June).

STEINER, T.R. 1975. English Translation Theory, 1650-1800. Amsterdam: Van Goum/ Assen.

TYTLER, Alexander Fraser (Lord Woodhouselee). 1978. Essay on the Principles of Translation. New ed. Amsterdam: John Benjamins. 


\title{
Chapter 4
}

\section{CULTURAL TRANSMISSION THROUGH TRANSLATION: AN INDIAN PERSPECTIVE}

\author{
Shantha Ramakrishna \\ Jawaharlal Nehru University (India)
}

This article is founded on the premise that Indian translators have, through their choice of texts and a well-defined translative project, contributed to changing the terms of cultural transmission and defining the space occupied by various literatures, both foreign and Indian, on the translation scene in India. In an effort to address the urgencies of the time, Indian translators have not traditionally been preoccupied with the question of fidelity; adaptations were and still continue to be quite common. Whereas in the past such adaptations were well received and welcomed by readers as important contributions to the development of language and literature, the modernday translator and his bilingual critic often attach undue importance to the question of fidelity. In fact, it was precisely the varying perspectives on translation and the diverse strategies adopted by Indian translators which gave birth to the creation and recreation of great epics and masterpieces. In this paper, I shall argue that translations should be assessed against the temper of their times and the translative projects that brought them into existence, and not in terms of whether or not they are faithful to their originals.

\section{Translation as Creation}

Translation is as much a creative activity as literature itself, and creativity is slave only to the dictates of the human mind, which knows no bounds. 
Consequently, neither creativity nor translation can be conditioned by the equations of power that are incidental to time measurements in history. The factor of power no doubt desperately attempts to mould every sphere in its domain according to its own agenda and its own requirements. Therefore, it is not appropriate to altogether ignore or dilute the efforts-intentioned or imperceptible - of the colonizer to influence translation activity in such a way that it conforms to his own agenda. Illustrative of this, and references thereto have been made in my earlier papers, are the structures built by the British in India with regard to the administration, the judiciary and seats of learning in higher education, institutions which in their own manner have attempted to attach translation to moorings suited to the overall political designs of the colonizer.

The dispatch on educational matters by the East India Companystill an indispensable reference point for discussion on postcolonial translations-claimed in 1854 that:

the vernacular literature of India will be gradually enriched by the translation of European books, or by the original composition of men whose minds have been imbued with the spirit of European advancement, so that European knowledge may gradually be placed in this manner within the reach of all classes of the people.

However, colonial intervention could not and did not go beyond the translation of Sanskrit and Arabic classics into English or that of English classics into certain Indian languages. As a result, it was primarily English literature, and not European literature, that was translated. The British took no initiative to promote the translation of European books into Indian languages, nor followed any avowed policy to foster translation among Indian languages. In fact, the monolingual and monoreligious British had a hard time comprehending India's multilingual and multireligious culture. With societal multilingualism as India's greatest asset permeating all aspects of life, Indian culture remains hybrid and multilingual: each language is nourished by other languages, both Indian and European, transacting - with vibrant creativity - with the diversity of the outside world. Indian literature is and has always been produced in a linguistic ambience that draws deeply from traditional sources. Traditionally, Indian writers not only write in more than one language, and this, without conscious effort or cultivated scholarship, but also translate their own works and those of other writers. The confluence of languages is and has always been a major impetus for creative writing in India, and this trend persisted, even during the colonial period.

As Harish Trivedi remarked with regard to translation activity in India in the last quarter of the nineteenth century:

As if in a counteracting compensatory activity [to the large number of English classics that were translated into Indian languages], an 
equally large number of Sanskrit texts were also translated into the modern Indian languages, often by the same multilingual translators, but, as yet, hardly any works from other Western languages. $(1997,250)$

Of greater significance is the fact that the translation activity engaged in by Indian creative writers ran counter to the agenda of the colonial power, and took the form of a resistance movement. The need of the hour-unshackling foreign domination - channelized translation activity toward literature wherever and in whatever Indian language it existed, thereby defying any logic of colonialist machinations. Bankim Chandra Chatterjee and Khandekar became household names in places far removed from Bengal or Maharashtra, mainly because their novels kindled the fires of the freedom Movement.

But, looking beyond the colonizer's language, Indian translators scanned other literary pastures-French and Spanish, for example-and sought inspiration from other freedom movements. Acase in point is Ganesh Shankar Vidyarthi's translation of Victor Hugo's Quatre-vingt-treize [Ninetythree]. Vidyarthi (1890-1931), an outstanding journalist and author of editorials, essays and novels, was closely associated with the freedom movement in India and emphasized the need to give due importance to the role of tradition and culture in the struggle for independence. This was also the period when Eugène Pottier's (1816-1887) well-known verse "Rise up, the curs' $d$ of every nation in all your hunger-goals arise" was being sung in different vernaculars all over India. Vidyarthi considered the task of translating works by great writers and making them accessible to the general public a nobler task than that of writing one's own work. He earnestly desired to convey the message of sacrifice contained in Hugo's writings to his Hindi-speaking readers, hence his translation of Hugo's Quatre-vingt-treize as Balidaan. ${ }^{1}$ Under the title, inscribed in bold in Hindi, can be read: "Resumé of the famous novel Quatre-vingt-treize by the influential French writer Victor Hugo."2 This subtitle is already an indication of Vidyarthi's approach to translation-a résumé of the original. Also, in the preface he gives a brief background history of the author and his work, and a lengthy note on the French Revolution, in simple terms so that readers might appreciate the translation in the context of the backdrop of the original. Then, in the introduction he explains the translation strategy adopted, and the reasons therefor. In Vidyarthi's opinion, an original and its translation can never be the same; therefore, the reader should never expect to find in the translation the same information as contained in the original. His objective was to motivate readers to draw inspiration from the French case history. Thus he retained in his version only such aspects of the original which he believed his readers would benefit from knowing, and with which they are not already conversant. Vidyarthi even considered that many of the details he included in his trans- 
lation could have been omitted without the work losing any of its charm; but he chose to retain them so as to provide readers with material that would widen their horizon of experience and emotions. Despite the omissions, Vidyarthi's translation effectively instilled in his fellow countrymen a feeling of inner strength and natural pride (Salil 1991).

\section{The Question of Fidelity}

Given the translator's note and the effect of the translation on its readers, should this translation be considered an act of violence perpetrated on the source text, or a salutary transaction which addressed the specific urgencies of its time, fostering a nationalist sentiment and filling a void in a literary context weighted in favour of English classics? Present-day translators and bilingual critics who argue that a translation should be faithful to the original would no doubt assert that Vidyarthi's translation of Hugo's Quatrevingt-treize is no translation at all, but an adaptation at its worst. I would remind them, however, that in nineteenth-century colonial India, fidelity was understood in a different way. Vidyarthi's approach to translation might be considered akin to Alexander Pope's translation of the Iliad (1720): Pope made his own decisions as to what would and would not interest the readers of the time, what to omit and what to retain in the translated version. His strategy is explained in the preface, and footnotes are used when he deemed it necessary to explain "infidelities" in his translation (Mohanty and Kuhiwczak 1997). Thus, instead of arguing in terms of a translation's fidelity to the original, I would prefer to argue in favour of the "relevance" of a translation to its specific time and audience. If the relevance of a translated work consists in how it is received by and what it means to the target culture, we may conclude that Vidyarthi's Hindi translation of Hugo's French text was a relevant one.

Another instance of personal choice which contributed to changing the terms of cultural transmission in India during the colonial period, toward the end of the nineteenth century and beginning of the twentieth century, is Premchand's translation of Anatole France's Thaïs. Premchand's choice of a French writer was not language-related but rather ideological: he was fascinated with the novel and considered the French author superior to many English writers. He selected the particular work for what he considered its special affinity to Indian values, and one which would serve as an eye-opener to another world for Indian colonial readers, his fellow writers and translators, or rewriters. He therefore sought to adapt the novel to the Indian cultural context with a view to making it reader-friendly. Premchand's strategy, however, might be considered less violent than Vidyarthi's in that his translation is not scarred by major omissions. The 
translations by Premchand, Vidyarthi and other contemporary writers of the time would pave the way for many later translations of European works, such as those by Molière, Dumas, Maupassant and Rolland, among others. ${ }^{3}$ The choice of work to be translated was usually determined by the translator's "existential hermeneutics," by his environment and historical space.

According to Trivedi, Premchand's choice and translation of France's Thaï came at a crucial phase of India's colonial history, and served to imbue it with "an extra-literary charge which turned it, among its other virtues, also into a small gesture towards the liberation of Hindi (and Indian) literature from the tutelage of the imperially-inducted master literature, English" $(1997,249)$. Trivedi's remark can certainly be extended to all regional Indian literatures. In Southern India, for instance, in the 1930s, creative stalwarts vied with one another to introduce the best in foreign literature to Tamil readers through translation. The translation strategy invariably adopted by the translators was that of "adaptation." In Trivedi's opinion, the translations thus produced should not be viewed as acts of "subversion against English literature" (261), but as necessary and salutary supplements thereto.

Premchand and Vidyarthi's translations are prime examples of how translators, by respecting auchitya (propriety) in their selection of texts have, during the colonial and anticolonial period in India, contributed to changing the terms of cultural transmission in India, and to defining and delimiting the space occupied by English literature on the Indian translation scene. Propriety with regard to translation requires that the translator place the author's views in proper perspective, especially if the source text deals with sensitive issues or if the target culture is at a critical phase in its history. As Avadhesh K. Singh remarks:

Auchitya in translation, without moving too far from its meaning in Indian poetics, should mean propriety in selection of a text for translation, of methodology and strategy used for translation, and of placing the translated text in proper perspective, so that the source writer's/text's intended, not merely articulated, meaning finds proper expression in the target translation. (1996, xi)

Not to respect the principle of auchitya in one's selection of a text to translate and choice of translation strategy would result in misrepresentation of the source culture. It is interesting to note that both Premchand and Vidyarthi, themselves eminent writers, opted for adaptation-resulting in appropriation-of the source text. Despite the modifications in the translated versions, the translators were able to create a wide readership for their translations, bring about a change in perception with regard to the donor potential 
of European languages other than English, as well as strike a balance on the contemporary translation scene in pre-independent India.

The various versions of great epics and masterpieces were for the most part "recreations," which could even be considered creations in their own right. These recreations often surpassed the original in creativity to become part and parcel of a regional literature. They were usually well received by the regional public of the time, and even present-day readers are grateful to the translators who made available the best literary works of the world to them. Though today these translations are often considered "appropriation through manipulation," at the time neither the translators of these works nor their readers were concerned about the question of fidelity.

Fidelity assumed importance with the beginning of Bible translations into Indian languages and has become a subject of serious debate in the postcolonial era. In the Indian context, opinions on what constitutes fidelity have varied from total liberty to transcreation to word-for-word translation. While literary translators in colonial India seemed more interested in the creative aspect of translation, modern-day Indian translators and bilingual readers seem, on the contrary, to be more concerned with the notion of fidelity, subscribing to the idea of a betrayal syndrome underlying all translation activity. Translations which the common reader finds interesting and enjoyable are often subjected to close scrutiny by bilingual academic readers seeking to establish the degree of, or to lament the lack of, fidelity to the original work. The rapid development of contrastive language study and an exaggerated belief in the notion of "equivalence," whereby for every word or expression in one language there must be a corresponding word or expression in another, is largely responsible for the discussion of translation in terms of loss and gain, rather than in terms of the "integrity of the value of the people who produce the text" (Mohanty and Kuhiwczak 1997).

\section{Independence and Translation}

The social responsibility of the translator and the functions of a translation have assumed great importance in independent India. Individual translators and translation sponsors now need to seriously evaluate their criteria for selecting texts to be translated, the translation strategy to adopt and the choice of target language. Satpal is a good example of an individual translator who was fully aware of his responsibility when he undertook to translate Sri Aurobindo's seminal work Savitri into Urdu. An officer in the Armed Forces, working on an Artificial Intelligence project based on Aurobindo's concept of the mind, Satpal explains why he chose to translate Savitri:

I am, therefore, quite convinced that all scriptures, irrespective of the religion, the race and the people they belong to, contain hints, 
which are either complete solutions in themselves or can lead us to the complete solution of some of the problems vexing the scientific community of today.

... I am of the firm view that the ability to appreciate a classic and/or a scripture like Savitri needs the same mental capability as is required to lead men in war or nations to prosperity or industrial houses to success. $(1996,67-68)$

As to the choice of Urdu as the target language, he added:

The choice of the target language was dictated by two fundamental urges: a) "The urge to be able to effectively participate- on the side of tolerance-in the Mandir-Masjid disputes of the late eighties"; and b) "to make Savitri accessible to a very large section of our society which understands Urdu, and is likely to, as a major social segment in India, be called upon to smoothen the sharp edges of Islam, when ... its revival in its resplendent glory of the past emerges as the most important phenomenon of the twenty-first century." (68)

Since Savitri is a contemporary epic of timeless, universal dimension, the translator ruled out "transcreation," the strategy normally used by Indian translators to translate poetry, as well as "adaptation," the strategy usually preferred by translators of epics. Apprehensive of diluting what he called the occult truth contained in each verse by adopting a transcreational approach or by indulging in adaptation, Satpal chose to respect the principle of fidelity. By fidelity he did not mean word-for-word mechanical translation, like a body without a soul, but rather fidelity to Sri Aurobindo's message, and fidelity to the nuances of the target language. He sought to respect the psyche of the target language, its genetic memory, its traditions with regard to idioms, adages and recitability, one of the most important criteria of Urdu verse (see 1996, 68).

Another example of auchitya with regard to the selection of texts to translate in contemporary India is furnished by Suman Venkatesh, who has translated into English 2,009 French documents dating back to the period between 1781 and 1796, and relating to the history of Mysore. These documents constitute part of the correspondence between the then rulers of Mysore and Louis XVI, King of France, and part of the correspondence between French troops stationed in Mysore and their hierarchical superiors in France. The translator justifies her text selection as follows:

it became evident that these documents are especially valuable as they are not "deliberately designed for the historians" and so they can be treated as objective residues of the past. These translations are directed at reinterpreting history, at striking a balance between 
Eurocentric and lndocentric versions of the history of the period in question, between the observer and the observed. (1996)

Again it seems that the translator's choice depended primarily on the extent to which the translation addressed the urgencies of the time, and how it would influence and meet its readers' experiences and expectations. On the other hand, a translation sponsor's choice of text, translation strategy and target language often depends on the extent to which the translation project is considered representative of a region, since translation facilitates the discovery of cultural elements which contribute to the making of a language, a literature and a culture. In Anjana Desai's words, a sponsored translation project which looks to cover only the classics of a certain region or language is merely a "surreptitious endorsement of the hegemonic establishmentarian process of centralising and marginalising cultural expression" $(1996,57)$.

\section{What Is Translation?}

The diverse strategies adopted by Indian translators to translate great epics and masterpieces have given rise to a rich nomenclature. Terms such as "translation," "transcreation," "transference," "tarzuman," "anukaran," "bhashantar," "roopantar," "code-switching" or "recodification," "reproduction" or "reconstruction," "sweekaran" or "sahsrajan (co-creation)," "domestication of the "other' or "foreign," "rewriting" and "recreation" have all been used to describe the process (Singh 1996, ix). In some cases, the term focusses on the external reality (bhashantar) or on the choice of form (roopantar); in other cases, on how the most complex feelings and sentiments are expressed (bhavanuvad) or on the creation of a new text (transcreation).

Indeed, the history of translation and literature in India is replete with "adaptations." Throughout the ages, Sanskrit epics and puranas have been told, retold, adapted, subverted, appropriated and translated without concern for fidelity to the source text (Paniker 1996, 37). In fact, the numerous adaptations of Sanskrit texts in Indian languages have had a unifying influence on the Indian psyche. This trend has continued well into the twentieth century, as translations of the Saratchandra into Telugu, Tamil and other languages indicate: each translation is an adaptation of the original so as to better suit the mood of the time and region. For instance, in his translation of the Saratchandra, Velluri Swarna Sastri has substituted Telugu names and scenic descriptions of the Andhra countryside so that it could pass for a creation in its own right. Literal adherence was not insisted upon, and deviations were tolerated, even preferred, in the name of creative freedom. This practice contributed to establishing translation as "appropriation through linguistic manipulation" (Paniker 1996, 37), for the various adap- 
tations in local or regional languages were welcomed by readers as contributions to the development of their own language and literature.

During the colonial period, translations of plays, in particular, from European languages were usually labelled as "translations," even though most of them were at best adaptations. However, it might be argued that in the colonial situation, Indian translators were faced with the question of loyalties-native or alien-especially as they worked under the supervision of the colonial master. Mahadev Shastri Kolhatkar's Marathi version of Shakespeare's Othello (Othello Natak, 1867), G.B. Deval's adaptation of the same play as ZunZarrao (1890) and V.V. Shirwadkar's (1965) translation of it demonstrate amply that perspectives and strategies depend largely on the cultural pressure faced by the translator at a given time. As Anand Patil (1993) observed, Shastri Kolhatkar's Marathi version of Othello, an institutionalized translation carried out under colonial supervision, reveals the dilemma faced by the translator with regard to choice of strategy: to foreignize or to domesticate? to Anglicize or to Sanskritize? It might be worth noting that Shastri Kolhatkar belonged to the elite class at a time when colonial readership was limited to the higher classes or castes. As such, he was no doubt strongly influenced by the colonizer's teachings and tastes, and the hegemonic power of "images" already propagated by translations of a particular kind. His translation of Othello bears the imprint of his own cultural values, on the one hand, and those of the colonizer, on the other. Playwright G.B. Deval's ZunZarrao adaptation of Othello was largely successful and well received by its audience, and Shirwadkar's translation was deemed a "return to Shakespeare's poetry in the postcolonial-neocolonial era" (Patil 1993, 46).

What needs to be pointed out here is that whereas it might have been easier for a Shastri to translate from Sanskrit into his own local or regional language under alien patronage, translating from English into a vernacular under the same patronage was quite a frustrating task, given the politics and the struggle between loyalties affecting the translator's decisions. As regards translation of Indian texts into English, the question of fidelity took on larger proportions. Even A.K. Ramanujam's translations of Sangam literature, which have made many ancient Tamil classics accessible to modern European and American readers, have not been spared criticism for misrepresenting the originals.

\section{About Self-Translation}

The case against a writer's translation of his own work is also often argued on the grounds of fidelity. Radindranath Tagore's translations of his own Bengali poetry into English have been highly eulogized by some, and 
severely denounced by others. W.B. Yeats in his introduction to Tagore's Gitanjali remarked:

these prose translations from Rabindranath Tagore have stirred my blood as nothing has for years... These lyrics display in their thought a World I have dreamed of all my life long ... a work of supreme culture... (qtd. in Parameswari 1996, 91)

Compared to the euphoria of Yeats-one of the early readers of Tagore's translations-the modern Indian bilingual reader's reaction is rather subdued. According to Avadhesh K. Singh:

Rabindranath Tagore ... did great disservice to himself by translating his Geetanjali from Bengali to English, though he earned the Nobel Prize for literature for himself ... The author-translator may not be so inspired (may be even more) as he was when he authored it. The new text will definitely depart from the original text but the bilingual human psyche will compare both the texts and search for, and lament, loss in translation. The author should better leave his work to find [a] translator for itself in different periods and ages and respond to its emotional and social needs. $(1996,14)$

Singh's remark is in stark contrast to Sri Aurobindo's remarks about the translation of poetry: "a translator is not necessarily bound to the original he chooses; he can make his own poem out of it, if he likes and that is what is generally done" (qtd. in Nandkumar 1981, 65). Sri Aurobindo talks of two ways of translating poetry: "one [is] to keep it strictly to the manner and turn of the original, [and] the other is to take its spirit, sense, and imagery and produce them freely so as to suit the new language" (Pathak 1996,27). These remarks are pertinent not only for translators translating other people's work, but for authors translating themselves. The main criticism levelled at Tagore, especially today, is that he took too many liberties in the translation of his verses into English and in so doing ended up denuding his poems of their original richness in order to make them acceptable to European tastes. In essence, the criticism is about his "rewriting" in English, rather than translating, his Bengali originals. Sujit Mukherjee (1994), for instance, suggests that Tagore wanted to stress the devotional aspects of his poetry in order to appeal to the English public; Mahasweta Sengupta (1996, 166) points out that this was because the devotional was perhaps "the domain that was familiar to the English as truly 'Oriental' or 'Eastern'; poets from Asia were, to the English, more like prophets who dealt with transcendental rather than with material issues which were part of their everyday struggle in the colony." Thus Tagore, by stressing devotion at the expense of other moods in his translation of Gitanjali and other anthologies, is 
considered a mystic in conformity with the image of the Oriental that is acceptable to the colonizer. Citing comments in Tagore's correspondences, Sengupta (1996) provides insight into the translation strategies he adopted, the whys and wherefores of his choices, and shows that Tagore's poetics were indeed "adjusted to the demands of the colonising power," that he endeavoured to present in English the essential meaning of his poems. Tagore's assessment of the target reader, the discursive limits of the target language, his own translative project, become evident through his remarks and comments. It seems necessary therefore to assess his translations against the temper of his times and his own translative project.

\section{Criticism and Translation}

The widely differing reviews of subsequent translations of Tagore's poems by Western critics on the one hand and by Indian critics on the other-for instance, Richard Casely's review of William Radice's translation of poems by Tagore, in contrast to Khushwant Singh's review (in Das 1989, 37) of the same translation - show that an English translation of Hindi, Tamil or Bengali writing is likely to evoke a more critical response from an Indian reader unfamiliar with the original language, than from a Western reader unfamiliar with the cultural elements of the original or a Western reader who is familiar with the culture, but whose infatuation with the East, its mysticism and abstraction has cooled. It would not be wrong to presume therefore that readers' tastes and literary sensibilities change over time. Indian bilingual translation critics might want to bear in mind that it is difficult to apply hard and fast rules to the translation of poetry. A translator of poetry usually achieves the best results by "transcreating," that is, by preserving in translation the magical web of meaning and imagery of the original, yet at the same time respecting the dictates of the target language. $\mathrm{Bi}$ lingual critics should also be aware that prose translation of popular literature is quite different from translating poetic texts such as Gitanjali or Bhagavad Gita.

Translation criticism in India has existed in various forms since the nineteenth century, the most predominant method of evaluation being that of contrastive analysis. But trying to establish a formal correspondence between a source and a target text is too feeble a link to legitimize translation. As Antoine Berman suggests, for a translation to achieve its purpose, a more viable link should connect it to the original, similar to the link between a base and its derivative, a plant and its cutting (1995, 28).

The questions which need to be addressed therefore are: 1) Is there an ethic for translation criticism? 2) What are the responsibilities of the translation critic? 3) Are critics sufficiently knowledgeable about the 
history and act of translation to fully comprehend the responsibilities borne by the translations they critique? Literary translators, as witnessed by Vidyarthi, Premchand, Satpal and Tagore, whose work I have referred to here, tend to explain and justify - in a preface or introduction or in correspondence - the strategies they chose to adopt for their translation. This indicates that they are aware of their responsibilities toward the original text and author, as well as toward their target audience, and that they have thought about their options before making a decision. I strongly feel that the translator's right to creative freedom, to take certain liberties with regard to an original text, should be recognized, and that a translation should be critiqued and judged against the temper of its time.

A more constructive approach to translation criticism is called for in India. Instead of concentrating solely on the linguistic aspects or the linguistic correspondences or the absence thereof, bilingual critics might want to look at other aspects of the translation: the effect of the translation on its readers; how it contributes to broadening its readers' knowledge and experience of the world; whether it attains the objectives of the translative project; how it demonstrates the translator's skill; how it enriches the literary culture of the target language; and, last but not least, does it contribute to promoting new expressive possibilities in the target language? Some of these concerns have already been voiced by scholars concerned with freeing translation from the grip of contrastive analysis and highlighting its real role and functions in a given society (see Simon and Viswanatha 1996).

The increasing globalization of culture and the concomitant spurt in literary publications have helped many postcolonial writers-writing directly in English or translated into English- to be marketed successfully. However, not all translations done in India find their way to the erstwhile colonizer's market. That the Empire translates back but there are not many takers for its translations must be viewed in terms of the evolving global context: some writers do not travel well, despite critical acclaim and impressive sales at home; what the Empire wants to give the Metropole is not what the Metropole wishes to receive from the Empire; there is already a crisis of excess on the British, American and European literary markets. I believe there is need for some introspection: by whom and, especially, for whom are translations done in India? The average monolingual reader? The academic bilingual reader? The colonial reader? The postcolonial reader? How does a translator create an audience?

There are imbalances in cultural transmission in the Indian context which are characterized by a lack of adequate interaction between the regional languages despite their shared traditions. But these imbalances should be perceived not in terms of a conscious policy of discrimination favouring one language over another, but in terms of the non-availability of compe- 
tent multilingual translators and the willingness of multilingual translators to translate certain types of texts, misguided criticism practices and above all the play of market forces. The English language is already saturated with translations of Indian works; Indian literature might find a more lucrative market in other European languages - German, French, Spanish, for example- - or in other Indian languages, here on the subcontinent. We, in India, need to look to ourselves, our history and our traditions for inspiration and models to take us into the twenty-first century.

\section{Notes}

1. I am told that the translation was published in 1822 by Pratap Pustakalay, a publication unit run by Vidyarthi. However, according to Sharad Chandra, it is difficult to find even a single published copy of this translation in circulation today. The manuscript is in the preserve of the admirers of Vidyarthi.

2. All translations from Hindi and French are mine, except where otherwise indicated.

3. Though I am only citing French authors here, many works in other European languages were also translated into Indian languages during this period. Whereas these translations were done almost "naturally," such is not the case today.

\section{Works Cited}

BERMAN, Antoine. 1995. Pour une critique des traductions: John Donne. Paris: Éditions Gallimard.

DAS, S.K. 1989. "The Common Reader and Translation of Poetry," International Journal of Translation 1, no. 1: 33-40.

DESAI, Anjana. 1996. “Translation Fitness." In Translation, Its Theory and Practice, ed. Avadhesh K. Singh, 56-60. New Delhi: Creative Books.

MOHANTY, Satchidananda, and Piotr KUHIWCZAK. 1997. "A Good Translation Is a Good Literary Text." The Hindu Literary Review (June 1).

MUKHERJEE, Sujit. 1994. “Translation as Perjury.” In Translation as Discovery and Other Essays on Indian Literature in English Translation." 101-24. Hyderabad: Sangam Books Limited.

NANDKUMAR, Prema. 1981. "Translation: A Creative Process." Cygnus 2, no. 2: 65.

PANIKER, K. Ayyappa. 1996. "The Anxiety of Authenticity: Reflections on Literary Translation." In Translation, Its Theory and Practice, ed. Avadhesh K. Singh, 36-45. New Delhi: Creative Books.

PARAMESWARI, D. 1996. "The Technique of Translation and Transcreation from English to Tamil." In Translation, Its Theory and Practice, ed. Avadhesh K. Singh, 89103. New Delhi: Creative Books. 
PATHAK, R.S. 1996. "Untranslatability: Myth or Reality?" In Translation, Its Theory and Practice, ed. Avadhesh K. Singh, 18-35. New Delhi: Creative Books.

PATIL, Anand. 1993. "An Author in Search of Translators/Translation: A Comparative Case Study." International Journal of Translation 5, no. 1/2. 36-62.

SALIL, Suresh. 1991. "Victor Hugo Aur Ganesh Shankar Vidyarthi." Anuvad 67 (Apr.June): 11-16.

SATPAL. 1996. "The Joys of Translating Sri Aurobindo's Savitri into Urdu." Anuvad 89 (Oct.-Dec.): 67-80.

SENGUPTA, Mahasweta. 1996. "Translation as Manipulation: The Power of Images and Images of Power." In Between Languages and Cultures: Translation and Cross Cultural Texts, ed. Anuradha Dingwaney and Carol Mair, 159-74. Madras: Oxford UP.

SIMON, Sherry, and Vanamala VISWANATHA. 1996. "A Relative of the Original." The Hindu Literary Review (Aug. 18).

SINGH, Avadhesh K. 1996. "Translation: Its Nature and Strategies." In Translation, Its Theory and Practice, ed. Avadhesh K. Singh, 1-17. New Delhi: Creative Books.

TRIVEDI, Harish. 1997. "India, England, France: A (Post-)Colonial Translational Triangle." In Translation and Multi-Lingualism: Post-Colonial Contexts, ed. Shantha Ramakrishna, 248-62. New Delhi: Pencraft International.

VENKATESH, Suman. 1996. "History of Mysore and French Documents of the XVIII Century." Paper presented at the Seminar on Translation and Multi-lingualism, Jawaharlal Nehru University, January 1996, New Delhi. 


\title{
Chapter 5
}

\section{LEGITIMACY, MARRONNAGE AND THE POWER OF TRANSLATION ${ }^{1}$}

\author{
Jean-Marc Gouanvic \\ Concordia University (Canada)
}

The aim of this essay is to examine the relationship between translation and the social practices resulting from colonialism and "postcolonialism,"2 as they are expressed in symbolic goods. This will be done not by analyzing the colonialist discourses present in translations carried out between the languages and cultures of former colonizers and colonized peoples, but rather by presenting hypotheses based on relationships of political domination as well as dominance, as they are inscribed in cultural productions, whether such productions have been translated or not. These relationships will be situated in terms of Pierre Bourdieu's theory of culture.

The main interest in locating translation within the problematic of colonization and "decolonization" is that it makes it possible to foreground essential elements of the practice of translation, insofar as it is a historically determined game of power, imbricated in transnational power relationships. A thorough examination of the subject, in all its practical implications, would require mapping out the worldwide flow of translations; without such a map, only tendencies based on local and necessarily partial observations can be identified. These will at least make it possible to put forward verifiable hypotheses from which the object translation, in its diverse geopolitical manifestations, can be constructed. 


\section{Domination, Co-operation and Translation}

It is important, first of all, to distinguish translation as an instrument of emancipation from translation as an instrument used to censure the Other's discourse. But whether emancipation or censure, translation is power-not simply an instrument of power or of a certain power, but intrinsically power, without which there is no translation. How can this power, part of the very essence of translation as of any other cultural practice, be described?

Commenting on K., the character in Kafka's The Trial, Pierre Bourdieu writes in one of his most recent works, Méditations pascaliennes:

Robbed of the power to give sense to his life, to express the meaning and direction of his existence, he [K.] is condemned to live in time determined by others, alienated. This is exactly the destiny of the dominated, obliged to depend on others for everything, on those who determine how the game will be played and what objective and subjective hope for gain the game offers; they are the masters, free to play on the anxiety which inevitably arises out of the tension between the intensity of the expectations and the improbability of satisfaction. $(1997,279-80)$

Clearly, Bourdieu is not describing the specific situation of the colonized; however, his remarks can be applied as well to those within a nation, "dominated nationals," who have also been colonized. Strictly speaking, K. does not live in a "colonized" society, unless this is taken metaphorically to mean "colonized from within," that is, domination experienced on an individual or collective, rather than state, level. Yet could such colonization from within not be the end result of all domination, whatever external form it takes? "Co-operative competition" (Bourdieu 1997, 286) is supposedly the rule in Western societies, yet democracy has its outcasts and its drop-outs. Symbolic violence is directed against such individuals, living on the fringes of society, by denying them the power to live their own lives, by not recognizing the legitimacy of their aspirations, thereby denying them the power to direct their own destinies.

This comparison between colonization from within and colonization in the strict sense is also justified in that present Western societies are still tied to their colonial pasts. The large-scale immigration toward Western metropolises and their suburbs is palpable proof of this. Judging from their linguistic, cultural and especially literary productions, when such exist, immigrants from former colonies usually find themselves in a sociolinguistic situation of "polyoecism" (Durisin 1991, 114). In this context polyoecism refers to what Dyonyz Durisin calls the "more or less conflictual associative co-existence ${ }^{3}$ of languages and cultural (literary) products" (1991, 
115). Durisin considers Yugoslavia, the former Soviet Union, the British Isles and Switzerland to be examples of situations of literary polyoecism. Although he does not mention colonial or former colonial situations, this notion could also be applied to them. This would be all the more justified since Durisin mentions the USSR in particular, whose "relationships" with the Eastern European countries exhibited certain characteristics typical of colonialism. One master often follows on the trail of another, as we shall see below.

The colonial era in Francophone countries is said to have come to an end in the 1960s; such a belief clearly conveniently forgets the situation of the French West Indies. The former colonies are supposedly living an era of independence, of "postcolonialism," following colonialism. But a key question remains: Who dominates in the postcolonial era? The same masters as during the colonial era? Or new ones? Or do the independent former colonies themselves become dominators, and in relation to whom? Should not the advent of the postcolonial era lead to a redistribution of powers worldwide, according to new global hegemonies?

Translation does not involve only a process of semantic transfer from a text in one language to a text in another; rather, it must be seen in terms of the power relationships which exist between languages, cultures and human beings, between groups whether or not they correspond to existing nation-states. A case in point which is instructive in this respect is the spread of American culture. In April 1961, John F. Kennedy launched the massive "Peace Corps" project, whose "Volunteers for Peace" would invade dozens of Third World countries, from Tanganyika to Malaysia, with the aim of promulgating the values of Pax Americana. The role of the Peace Corps, it was claimed, was completely disinterested: "We do not want to sell America," proclaimed Kennedy in 1961. His heritage lives on in the nineties, but it is no longer the Third World which is being targeted. This time the Peace Corps is being posted to the former Communist countries with the mission of "bringing English to the Eastern bloc." Through the English language American development and democracy are being exported. ${ }^{4}$ This dissemination of American language and culture by the Peace Corps can be called "soft" colonialism; it is just enough to create a social demand for the "American way of life" in the countries targeted, and, at the same time, form a class of intellectuals well versed in the American language and culture who could become the national agents for translation and cultural importation in these countries.

The "gift of culture," especially of culture vehicled through language, can take on the guise of disinterestedness while producing greater dividends than if the "gift" is seen as self-interested. But translations do not necessarily correspond to strategies on the part of source cultures to impose 
social values. In situations of polyoecism, situations in which former colonies find themselves, power relationships and power struggles are also experienced politically through cultural, and more specifically linguistic, products. Different forms of cultural production have their own characteristics and implications, but they tend to reproduce by homology the issues at stake in the global social space. This is particularly clear in the case of cultural fields, such as literature, directly involved with translation.

\section{Translation and the Illusion of Legitimacy}

In terms of translation, the logic of the cultural game is such that power relationships are hidden as a result of the acceptance of dominant models, presented as the only viable ones. In translation, we live with such an illusion of legitimacy, and this for several reasons. First, because translation is generally unidirectional. ${ }^{5}$ The demand for translation is heavier on the part of the dominated. In fact, the dominator need not be concerned with the exportation or imposition of his culture beyond his borders. Once the structures are implanted, and the agents of translation/importation determined, the dominator has only to let the laws of the "free" market and of globalization have their way. This is the second reason for saying we live with the illusion of legitimacy, since the laws of the market, the opening up of borders, the laissez-faire/laissez-passer policies in the end always work to the advantage of the dominator. The aura of legitimacy which the dominated invest in the dominator rests upon a belief-effect: their social future seems inscribed in his, and there does not seem to be any viable alternative to his vision of the future. The dominated and the dominator seem to agree on a common destiny founded on the legitimacy of the dominator and the social future he represents.

There are cases in which dominators show a strong individual interest in the dominated, some even going so far as to become "transculturals": Lawrence of Arabia or Isabelle Eberhardt ${ }^{6}$ come to mind. Transculturals tend to identify with the dominated, and attempt to live as they do. Such individual cases, seemingly characterized by the desire to reverse the power relationship between the colonized and the colonizer, arise from a mysticism of fusion which is doomed to failure since it rests on an aporia of the self/other relationship and is based on illusory self-effacement. In the case of translation, the other side of this fantasized fusion of the dominator in the culture of the dominated could well be literalism, when the source language is the historically dominated language. The exact opposite of the fantasy of fusion is that of original purity, preserved through orthodoxy. In fact, everything in social space involves struggle; nothing is definitively acquired and preserved. Social existence is realized only in the struggle to impose meaning on the social world, a struggle in which translation plavs a role. 
In order to provide an answer for the question as to whether the postcolonial era established a new power relationship between the former colonizers and colonized, with regard to cultural and more especially literary productions, another question first needs to be raised: What constitutes the exercise of power in a given social situation? Bourdieu writes: "Every exercise of power is accompanied by a discourse whose purpose is to legitimize the power of the person exercising it: it could even be said that for power relationships to have their full force they must remain hidden" (1984, 224). After independence-attained by peaceful or by violent means-a postcolonial society is characterized by power relationships in which the essential element at stake is the imposition of legitimacy, in the sociological sense of the word. Bourdieu defines legitimacy as follows: "Is legitimate an institution, action or practice which is dominant but not explicitly recognized as such, that is, which is tacitly recognized as such" (110). I will now sketch out the social implications of translation, referring to translation of "paraliterary" or "popular" genres, and in particular to translation in what is perhaps its most ambiguous form, pseudotranslation.

\section{Translation as Resistance and Transgression}

Too often, resistance to domination is considered to be exceptional. Several analogies, however, can be drawn between the position in which cultural producers find themselves, a position of being dominated, and that of a position of resistance to the imposition of a power which denies the individual the right "of feeling justified in existing as he does" (Bourdieu 1997, 280).

In source societies, some authors resemble Franz Kafka, whose entire work plays on the fictional mode of transforming power relationships within society by illuminating the "inert violence" (Bourdieu 1997, 276) of structures and institutions, relayed by the active violence of human beings. The populist illusion of the resistance of the dominated can be seen in "one of the most tragic effects of the dominated's situation, that is, the inclination to violence which is brought about by early and continual exposure to violence" (Bourdieu 1997, 275). There are also, however, "unrecognized forms of resistance," among which Bourdieu counts irony and humour. Other types of texts could also be included here, in particular the so-called "popular" genres, through which large segments of Western societies symbolically live out their utopian aspirations. "Co-operative competition" is fuelled by compromises arrived at between partners capable of selective co-operation or resistance. This is pushed to the extreme in situations of territorial occupation, with imprisonment or voluntary exclusion, as with resisters going underground or slaves taking to the hills and the forest, beyond the reach of 
the "authorities." The Maquis and the Maroons affirmed the possibility of liberty, of freedom, in their desire for a liberated state. The agents involved in this struggle clash not so much over the meaning of the world, as over the recognition of the right of every human being to express the meaning of his world. It is only if such is possible that there can be "co-operation" over the meaning of the world.

In relation to translation the question is: What are the implications of inserting imported foreign texts into target societies where power relationships are exercised? As Bourdieu states: "The symbolic transgression of a social boundary has a liberating effect, because it brings the unthinkable into being on the level of practice" $(1997,279)$. The crucial question for translation, as for other cultural practices which deal with texts, is whether the activity or practice is on the side of emancipation through the symbolic transgression of a social boundary. Does translation contribute to reinforcing the power of the dominators, or does it submit that power to the corrosive effect of irony? Translation necessarily is involved in the struggle of cultural productions for legitimation and recognition, through the fact that the interests of the agents engaged in that struggle push them toward works which can dislodge existing hierarchies of legitimation at work in certain fields.

With the cultural space of translation, the agents-beginning with the translators - belong to the target culture, which, in the present context, corresponds to the formerly colonized society. But are such agents "mercenaries" of the source culture, or even "double agents," as they are sometimes referred to? In that context it might be more accurate to portray translators as collaborators or resisters, with all the nuances that these terms have acquired during the history of their usage and which run the risk of slipping into political dogmatism when used outside their specific context. But it is perhaps marronnage which provides a more appropriate analogy for resistance in the context of colonialism. ${ }^{?}$

\section{Marronnage and Translation}

During the seventeenth and eighteenth centuries in the Caribbean, slaves who took to the mountains to escape from their white masters and from there launch attacks were known as maroons. Even though translation is generally carried out under the domination of legitimate powers, the concept of marronnage makes it possible to break out of the vicious circle of domination by these powers. Can translation exist in any other way than as an activity reinforcing the power of the dominators, given the power relationships between cultures? Can translation constitute an activity of resist- 
ance and liberation in terms both of the source and target societies? Marronnage was not a perfect solution; for once regrouped into societies, the runaway slaves could not avoid certain socio-historical choices, such as the best form of government for individuals henceforth liberated from the constraints of the colonial state. While the conception of translation as marronnage radically frees the text from domination, marronnage should not be adopted as a euphoric vision of translation, for there was no greater salvation inherent to marronnage than there is in translation. There is some degree of angelism in certain communicative conceptualizations of translation, as if it were the messenger of civilization, capable of breaking down national boundaries and of promoting the movement of progress-of the kind usually proposed by the so-called "developed" nations-those very nations which have merged with the former colonizers, the "postcolonizers."

The metaphor of literary translation as marronnage is based on the presupposition that there is a similarity between the State in which we live and the colonial State. This may seem shocking at first, for the "legitimate violence" which (intellectuals of) dominant groups exercise over dominated groups seems to have nothing to do with imprisonment in slave societies. However, in present-day societies, governed by an economic variant of Darwinism, the strong tend to get stronger and to dominate the weak, who cannot or do not have the right to resist. Resistance based on difference is stigmatized as retrograde, as a conservative reaction to ineluctable progress. ${ }^{8}$

But marronnage has conceptual value beyond translation. Marginalized writers and artists, the so-called écrivains maudits, those who do not play by the rules of the game, protesters ... are the maroons of the source culture, as they attempt to remove themselves from the hold of legitimacy. And translators too can be the maroon agents of that source culture, as they break away from the discourses of legitimacy. With regard to translation, marronnage begins before the actual act: translation marronnage consists, first of all, in the translation of the source culture's maroon writers, the least cynical writers and translators, those who are the least directly and exclusively market-oriented. Translation can also be marronnage in another way, such as when it uses the orthodoxy of the source culture in order to effect the emergence of heterodoxy in the target culture. This heterodoxy can, however, at any moment become a new orthodoxy, tied to the legitimacy of the source culture within the translation culture, as was the case of American literature translated in France after World War II.

Literatures in dominant cultures all have their maroon writers: in the United States, for example, one could name Dos Passos, Faulkner, Steinbeck, Dreiser, Wright, Hurston, Himes and Dick, in three different genres (realism, the detective story and science fiction), along with a plethora of 
mythifying WASP American writers. Indeed, today in the West, there is a type of "neocolonialist" influence, which characterized the relations of the United States and France after World War II. Elsewhere I have attempted to show this (Gouanvic 1999) using a corpus demonstrating how American literature in translation, in particular science fiction, was parachuted into France after 1950. The legitimacy of the United States was so great that any translated American text could be successfully marketed in France. Consequently, American texts quickly dominated the French market, and caused French authors to languish. This is evident in print runs. During the 1970s, the books of Michel Jeury, the most talented French author of science fiction, were printed in the tens of thousands, while translations of mediocre American authors sold in much greater quantities. This eventually culminated in French authors adopting American pseudonyms and telling their stories in an American fashion, setting them in the United States, all in order to garner favour with the French public. ${ }^{9}$ How is it possible to account for such behaviour on the part of agents in literary fields, if not in terms of individual and collective alienation?

Pseudotranslations are particularly significant in terms of the collective nature of the relations between cultures, as Aniko Sohar clearly saw when she criticized Gideon Toury: "the decision to put forward a text as if it were a translation is always an individual one" (qtd. in Sohar, 156). Indigenous writers and the publishers of pseudotranslations position themselves from the outset on the side of the most highly legitimized source culture within the target culture. Even Boris Vian pseudotranslating Vernon Sullivan (see J'irai cracher sur vos tombes. Et on tuera tous les affreux...) explicitly takes the reader back to American culture, to Dashiell Hammett's and Raymond Chandler's detective novels, works which have been grouped together by Marcel Duhamel as translations in Gallimard's "Série Noire" since 1944. The pseudotranslations unearthed by Sohar in the genres of science fiction and fantasy are an indication of the hegemony of these genres, construed as American, in Hungarian culture. An analysis of the themes and discursive elements of these texts would probably demonstrate how far the imitation of American works goes in pseudotranslations. Are they formulaic replications of American science fiction? Are they adaptations in which markers of Hungarian culture are still readable? And if so, are such markers hegemonic in the texts? The central question which arises in the case of pseudotranslations, where alienation seems clearest, is whether they constitute in their own way transgressions of practices inscribed within the doxa of the national target culture. To answer this question, the problem needs to be considered from the perspective of the literary genres involved. Ever since Western cultures (e.g., France, Germany, Italy, Spain and so forth) adopted the American institutional model, with science fiction as a specific genre, science fiction has been ghettoized within national cultures. 
As a result of such compartmentalization, literary innovations in science fiction have little or no effect on other genres, and in particular on the dominant genre of realism. If pseudotranslations are able to have influence beyond the limits of a particular genre, it is less because the genre itself has gained influence than because the source culture possesses a legitimacy encompassing several genres.

It may not be politically correct to speak of "neocolonialism" with reference to symbolic domination. In the area to culture, dominators have no need of exercising their power for it to work in their favour. With Darwinian laissez-faire, identities are put to the test: traditionally liberal regimes invoke the "cultural exception" as a way of protecting themselves against the increasing ascendancy of dominating factors; the champions of liberalism, ultraliberals, who surrender to the laws of the market, profit most from those so-called "laws," both in terms of consumer goods and cultural goods. Nor should the capacity of cultural producers to make a virtue out of necessity be underestimated, as they appropriate the most orthodox discourses, dislodging the hierarchies of legitimacy in the target fields. Pseudotranslations are cultural practices that assume all the appearances of trickery, and which are therefore subject to moral condemnation. In fact, nothing prohibits the transgression of other, otherwise untouchable, social boundaries by way of this alienated form of translation.

\section{Conclusion}

From the point of view of cultural products, and especially of the exportation of these products by way of translation, postcolonialism represents the domination of certain cultures over others. This domination can wear different faces: it can be accepted as positive by the dominated or it can be considered harmful. If domination is accepted, it rests on the recognition by those formerly colonized of a certain legitimacy of the former colonizer, on the recognition of a common destiny of cultural partners. Cultural exchange, through translation or in the language of the former colonizer, is likely to be affected by different agendas in the fields which determine them: the field of power where the clientele for available cultural products is recruited; the literary fields to which the text belongs; the journalistic field, which produces and diffuses judgments on cultural texts; and the political field, which can override the others, at least locally.

Another model, which rationalizes the heterogeneity of the cultures in question, must be added to this colonial/postcolonial one. In any culture there are maroon writers, publishers and translators who do not always play according to the laws of the market and who position themselves to resist orthodoxy and the illusion of legitimacy. The maroons are heterodox, her- 
etics within dominant cultures, resisters at particular historical moments, like the French publishers Éditions de minuit or Maspéro, or, in the case of translation, translators of non-legitimized genres such as Marcel Duhamel and Boris Vian.

To better understand the phenomena of cultural hybridity arising out of colonialism, and to grasp what is at stake in it, the question to be asked is: To whose detriment is the legitimate violence assumed by the agent of translation exercised? The dominated's or the dominator's? It will then be possible to see whether the discourse on hybridity in fact hides stakes other than those brought to the fore, stakes more in keeping with the interests of the dominator and which, in a sleight of hand, translate into a reinforcement of the dominator's power.

\section{Notes}

1. This study has benefited from support from the Social Sciences and Humanities Research Council of Canada for a research project (1997-2000) entitled "Socio-analysis of the Translation of American Realist Literature in France after the Second World War (1945-1960)." This text and the quotations from Bourdieu 1984 and 1997 were translated by Donald Bruce (University of Alberta), and revised by Joanne Akai and Paul St-Pierre (Université de Montréal).

2. The quotation marks indicate a certain distancing from this commonly used, but not unproblematic, term.

3. Durisin is paradoxically silent on the question of the nature of this co-existence, as if polyoecism were free of all political implications. An analysis of the institutional status of a minority language or culture in a situation of polyoecism would show that the main determinant in the relationship is definitely political. See Cronin 1995.

4. See Time and Again, NBC documentary, April 25, 1997.

5. There are cases which seem to prove the opposite, and it is true that certain dominant national cultural fields may be historically constructed on the model of associative cooperation with the dominated cultures. It remains to be seen, however, if such cases are not just "islands" of difference which hardly, if ever, modify the power relationships between the languages/cultures although they make it seem as if the dominated culture is being taken into consideration. On the question of the implications of translation for minority languages, see Michael Cronin's study of the situation in Ireland.

6. For Isabelle Eberhardt, see in particular Houria Daoud-Brikci (Forthcoming).

7. See Jean Fouchard's fine book Les marrons de la liberté (1972).

8. Basing himself on the work of Canadian sociologist Anthony Wilden (Imaginary Canada, Toronto, Pulp Press, 1980), Michael Cronin (1995), 90-91, observes: "Wilden claims that Freud's Oedipal and paranoia theories ultimately blame the victims for their own plight and he extends the remit of his analysis to cover other theories that blame the oppressed for their own oppression... Language relationships are asymmetrical. The powerless or those with less power will always appear to be on the 'defensive' to those in power." 
9. The case of science fiction in Hungary is even clearer. In her $\mathrm{Ph} . \mathrm{D}$. dissertation, Aniko Sohar shows that of 712 novels published between 1989 and 1995, ninety-four were pseudotranslations, overwhelmingly "translated from" the Anglo-American. According to Sohar, this phenomenon is even more widespread in "romance" and detective novels (158).

\section{Works Cited}

BOURDIEU, Pierre. 1984. Questions de sociologie. Paris: Éditions de Minuit. 1997. Méditations pascaliennes. Paris: Éditions du Seuil.

CRONIN, Michael. 1995. "Altered States: Translation and Minority Languages." TTR 8, no. 1: 85-103.

DAOUD-BRIKCI, Houria. Forthcoming. "Le double meurtre symbolique du désert et du nomade: Isabelle Eberhardt et le maréchal Lyautey." In Le désert dans les littératures francophones, ed. Sandra Beckett and Rose-Marie Kuhn. Toronto: Éditions du GREF.

DURISIN, Dyonyz. 1991. "Artistic Translation in the Interliterary Process." TTR 4, no. 1: 113-27.

FOUCHARD, Jean. 1972. Les marrons de la liberté. Paris: Éditions de l'École.

GOUANVIC, J.-M. 1999. Sociologie de la traduction. La science-fiction américaine dans l'espace culturel français des années 1950. Arras: Artois Presses Université, coll. Traductologie.

SOHAR, Aniko. "The Cultural Importation Process of Popular Genres: The Case of SF and Fantasy in Hungary (1989-1995) from the Point of View of Translation Studies." Diss. Katholike Universiteit Leuven. 
This page intentionally left blank 


\title{
Chapter 6
}

\section{BALAI PUSTAKA IN THE DUTCH EAST INDIES: COLONIZING A LITERATURE}

\author{
Elizabeth B. Fitzpatrick \\ University of Massachusetts, Amherst (USA)
}

The study of the development of modern Indonesian literature is one context where overemphasis on the colonial influence has sometimes obscured other influences and assimilations. Balai Pustaka (Hall or Bureau of Books) was a Dutch colonial-government agency, active from around 1905 until World War II, whose purpose was to provide literature to the native population of the Dutch East Indies colonies. Until recently, it was considered a truism among scholars of modern Indonesian literature that the agency nurtured the development of modern Indonesian literature by introducing and promoting Malay-language novels. Thus, Andries Teeuw wrote, "It is no exaggeration to state that the coming into being of the modern Indonesian novel, and its popularity, was largely made possible through the existence of Balai Pustaka" $(1967,7)$. But in fact, Indonesian literature has always been marked by a continuing process of translation, narrative importation, genre shifts and adaptations from literatures throughout East Asia, the Indian subcontinent, Arabia and Europe.

Furthermore, the view that Balai Pustaka's intervention was primarily cultural and positive obscures a whole spectrum of Dutch ideological intentions; the agency's political and social agenda is just beginning to be scrutinized. In this paper, I shall look at six main projects that were initiated during Dutch colonization of Indonesia: the standardization of Malay, the distribution of literature, the collection and publication of traditional oral literature, the translation of European works, the sponsorship of original 
Malay novels, and the publication of magazines and newspapers. I will attempt to show how Balai Pustaka, under the guise of developing literature in the Indies, determinedly manipulated and disrupted local literary practices in the interest of promoting European values and maintaining Dutch power.

\section{Historical Background}

Explaining the disparate origins of the instruments of the gamelan (the Javanese orchestra)--which includes the rebab, a Chinese bowed instrument; gongs and wooden xylophones from Southeast Asia; and drums from the Melanesian islands to the east-an Indonesian friend said to me, "Look at the map. Indonesia is a basket at the bottom of Asia. Everything falls down here eventually, and gets caught." So it is with Indonesian history, culture and literature. The region comprising present-day Indonesia consists of many hundreds of islands, with a corresponding number of languages and cultures. Historically, there has been frequent contact between Indonesia and the Indian subcontinent.

Javanese culture has traditionally dominated the area. From about the fifth to the fifteenth century, cities on Java were the centres of a succession of kingdoms or sultanates which were strongly influenced by contemporaneous Indian Hindu-Buddhist culture. As a legacy of this period, Javanese (and modern Indonesian also) contains many Sanskrit loanwords, particularly for abstract terms. The hereditary sultans of the central Javanese cities, Jogjakarta and Surakarta, still inhabit their kratons (courts), and still preside over a matrix of cultural practices. Schools in the kratons provide training in the arts, gamelan and, most importantly, wayang kulit, the leather shadow-puppet performance, the most characteristic of Javanese art forms.

Like so much else in Javanese culture, the stories told in the wayang originated on the Indian subcontinent: episodes from the Rämäyana and the Mahäbhärata, the Hindu "oceans of story" that trace the two families of cousins whose final, inevitable war marks the end of the Golden Age on earth. Traditionally, the textual authority of the wayang resided with the kraton; the palm-leaf manuscripts housed there were available for consultation by the dalang, the professional puppeteers and conductors. However, "readings" were always performed and delivered as social phenomena, enacted in night-long sessions or in a series of sessions extending over several nights. Wayang kulit was usually performed at weddings, christenings and other celebrations. The audience would sit in the dark in front of a screen; a light source came from behind the screen, which also concealed the gamelan musicians and the dalang, who manipulated the flat leather puppets against 
the screen, speaking or singing in stylized voices. What the audience experiences in wayang kulit then is a more or less dimly lit and flickering screen, against which shadowy silhouettes, quickly recognizable and familiar characters which embody the ideal traits of Javanese culture-refinement, loyalty and bravery - suddenly loom up. The characters are intentionally unrealistic, and whether they represent refined princes or their uncouth attendants, wayang characters are considered supernatural, sacred, different and better than the real person. They are cultural models for correct behaviour. The audience already knows the characters and the formulized appellations the dalang uses for each, so much so that Arjuna, Hanuman, Sita and the others serve as shorthand for certain personality types. Literature conveyed in this manner has a powerful socializing effect. The drowsy atmosphere of the shared reception of familiar stories promotes a common understanding of social norms and behavioural values, as well as the glories of history, nationhood and battle. The wayang serves as a unifying setting for popular opinion on contemporary issues, for it is customary for the dalang to insert references and commentary on local events in the long section of story after the climax.

The second most important literature in the region was Malay. The Malay language has long existed in the archipelago as a lingua franca. It was used by Chinese Buddhist pilgrims on their way to India in the seventh century as the language of study in the monasteries of Sriwijaya, a kingdom on Sumatra. Later, Islamicized Malay sailors used Malay as a language of trade in the coastal regions of the Indian Ocean and the South China Sea. (The history of the region shows a pattern of cultural pluralism in littoral districts, culminating in large polyglot coastal cities such as Jakarta ${ }^{l}$ and Surabaya on Java, and comparatively insulated, traditional, monolingual cultures in the interior.) Malay literature was dominated by three genres: pantun, an extemporaneous short rhyme; syair, a ballad-like form; and hikayat, long epic stories in verse. Hikayat, like the Javanese wayang, is a performative genre, if much less elaborate: at night, a storyteller would recite episodes from memory or read from printed texts to large audiences. The two forms are also similar structurally: the epics of the performative wayang and the recitative hikayat are characterized by plots and subplots, which also stand well on their own. But the hikayat has a certain elasticity; the stories are translations from Sanskrit, Arabic or Persian, and they usually undergo a formal shift and variations in plot emphasis and locale. In fact, the underlying principle of literature in the region seems to be the easy transposition of stories from place to place, with form and genre being much more locally rooted. ${ }^{2}$

The traditional, mainly oral literary forms in the region began to be supplemented by other types of literature in the nineteenth century. By 1850 , 
independent newspapers were being published in several variants of Malay in the larger polyglot coastal cities. These papers were owned and operated by peranakan (semi-assimilated ethnic Chinese), Eurasians and Dutch private citizens. Their straightforward reporting brought new possibilities for the kinds of stories that could be told in Malay: for example, a story could be brought down out of the fantastic world and made to operate in the here and now. While literacy was still uncommon, those who could read had access to factual narrative, as well as serialized stories in the independent press. Thus began the leap in development from the oral mode and the ideal, semi-religious setting of wayang and some forms of hikayat, to the realism of modern Indonesian written literature.

As literacy increased, the independent press began publishing books in various variants of Malay, for the language was native to at least three populations: the Batavians (i.e., Jakartans), peranakan and certain groups on Sumatra, which is close to Malaysia. Book prices were low; publishers expected that books would be read aloud to an audience. Two main types of books were published: prose translations of great Chinese verse classics, whose audience was the peranakan, who were interested in Chinese culture, but who did not read Chinese; and thrillers written in Malay, which were just as improbable perhaps as the older epics and legends, but set in present-day cities and liberally sprinkled with sex and violence. The thrillers were intended for an audience seeking distraction; the violence was usually quite graphic, characters were oversimplified, the supernatural figured prominently in the plots and coincidence was rampant. The plot of Seitang-Koening, a thriller written by Raden Mas Tirto Adhi Soerjo, a journalist whose title suggests that he was a member of one of the princely families of Java, is summarized by C.W. Watson (1971): a njai (native wife or mistress of a Dutchman) is blackmailed into sleeping with an Arab to whom she is in debt. At the critical moment, however, they are interrupted by the Dutchman bearing a rifle, who in turn extorts a large sum of money from the Arab. Hilarity ensues. The language and independent nature of these productions made them antithetical to the colonial government of the time, and spurred the foundation of Balai Pustaka as a corrective measure.

In their role as colonizer, the Dutch saw themselves as different from the larger European powers. As C. van Eerde (1914) explained in "Omgang me inlander":

When history calls upon small nations to engage with energy and intelligence in the demanding work of empire, a little country such as Holland provides better guarantees than larger nations to implement the appropriate policies. Bigger European countries have a proclivity to use brute force in colonial administration- a blunt vio- 
lence that is grounded in their self-assurance as a society that can wield superior political and military might. Large countries tend to ignore the gradual adjustment process and evolutionary development that indigenous people must go through in order to achieve a higher level of civilization. (qtd. in Gouda 1995, 25)

Small the Dutch certainly were: in the East Indies they were grotesquely in the minority even at the height of their power. In 1938, there were 30,000 Dutch soldiers controlling a population of 70 million. This "little country" relied on scholarship to provide the leverage necessary to "implement the appropriate policies," which varied over time from the control of trade routes in the early days under the Dutch East Indies Company to the virtual enslavement of farmers in the plantations of the nineteenth-century Culture System.

Throughout the period of their colonization of the Indies, the Dutch carefully studied the local law, art, music, ethnography, botany and so forth, in order to be able to insert themselves effectively into the existing power structure. As they moved inland-in classical colonial fashion-they succeeded in controlling local rulers by various well-informed tactics such as backing malleable candidates, exploiting rivalries and appealing to greed. Local princes and sultans became Regents of their districts-highly paid employees of the Dutch government-but the real ruler was the Dutch Resident. Under the Culture System - which brought in revenues totalling about one-third of the Dutch national income-peasants were forced to grow cash crops - mostly coffee, indigo and cloves - for the Dutch to export. The Regent's salary was partly dependent on his ensuring that the farmers in his district meet the quotas set by the Dutch; traditional agriculture-rice cultivation-was slighted, and great suffering ensued.

The horrors of the Culture System were graphically described in Max Havelaar, the bestseller by Multatuli (c. 1900). Under this curious, Javanese-sounding pseudonym (which means in Latin "I have suffered much"), E.W.W. Douwes Dekker reveals the untenable position in which the Dutch put the local aristocracy, and describes how promises of prestige, status and multiple benefits from dependence made despots of the most well-meaning of the Javanese aristocracy. The publication of Max Havelaar in the Netherlands at the turn of the century galvanized opposition to the Culture System in the same way that Uncle Tom's Cabin influenced the abolitionist movement in the United States. Popular opinion in the Netherlands gave rise to a shift in colonial policy: the Culture System was dismantled, and a series of reforms, known collectively as the Ethical Policy, came into being with an emphasis on native education. Teachers' colleges and native schools were established throughout Indonesia, and several 
Minangkabau graduates of the Teachers' College at Bukittinggi, near Riauhome of the Malay dialect privileged by the Dutch — became mainstays of Dutch efforts to shape its Indies subjects.

\section{Standardization of Malay}

The Dutch impulse to study and codify extended to the field of linguistics. Malay was used by the Dutch as a lingua franca, partly in continuation of regional practice and partly because Javanese - the native language of about two-thirds of the area's population-is an extremely difficult language with five increasingly refined vocabularies, the choice of which indicates the relative social positions of the speakers. The Dutch were evidently unwilling to risk mistakes when every misspoken or misunderstood word could threaten the perception of Dutch superiority. The promulgation of Malay, a "foreign language" for the Javanese, therefore put both the Dutch and the Javanese on an equal footing.

But which variant of Malay was used? When they adopted Malay as the language of colonial administration, Dutch lexicographers elected to "standardize" the language to what they deemed "the classical dialect," as spoken in Riau, on Sumatra. Dictionaries and textbooks were therefore written in Riau Malay, as was all of Balai Pustaka's Malay-language output. Thus, the Dutch became arbiters of language itself. People who used non-Riau Malay as a first or second language found themselves speaking a devalued language_- "servant" or "market" Malay.

\section{Distribution of Literature}

The organization that became known as Balai Pustaka effectively came into operation around 1905 as an arm of the commission for native education. The first substantial history of the agency was written by Doris Jedamski, who noted that most of the previous references to Balai Pustaka were vague and unexamined (along the lines of Teeuw's comments above). Jedamski examined primary source materials, including memos between the agency's heads and their superiors in the Netherlands, and the agency's periodical publications. In the memos, she uncovered explicit statements confirming that as the agency grew, its goal became social manipulation via monopolistic control of all modes of literary production in the Indies (Jedamski, 1992).

The agency's initial goal was modest. Dutch educators in the Indies were of the opinion that new readers (adults and children) and their teachers in rural areas, away from the active publication environment of the coastal 
cities, needed books. Over the next five years, a complex and highly organized bureaucratic apparatus was slowly assembled to meet this goal. In 1913, D.A. Rinkes, who had joined the agency a few years earlier, became its head. By 1917, the increase in Balai Pustaka's activities justified its establishment as a separate bureaucratic entity, which was headed by Rinkes until his retirement in 1926. Subsequent heads of the agency followed Rinkes's blueprint, and Balai Pustaka continued to operate under Dutch control until the Japanese invasion of Indonesia in 1942.

Rinkes was, it seems, a visionary of social manipulation. He understood explicitly what others may have only intuited: controlling the literature of the people of the Indies would be a means of controlling their aspirations, values and actions. Literature, then, would be a tool in the Dutch campaign to "uplift" its native subjects (van Eerde qtd. in Gouda 1995, 25).

\section{Collection and Publication of Traditional Oral Literature}

Even before Rinkes had articulated his vision for the manipulation of literature, Balai Pustaka's efforts had already had profound implications for social control. Relying heavily on the cadre of Bukittinggi-educated Minangkabaus, in particular Nur Sutan Iskander, who worked as a translator and author with Balai Pustaka for thirty years, the agency began reworking Javanese and Malay epics. These epics, as well as oral narratives and traditional tales from various ethnic groups like the Minangkabau and Minahasa, which had been collected and recorded by earlier Dutch ethnographers, were bowdlerized, translated into Riau Malay and sometimes transposed from the realm of legend to modern-day settings for publication. The ostensible aim of this activity was to preserve impermanent oral literature and provide readers with stories more suited to their taste. But in fact, the Dutch had placed themselves in the position of arbiter of the people's own culture. They sought to deracinate the living narratives that had been templates of cultural identity. And most profoundly, they sought to change the modality of literature in the Indies from performative to written. No longer would stories be heard and experienced in the ornate performances of the wayang; no longer would the experience of the culture's central text be enlivened by the social nature of its reception. Under Dutch intervention, literature became a commodity to be individually consumed, just in time for the axiomatic last phase of colonial economics, when the colony became less valuable as a provider of natural resources, and more valuable as a market for manufactured goods from the "motherland."

On many levels, the traditional wayang performance was a threat to the Dutch. In its episodic, non-linear form, the wayang was a parallel world, 
in and out of which the audience could drift at will. The Dutch were absent from the wayang world or they (very occasionally) appeared as dangerous buffoons. In the wayang, authority - texts, voices, worlds-resided not with the Dutch, but with the dalang and the kraton. Thus wayang reinforced and was reinforced by indigenous power structures. It is set in the Golden Age, allegorically the period of Javanese empire. The audience's identification with the wayang world is so intense that, sometimes, it is as if reality is on the other side of the screen and the real world is only shadows. The Dutch did not want to cope with that. There were also practical concerns. In the wayang performance, the dalang comments on local events from a traditionalist stance, thereby focussing public opinion away from Western values. In addition, performative literature like the wayang generates crowds, a real danger to the numerically tiny Dutch presence.

\section{Translation of European Works}

By 1917, Balai Pustaka had expanded its production of appropriate literature by translating and publishing European and Malay stories and novels, and ensuring their distribution throughout the colony. Because massive government funding underwrote all aspects of production, the agency-sponsored book prices were much lower than those distributed by independent publishers. Sophisticated sales techniques were employed: Balai Pustaka "bookmobiles" circulated through the villages, usually parking in front of the village headman's house; and Balai Pustaka also had the monopoly on small libraries set up in each new village-school. By 1923, there were 623 Balai Pustaka libraries stocking Malay-language originals or translations, for example, Alexandre Dumas's Trois mousquetaires, Marah Rusli's Sitti Nurbaya, Rudyard Kipling's Jungle Book, Jules Verne's Le tour du monde en quatre-vingt jours, the Syair Siti Amina (see Ali 1991, 83). The language of translation and publication was Riau Malay. ${ }^{3}$ According to reports, some of the translations were fairly faithful to their originals, while others, true to the kind of story-shifting that occurs in Indonesian literature, transposed settings from Europe to familiar locales, and sometimes even changed the genre. For example, Teeuw mentions that Justus van Maurik's popular short story Jan Smees, set in the slums of Amsterdam, and relating Jan's struggle with demon num, became Si Djamin dan Si Djohan in Merari Siregar's translation. The translated version sets the action in a poor section of Jakarta, and substitutes opium for rum. The realistic short-story genre is changed to the more elevated tone of the hikayat (though the situation is more sordid than in the typical hikayat); and two Javanese charactersDjamin and Djohane - replace Jan, the Dutchman $(1967,54)$. There is also a version of Baroness Orczy's The Scarlet Pimpernel reset in the Indies. 
It is noteworthy, but not surprising, that most Balai Pustaka translations are children's fiction-gripping adventure stories, suitably compelling for new readers, but not necessarily intended for adults. Indeed, the Ethical Policy's custodial ideal for the colonial situation translated neatly into a parent/child model that necessarily infantilized the people of the Indies.

Balai Pustaka's standards for selecting texts to be translated and distributed were clearly stated: no overtly religious content, no political views contrary to the Government, nothing of low moral character. Literature should "cultivate awareness" and "promote good upbringing" (Ali 1991, 59). However, in her research, Jedamski (1992) uncovered a less public set of criteria, which were proposed by Rinkes, accepted by his superiors and reflected in the periodicals examined. Rinkes believed that the key to modernization (that is, Westernization) was to undermine traditional authority by highlighting situations where people ran into conflict with the adat (local law, customs or practices), and providing literary models for flouting it. Jedamski identifies three specific aspects of Westernization which Rinkes considered important: time, money and hygiene. Books should teach local workers how to participate in the shift from a barter economy and agricultural labour governed by the adat and based on the sun and the rain, to a wagebased economy where clean, punctual workers sell their time for money so as to buy consumer goods. By undermining the adat and controlling the process of modernization, the Dutch sought to lead the natives toward a new phase of colonization, and away from any nationalist tendencies.

\section{Sponsorship of Original Malay Novels}

Balai Pustaka was to provide diverting alternatives to the burgeoning independent publishing industry, where nationalist tendencies were already being noted. Both the overt and covert standards endorsed by Balai Pustaka can be traced in its sponsorship of original Malay novels, most of which were written by Dutch-educated Minangkabaus. These novels were usually formulaic, containing the following elements: conflict between young and old; conflict between Western values and the adat; tragic, forced marriages where these conflicts are played out in favour of Western ways (Situmorang 1981, 36). The formulaic plot consisted of young lovers separated by the girl's family, who forces her into marriage with a repulsive older man. By the end of the novel, the couple and the older man have all died. The bestknown of these Malay novels is the still-popular Sitti Nurbaya [Miss (or Princess) Nurbaya] by Marah Rusli. From the very first chapter, the novel's "modern," Western bias is obvious: the young couple, Nurbaya and the virtuous Samsulbara, are described approvingly as looking Dutch from a distance; the two characters representing the adat are portrayed as unsympathetically as possible; the ubiquitous, rapacious and scheming aunt is there; 
and of course, the horrible rich old man, the Datuk, who manoeuvres Nurbaya's father into giving her to him in marriage. Tragedy ensues when Samsulbara learns of Nurbaya's despairing death. He joins the Dutch army to help quell a tax revolt led by the Datuk, and is killed in battle. ${ }^{4}$ Sitti Nurbaya is particularly interesting because it superficially identifies with Western values as required by Balai Pustaka, but the genre in which it is written is fundamentally a descendant of the hikayat form. Rinkes's touchstones-time, money and hygiene-are right in the first chapter of Sitti Nurbaya, where the sparkling clean young couple are checking the clock as they wait impatiently for the old, outmoded family servant to drive them home from school. However, the elevated tone, the quasi-royal, non-representational characters, the frequent pauses for genteel dispute, the length of the novel and its episodic structure are all hikayat elements.

\section{Publication of Magazines and Newspapers}

Rinkes's fear of the indigenous press was prophetic. During the 1920s, the nationalist movement and the independent press mushroomed. In addition to thrillers and adaptations of Chinese classics, independent publishers began producing novels with nationalist themes. As Jedamski noted, in "the domestic newspapers, nationalist and communist movements were the focus of attention," while various Balai Pustaka periodicals "brought features of the quality of The National Enquirer or Reader's Digest" $(1992,35)$. At the same time, Dutch-educated native intellectuals were gaining access to Western literature without Dutch intervention, reading in the original languages, or in translations put out by private publishers, authors that Balai Pustaka considered too agitating or immoral to be translated, such as realists with clear political agendas like Émile Zola and Mark Twain. An excellent novel of the period, Suwarsih Djojopuspito's Out of Harness, originally written in Sundanese and subsequently translated by the author into Dutch, and published in the Netherlands, was rejected by Balai Pustaka (Teeuw 1986). Set in a milieu of student nationalism, the novel portrays one woman's struggle to balance her identity as a wife and her existence as an autonomous person. The works of novelists, activists and journalists often overlapped in the Indonesian situation during the 1920s and 1930s. Using the vernacular Malay, which was starting to be known as Bahasa Indonesia, the unifying "language of Indonesia," they produced reportages, journalism, fiction, theory and polemic.

Dutch efforts to mediate the cultural exchange between Europe and the Indies, and to divert its subjects from discussions of independence, were breaking down. The beginning of the end of Balai Pustaka's control of the Indonesian literary system was its rejection of Armijn Pane's Belenggu 
[Shackles] in 1939. Belenggu, about the inner lives of three contemporary Indonesians involved in a love triangle, is considered the first "psychological novel" in Bahasa Indonesia. At the urging of his friend Sutan Takdir Alisjahbana, who was an editor at Balai Pustaka, Pane submitted the work only to have it rejected on the grounds that it insufficiently condemned adultery: nobody died, as was customary. This showed that when a novel is not about conflict between a Westernized native and the adat, but portrays modern Indonesians trying to keep abreast and move with a changing nationalist society, the material is too hot for Balai Pustaka to handle.

Pane and Takdir published Belenggu themselves, and went on to found the independent literary journal Pujangga Baru [New Poetry]. In its first publication, in 1933, Pane proposed the following explicit connection between nationalism and the need to establish a new national literature, free of the influence and valuations of the Dutch:

An old teacher will shake his head when his pupils in their compositions do not pay attention to the grammar which he has taught them. The idioms which are always found in writings of former times are utterly rejected and discounted by them as cliches which are utterly meaningless and which no longer have any effect on them, and they employ their own idioms, their own symbols... During this change, the new literature-indeed like the society-is looking for stability, is looking for a firmer foothold, at the same time establishing a unifying literature and a unifying language, which is different from the Malay spoken at Deli, Riau, or any other region, and which is the language of general culture needed by these people; that is the Indonesian language. (qtd. in Teeuw 1967, 31)

Note that Pane pointedly rejected Riau Malay, the dialect standardized by the Dutch.

In its manipulation of all aspects of the Indonesian literary polysystem, Balai Pustaka was involved in what may have been a unique attempt to create ("falsify") a cultural discourse concerning "happy" Westernized native subjects and the benevolent paternal Dutch. But, Pane acknowledged and predicted a parallel discourse, ultimately more vigorous: the true discourse of Indonesia, in part descending from the classical performative genres of wayang and hikayat. Despite some government censorship, Indonesia literature today includes the vernacular Malay press, reportages, serialized stories, thrillers and adaptations of Chinese classics published in Jakarta. Its themes are innumerable, but the reader of modern Indonesian fiction will be struck by two particular commonalities. Works by Javanese authors very frequently incorporate wayang. In Pramoedya Ananta Toer's Perburuan [The Fugitive], for example, wayang is both a part of the plot (a performance is taking place in the background of the action) and a structural model 
(the perspective is bounded by the wayang stage: a character ducks down behind a bush, out of the reader's consciousness; a character delivers a monologue aloud, alone, as though on stage). In other novels, the characters have wayang names or certain constellations of relationships are plucked from the wayang world and played out in a modern-day setting. The second commonality is the portrayal of nation formation, often in its most dramatic phase, the war of independence.

Arguably, the preoccupation with the war of independence against the Dutch puts Indonesian literature in the postcolonial category, as it is defined in The Empire Writes Back. Referring to Asian and African novels, the authors write:

they emerged in their present form out of the experience of colonization and asserted themselves by foregrounding the tensions with the imperial power, and by emphasizing their differences with the imperial center. (Ashcroft, Griffiths and Tiffin 1989, 2)

True, many modern Indonesian novels foreground "their differences with the imperial centre," but I propose that their project is less to engage the West, than to celebrate nation formation. Western critical discourse on nonWestern literature is, ultimately, as inadequate as Balai Pustaka's attempts to control the cultural discourse of emerging Indonesia.

Pane was a pioneer in the development of a local critical discourse on the text-based phase of Indonesian literature. However, scholarship is not new in the area. Local scholarly constructs have long provided a framework within which material has been judged and ranked and performed. This scholarship is now concerned with building a typology of Indonesian fiction. It indicates that Western histories of Indonesian literature have overlooked local forms that underpin it and influence its development, in terms of both structure and story. In Indonesia, as elsewhere, the development of the "novel" coincides with the shift from a predominantly oral tradition to one where written texts are the norm. However, nowhere else, to my knowledge, was such concerted social control by a colonizing power attempted during the transition. The Dutch project was to discredit traditional Indonesian values and to direct cultural discourse away from emerging discussions of nationalism. But a real literary polysystem expresses the true cultural discourse of its time and place. In the end, Balai Pustaka's influence on Indonesian literature was inconsequential.

\section{Notes}

1. The colonial Batavia. 
2. It would be interesting to investigate the progress of these stories as they move back and forth in shifting languages and genres. Why is a particular text chosen? How does it change as it moves from one literary system to another? What is its impact on the host system? What other changes does it undergo within a particular system, in terms of genre shifts?

3. Among the Western authors translated and published were Alexandre Dumas, W.F. Oltmans, Mark Twain, Hector Malot, Baroness Orczy, Rudyard Kipling, Jules Verne, Pierre Loti, Robert Louis Stevenson, Henryk Sienkiewicz, Hans Christian Andersen, Arthur Conan Doyle, Grant Allen, Molière.

4. In keeping with the genre shifting that occurs frequently in Indonesian literature, Sitti Nurbaya was made into a film and a television series. And as an example of how stories remain constant, but meaning shifts over time, Teeuw mentions a revisionist reading of Sitti Nurbaya which turns the story's meaning on its head: as a tax evader and fighter against the Dutch, the Datuk is viewed as a nationalist hero, and Samsulbara, his enemy, is considered a stooge of the Dutch.

\section{Works Cited}

\section{Theory and Criticism}

ADAM, Ahmat B. 1995. The Vernacular Press and the Emergence of Modern Indonesian Consciousness, 1855-1913. Cornell: Cornell U Southeast Asian Program.

ALI, A. Wahab. 1991. The Emergence of the Novel in Modern Indonesian and Malaysian Literature: A Comparative Study. Kuala Terengganu, Malaysia: Percetakan Yayasan Islam Terengganu.

ASHCROFT, Bill, Gareth GRIFFITHS and Helen TIFFIN, eds. 1989. The Empire Writes Back: Theory and Practice in Post-Colonial Literatures. London/New York: Routledge.

FOULCHER, Keith. 1980. Pujangga Baru: Literature and Nationalism in Indonesia, 19331942. Australia: Flinders U Asian Studies.

GOUDA, Frances. 1995. Dutch Culture Overseas: Colonial Practice in the Netherlands Indies, 1900-1942. Amsterdam: Amsterdam UP.

GRIJNS, C.D., and S.O. ROBSON, eds. 1986. Cultural Contact and Textual Interpretation. Leiden: Koninklijk Instituut voor Taal-, Land- en Volkenkunde.

JEDAMSKI, Doris. 1992. “Balai Pustaka: A Colonial Wolf in Sheep's Clothing." Archipel 44: $23-46$.

PEACOCK, James L. 1968. Rites of Modernization: Symbolic and Social Aspects of Indonesian Proletarian Drama. Chicago: U of Chicago P.

SITUMORANG, B.P. 1981. Sejarah Sastra Indonesia, Vol. 1. Flores: Penerbit Nusa Indah.

TEEUW, Andries. 1967. Modern Indonesian Literature. The Hague: Martinus Nijhoff.

. 1986. "Translation, Transformation and Indonesian Literary History." In Cultural Contact and Textual Interpretation, ed. C.D. Grijns and S.O. Robson. Leiden: Koninklijk Instituut voor Taal-, Land- en Volkenkunde. 


\section{6 (POST)COLONIALISM AND THE POWERS OF TRANSLATION}

WATSON, C.W. 1971. "Some Preliminary Remarks on the Antecedents of Modern Indonesian Literature." Bijdragen tot de Koninklijk Instituut voor Taal-, Land- en Volkenkunde 127, no. 4: 417-33.

\section{Novels}

PANE, Armijn. 1949. Belenggu. Djakarta: Pustaka Rakjat.

RUSLI, Marah. 1922. Sitti Nurbaya. Weltvreden: Balai Poestaka. 


\title{
Chapter 7
}

\section{THE THIRD SPACE IN POSTCOLONIAL REPRESENTATION}

\author{
Michaela Wolf \\ Universität Graz (Austria)
}

"Where there is power, there is resistance." Michel Foucault, The Discourse on Language

The drive toward global uniformity in cultures, lifestyles and mentalities also extends to the production of literature. In literature, translation as an activity that always takes place in a specific social, historical and political context involves - voluntarily or not-asymmetrical power relations. With regard to "Third World" literatures, these power relations go as far back as the colonial period. Translation has played an eminent role in anticolonialism-witness the discourse of opposition to colonialism from the very beginning - and has therefore always been a part of the colonizing process. Postcolonialism, which generally refers to the period following independence, encompasses, more specifically, the ways of thinking and modes of behaviour in the "new" states, which are partly a result of independence. Therefore, the role of translation in the postcolonial context is closely related to the perpetuation of colonial structures.

Colonialism involved territorial, economic, political and cultural subjugation, appropriation and exploitation of another country and people, with the aim of establishing one's dominance in the world. Colonialism was not restricted to the countries and peoples of the "Third World," but also applied to other contexts. In fact, the disintegration of the AustroHungarian Empire can be compared, in some aspects, to the situations 
occasioned by Third World colonies' independence from the colonizing powers. Decolonization affects both the colonized and the colonizer: both feel fragmented, dismembered, exhausted, inferior and weak. The new situation is marked by ambivalence on both sides. A shared coat, which somehow held together different cultural manifestations, is shed, and both parties must look for a new coat or create a patchwork from the remnants. The newly independent country remains determined from the outside as the empty spaces inside are filled with nationalism, fundamentalism and essentialism (see Weibel 1997, 15).

Austria, a former hegemonic country which had built up numerous colonies in Europe, is still in the throes of an identity crisis that can only be described as postcolonial in nature. The loss of the prestigious position which the empire had enjoyed for centuries within Europe, the loss of two world wars and a considerably weakened cultural situation have all contributed to a definite lack of cultural identity in Austria. Moreover, the aftershocks of the 1918 disintegration of the Austro-Hungarian Empire are still being felt eighty years after the fact: the division of Czechoslovakia into the Czech Republic and Slovakia, the dissolution of Yugoslavia into several small national states-all symbolize the violence of dismemberment of a multiethnic empire.

What is the value of this to the current discussion on postcolonialism? While it may be true, from an ideological standpoint, that the various individual ethnic and national groups did not enjoy equal opportunities within the Austro-Hungarian Empire, the overall cultural climate that reigned cannot in any way be compared to that of Third World countries under colonialism. Under Austrian rule, the various states maintained a large part of their cultural traditions. If literary and artistic productions were censored, overall cultural output was not suppressed or wiped out, as was the case in Latin America and Africa. Consequently, after the disintegration of the Austro-Hungarian Empire, the independent countries found themselves in a culturally weakened-but not necessarily "hybrid"-situation, in the postcolonial sense of the word. Also, what remained of the Habsburg monarchy cannot be compared to the more or less well-established-politically and culturally, at least-hegemonic nations.

About four-fifths of the world's population, most of whom live in what is commonly called the Third World, have had their lives shaped by the experience of colonialism. However, global-impacting developments since the end of the 1980s (in particular, the end of the Cold War) and the whole phenomenon of globalization have contributed to a more dynamic foregrounding of postcolonialism. Frantz Fanon's Les damnés de la terre (The Wretched of the Earth, 1968), which came out in 1961, looks at the 
metropolises of former colonial empires, and questions the predominant cultural canons and consensus. Today, the cultural map needs to be redrawn. Cultural identity - which has always been far from simple and unequivocal - has become even more complex, and a matter of particular interest in social studies. Several questions which are crucial to the discussion of postcolonial translation arise. If it is true that the discourses of Western institutions are being perpetuated in the discourses of so-called Third World societies, thus perpetuating colonial structures (Niranjana 1992, 3), one must wonder to what extent Western democracy allows us to translate social differences beyond the polarities of us and them, East and West, First and Third World? Is not the Other, as represented through translation, undeniably caught within the web of these discourses? ${ }^{1}$ Are not the various forms of Otherness still illusions or reflections, rather, of our own identities? To what extent are constructions of the Other still postcolonial or neocolonial phenomena in so-called multicultural societies?

It seems that what is at stake is the assumption that Western cultures are based on exclusion and delimitation, that they draw a line between themselves and other cultures, peoples, races and religions. Consequently, they tend to represent their authority primarily through binary oppositions such as the ones mentioned above or others like self/other, colonizer/colonized, developed/underdeveloped. The phenomena of visible and invisible "clashes of civilization" (Huntington 1996), however, result in different forms of acculturation, syncretism, hybridization or pidginization. A dramatic turn in the representation of the Other that goes far beyond the Manichean division of self and other is being taken. Advocates of this "turn" in cultural studies recognize the danger in simply reversing these dichotomies, and therefore look to deconstruct them by analyzing the complex processes involved in cultural contact and its various implications, and by emphasizing the concept of "difference" in the formation of cultural identity. Thus, the key concept in cultural studies is hybridity.

In this paper, I will attempt to outline the development and various applications of the term hybridity in cultural studies, and trace the various stages of its implementation in postcolonial representation. I will attempt to show that postcolonialism, as a "continuing process of resistance and reconstruction" (Ashcroft, Griffiths and Tiffin 1995, 2) can be considered as a reading and writing practice which questions the production of knowledge of the Other. Several trends in cultural anthropology which analyze the ways in which ethnographic discourse is generated and sustained have proven effective for highlighting changes in cultural representation. I will discuss these first. I will then look at models of representation that have already been adopted, mainly in ethnography and gender studies, based on the concept of the space-in-between, which in turn is based on the concept of 
hybridization. Finally, I will argue in favour of a postcolonial translation practice that emphasizes interventionist strategies, and that seeks to transcend dichotomizing notions of translation.

\section{Ethnographic Representation}

In ethnography, representing cultures which are characterized by value systems different from those of the observing and describing scholars has always been a major problem. Since the 1940 s, scholarly interest has shifted to the analysis of ethnocentrism, among others. It was realized that the "observers" "perception, judgment of and behaviour toward members of the other culture were strongly influenced by the patterns of perception, valuation and behaviour acquired in their own culture (Gewecke 1986, 285). This realization has had an effect on the object of study, the ideological support and the organizational base of ethnography itself. Furthermore, the independence of many (mainly African) countries in the late 1950s and early 1960 s accelerated the trend. The newly independent countries implemented extensive national-planning programs which brought about radical socio-economic change. Issues arising from such change concern, among others, the implications of the power relationship between dominant (European) and dominated (non-European) cultures on the practicalities of ethnography, the uses to which ethnographical knowledge was put, the theoretical treatment of particular topics, the mode of perceiving and objectifying alien societies, and ethnographers' claim of political neutrality (Asad $1975,17)$.

Immediate consequences of these reflections were the development of new ethnographical methods of inquiry. With the awareness that having worked on a foreign culture does not necessarily imply complete knowledge of it came the proposal that ethnographers speak for their co-subjects of knowledge. This proposal emphasized a reflexive approach to ethnographic writing. Marcus and Fischer (1986), for example, highlight representation as the key feature of reflexivity. They consider "writing" as a social praxis engaged in the construction and dialectical reformulation of the Other, and argue in favour of an ethnographic writing which opens itself to a plurality of voices. This style of ethnography decentres the authority of the anthropologist, and involves much more than simply reporting information provided by informants (see Ulin 1991, 70). Cultural representation not only defines a specific method of observation and recording, but also includes the social discourse of the informant. It became important to express other discourses in one's own discourse, as well as to identify and capture differences in language. The encounter between the two cultures (the observing and the observed) is therefore no longer destined to result in 
the clash that ethnographic discourse, primarily shaped by academic, institutional and political forces, tends to produce. If it is true that discourses in postcolonial contexts are generally constructed against the backdrop of societies where power and privilege are still a reality (Wolf 1996, 285), the approaches adopted by postmodern ethnographic writing seem to represent a paradigmatic turn of the "writing between cultures." Not only is discourse preferred to text, dialogue to monologue, but ethnography now also privileges collaboration between the parties involved. The discourse produced should result from a reciprocal, joint, dialogic process. Ideally, the product should be a "polyphonic text" or as Tyler puts it:

A post-modern ethnography is a cooperatively evolved text consisting of fragments of discourse intended to evoke in the minds of both reader and writer an emergent fantasy of a possible world of commonsense reality. $(1986,125)$

It is precisely in the field of discourse production that an interesting overlap of the ethnographer's and the translator's main tasks can be seen. For both, translation ${ }^{2}$ between two different cultures (e.g., Northern and Southern hemisphere societies) ideally consists in mutual, dialogical production of a discourse. Such discourse can be regarded as the result of the meeting of two cultures which merge or "hybridize" without giving up or neglecting their own specific cultural features, but which emphasize, rather, the various perspectives that converge in the translation product. ${ }^{3}$ This process is based on the assumption that language, as Bakhtin $(1994,293)$ wrote, is "a concrete heteroglot conception of the world"-it is, by its nature, a hybrid construction. I will come back to this Bakhtinian reflection later.

Such a multi-voiced representation also has its dangers. Considering "difference" as an effect of inventive syncretism, Edward Said and other scholars have cast radical doubt on the procedures by which alien human groups are represented, without however proposing systematic new methods or epistemologies. Their studies suggest that while ethnographic writing can never entirely escape the reductionist use of dichotomies and identities, it can at least struggle self-consciously to avoid portraying the Other as abstract or ahistorical (Clifford 1983, 119). I shall now examine these views of representation.

\section{Hybridity or the Location of Cultural Encounter}

Edward Said's Orientalism, published in 1978, inaugurated a new era in postcolonial studies. His focus on discourse analysis, in the Foucauldian sense (Foucault 1972), enabled him to unmask the discriminatory image 
that Western writings offered of the Orient. Said examines various European representations of the Middle East-literary, scientific and journalistic texts, travel writings, anthologies of nineteenth-century translations. He shows the collusion between literary texts and Western political domination, which results in the creation of images of the Orient that separate the spheres of the colonizer and the colonized, and portrays the latter as backward and passive. Through his analysis of colonial discourse, Said tries to show how the West-like every conqueror and empire - objectified the rest of the world and constituted itself as the Subject of History, within the framework of the emerging constellation of modernity (Chambers 1996, 47). In so doing, the West produced and codified knowledge about non-metropoli$\tan$ areas and cultures, especially those under colonial domination. Orientalism, in Said's words, is simply "a kind of Western projection onto and will to govern over the Orient" $(1978,95)$.

As Robert Young (1990) argues, Said refers the whole structure of colonialist discourse back to a single originating intention within colonialism- the intention of the colonialist power to possess the territory of the Other. It is this assumption which seems to be the most controversial part of Said's theory. In Dennis Porter's (1983) opinion, for example, Said's construct of Orientalism is overly monolithic. Porter also identifies fundamental contradictions throughout Said's book, which, in his opinion, are due to Said's use of two theories whose positions are incommensurable: Foucault's and Gramsci's. Witness Porter's concluding remarks to his critique of Said's Orientalism:

In the light of all this, the reason why Said is unable in the end to suggest alternatives to the hegemonic discourse of Orientalism is not difficult to explain. First, because he overlooks the potential contradiction between discourse theory and Gramscian hegemony, he fails to historicize adequately the texts he cites and summarizes, finding always the same triumphant discourse where several are frequently in conflict... Finally, he fails to show how literary texts may in their play establish distance from the ideologies they seem to be reproducing. $(1983,192)$

In Culture and Imperialism, Said (1993) tries to further develop his theory. On the one hand, he aims at elaborating a more comprehensive theory of the interrelations between culture and imperialism, extending his area of research to other colonized regions (e.g., the Caribbean, Black Africa and India). On the other hand, he stresses anti-imperialist resistance in an attempt to draw a more balanced picture of the processes of colonization and decolonization. In so doing, he tries to get away from using binary oppositions and to offer a view of both sides of the "imperial divide" between 
colonizer and colonized (Kreutzer 1995, 203). He therefore disapproves of essentialist argumentation--for example, the European against the African, and vice versa - and seeks to focus on the heterogeneity of culture. It is in this heterogeneity that Said locates hybridity, a dynamic diversity which ultimately, according to Said, characterizes every culture.

It should be noted that the term hybrid has its origins in biology and botany; it became a key term in nineteenth-century positivist discourse, mainly to describe physiological phenomena, and has been reactivated in the twentieth century to describe cultural phenomena. Today, "the use of hybridity prompts questions about the ways in which contemporary thinking has broken absolutely with the racialized formulations of the past" (Young 1995, 6). Bakhtin introduced the concept of hybridity in philological reflections on representation. For Bakhtin, hybridity defines the way in which language, even a single sentence, can be double-voiced. According to his literary theory, a language can represent another language while still retaining "the capacity to sound simultaneously both outside it and within it" (1994, 358). He continues:

What is hybridization? It is a mixture of two social languages within the limits of a single utterance, an encounter, within the arena of an utterance, between two different linguistic consciousnesses, separated from one another by an epoch, by social differentiation or by some other factor. (358)

Where he considers a language to be simultaneously the same, yet different, he associates it with the Romantic concept of irony. However, hybridization "doubles" irony in its ability to cause one voice to ironize and unmask the other within the same utterance. For Bakhtin, therefore, hybridity describes the process of the authorial unmasking of another's speech through a language that is "double-accented" and "double-styled." A "hybrid construction" is an utterance that belongs, by its grammatical and compositional markers, to a single speaker, one that actually contains within it two utterances, two manners of speech, two styles, two "languages," two semantic and axiological systems. Bakhtin (1994, 304-5) showed that frequently even one and the same word belongs simultaneously to two languages or two belief systems that intersect in a hybrid construction. It is through this hybrid construction that one voice is able to unmask the other within a single discourse. It is at this point that authoritative discourse becomes undone. Authoritative discourse is univocal, it "is by its very nature incapable of being double-voiced; it cannot enter into hybrid constructions" (344); if it does, its univocal authority will immediately be undermined. ${ }^{4}$

Hybridization as subversion of authority in a dialogical situation of colonialism is examined by Homi Bhabha. He argues in favour of the 
double vision that individuals, such as migrants or social minorities, positioned at the merging of cultures possess, and stresses the intercultural tension produced by this merging. Bhabha's "double vision" recalls Norbert Elias's metaphor of man on the threshold of a new age, between what we call the Middle Ages and the Renaissance $(1990,107)$. Elias's man is standing on a bridge and has the face of Janus-his gaze is turned in two directions: one looking forward, one looking backward. In the "double vision" situation, the complex perspective of the marginalized is transmitted through the creativity of translation and transformation, thereby contributing to transcending social binarities of race, nation, gender or generation.

Bhabha's view of representation takes hybridity as a starting point. He analyzes different types of hybridizations produced by various postcolonial societies. In a colonial context, cultural hybridity is produced at the moment of the colonial encounter, when self and other are inseparable from mutual contamination by each other. The colonial encounter is therefore embedded a priori in power relations, and requires constant awareness of the limits and possibilities of representation. Bhabha transforms Bakhtin's definition of the hybrid into an active moment of challenge and resistance to the dominant cultural power. He sees hybridity as a "sign of the productivity of colonial power, its shifting forces and fixities" (1994, 112 ), and as a moment in which the discourse of colonial authority loses its univocal claim to meaning. In Bhabha's words:

Hybridity is a problematic of colonial representation and individuation that reverses the effects of the colonialist disavowal, so that other "denied" knowledges enter upon the dominant discourse and estrange the basis of its authority-its rules of recognition. (114)

Hybridity is thus not simply a third term that resolves the tension between two cultures in a dialectical play of "recognition," and cannot be discussed as an issue of cultural relativism. Bhabha argues that an important change of perspective occurs when the "effect of colonial power is seen to be the production of hybridization rather than the noisy command of colonialist authority or the silent repression of native traditions" (112). Hybridity therefore describes a process in which the single voice of colonial authority undermines the operation of colonial power by inscribing and disclosing the trace of the other so that it reveals itself as double-voiced (Young 1995, 23). Bhabha's concept of hybridity can thus be viewed as radically heterogeneous and discontinuous, a dialectical articulation that involves a new perspective of cultural representation. Cultural difference is no longer seen as the source of conflict, but as the effect of discriminatory practices; the production of cultural differentiation becomes a sign of authority. This changes the value of difference and its rules of recognition $(1994,114)$. 
Under Bhabha's concept of hybridity, cultural dimensions, such as space and time, can no longer be understood as being homogeneous or selfcontained. Cultures are never unitary in themselves, nor simply dualistic as in the relation selflother $(1994,36)$, rather there is a Third Space, which can neither be reduced to the self nor the other, neither to the First nor to the Third World, neither to the master nor to the slave. Meaning is produced beyond cultural borders and is principally located in the Third Space, a sort of "in-between space" located between existing referential systems and antagonisms. The production of meaning

requires that these two places [the I and the You] be mobilized in the passage through a Third Space, which represents both the general conditions of language and the specific implication of the utterance in a performative and institutional strategy of which it cannot "in itself' be conscious. (36)

It is in this Third Space between former fixed territories that the whole body of resistant hybridization comes into being in the form of fragile syncretisms, contrapuntual recombinations and acculturation. And, as Bhabha states, the Third Space is also the potential location and starting point for postcolonial translation strategies:

It is that Third Space, though unrepresentable in itself, which constitutes the discursive conditions of enunciation that ensure that the meaning and symbols of culture have no primordial unity or fixity; that even the same signs can be appropriated, translated, rehistoricized and read anew. (37)

What Bhabha calls the Third Space of representation in the postcolonial context has already been discussed and shaped in other discourses under different forms, and not necessarily within an elaborated model of representation. I shall now discuss some of these approaches, as adopted in ethnography and gender studies. These approaches will serve as a basis for my argument in favour of a translation practice in which the Third Space "carries the burden of the meaning of culture" (Bhabha 1994, 38), thus enabling an engaged, interventionist translation strategy to come into being. ${ }^{5}$

\section{Space(s)-in-Between}

Already in 1949, Margaret Mead argued in favour of an ethnographic representation evolving from a space located between her observations and subsequent statements thereof, and the reader's consideration. This space should serve to convey to the reader not only the results of her observations as a fieldworker, but also the method by which she obtained her results. The 
ethnographer should thus be able "to interpose between my statement and the reader's consideration of that statement a pause, a realization not of what authoritative right I have to make this statement I make, but instead of how it was arrived at, of what the anthropological process is" $(1974,13)$. The encounter of the culture being observed and to be represented, and the anthropologist's textualization in "strong" academic language (in Mead's case, English) on the one hand, and the reader's reception and consideration on the other hand, is perceived by Mead as a means of reflecting the process of cultural representation at the very border where the observer and the observed's perspectives merge.

In gender studies, the "space-in-between" stands for the desire for representation beyond the traditional male/female binarity. Women in different societies have been relegated to the position of the "Other." In this respect, a parallel might be drawn between women and colonized cultures: both have experienced oppression, and both are obliged to express themselves in the language of their oppressors. This "double colonization," as it were, by imperial and patriarchal supremacy is also a key concept in postcolonial translation theory.

Rosemary Arrojo's discussion (1995) of Susan Bassnett's essay (1992) on the elaboration of an "orgasmic theory of translation" seeks to deconstruct the male/female dichotomy, without however reversing the male/ female power relationship, and equating the female with the non-violent and, therefore, legitimate. Bassnett argues that an "orgasmic" theory would transcend the violence implied in "colonialist" and "sexist" conceptions of translation which describe the translator's task in terms of "rape and penetration, of faithfulness and unfaithfulness" $(1992,72)$. She uses Hélène Cixous's notion of the "in-between" to illustrate the parallels between the development of Translation Studies and feminist theory in the 1970s. Cixous describes the feminine as being a place "in-between" the male and female poles:

To admit that writing is precisely working (in) the in-between, inspecting the process of the same and the other without which nothing can live, undoing the work of death-to admit this is first to want the two, as well as both, the ensemble of one and the other, not fixed in sequence of struggle and expulsion or some other form of death but infinitely dynamized by an incessant process of exchange from one subject to another. (qtd. in Bassnett 1992, 64)

Cixous, as well as other feminist poststructuralist theoreticians, principally questions binarities such as transcendence/immanence, spirit/body, subject/other. She calls for another sort of subjectivity-one which no longer devalues and denies the body. Cixous, after Jacques Derrida, adopts these traditional logocentric oppositions as a starting point. In doing so, she con- 
siders the whole system of Westem knowledge as based on male supremacy, the result of patriarchal hierarchization. Arrojo $(1995,72)$ argues that Cixous's "feminine" becomes the new paradigm, the new logos, synonym for the non-violent, the good and the positive. Cixous, in attempting to empower the "feminine," which she associates with everything that is good and desirable, inevitably emphasizes not only the male/female polarity, but all the other polarities her argument implies, for example, violence/non-violence, evil/good, life/death. Cixous ends up defending an essentialist thesis. The intervention in the text-in other words, the "woman-handling" of the text (Godard 1990, 94)-becomes just an inverted version of the patriarchal practice.

Inversion of male and female power relations endangers both the feminist stand and a feminist theory of translation which seeks to go beyond the binary concept of "equivalence." Also, considering the "turnaround" in the role of the parties involved (man-author/woman-translator), one would have to admit that Bassnett's "orgasmic theory of translation" does not differ very much from the violent intent of the theories she herself rejects (Arrojo 1995, 67). What is important, however-as Arrojo points out in her concluding remarks-is recognition of the "need to make reality (and, consequently, also texts and objects) our own, the need to fight for the power to determine and to take over meaning" (74). Such recognition is surely possible if there is a mutually respectful collaboration between author and translator. While Arrojo's critique of Bassnett underlines the ineluctability of violence in any act of interpretation or writing (Simon 1996, 29), it must also be borne in mind that language, although a vehicle of meaning that is always driven by the will to power (Foucault 1970), is also a means of social change. The use of an inclusive language, at the level of parole and discourse, entails changes in perspectives, which in turn act as stimuli to changes in human action and reality ${ }^{6}$ Cixous's "writing in the inbetween" stands precisely for this dialectical process of change.

The space-in-between, the encounter of male and female concerns which cannot be seen as an ahistoricized phenomenon, exists in everyday life. It is in this everyday encounter that new meaning can be produced. As Homi Bhabha puts it:

Translation is also a way of imitating, but in a mischievous, displacing sense-imitating an original in such a way that the priority of the original is not reinforced but by the very fact that it can be simulated, copied, transferred, transformed, made into a simulacrum and so on: the "original" is never finished or complete in itself. The "originary" is always open to translation so that it can never be said to have a totalised prior moment of being or meaning - an essence. (1990, 210) 
So far in this article, I have discussed Homi Bhabha's concept of the Third Space, that is, the space between two poles or binarities. Feminist translation has created its own space-in-between. Whereas Bhabha's space is a natural creation born of the more or less violent "clash of civilizations," the feminist notion of intertext is a conscious creation of a space-in-between. Susanne de Lotbinière-Harwood defines the intertext as a

communicating and resonating collective text scripted in the feminine by feminists rereading and rewriting what other feminists have written and spoken. It is composed of the women's voices and words constantly present in our own voices and words, gynergizing our memories, our imaginations, our actions. $(1991,126)$

In translation, the production of the translated text is usually dependent on the translator's knowledge of various other pertinent or related texts and contexts. This seems to be the classical conception of the notion of intertextuality. However, if we look at Michael Riffaterre's use of the terms "intertext" and "intertextuality," we see a clear distinction between the two notions. Indeed, as Barbara Godard points out:

Riffaterre makes a distinction between "intertext" (the totality of texts that may be related to the text being considered) and "intertextuality" (the reader's perception of significance, that is, of the literariness of the text). $(1993,570)$

Here, intertext is considered very generally as a semiotic transformation, whereas intertextuality is limited to the reader's personal perception. Therefore, in our context, intertext refers to the presence of expressions, themes, stylistic devices and so forth in a text, which obviously have their origin in other previous texts. Like all writing, translation is nourished by reading. In this sense, the feminist intertext would consist of all feminist texts read by the translator-fiction, theory, criticism, translations-which can be considered a sort of memory bank of words, meanings and references that constitute the background for feminist translation strategies. But, the result goes beyond feminist translation which is marked by feminist intervention. Lotbinière-Harwood observes:

d'une part elles [les re-belles et infidèles] bénéficient de l'apport créateur de l'intertexte, de l'autre, elles contribuent à l'émergence d'une culture au féminin en opérant un élargissement du vocabulaire, du sens et de la conscience. $(1991,58)$

[on the one hand they (the re-belles et infidèles) benefit from the increased creativity brought by the intertext, and, on the other, they contribute to the emergence of a culture in the feminine, by broadening vocabulary, meaning and consciousness.] 
What we end up with, in fact, is a "shift from discourse, from ideologeme, to body, to identity," a shift from "conflicting ideologies ... toward a vision of sororal harmony" (Godard 1995, 78). The "clash of civilizations" concept is substituted by a concept of harmony created in the space-in-between, which views voice, sound and rhythm as the main features of writing in the feminine.

\section{Does liget Translate as "Heart"?}

An example from ethnographic representation will illustrate the creativity of the space in-between of diverging cultures. The ethnographer and the translator are usually the "first readers" of the other culture, and both must represent the other in a primary process. On the surface, the process of translation seems quite different for ethnographers and translators. The ethnographer first interprets the social discourse of the informants by trying to find out what they mean by what they say; then she/he systematizes and textualizes her/his interpretation for a target audience who is usually of the "First World." This is therefore a two-step translation process, at the very least. The translator, however, is already faced with a written or encoded text, which she/he must decode, interpret and reconstruct in her/his language, usually also for a "First World" audience. This is a manifold process (Wolf 1997, 128). As has been shown, both ethnography and translation in Third and First World contexts are positioned between systems of meanings that are marked by power relations. Translating between cultures must therefore be understood as the transfer of meanings of the "other" culture to the (con)texts of the "developed" world, which are determined by their own institutions, traditions and history.

With regard to the representation of rituals or, more generally, belief systems of other cultures, the ethnographer in the role of translator must "think in terms of essence, shape and image when translating" (my translation) (Kramer 1987, 73). In doing so, she/he must consider different layers of meaning separately, and include each in the decision-making process that the translation entails. For example, cultural phenomena attached to belief systems could have cosmological, sociological or psychological layers of meaning. The following example of the emotional layer of meaning attached to liget illustrates the diversity of cultural categories. Philippine Ilongot head-hunters consider that the liget ("heart") is the driving power behind the head-hunting ritual (Rosaldo 1980, 27). The liget encompasses energy, anger and passion. "Heart," therefore, contrary to its meaning in Western cultures, is not the locus of individual expressions of emotion, but of "social passion." It is the source of action and awareness, the centre of vitality and will (36). The term liget suggests the "passionate energy that 
leads young men to labor hard, to marry, kill and reproduce, but also, if ungoverned by the 'knowledge' of mature adults, to engage in wild violence. Ideally, 'knowledge' and 'passion' work together in the 'heart'" (27).

In Rosaldo's opinion, the ethnographer's exploration of meanings and intentions in order to "translate between cultures" is a crucial concern:

We can learn about Ilongot life by using words like liget as an initial text ... because a proper understanding of what liget means requires us to look beyond the word itself to sentences in which it is employed, images through which it is invoked, and social processes and activities that Ilongots use it to describe. (24)

Rosaldo opens up a space between her interpretative labour, which is necessarily marked by Western thought, and the motivations which lead Ilongot head-hunters to claim that "liget is what makes men kill" (24). Only a detailed analysis of the ritual (e.g., ceremonies, songs, speeches, tales) will enable deeper insight into this imagery. And Rosaldo can do this only by using a terminology embedded in Western institutional language. But in so doing, the terms she uses in specific contexts are already marked by hybridity. The colonial encounter takes place precisely in this (ethnographic) interpretation, and continues into the translation process. Once translated, none of the parts involved remains the same: meanings are remixed; a dialectical interaction of the two cultures involved takes place (Bhabha 1994, 114). By highlighting the background of the concept of liget, Rosaldo creates a fertile space of understanding between different, already existing reference systems. Thus, liget can never be represented/translated as a sign, but must pass through a "space-in-between" where it is "appropriated, translated, rehistoricized and read anew" $(1980,37)$.

\section{Intervention from the Third Space?}

As can be seen in the different approaches to translation between cultures considered in this paper, as well as in the textual example, the question as to whether it is "legitimate" to intervene in a text using any of the abovediscussed strategies becomes an important one. Indeed, "spaces-in-between" provide the terrain for elaborating strategies of individuality, and contributing to initiating new identities (Bhabha 1994, 1). Both colonial and patriarchal power produce hybridity. Once we understand the process of hybridization, we can see how "the discursive conditions of dominance" can be turned into "the grounds of intervention" (Bhabha 1994, 112). Recognizing the hybrid therefore means translation, deformation, displacement. In her article "Translation and the Postcolonial Experience," Samia Mehrez observed that postcolonial texts understood as hybrids have created their own language: 
Hence, in many ways these postcolonial plurilingual texts in their own right resist and ultimately exclude the monolingual and demand of their readers to be like themselves: "in between", at once capable of reading and translating, where translation becomes an integral part of the reading experience. $(1992,122)$

Anuradha Dingwaney goes even further when she locates in the between a space "from within which the (colonized) native deliberately (mis)translates the colonial script, alienating and undermining its authority," proceeding from an "awareness of the 'other's' agency and own forms of subjectivity, which 'returns' the 'other' to a history from which she or he was violently wrenched" $(1995,9)$. The space-in-between is therefore a fertile and, at the same time, disquieting space where the dialectical interaction of at least two cultures takes place. It is a place where the dominant culture and language can be subverted, and thus functions as a sort of resistance. If we consider the Third Space as the potential and starting point for interventionist translation strategies, we realize that such strategies go far beyond the traditional concepts of "original" and "translation," and the old dichotomy of "foreignizing" versus "domesticating" in all its implications. These strategies imply a shift toward the centre, where cultures encounter each other, and where meanings are effectively "remixed" (as shown in the example of liget). The place where cultures overlap and hybridity comes into being can already be considered as the locus of translation. This implies that culture is already itself translation. Doris Bachmann-Medick sees this equation as a new paradigm which substitutes the notion of "culture as text" (Geertz 1973):

Culture as translation ... is a new paradigm which stresses the aspect of negotiation in the constitution and assertion of cultures as well as emphasizing the problematic search for cultural commensurability and, at the same time, for local-historical grounding. (BachmannMedick 1996, 11)

What then does this turn in cultural representation mean to the role of translators? It would seem that much needs to be done to facilitate a "translation culture" which could address certain questions that arise. Translation obviously no longer means bridging a gap between two different cultures but, rather, producing meanings which are created through the encounter of cultures that are already characterized by multiculturality. Multiculturality is an ambiguous notion. According to the philosophy of multiculturalism, "the other" is an excepted entity, which implies the existence of difference. At the same time, however, this permissive philosophy can also serve as a pretext for exclusion precisely because of alterity. Unfortunately, the logic of multiculturalism does not transcend the dialectics of 
inclusion and exclusion. The translator must always be aware of this ambiguous situation and act accordingly. She/he must also be aware of the ambiguity of the term globalization as it is used today. Politically, Western societies are drawing their curtains and getting ready to build fortresses; culturally, these societies are pleading for transcultural flexibility. Difference and alterity may have become legitimate, but they do not necessarily imply the basic right of equality. ${ }^{7}$ In fact, colonialism is perpetuated under a different form and name; globalization can be considered akin to neocolonialism, this time by transnational corporations.

The translator is caught within the web of this contradiction. Her/his task is primarily a cultural one. Yet the political implications of her/his activities cannot be ignored. Awareness of this double-bind situation can open new avenues for the translator. In a situation of hybridity, the translator operates in an environment characterized by the hybridization of language, culture, behaviour, institution and communication. She/he becomes shaped by a sort of exile, involved in, yet still on the borderline of, culture. The translator is no longer a mediator between two different poles, but her/his activities are inscribed in cultural overlappings which imply difference. This difference is no longer taxonomical, but interactive and refractive. In this way, the translator realizes that translation is not a transparent activity, but one which, as Iain Chambers $(1996,49)$ states, always involves "a process of re-citing, hence cultural and historical re-siting, and is therefore a travesty, a betrayal, of any 'original' or 'authentic' intention."

Hybrid identities and the multiplicity of cultural borders are permanent features of contemporary societies. They call for a state of knowledge and a state of consciousness that can withstand the pressure of constantly being called into question. This might be viewed as our chance to listen to the unsaid in our own and in others' discourses, as our chance to be continuously aware of the power relations governing the limits and possibilities of translating between asymmetrical cultures.

\section{Notes}

1. Discourse is meant here in the Foucauldian sense, as a system of possibility of knowledge. What rules, for instance, govern the identification of certain individuals as authors, and of certain texts as literature? At the same time, however, these discourses are subject to the will to power which penetrates them with the intention of controlling them: the will to knowledge is the will to power (see Foucault 1970, 1972).

2. For the dangers of using the term "translation" as a metaphor in cultural studies, see Simon (1997), 462.

3. An illustration of this sort of "cultural translation" is described in Clifford (1983), 126-27. 
4. For a detailed discussion of the concept of hybridity in the Bakhtinian sense, see Young (1995), 20-24.

5. Bhabha's notion of cultural translation is discussed in detail by Simon (1997), 47273.

6. In traditional translation studies, the creation of consciousness as one of the translator's functions is not always approved of. Katharina Reiß (1993), 38, for instance, is of the opinion that "it is not the translator's task to bring about a change in language and consciousness" (my translation). This, according to Reiß, is tantamount to the manipulatory practices of dictators and ideologues.

7. See Kahn (1995) for an in-depth analysis of problems relating to liberal, postcolonial multiculturalism.

\section{Works Cited}

ARROJO, Rosemary. 1995. "Feminist, 'Orgasmic' Theories of Translation and Their Contradictions." Tradterm 2: 67-75.

ASAD, Talal. 1975. Introduction. In Anthropology and the Colonial Encounter, ed. Talal Asad, 9-19. London: Ithaca Press.

ASHCROFT, Bill, Gareth GRIFFITHS and Helen TIFFIN, eds. 1995. The Post-Colonial Studies Reader. London/New York: Routledge.

BACHMANN-MEDICK, Doris. 1996. “Cultural Misunderstanding in Translation: Multicultural Coexistence and Multicultural Conceptions of World Literature." Erfurt Electronic Studies in English [EESE] 7: 1-15. http://webdoc.gwdg.de/edoc/ia/eese/ artic96/bachmann/7_96.html

BAKHTIN, Mikhail. 1994. The Dialogic Imagination: Four Essays by M.M. Bakhtin. Trans. Caryl Emerson and Michael Holquist; ed. Michael Holquist. Austin: U of Texas P.

BASSNETT, Susan. 1992. "Writing in No Man's Land: Questions of Gender and Translation." Ilha do Desterro 28, no. 2: 63-73.

BHABHA, Homi K. 1990. "The Third Space. Interview with Homi Bhabha." In Identity, Community, Culture, Difference, ed. Jonathan Rutherford, 207-21. London: Lawrence and Winhart.

1994. The Location of Culture. London/New York: Routledge.

CHAMBERS, Iain. 1996. "Signs of Silence, Lines of Listening." In The Post-Colonial Question. Common Skies, Divided Horizons, ed. Iain Chambers and Lidia Curti, 4762. London/New York: Routledge.

CLIFFORD, James. 1983. "On Ethnographic Authority." Representations 1, no. 2: 118-46.

DINGWANEY, Anuradha. 1995. Introduction: "Translating 'Third World' Cultures." In Between Languages and Cultures: Translation and Cross-Cultural Texts, ed. Anuradha Dingwaney and Carol Maier, 3-15. Pittsburgh/London: U of Pittsburgh P. 
ELIAS, Norbert. 1990. Über den Prozeß der Zivilisation. Soziogenetische und psychogenetische Untersuchungen. Band 1. Wandlungen des Verhaltens in den weltlichen Oberschichten des Abendlandes. Frankfurt am Main: Suhrkamp.

FANON, Frantz. 1968. The Wretched of the Earth. Trans. Constance Farrington. Harmondsworth: Penguin Books.

FOUCAULT, Michel. 1970. The Order of Things: An Archaeology of the Human Sciences. Trans. A.M. Sheridan. New York: Pantheon. Pantheon.

1972. The Archaeology of Knowledge. Trans. A.M. Sheridan-Smith. New York:

GEERTZ, Clifford. 1973. The Interpretation of Cultures. New York: Basic Books.

GEWECKE, Frauke. 1986. Wie die neue Welt in die alte kam. Stuttgart: Klett-Cotta.

GODARD, Barbara. 1990. "Theorizing Feminist Discourse/Translation." In Translation, History and Culture, ed. Susan Bassnett and André Lefevere, 87-96. London/New York: Pinter.

1993. "Intertextuality." In Encyclopedia of Contemporary Literary Theory: Approaches, Scholars, Terms, ed. Irena R. Makaryk, 568-72. Toronto: U of Toronto P.

1995. "Translating (as) Women. Review of Susanne de Lotbinière-Harwood: Re-Belle et Infidèle." Essays on Canadian Writing 55: 71-82.

HUNTINGTON, Samuel. 1996. The Clash of Civilizations. New York: Simon and Schuster.

KAHN, Joel S. 1995. Culture, Multiculture, Postculture. London: Sage Publications.

KRAMER, Fritz W. 1987. Der rote Fes. Über Besessenheit und Kunst in Afrika. Frankfurt am Main: Athenäum.

KREUTZER, Eberhard. 1995. "Theoretische Grundlagen postkolonialer Literaturkritik." In Literatur-wissenschaftliche Theorien, Modelle und Methoden. Eine Einfiihrung, ed. Ansgar Nünning, 199-213. Trier: Wissenschaftlicher Verlag.

LOTBINIÈRE-HARWOOD, Susanne de. 1991. Re-Belle et Infidèle. La traduction comme pratique de réécriture au féminin. The Body Bilingual. Translation as a Rewriting in the Feminine. Toronto/Montreal: Women's Press/Les éditions du remue-ménage.

MARCUS, George E., and Michael M.J. FISCHER. 1986. Anthropology as Cultural Critique. Chicago: $\mathrm{U}$ of Chicago $\mathrm{P}$.

MEAD, Margaret. 1974. Male and Female: A Study of the Sexes in a Changing World. Harmondsworth: Penguin Books.

MEHREZ, Samia. 1992. "Translation and the Postcolonial Experience: The Francophone North African Text." In Rethinking Translation: Discourse, Subjectivity, Ideology, ed. Lawrence Venuti, 120-38. London/New York: Routledge.

NIRANJANA, Tejaswini. 1992. Siting Translation: History, Post-Structuralism and the Colonial Context. Berkeley: $U$ of California P.

PORTER, Dennis. 1983. “Orientalism and Its Problems." In The Politics of Theory, ed. Francis Barker, Peter Hulme, Margaret Iversen and Diana Loxley, 171-93. Proceedings of the Essex conference on the Sociology of Literature, July 1982. Colchester: U of Essex. 
REIß, Katharina. 1993. "Frauengerechte Sprache?" In Die vergessenen Schwestern. Frauengerechte Sprache in der Bibelübersetzung, ed. Siegfried Meurer, 37-52. Stuttgart: Deutsche Bibelgesellschaft.

ROSALDO, Michelle Z. 1980. Knowledge and Passion: Ilongot Notions of Self and Social Life. Cambridge: Cambridge UP.

SAID, Edward. 1978. Orientalism: Western Representation of the Orient. London: Routledge and Kegan Paul.

1993. Culture and Imperialism. London: Chatto and Windus.

SIMON, Sherry. 1996. Gender in Translation: Cultural Identity and the Politics of Transmission. London/New York: Routledge. 77.

1997. "Translation, Postcolonialism and Cultural Studies." Meta 42, no. 2: 462-

TYLER, Stephen. 1986. "Post-Modern Ethnography: From Document of the Occult to Occult Document." Writing Culture: The Poetics and Politics of Ethnography, ed. James Clifford and George E. Marcus, 122-40. Berkeley: U of California P.

ULIN, Robert C. 1991. "Critical Anthropology Twenty Years Later: Modernism and Postmodernism in Anthropology." Critique of Anthropology 11, no. 1: 63-89.

WEIBEL, Peter. 1997. "Jenseits des weißen Würfels. Kunst zwischen Kolonialismus und Kosmopolitismus." In Inklusion: Exklusion. Versuch einerneuen Kartografie der Kunst im Zeitalter von Postkolonialismus und globaler Migration, ed. Peter Weibel, 8-36. Köln: Dumont.

WOLF, Michaela. 1996. "Reading 'Other' Cultures: The Dilemma of the Cultural Translator." In New Horizons, vol. 1, 282-88. Proceedings of the XIV World Congress of the Fédération Internationale des Traducteurs (FIT) (February 12-16, 1996). Ausit.

1997. "Translation as a Process of Power: Aspects of Cultural Anthropology in Translation." In Translation as Intercultural Communication, ed. Mary Snell-Hornby, Zuzana Jettmarová and Klaus Kaindl, 123-33. Selected papers from the EST Congress, Prague (1995). Amsterdam/Philadelphia: John Benjamins.

YOUNG, Robert. 1990. White Mythologies: Writing History and the West. London/New York: Routledge.

1995. Colonial Desire: Hybridity in Theory, Culture and Race. London/New York: Routledge. 
This page intentionally left blank 


\title{
Chapter 8
}

\section{TRANSLATIONS OF THEMSELVES: THE CONTOURS OF POSTCOLONIAL FICTION}

\author{
Maria Tymoczko \\ University of Massachusetts, Amherst (USA)
}

Although it is generally acknowledged that postcolonial literary works written in the colonizers' language are a form of intercultural transfer (see Pym 1992) involving the transposition of aspects of the indigenous language, cultural patterns, beliefs and literary traditions, some critics go a step further and claim that postcolonial fictions are translations. For example, in his introduction to Amos Tutuola's The Palm-Wine Drinkard, Michael Thelwell writes:

This novel is a cultural hybrid, the child of the clash of cultures... The stories in it are translations-more accurately, transliterations-of conventional folktales into the idiomatic "young English," as Dylan Thomas called it, of the Nigerian masses. It is clear from the reading, and even more so when one listens to the author telling a story, exactly how difficult the translation process really is. This is not simply "young English" but new English, an English whose vocabulary is bent and twisted into the service of a different language's nuances, syntax, and interior logic. The result is original and often startling. $(1984,188)$

In this paper, I will address certain fundamental aspects of language and text that make postcolonial literary works seem-like Tutuola's work to Thelwell--to be translations, even, paradoxically, translations of 
themselves (see Mehrez 1992, 129ff.; Kálmán 1986, case 5a). As "translations," postcolonial texts are communicative agents with powerful resonances, having the capacity to mediate between languages and cultures in radical and empowering ways. These capacities in turn reflect back on interlingual translation itself, illuminating aspects of its own revolutionary potential and its powers of cultural transformation.

Elsewhere I have addressed the intersection of postcolonial literature and translation theory (Tymoczko 1998), analyzing a wide variety of formal and functional commonalities between postcolonial works and translations, and suggesting that the relatively more established field of translation theory has a great deal of insight to contribute to postcolonial theory. ${ }^{1}$ Although the enterprise of writing postcolonial literature is different from the enterprise of translating - a translation is usually constrained by a preexisting fixed text, for example- - both involve similar representations and transpositions of language and culture, both types of writing show similar formal patterns. In straddling two cultures, postcolonial writers, like translators, mediate cultural difference by means of a common variety of techniques. On the textual level, for example, both postcolonial texts and translations often show deviations from the standard receiving language: perturbations in lexis (including imported lexical items, unusual collocations, non-standard frequency distributions, variant semantic fields and neologisms), unusual syntax and defamiliarized language, including unexpected metaphors and unusual turns of speech. Moreover, the unfamiliar cultural substrata in both types of writing give rise to a heavy information load, which both authors and translators relieve by inserting explanations or by supplying cultural information that would normally be presupposed or implicit in other literary works. Thus, postcolonial writing and translation are both more explicit than other types of literary writing (see Baker 1993). At the same time, the two types of texts can show radical selectivity of their source materials, a selectivity that generally has political or ideological motivation, as well as ideological consequences for the author/translator.

Rather than adumbrate commonalities that I have already discussed at length, in this paper I will look at another shared property of the two forms of writing - the ability to evoke two languages simultaneously. This will enable me to explore still other intersections of postcolonial writing and the practice of translation, as well as ensuing theoretical implications. Following Abdelkebir Khatibi, Samia Mehrez (1992) argues that bilingual postcolonial writing is a form of "radical bilingualism" and that postcolonial works often only reveal their full meanings when translated into the other language(s) of their cultural context. I will extend Mehrez's arguments and explore various mechanisms of radical bilingualism. Texts that evoke two languages simultaneously achieve linguistic multivalence and polysemous 
communication, typically while maintaining a monolingual surface. This polyphonous potential, which gives both translations and postcolonial texts much of their evocative appeal and their subversive power, often turns on specific vehicles of polyvalent writing, in particular lexical items that I will call conventional translation equivalents (CTEs). CTEs are used by postcolonial authors to mediate not only culture but language, as they grapple with linguistic interface and intercede between languages, as do translators also. CTEs provide a most productive means for writers to write in the multiple languages of their home-culture simultaneously.

\section{The Double Language of James Joyce}

James Joyce, Ireland's greatest fiction writer, provides very pertinent examples of this phenomenon. Joyce's texts have been canonized in-positioned, in fact, at the centre of - modern literature in English. But they also serve, paradoxically, as epitomes of the questions at issue here, including the radical potential of bilingual writing and CTEs in the hands of a postcolonial writer. Only relatively recently have Joyce critics turned to postcolonial theory, recognizing Joyce as a postcolonial writer, despite the fact that Ireland was England's first and longest-held colony, and despite the fact that Joyce explicitly identified himself with Irish culture, even in some ways acknowledging himself an Irish nationalist (see Joyce 1966, 2:187). Recognition of this aspect of Joyce's writing was in part dependent on the development of a suitable theoretical discourse that could provide a framework for his position as writer, but the delay is also due to Joyce's shaping of his own image. Perhaps to secure the patronage of international modernists, or to avoid being labelled as provincial, or to enhance his own inventive powers, Joyce obscured the Irishness of his literary works (see Tymoczko 1994, ch. 9). The analysis of Joyce as a postcolonial writer is typically conducted in terms of Joyce's attitudes regarding politics, economics and ideology, rather than in terms of language and cultural hybridity, even though Joyce was primarily a literary man whose Irish allegiances are visible as much in his language and literary forms as in politics or ideology (see Tymoczko 1994). ${ }^{2}$ All of Joyce's major works, except for Finnegans Wake, were written while Ireland was struggling under the political and cultural domination of England, and they reflect this struggle. Indeed, Ulysses appeared in February 1922, almost simultaneously with the emergence of the newly independent Irish state. Ireland's struggle for independence is reflected not merely in the content of Joyce's works but also in their formal properties: writing for both Irish and international audiences, Joyce pioneered various literary and linguistic techniques that foreshadow later postcolonial strategies. 
Joyce's localism (see Tymoczko 1994, 153ff., 260ff.) and his interest in things Irish resulted in a multifaceted inscription of Irish and Irish ways of speaking English in his texts. Most pervasive are the rather direct uses of Irish: transposition of Irish phonology, inclusion of English words that are in fact borrowings from Irish into English, semantic fields that are skewed compared to those of standard English, Irish idiom and syntax typical of the English dialects spoken in Ireland and other Hiberno-English markers that can be traced back to Modern Irish Gaelic. These features of Joyce's language have been well canvassed (see Wall 1986). They are verbal means exploited by any great realist attuned to language and are standard features of postcolonial writing, as well as of other realistic works whose subject involves the use of dialect or specialized registers. Here I will focus on the more occasional, but also more symbolic, uses of Irish in Joyce's texts that emerge at points in his writing where an Irish-language subtext is activated to create significant nodes of meaning simultaneously in Ireland's two languages.

In some instances, linguistic polyvalence is achieved through the use of words borrowed or imported directly (though at times, covertly) from the other language or languages of the plural tradition of the postcolonial writer. In Dubliners, the words that Joyce imports from Irish are, surprisingly, proper names. These names are significant because in Irish, unlike English, names have semantic meanings. However, the semantic meanings of the Irish names in Dubliners are not accessible to the monolingual English-speaking reader, because their spelling is Anglicized, and the English-language reader presumes that proper names are semantically opaque (see Tymoczko 1999). Thus, the well-known English-language theme of "paralysis" in Dubliners (259ff., $316 \mathrm{ff}$.) is doubled by a number of proper names with meanings relating to darkness, gloom and death, as well as to mythological figures associated with death (see Nilsen 1986). For instance, the name Browne (cf. Ir. donn, "brown" and Donn, the name of the Irish god of the dead), as well as the names Dunn, Dunne, Downe, Donnelly, Doyle, Duffy, Duggan and D'Arcy are all derived from Irish roots meaning "brown," "dark" or "black." In fact, the most important name of this series, whose meaning is known to all readers of Joyce, is that of Dublin itself; in Irish, Dublinn means "the black pool." Nilsen concludes that "Joyce... was fully aware of the meanings of surnames and place-names that he used, and he chose them to strengthen this theme that the Dubliners of his day were wallowing about in a black pool from which they could not escape" (33). ${ }^{3}$ This thread of reference to Irish words associated with death and darkness in Dubliners functions as the earliest example of a Joycean dissociated metaphor (see O'Connor 1956) that depends on knowledge of the native language of Ireland, the language undermined and suppressed by English colonialism. 
By choosing proper names whose thematic significance derives from their semantic meanings in Irish, and is only perceptible in an Irish context, Joyce allies himself with his country's precolonial culture and speaks to the Irish side of his multilingual culture. When perceived in an Irish historical and linguistic light (i.e., when translated into Irish or analyzed etymologically), these names function as an Irish-language thematic counterpart to the English-language thematics of the stories in Dubliners. I am speaking of English-language and Irish-language themes and thematics because, if the course of linguistics and semiotics from Peirce and Saussure, Sapir and Whorf onward is taken seriously by literary critics, then it must be recognized that literary meaning, like meaning in general, is language specific. One advantage of multilinguistic literary writing is the possibility of evoking multiple layers of thematic meaning simultaneously by invoking meanings in more than one language simultaneously. Thus, writers who use this technique - notably postcolonial writers - have a tremendous literary advantage over their monolingual peers. By incorporating Irish words and names with semantic meanings in Irish (meanings inaccessible to most monolingual English or international readers) into his English-language text, Joyce constructs a double language in Dubliners, a language that accesses both Irish and English meanings simultaneously.

It is perhaps not surprising that to construct the Irish thematic thread in Dubliners, Joyce relied on names to carry the Irish meanings. Aside from his particular interest in and fondness for onomastics (see Tymoczko 1994, 159-66, 280-81), by basing his form of double writing on proper names, Joyce used words which in Irish culture have the least ambiguous and least disputable fields of reference in Irish Gaelic itself. That is, he chose those words that in a seemingly English text would unequivocally signal their Irish origins and their Irishness and, hence, their specifically Irish meanings to readers who knew Irish. At the same time, Joyce's Irish meanings were hidden from monolingual English readers, available only to those in his culture who were initiates, so to speak, like the members of the Gaelic League who knew the Irish language of the colonized population, in however rudimentary a fashion. It is worth noting that although Joyce was critical of various facets of Irish cultural nationalism, and although he opposed the elimination of English as the primary language of Ireland, he did participate in the Irish-language movement for a time, studying Irish for a year or two before leaving Ireland at the age of twenty-two. Joyce came to Irish "late," learning it not as a second language, but at best as a fifth or sixth language, after Latin, French, Italian and, perhaps, German and Dano-Norwegian. Moreover, never having lived in an Irish-speaking milieu, Joyce never had the chance to become fluent in Modern Irish, as he did with Italian, French and German. There is evidence, nonetheless, that he continued to be interested in the Irish language after he left Ireland, suggesting that his mastery 
of Irish increased throughout his lifetime, playing an ever-greater role in his literary works. Though Joyce's mastery of Irish was rather rudimentary, it was nonetheless more extensive than that of many, even most, Gaelic League members, in part due to his facility at language learning (see Tymoczko 1994, 278ff. and sources cited).

\section{The Language of the Other and Conventional Translation Equivalents}

Mehrez locates similar textual phenomena in twentieth-century North African postcolonial Francophone literary works. She gives examples from the works of Assia Djebar and Tahar Ben Jelloun which clearly allude to passages of the Koran when translated into Arabic, but these references remain opaque in the French-language texts. Mehrez concludes that "the language of the Other comes to encode messages which are not readily decoded by the monolingual reader whose referential world continues to exclude, ignore, and deny the existence of other referential worlds that are crucial to a more 'global' rather than 'colonialist,' 'imperialist' reading of the text" (1992, 122). Mehrez argues that the reading experience of such a text "can be no other but a perpetual translation" (122; see also 135) and, furthermore, such postcolonial works often expose their full meaning only when translated into the other language(s) of the author's plural tradition. ${ }^{4}$ My earlier work on the formal similarities between postcolonial writing and translation suggests that for reasons as diverse as particularities of semantic fields, allusions, intertextuality and the semiotics of traditional metaphors, the meaning of a literary passage often needs to be considered in light of all the languages of a postcolonial author's culture. Double levels of language are at times also implicit in translation, as in the case of transposed source-language names, which, like Joyce's Irish names in Dubliners, can carry veiled, if not semantic or at the very least semiotic, meanings.

The incorporation of both Irish and English elements simultaneously in his texts is a pervasive, though submerged, feature of Joyce's writing, made all the more startling when one considers that Joyce's radical bilingualism has remained essentially unrecognized despite the intense critical scrutiny associated with the canonization of his work. That this important feature of Joyce's writing should have gone so long unnoticed suggests, by extension, that it may be an as yet unrecognized commonality of much, if not all, postcolonial writing. Aside from covert intertextual allusions and covert importations of source-language words (as with transposed proper names), writing in two languages simultaneously is often achieved at the lexical level by means of conventional translation equivalents (CTEs), which can be defined as "words that have been established as counterparts be- 
tween any two given languages as a result of cultural interface and common usage over a long period of time." 5 The use of CTEs is, as I have already mentioned, one of the most powerful techniques employed by Joyce and other postcolonial writers. It makes their works read like translations, and that in turn makes reading their narratives, in Mehrez's words, "none other than a perpetual translation."

CTEs are familiar means in ordinary translation practice. They include automatized standard transpositions such as the translation of greetings: "hello" and not "good day" for "bonjour" (French), "pronto" (Italian) for "hello" when answering a telephone and so forth. These types of CTEs are drilled into beginning language students as part of the functional language they must master to operate in an acceptable sociolinguistic manner in a second language and culture. CTEs are also important in technical translation, and indeed mastering them is a large part of technical-translation training, for CTEs in a specialized field are usually seen as alternate signifiers for a single referential entity, such as a scientific concept, a technological apparatus, an industrial application, a legal principle or a medical condition, any of which may exist in a cultural context that crosses linguistic boundaries. CTEs usually operate in a transitive manner; that is, they serve as equivalents irrespective of the language serving as source or target language.

Normally in a bilingual or multilingual culture, as are most postcolonial cultures, there are series of equivalents, or pairings, that link or mediate common cultural concepts across existing linguistic boundaries. Between English and Irish, for example, there is "fairy mound" for síd, "hostel" for bruiden, "hag" for caillech, "satire" for áer, "taboo" for geis. In postcolonial contexts, such pairings more resemble the automatized equivalents instilled in beginning language students, than the pairings technical translators are required to master. This is because the English words above do not really mean the same thing as their Irish equivalents, nor do they have the same referents. Indeed, the English words have English meanings and English associations quite different from those of the Irish members of the pairs. ${ }^{6}$ The semiotics and semantic fields of any such pair of verbal counterparts which are conventionally treated as "equivalent" for the purpose of translation or communication in a multilinguistic culture are often -indeed usually - radically different.

In the case of the words before us, the Irish sid etymologically means "peace," and refers to the Irish otherworld, originally located in an alternate space-time continuum, and entered through a variety of portals, including the old neolithic burial mounds of Ireland. A bruiden is an otherworldly feasting hall, almost invariably, in the literature, a site of fights, deceptions 
and other difficulties. "Satire" is the universal translation of aer, but the meaning of the Irish word is much closer to the concept of magic, than to the concept of literary mockery associated with the English word, a meaning deriving from Classical traditions. Moreover, etymologically, the Irish word means "cutting, incising," since áer was thought to have the ability to inflict physical debility or even death on its object (see Robinson 1912). Similarly, a geis, unlike a "taboo," can be a positive injunction as well as a prohibition; and caillech does not carry the same meanings as "hag," for it is the normal Irish word for "nun" as well. These differences notwithstanding, for a reader who knows Irish and who is also familiar with the conventional English equivalents of certain Irish words, the presence of any of these English words in a text translated from Irish will indicate the existence of the corresponding Irish word in the source text. Thus, to a bilingual reader familiar with both languages and cultures, the English part of such a pair will trigger a dual semiosis, semiosis associated with the ordinary sense of the English word, accompanied or modified by semiosis associated with the Irish word, and including, for example, awareness of the variant semantic fields of both words of the pair. For monolingual/monocultural readers, by contrast, the text will have a seemingly transparent monolingual surface.

Another example from Joyce will show how such CTEs function in postcolonial literary works. At the end of "The Dead," Gabriel comes to the realization that "the time had come for him to set out on his journey westward" (Dubliners, 223). The "journey westward" has been interpreted in various ways: literally, as a journey west toward the Irish-speaking part of Ireland, where Irish customs and literature still survive; and symbolically, as, among others, a journey toward the setting sun and, hence, toward death. The latter reading is particularly suggestive inasmuch as in Irish mythology, the west is associated with the otherworld and specifically otherworldly islands, including the land of the dead, abode of Donn, the god of the dead. Therefore, the ending of "The Dead" is open and multivalent, not admitting of a single interpretation. But we might nonetheless ask why Joyce uses the term "westward" instead of "west." One of the valences of the text hinges on the meaning of the Irish word for "westward," and Joyce signals this word, siar, by using in his text "westward," instead of the more natural locution "west," as in "go West, young man" (see Ulysses, 17.4).7

Irish directional words have some notable particularities compared to their English counterparts, not the least of which being that Irish directional words are predicated upon the body's facing east, toward the rising sun. Thus, the word for east in Irish literally means "in front of," south and north mean "on the right" and "on the left," respectively, and west means literally "behind." Position, as well as motion to or from any direction, involves a fusion of the directional word with an amalgamated preposition or 
particle: Irish uses "to the west" or "westward" rather the simple directional word or preposition itself (i.e., west or behind). So the Irish word siar, which one would use to indicate a journey to the west, does actually mean "westward," and the English word westward serves as a CTE for the Irish term. In choosing the term westward, Joyce seems to be simultaneously signalling the Irish term siar as well as English meanings relevant to the text. ${ }^{8}$ What is the advantage of implicitly signalling or activating the Irish word siar at the end of "The Dead"? Because of the physical orientation presupposed in Irish directional words, siar means not only "westward," but also "behind," "backward" or, by extension, "toward the past," that is, backward in a temporal, rather than a spatial sense. Therefore, when "The Dead" is read with an awareness of Irish Gaelic meanings, Gabriel's decision to go westward can be read as his resolution to undertake a spiritual journey back to his personal past, and to his Irish linguistic and cultural heritage, as well as a spatial journey to the western, Irish-speaking part of Ireland, the Gaeltacht (see Owens 1992). ${ }^{9}$ The extended temporal meaning of the Irish word for westward would be understood by anyone familiar with the meanings of Irish directional words. By the time Dubliners was completed, Joyce himself, like Gabriel, had already undertaken an artistic journey "backward" to the Irish language and his Irish cultural heritage, as indicated by the chain of Irish words-cum-names encoded in Dubliners. ${ }^{10}$ The double sign on which "The Dead" ends serves to establish an Irish-language subtext at the end of Dubliners that casts a shadow backward over the entire collection, begging a rereading of the initial interpretation and qualifying the meaning of all that has gone before. ${ }^{11}$ The duality of this sign is unreadable by readers and critics who have no knowledge of Irish - and has indeed remained unrecognized in the criticism to date, partly because few Joyce scholars know Irish.

\section{Double Writing}

The ending of "The Dead" shows that Joyce, as a writer from a dual tradition, positions himself between the two strands of his linguistic and literary tradition. Often the lexicon of his works carries meanings in both of his country's languages, simultaneously. His texts involve a form of double writing related to Ireland's history of colonization by the English, and its national culture. The texts are thus hybridized, dependent upon both languages of the author's culture and carrying a double referential load that communicates differentially to its readers, depending on their ability to decipher the veiled linguistic code, and their familiarity with the indigenous culture underlying the postcolonial text. For a colonized people subjected to oppression, such covert communication is a powerful means of subversion and emancipation. This example from Joyce, as well as examples from 
the Francophone texts analyzed by Mehrez (1992), indicates why it is usually necessary to consider all the languages of the given author's culture when reading a postcolonial literary text. In the case of Joyce, both the proper names in Dubliners and the word "westward" in "The Dead" take on their full meaning when translated into Irish; only if "westward" were translated into Irish as siar, then back-translated into English with a paraphrase of the Irish semantic field, thus transposing the spatio-temporal quality of the Irish word, could a monolingual colonialist English reader understand the full implication of Joyce's thought at the end of Dubliners. Rather than merely being peppered with a few overt borrowings from Irish as signs of cultural otherness, Joyce's texts are pregnant with CTEs that carry a double cultural load and that actively construct the complex double meanings of his texts. ${ }^{12}$

In ways such as these, CTEs are primary vehicles for inserting meanings from a colonized people's native language into a text written in the colonizers' language. The same technique is encountered in translations: the use of CTEs in the target-language (TL) text gives the illusion of surface transparency, because the CTEs are actual words in the TL, but at the same time, they import or transfer the source-language (SL) meanings associated with the SL words. This technique resembles what John Catford (1965, ch. 6) calls "transference," rather than translation, and partly explains Mehrez's contention that certain bilingual texts achieve a "migration from one system of signs to the other, ... one symbolic world to another" (1992, 134). The presence of words established or even reserved as CTEs between two languages underlies the sense that postcolonial texts are translations of themselves or translations of texts never written in the other (usually native) language of a culture. Indeed, the presence of CTEs in a literary work suggests the existence of a pre-text in another language. Because of the long co-existence of English and Irish speakers in Ireland, and because of the long history of translation between the two languages, there was a large and well-established repertory of word pairs, viewed as "equivalents," available to Joyce for the purpose of double writing. They enabled him to write into his international, modernist English texts a covert network of references to Irish literature and culture. Readings of Joyce's texts that flag such CTEs will open promising new avenues of inquiry into Joyce's politics and poetics, just as they might in the case of more recent postcolonial writers as well. This is, implicitly at least, the approach adopted by both Anthony Roche (1987-1988) and Cóilín Owens (1992), who used keywords to identify and analyze certain Irish themes in A Portrait of the Artist as a Young Man. I have found this approach useful in my own work on Ulysses as well.

As in the case of other postcolonial writers, recognition of Joyce's double language obviously depends upon familiarity with both languages 
of his dual tradition. A precondition of recognizing Joyce's CTEs is, moreover, knowledge of the translation tradition between the two languages. For an initiated reader, a bilingual or bicultural reader, one half of a conventional equivalence pair used by a postcolonial writer will implicitly call forth the other half, so that the meaning of the text optimally includes both terms and both languages. For the bilingual and bicultural Joyce reader who knows both Irish and English, and both fields of reference behind a multilingual node, the entire range of meanings in both languages will be triggered simultaneously, and each set of meanings will be dependent upon the other. For such a reader, reading a postcolonial text is like having a conversation with another bilingual person: typically the two speakers do not speak solely in one or the other language ( $\mathrm{L} 1$ or $\mathrm{L} 2$ ), but rather communicate in a language ( $\mathrm{Lx})$ that draws on the resources of both languages, and that effectively mixes the two languages. ${ }^{13}$

Such a text is literally hybridized because it is written in the mixed language ( $\mathrm{Lx}$ ) of the bilingual/bicultural writer. The power of hybridization inheres in these texts, but hybridity, as Homi Bhabha, the cultural critic who initiated this discourse, cautions, "is not a third term that resolves the tension between two cultures" $(1985,156)$. Instead, as in the examples from Joyce discussed above, it creates "a crisis for any concept of authority based on a system of recognition," allowing "other "denied' knowledges [to] enter upon the dominant discourse and estrange the basis of its authority-its rules of recognition" (156). The challenge to hegemony by hybridity ${ }^{14}$ lies behind Mehrez's argument that bilingual postcolonial writing can contest "all forms of domination, and all kinds of exclusion" $(1992,123)$. Extending Abdelkebir Khatibi's concept of "radical bilingualism," Mehrez considers bilingual writing as a form of linguistic appropriation that makes the colonizers' language "“foreign' to its own monolingual native speaker" (130); the subaltern subtext dominates the colonizers' language and surface text. In such a text "native speakers ... lose their way in their own language," for the text contains a range of referents which the monolingual person cannot translate (124ff.). Mehrez analyzes this strategy as one which defies "imperialist monolingualism which continues to believe that it can read the world through its own dominant language" (137). Such texts are, therefore, examples of "resistant texts," as defined by Sommer (1992); they circumscribe the privileged position and competence of the monocultural hegemonic reader.

\section{Joyce and the Postcolonial Hybrid}

In most cases, the postcolonial writer whose texts incorporate radical bilingualism has the precolonial language as his/her mother tongue, and comes 
second to the colonizers' language. As such, the bilingual or double writing strategy grows out of a lived experience of bilingualism and biculturalism. What is extraordinary and eloquent in the case of Joyce is that he came to Irish so late and mastered it so incompletely, yet his texts-from Dubliners to Finnegans Wake-exhibit an ever-growing commitment to Irish. Joyce's commitment to Irish in his literary works must therefore be understood as fundamentally political: the use of Irish in his texts is an ideological choice attendant upon the representation of Irish life from the perspective of the colonized, rather than a natural linguistic reflex of his own liminal ways of thinking and speaking since birth. In this regard, Joyce is quite different from postcolonial writers whose entire experience of language is double, predicated upon linguistic multiplicity, in speaking and in writing, throughout their lives. Unlike Ngũgĩ wa Thiong'o or the Francophone writers Mehrez discusses, Joyce was not fully bilingual in his country's two languages; he made a deliberate choice to write Irish into his work. It is all the more significant, then, that at critical points in his work Joyce constructs an alternate code, and reclaims a linguistic heritage that was, in a sense, lost both to himself and to his country. Joyce stands as a reminder that such bilingual writing - whatever the status of the writer's linguistic competence-is fundamentally an ideological strategy and not merely a matter of linguistic expedience. Joyce emerges as a pioneer of this effective writerly technique so often exploited by postcolonial writers.

Increasingly, translation is seen not as a locus of equivalence, but as a locus of "difference," a perspective represented, for example, by Jacques Derrida in "Des tours de Babel." 15 For this reason, I have called word pairs such as those discussed above conventional translation equivalents (CTEs). In investigations of such conventional pairs, it is essential to recognize the differences implicit in the conventional translations of such words, and to look at the differences of meaning across the boundaries of these conventional equivalences. Indeed, it is the simultaneous evocation of words with different semantic fields and different semiotic significance, rather than identity of reference and meaning, that leads to the effects discussed here. The Irish meanings evoked by Joyce's choice of words, for example, are not simple restatements of the English: they complement and extend the English meanings and thematics and they construct an alternate frame of reference. In fact, Joyce depends on this locus of difference to achieve his complex contrapuntal significance. An understanding of translation as a site of difference leads us to appreciate how multilingual writing in a postcolonial text is a means of achieving dense and layered meanings, how it can convey multiple messages in coded and covert language aimed at specific audiences, and how it can mobilize the precolonial language to escape the hegemonic traps implicit in the language of the colonizing power-a language that may limit the terms of debate and set a boundary on confronta- 
tion. All these strengths emerge when a postcolonial work appears to be a translation of itself.

In this paper, I have primarily stressed the applicability of translation theory to the understanding and analysis of postcolonial literature. But, I will conclude with the inverse: the value of postcolonial theory for understanding the phenomena of translation, as well as for analyzing specific translations. Increasingly sensitized to the impact of ideology on the production and reception of literature, scholars of postcolonial literature offer essential insights by defining the importance of covert communication and masking in situations of cultural oppression, and by exploring the mechanisms of multivalent language and polysemous communication, as well as their subversive power. Similarly, the impact of a double consciousness on bilingual or bicultural populations, and the strategies of cultural recuperation and resistance of groups in linguistic and cultural transition, are also becoming increasingly clear in postcolonial theory, as are the power implications of the norms of discourse and the canons of knowledge embedded in both colonialist and resistant texts (see Bhabha 1985; Sommer 1992). Postcolonial theorists, such as Bhabha, have explored the phenomenon of hybridity in detail. Since polyphony, polyvalence and dialogism in postcolonial texts have affinities in translation, postcolonial theory has some invaluable insights to offer Translation Studies. ${ }^{16}$

Translations and postcolonial literary works are distinct, and I take the view that it is finally a metaphorical assertion to suggest that a postcolonial work is a translation, even a translation of itself. But, translation and postcolonial writing share commonalities, both formal and functional ones. ${ }^{17}$ By focussing on the specific workings of devices such as covert bilingualism (implicit in names, for example) and the use of CTEs, translation theorists will acquire a more adequate understanding of the similarities of postcolonial writing and translation, and the mechanisms through which they achieve their related effects. In the process, how to apply to descriptive studies of translation and to translation theory the dynamic concepts developed within postcolonial theory, including the concepts of resistance, double consciousness, cultural recuperation, masking and hybridity, will become more apparent, as will how to better see the revolutionary potential of translation-its transformative power-in mediating between cultures.

\section{Notes}

1. My arguments presuppose that the postcolonial texts under discussion emerge from a cultural milieu that uses at least two languages or two significantly different varieties of one language. 
2. For other studies of Joyce as a postcolonial writer, see Cheng (1995); Deane (1985); Duffy (1994); Eagleton, Jameson and Said (1990); Kiberd (1995); Lloyd (1993); and Nolan (1995).

3. Nilsen indicates that Joyce would have learned etymologies such as the ones he encoded in the names in Dubliners from the Gaelic League Irish classes he attended, as well as from the works of P.W. Joyce. See also Tymoczko (1994), 159ff., 291.

4. Simon (1994) also discusses the power of plurilingual texts. She argues that they are deliberate challenges to literary conventions, as well as national and cultural boundaries, possessing a dialogic force.

5. I am calling such pairings "conventional translation equivalents" precisely to flag the asymmetries between an utterance and its translation. The problem of equivalence in translation has been widely discussed in translation theory. See, among others, Catford (1965), chs. 3-6; Nida (1964), chs. 3-9; Bassnett (1991), ch. 1; Even-Zohar (1990), 75; Snell-Hornby (1988), 13-22.

6. See discussions in Catford (1965), chs. 3-6; Nida (1964), chs. 3-9; Bassnett (1991), ch. 1. The concept of equivalence is also discussed in Bassnett (1991), 23ff.; EvenZohar (1990), 75; Holmes (1994), 53ff.; Lefevere (1992), ch. 1; Snell-Homby (1988), 13-22; and Van den Broeck (1978), as well as in references cited in these sources. See also Bolinger (1977).

7. Note also that in Irish dialects of English the idiom "to go west" means in certain contexts "to die" (see O'Casey [1956], 281).

8. Joyce's knowledge of the Irish word siar is established by his use of the word in Finnegans Wake (see O Hehir [1967], 86.15, 89.28, 582.25, 600.08).

9. Joyce also suggests that Irish is Gabriel's unconscious language, undermining Gabriel's denial of the language (see Dubliners, 189).

10. Joyce also visited western Ireland in 1909 , shortly after finishing "The Dead." See Ellmann (1982), 276ff., for an account of the trip.

11. Note that "The Dead" was later added to the original manuscript sent to the publisher, Grant Richards. The story signals a shift in Joyce's view of Dublin and Ireland, and acts as a countersign to the other stories in Dubliners (see Ellmann [1982], 230ff., 245ff.).

12. O Hehir's (1967) book-length lexicon of Irish words in Joyce's Finnegans Wake gives an indication of the pervasive presence of Irish in that work, even though the covert presence of Irish signalled by CTEs is seldom noted in his study.

13. Oksaar (1978) discusses such communication between bilinguals, labelling the operation that draws on the resources of both languages simultaneously as "rational" strategies of communication. Thus, it would seem to be an optimal mode for a postcolonial writer to adopt.

14. See Bhabha (1985) for a fuller discussion of the radical challenge of the hybrid to hegemonic structures.

15. "Difference" in translation, as well as strategies for highlighting difference, is also discussed in Graham (1985); Venuti (1992; 1995); Gentzler (1993), ch. 6; Bassnett (1993), ch. 7. 
16. These notions are not unrelated to Benjamin's (1969) points about translation. See also Niranjana (1992) and Robinson (1997).

17. Perhaps it is the similar functional orientation of the two types of texts that, under certain circumstances, most inclines critics to join them together into one ad hoc category. This is a topic that needs further exploration. See Lakoff (1987), 45, on categories determined by goals.

\section{Works Cited}

BAKER, Mona. 1993. "Corpus Linguistics and Translation Studies: Implications and Applications." In Text and Technology: In Honour of John Sinclair, ed. Mona Baker, Gill Francis and Elena Tognini-Bonelli, 233-50. Amsterdam: John Benjamins.

BASSNETT, Susan. 1991. Translation Studies. Rev. ed. London/New York: Routledge. 1993. Comparative Literature: A Critical Introduction. Oxford: Blackwell.

BENJAMIN, Walter. 1969. "The Task of the Translator." In Illuminations, trans. Harry Zohn, 69-82. New York: Schocken.

BHABHA, Homi K. 1985. "Signs Taken for Wonders: Questions of Ambivalence and Authority Under a Tree Outside Delhi, May 1817." Critical Inquiry 12: 144-65.

BOLINGER, Dwight. 1977. Meaning and Form. London: Longman.

CATFORD, J.C. 1965. A Linguistic Theory of Translation: An Essay in Applied Linguistics. London: Oxford UP.

CHENG, Vincent J. 1995. Joyce, Race, and Empire. Cambridge: Cambridge UP.

DEANE, Seamus. 1985. Celtic Revivals: Essays in Modern Irish Literature, 1880-1980. London: Faber.

DUFFY, Enda. 1994. The Subaltern "Ulysses." Minneapolis: U of Minnesota P.

DERRIDA, Jacques. 1985. "Des Tours de Babel." In Difference in Translation, ed. and trans. Joseph. F. Graham, 165-248. Ithaca: Cornell UP.

EAGLETON, Terry, Fredric JAMESON and Edward W. SAID. 1990. Nationalism, Colonialism, and Literature. Minneapolis: $U$ of Minnesota $P$.

ELLMANN, Richard. 1982. James Joyce. 2nd ed. New York: Oxford UP.

EVEN-ZOHAR, Itamar. 1990. "Polysystem Studies." Poetics Today 11, no. 1. Special Issue.

GENTZLER, Edwin. 1993. Contemporary Translation Theories. London/New York: Routledge.

GRAHAM, Joseph F., ed. 1985. Difference in Translation. Ithaca: Cornell UP.

HOLMES, James S. 1994. Translated! Papers on Literary Translation and Translation Studies. 2nd ed. Amsterdam: Rodopi. 
JOYCE, James. 1966. Letters of James Joyce. 1957. Vol. 1, ed. Stuart Gilbert, reissued with corrections. Vols. 2 and 3, ed. Richard Ellmann. New York: Viking.

1969. Dubliners: Text, Criticism, and Notes. Ed. Robert Scholes and A. Walton Litz. New York: Viking.

1986. Ulysses: The Corrected Text. Ed. Hans Walter Gabler et al. New York: Random House.

KÁLMÁN, G.C. 1986. "Some Borderline Cases of Translation." New Comparison 1: 117-22.

KIBERD, Declan. 1995. Inventing Ireland. Cambridge, Mass.: Harvard UP.

LAKOFF, George. 1987. Women, Fire, and Dangerous Things: What Categories Reveal About the Mind. Chicago: $\mathrm{U}$ of Chicago $\mathrm{P}$.

LEFEVERE, André. 1992. Translating Literature: Practice and Theory in a Comparative Literature Context. New York: Modern Language Association.

LLOYD, David. 1993. Anomalous States: Irish Writing and the Post-Colonial Moment. Durham: Duke UP.

MEHREZ, Samia. 1992. "Translation and the Postcolonial Experience: The Francophone North African Text." In Rethinking Translation: Discourse, Subjectivity, Ideology, ed. Lawrence Venuti, 120-38. London/New York: Routledge.

NIDA, Eugene A. 1964. Toward a Science of Translating: With Special Reference to Principles and Procedures Involved in Bible Translating. Leiden: E.J. Brill.

NILSEN, Kenneth. 1986. "Down Among the Dead: Elements of Irish Language and Mythology in James Joyce's Dubliners." Canadian Journal of Irish Studies 12: 23-34.

NIRANJANA, Tejaswini. 1992. Siting Translation: History, Post-Structuralism and the Colonial Context. Berkeley: U of California $\mathrm{P}$.

NOLAN, Emer. 1995. James Joyce and Nationalism. London/New York: Routledge.

O'CASEY, Sean. 1956. The Green Crow. New York: George Braziller.

O'CONNOR, Frank. 1956. "Joyce and Dissociated Metaphor." In The Mirror in the Roadway: A Study of the Modern Novel, 295-312. New York: Knopf.

O HEHIR, Brendan. 1967. A Gaelic Lexicon for "Finnegans Wake" and Glossary for Joyce's Other Works. Berkeley/Los Angeles: U of California P.

OKSAAR, Els. 1978. "Interference, Bilingualism and Interactional Competence." In Theory and Practice of Translation, ed. Lillebill Grauhs, Gustav Korlén and Bertil Malmberg, 295-305. Bern: Peter Lang.

OWENS, Cóilín. 1992. “The Mystique of the West in Joyce's 'The Dead." Irish University Review 22: 80-91.

PYM, Anthony. 1992. Translation and Text Transfer: An Essay on the Principles of Intercultural Communication. Frankfurt: Peter Lang.

ROBINSON, Douglas. 1997. Translation and Empire: Postcolonial Theories Explained. Manchester: St. Jerome Publishing. 
ROBINSON, Fred Norris. 1912. "Satirists and Enchanters in Early Irish Literature." In Studies in the History of Religions Presented to Crawford Howell, ed. David Gordon Lyon and George Foot Moore, 95-130. New York: Macmillan.

ROCHE, Anthony. 1987-1988. "“The Strange Light of Some New World': Stephen's Vision in A Portrait." James Joyce Quarterly 25: 323-32.

SIMON, Sherry. 1994. Le trafic des langues: Traduction et culture dans la littérature québécoise. Montreal: Boréal.

SOMMER, Doris. 1992. "Resistant Texts and Incompetent Readers." Latin American Literary Review 20, no. 40: 104-8.

SNELL-HORNBY, Mary. 1988. Translation Studies: An Integrated Approach. Amsterdam: John Benjamins.

THELWELL, Michael. 1984. Introduction. The Palm-Wine Drinkard and My Life in the Bush of Ghosts, by Amos Tutuola, 177-90. 1994. New York: Grove P.

TYMOCZKO, Maria. 1994. The Irish “Ulysses." Berkeley/Los Angeles: U of California P. 1998. "Postcolonial Writing and Literary Translation." In Post-Colonial Translation: Theory and Practice, ed. Susan Bassnett and Harish Trivedi. London/New York: Routledge.

1999. Translation in a Postcolonial Context: Early Irish Literature in English Translation. Manchester: St. Jerome Publishing.

VAN DEN BROECK, Raymond. 1978. "The Concept of Equivalence in Translation Theory: Some Critical Reflections." In Literature and Translation: New Perspectives on Translation Studies, ed. James S. Holmes, José Lambert and Raymond Van den Broeck, 4958. Louvain: Acco.

VENUTI, Lawrence, ed. 1992. Rethinking Translation: Discourse, Subjectivity, Ideology. London/New York: Routledge.

1995. The Translator's Invisibility: A History of Translation. London/New York: Routledge.

WALL, Richard. 1986. An Anglo-Irish Dialect Glossary for Joyce's Works. Gerrards Cross: Colin Smythe. 
This page intentionally left blank 


\section{II}

\section{SCENES OF NEGOTIATION}


This page intentionally left blank 
Chapter 9

\title{
A GESTURE TO INDICATE A PRESENCE: TRANSLATION, DIALECT AND FIELD DAY THEATRE COMPANY'S QUEST FOR AN IRISH IDENTITY
}

\author{
Maria-Elena Doyle \\ West Georgia State University (USA)
}

Lt. George Yolland in Brian Friel's play Translations finds himself in something of a romantic quandary: he is enamoured of Maire, a Gaelic-speaking peasant girl, but he finds himself unable to express his affection, as he speaks only English. For the first half of the play, the would-be lovers expend a great deal of effort in failed communications - they try gesturing at each other, speaking their own languages loudly and slowly, employing an unwilling translator, and Maire even attempts to use Latin as a possible neutral medium. But it is not until George hits upon the idea of reciting the only Gaelic he knows, the place names he has been learning during his stay in Baile Beag, Maire's village, that he finally meets with success. As Maire turns to him and answers each hill with another hill and each fort with another fort, the lovers slowly move toward each other across the stage, using the local scenery in a kind of call and response. Of course translating the words themselves gets an audience nowhere, for it is not in what the names themselves mean but rather in what Maire and George have made them mean that they gain importance here. In this moment, in the ridges and lakes the lovers use as stepping stones to intimacy, Maire and George quite literally find a common ground and construct upon it their own personal language, a "dialect," if you will, which draws on a shared understanding of the world and thus reinforces and expresses their connection to one another. 
This scene is emblematic of the linguistic attitudes TranslationsNorthern Ireland's Field Day Theatre Company's first production-expresses, for in the absence of a clear central character, the play takes language as its focus. ${ }^{1}$ Such a "dialect of endearment," as Tom Paulin, one of Field Day's directors, would call the language of George and Maire's encounter, gathers together a "hoard of relished words" which creates an intimacy among speakers by acting "as a kind of secret sign [that] serves to exclude the outside world" $(1985 \mathrm{a}, 16)$. The ability to create such connections makes dialect itself a powerful tool for postcolonial writing, particularly in the world of the theatre, which offers a writer far greater potential to forge an immediate connection with a local audience than is available in other comparatively silent genres: local actor and local audience form an aural bond, and it becomes immediately apparent, based on which observers laugh at the jokes, who is or is not an outsider. For a company wishing to broaden the Irish theatre audience by bringing plays to smaller communities around Northern Ireland and the Republic, which rarely saw professional theatre, dialect has functioned as a significant means of connectivity, and Field Day has not only explored the potential of Hiberno-English-a variety of English that is strongly influenced by Gaelic in its lexicon, syntax and idiom - in its productions, but also pondered the dialect's significance in its pamphlet series. ${ }^{2}$ Moreover, in its first four years, Field Day produced three dialect translations of foreign dramas, a fact which emphasizes the ability of local language to make such work more accessible to an audience which might previously have only encountered these plays in standard English versions.

\section{The Politics of Dialect}

Dialect is by definition a linguistic hybrid, and it is particularly significant that a company co-founded by a playwright who has himself stated that he is not interested in the revival of the Irish language would make such prominent use of it (see Richtarik 1994, 37). According to founders Brian Friel and Stephen Rea, and their co-directors, Field Day wants to redefine Irishness in the context of the Northern crisis "by producing analyses of the established opinions, myths, and stereotypes which [have] become both a symptom and a cause of the current situation" (Field Day 1985, vii). The Gaelic language, as a number of nationalist attempts to revive it have shown, certainly qualifies as one of those enduring myths of a unitary Irish culture, and Field Day's interest in dialect and its ability to express adequately a new sense of Irishness is itself a significant challenge to that myth: the company, as W.B. Worthen tells us, "sees 'Irish' identity to be inextricably bound to the languages of Ireland" (my emphasis) rather than to the ancient 
native tongue alone $(1995,24)$, and dialect becomes a way of negotiating between the English/Gaelic poles. As Translations argues, linguistic hybridity also suggests cultural hybridity, and if Field Day's first play attempts to define a close relationship between the nuances of dialect and the fusion of identities that embodies Northern Ireland, its later translations have built upon this model, although with somewhat varying degrees of success, in an attempt to solidify that shifting identity, not only in theory but also within the walls of theatre itself.

That Maire and George's encounter reaches the audience on an emotional level but significantly not on a linguistic level reveals several characteristics of the milieu that created Translations. Friel's rendering of this encounter is at once the most poignant moment of the play and the most futile, beautiful in its innocent belief in the power of romance and hopelessly naive in its refusal to acknowledge the realities of the moment. On one level, Maire and George simply represent the traditional union of "male" England and "female" Ireland, yet Friel is unwilling to allow us such an easy association; after all, George is rather too sympathetic and too ambivalent about his status as invader to typify Empire, and Maire is rather too ready to leave her homeland to become its feminine embodiment. In attempting to define a world for themselves, Maire and George merely conjure up "the spirit of the past, of names that no longer exist" because they have literally been erased from the map (Zach 1988, 88). The new map, of course, is an English one, which George and his fellow soldiers have come to Baile Beag to create as part of the Ordnance Survey of the 1830s. George's job, with the help of his friend and translator Owen, is to determine English-language equivalents for all Gaelic place names-each ridge, fort and rock-and to record these new designations in the Namebook, a document which becomes the physical symbol of linguistic change. Maire and George's literal use of Gaelic marks them as romantic holdouts and cuts them off from the English-speaking soldiers (represented onstage by standard English) and the Gaelic-speaking villagers (represented by Hiberno-English) as well as-and perhaps more importantly-from a primarily English-speaking audience, a circumstance that attests to the success of the historical moment the play describes. Indeed, the lovers' retreat into their own linguistic world represents a flight into history rather than an understanding of the present, ${ }^{3}$ a move which blinds them to the powerful social forces marshalling around them. Friel's characterization of the only exclusively Gaelic moment in the play, and his depiction of the violence and confusion that follow it, reinforce the play's conclusion-for which Friel was of course largely indebted to George Steiner's After Babel-that "words ... are not immortal" and that to retain "a linguistic contour which no longer matches the landscape of ... fact" (Translations, 51) is to "fossilize" (81). ${ }^{4}$ 
Privileging Hiberno-English over the literal use of Gaelic in the play is a way of acknowledging the play's roots in the contemporary moment; it asserts some continuity of culture in the face of a new linguistic reality. In this vein, many critics of the play have noted that Friel employs the dialect as a way of linguistically marking his Irish characters, yet many have stopped there, and thus have not sufficiently interrogated the ends to which the play employs dialect. Michael Toolan, for instance, correctly points out that Hiberno-English is sometimes meant to represent Gaelic and sometimes meant to represent standard English, but his argument does not consider the further implications of these important shifts: instead, he elides the differences between dialect and the standard by offering only that the similarity of the two languages lends the play great comic potential when people who appear to be speaking the same language cannot understand one another $(1988,143)$. Worthen, too, argues that dialect "becomes the medium through which all other languages - including 'Standard English'-are represented," and, by pointing to a number of moments in the play when the audience cannot immediately tell which language the characters' words are meant to represent, asserts the power of dialect to disrupt the standard $(1995,32-$ 33). ${ }^{5}$ While both of these observations are accurate up to a point, Friel's manipulation of dialect here has a further, deeper resonance, and by allowing his multilingual characters to switch back and forth between standard English and Hiberno-English, he permits them to demonstrate the fluctuations in their cultural consciousness at any given moment, rather than simply indicating which language they are speaking: the representation of speech here alerts an audience not only to the slipperiness of language but also to individual characters' need to reconcile their disparate poles of identity. This method suggests that with the change in language comes a change in self-understanding, or conversely that the new language comes to reflect an already altered culture: the community that speaks Hiberno-English is by its very nature unlike the community that speaks Gaelic, and thus the two languages must be employed differently. Particularly through his multilingual characters, Friel reveals that both their speech and their identities are irrevocably hybrid. Indeed, the play's translation expert even bears a double name- Owen to the villagers and Roland to the soldiers- and the play at one point attempts to fuse these two to see what might come of the composite. If Ireland is itself divided, and the North more obviously so, then the play raises the question of how language itself can come to represent both that disjunction and its solution. As such, the play has far more to say about the state of affairs in modern Ireland than it does about the facts of Irish history. ${ }^{6}$ 


\section{Uncertain Affiliations}

British colonialism certainly played a decisive role in the declining fortunes of the Gaelic tongue, but internal forces exerted a fair amount of pressure themselves. Sean Connolly's critique in Theatre Ireland of the play's presentation of history calls Friel to task for figuring "the decline of Irish ... as something imposed by outside forces on a passive and culturally self-sufficient community" $(1987,42)$. Yet the very counter-examples Connolly cites, only to dismiss as irrelevant, reveal the playwright's concern to present the variety of factors involved in the creation of a linguistic identity. Friel's audience can hear that language is already slipping and changing, adapting to the new needs of the moment even before the soldiers appear onstage. Maire, for instance, has already begun learning English, although not very thoroughly, before the mapping project makes this skill a necessity. Still, she can never quite pronounce correctly that one sentence her Aunt Mary taught her, as she always renders the word "maypole" as "maypoll." That substitution of the short "o" in "poll" for the long "o" of "pole" clearly marks Maire as a Gaelic, or here Hiberno-English, speaker, for it is the same vowel shift that other monolingual Gaelic speakers in the play use when they render the word "old" as "aul." Bridget and Doalty, fellow classmates who are the most consistent Hiberno-English speakers in the play, employ this pronunciation frequently, as when Bridget critiques the quality of her writing equipment saying, "D'you hear the whistles of this aul slate?" (20). Yet Maire has set her sights on America, albeit out of necessity, and when she demands in Act One that Hugh teach her English, she succeeds in pronouncing that vowel sound correctly: quoting Daniel O'Connell, she offers with perfect pronunciation, "The old language is a barrier to modern progress" (28). O'Connell himself represents one of the most profound native influences on the decline of the Irish language, and that Maire cites him and alters her pronunciation while making the reference reveals a shift in her loyalties, precipitated by factors internal to the community, rather than her language, which the substance of her argument itself reveals must be Gaelic. The fact that Maire's new attitude spills over into her speech patterns marks her subconscious acceptance of a conscious decision, and thus her rejection of "the old language" is an important assertion of a new, particularly modern cultural identity.

More pronounced than the shifts in Maire's language are the movements of Owen's dialect. As the play's hired translator, Owen straddles the boundary between English and Gaelic and finds himself constantly manoeuvring between these two poles. Yet, as with Maire, what the audience hears is an inaccurate guide to the literal language he is supposed to be speaking. When asked to translate the British Captain Lancey's initial orders to his father's hedge school class, Owen simplifies Lancey's syntax 
but does not communicate the directives in Hiberno-English; instead, his language, as he acts in this official capacity, loses most of its local flavour, as he adheres instead to a recognizably British standard. Similarly, when Owen is obviously speaking English to George, his syntax sounds Gaelic. As Act Two opens, the two men are simply talking business, going through the tedious process of checking the name "Bun na hAbhann" against various registry lists. Owen's language here reveals no distinct dialect markers until the conversation begins to take on a more jovial tone. As Owen goodnaturedly quizzes George on the Irish he has been teaching him, he tells him, "Put English on that, Lieutenant... We'll have you fluent at the Irish before the summer's over" (42). This "put X on Y" construction appears periodically throughout the play in Bridget's query, "What name did she put on [the baby]?" (25) and Hugh's panicked, "Put some order on things!" (32). The form itself is a common feature of Hiberno-English, derived from Gaelic's affinity for expressing important concepts with nouns rather than verbs, as it overlays nouns by "putting" one on top of the other rather than specifying an action, such as "naming" or "translating," to be done to one of the nouns. ${ }^{7}$ That Owen slips into what sounds like dialect here gives the audience a sense of the growing friendship between the two men, and as the conversation progresses and Yolland begins to reveal his personal history, Owen continues to speak to him in dialect. The usage marks Owen's national affiliation, his sympathy with home rather than his language of choice, which here must be English, for George not only speaks little Gaelic as of yet but also still worries about his position as an outsider. More importantly, however, Owen's dialect marks his acceptance of George into his own circle; as the English Hibernophile despairs of ever truly integrating himself into the life of Baile Beag, even if he does acquire the language, Owen reassures him, "You can learn to decode us" (48). For an audience that might not understand Gaelic but does recognize the intimacy that dialect suggests, Friel's linguistic device intensifies our understanding of this growing bond. Moreover, Owen's assertion, both of his own position as part of the "us" and of George's ability eventually to join that group, broadens the boundaries of national identification.

Owen's statement finds its proof in George's tendency to slip into Hiberno-English at certain moments in the play. Indeed, just as he is beginning his closest identification with Maire, he adopts her Irish syntax, mimicking the form of a dialect he doesn't even understand. Contemplating the others' reaction to their departure from the dance, George asks, "I wonder did anyone notice us leave" (59) instead of the more standard "I wonder if anyone noticed us leave," and in so doing employs an untransformed question, an element of Hiberno-English syntax which closely mirrors the Gaelic treatment of imbedded questions (Todd 1989, 44). Similarly, he mimics Maire's particularly Irish use of the progressive, rather than the past partici- 
ple: she exclaims, "The grass must be wet. My feet are soaking," and he replies, even though he has no idea what she has just said, with the same form, "Your feet must be wet. The grass is soaking" rather than the more standard "soaked." Such a preference for the "-ing" form is a common feature of Hiberno-English as the adjective mimics the gerunds and progressive verb forms which seem to be the English rhythmic equivalents of Gaelic verbal nouns (Todd, 72). After hearing the hedge school students pepper their speech with the construction throughout the play, it is difficult not to notice that a British soldier, who has thus far spoken only the standard, seems to have crossed a boundary by joining them.

George's linguistic shift here is quite telling, and, in this moment, the play seems to hold out the possibility of a more inclusive definition of Irishness, one which incorporates both the Catholic native community and the Protestant settler community. After all, setting out to establish a Northern theatre company with particularly Northern concerns meant that ideally Field Day would attempt to negotiate both sides of the region's tumultuous political divide. Yet following through on this ideal has not always been easy. When in an effort to broaden its base of playwrights Field Day commissioned a piece from Protestant writer David Rudkin in 1983, they seemed to ignore the possibility of diversity of opinion within the Protestant community, and when Rudkin's The Saxon Shore turned out to be vehemently critical of the Plantation settlers, represented in the play by bloodthirsty Saxon werewolves, the board, which has been generally perceived as "green" in spite of their more non-partisan goals, was understandably reluctant to launch a production. ${ }^{8}$ What better way to cut off communication than to have your biggest gesture of inclusiveness condemned for bigotry? Field Day settled instead that year for Boesman and Lena by Athol Fugard, whose background made him, according to Rudkin, "the next best thing to an Ulster Protestant," and whose distance from the Irish question made him a somewhat safer choice in a volatile political atmosphere (Richtarik 1994, 203) ${ }^{9}$

There is nothing easy about having to recreate one's sense of identity, and in Translations, even Hugh, who believes that Irish culture has a much greater affinity with classical culture than with England and reflects this in his speech not only by speaking Latin but also by often employing a Latinate structure in his English, lapses, in a moment of panic, into HibernoEnglish: as the story he tries to tell from the Aeneid trails off at the end of the play, the elaborate façade which insulated him from the world around him crumbles, and he curses in the dialect, "What the hell's wrong with me. Sure I know it backways. I'll begin again" (83). By employing the dialect word "backways" and prefacing his sentence with the Hiberno-English filler "sure," Hugh shows the new reality of his Irish identity. This "new" identity cannot live in the past but must be allowed to evolve; it is an identity which, 
as his infrequent use of dialect shows, he has spent most of the play trying to subdue, and it finally emerges as his stories of antiquity fail him.

\section{Communication and Subversion}

Each of these characters is thrust by choice or force into a new Ireland, one which must cope with the realities of the world outside its borders, and it is with that awareness that they must begin to fashion new identities. Yet the need to recreate oneself does not equate with a lack of identity, and although Hugh at the end finds that the story he knows "backways" fails him, he does not cease trying to tell it, for only in that effort can he find himself. Similarly, Field Day's translation efforts serve, like Doalty's tampering with the soldiers' equipment, as a "gesture ... to indicate ... a presence" (17) while expanding the scope of what that presence can mean. Three of Field Day's first six plays were translations of foreign works: Friel's own rendering of Chekhov's Three Sisters, Paulin's The Riot Act (a version of Sophocles's Antigone) and Derek Mahon's High Time (a translation of Molière's The School for Husbands). It might seem strange at first that a company devoted to creating an Irish sense of identity would be so intent on producing foreign plays, especially considering the argument that the company's production of Boesman and Lena suffered at the box office because it "was not new, was not Irish, and was not by Brian Friel" (Richtarik 1994, 212). But in choosing to translate some of the central canonical texts of Westem drama, Field Day writers gave themselves the opportunity to place their stamp on these texts, a form of dramatic appropriation which, as Worthen proposes, has made translation "a staple means of political critique in the theatre" in general and in postcolonial theatre in particular $(1995,22)$. If, as Benjamin has argued, "even the greatest translation is destined to become part of the growth of its own language" (1992, 75), then Field Day's efforts can be seen as an attempt to stimulate that growth by establishing, or at the very least perpetuating, a Hiberno-English tradition.

Translation also offered the dual possibility of communication and subversion, a potential multiplied in the theatre, which can use layered modes of expression. Gilbert and Tompkins argue that the theatre's ability to employ not only dialogue but gesture and visual cues as well to refine interpretation makes it a particularly effective mode of counter-discourse, as body language, lighting and set design can either support or undermine the meaning of the spoken word, an ability which also expands the capacity of the dramatic translator to convey the nuances of, or obliquely critique, the language of the original $(1996,18)$. While such manipulation may not produce an entirely "faithful" translation, resulting in a finished product that is closer to Goethe's definition of parodistic translation rather than the higher trans- 
lation which sought "to achieve perfect identity with the original" (1992, 60-61), it is also an outgrowth of historical distance from the original, which in its "afterlife [necessarily] undergoes a change" (Benjamin 1992, 74). At the same time, this need to rethink the presentation of the original derives from the need to create stage productions, as David Johnston has argued, for actors (and audiences) rather than readers: "translation for the stage is about giving form to a potential for performance" (1996a, 58). Theatrical presentation must have an immediate impact in a way that a privately read text which can employ footnotes to explain unfamiliar passages need not, and thus, performance must enable a play to speak, literally, to its audience's current context and surroundings. Potentially, then, such transformation of the dramatic text could offer Field Day a particularly apt forum for challenging the assumptions of these canonical works and in the process interrogating the question of Irishness.

Of the three texts by Friel, Paulin and Mahon, only Mahon's fits the traditional definition of translation: the author was sufficiently fluent in French to have already produced other works from that language (Richtarik 1994, 229). Mahon himself calls High Time a "free translation" and offers in his preface a rationale for altering the play's setting to make the action more comprehensible to a contemporary audience by "go[ing] for immediacy instead of nostalgia" (7). Yet the contemporary audience Mahon's translation targets is not as particularly Irish as one might expect, for although the stage directions specify that "the action takes place in Ireland" (10), only the Georgian doorways and the occasional Irish pronunciation clarify the setting at all. Indeed, Mahon's language itself adheres quite closely to the standard, with Tom's proclamation that people like his brother Archie are "a bunch of eejits" (11) and Isabel's exclamation "for Jesus' sake" (32) serving as rare markers of national identity. Perhaps Mahon's most ingenious use of dialect is in the occasional fudged rhyme: employing Irish pronunciation can make thymes of "Val" and well ("waal") or "honour" and wonder ("wonhour"). Yet as Richtarik's analysis of the text's split words and odd phrasings reveals (1994, 231-33), Mahon relies much more heavily on other methods to craft his verse, consequently allowing the dialect to enliven his text only sporadically. Thus Field Day's most direct early translation seems to have the least to say about the question of language and nation-building; for the "non-political" topic of romance, Mahon seems to have felt that the generic standard would serve.

Unlike High Time, neither Paulin's nor Friel's play functions as a conventional translation. Rather, both were "translated" from traditional English sources into dialect: Friel, who knows no Russian, created his play by collecting a number of English-language versions and writing his own answer to them (Richtarik 1994, 120), and Paulin similarly drew his work 
from Sir Richard Claverhouse Jebb's nineteenth-century prose-translation of the original (Roche 1988, 225). Applying the term "translation" to these texts then may seem a dubious endeavour, but only if we fail to consider the political motivations of the authors. Friel certainly saw his work as a translation: the published version of Three Sisters is deliberately subtitled "A Translation of the Play by Anton Chekhov," and the description on the back cover states that "Friel's translation ... was undertaken ... since the only Chekhov translations available to the Irish theater at the time (1981) were American and English, in the hope that it might make the unique experience of Chekhov more accessible to Irish audiences" (my emphasis). Such a designation, then, makes this linguistic work into a political act aimed at legitimizing Hiberno-English as a mode of communication, and legitimizing its speakers as having a manner of expression and a culture which standard English alone cannot express. To translate from English into dialect is to eradicate the Britishisms which had previously made these canonical characters more distant, doubly foreign to an Irish audience, and instead to make them as familiar as Athena is to Jimmy Jack in Translations itself, by giving them recognizable local speech cadences. Indeed, Friel even calls attention to the language of his play, as when Kulygin, who in an attempt to revive his wife's spirits has disguised himself as his school's German instructor, replies to Natasha's exclamation of shock by intoning with a German accent, "What means I put the heart across you?" (Three Sisters, 120). Such a comment works on many levels, serving to include an Irish audience which understands the saying while at the same time alerting non-Irish Englishspeaking audiences both to their own distance from the site of the play's creation and to the need for outsiders to learn this particular idiom. Moreover, by drawing attention to his characters' dialect, Friel highlights his own project; Natasha makes no such exclamation and Kulygin, no such comment, in Elisaveta Fen's more traditional translation of the play (Chekhov 1959, 327).

Manoeuvring between English and dialect offers Field Day the power to subvert the status of English by asserting the distinction between English and Irish culture. As Annie Brisset argues concerning the similar relationship between Québécois and French, such "retranslation constitutes first and foremost a symbolic act of rupture, of declaring autonomy" in relation to the dominant language $(1989,21-22)$. The translator from English to Hiberno-English, after all, offers his belief in the inadequacy of the standard to express his own culture. Ultimately, however, translating from English can also subvert that claim to autonomy. By launching this challenge against the authority of British culture, the playwrights also attest to the impact of that authority in their own education and their own lives, revealing what Ashis Nandy has called the "unbreakable dyadic relationship" between colonizer and colonized $(1983,7)$, for on some level, going back 
to the English rather than the Russian or the Greek does not dissolve but rather reinscribes the connection between England and Ireland by arguing that the Russian culture which created Chekhov's plays and that country's potential ties to Ireland are not as important as the English culture which translated him in the first place. While the use of English source texts was in this case apparently a practical necessity, and in other historical circumstances might not bear such political weight, in a nation striving to forge an independent notion of itself, such dependence on the English can make Irish work appear doubly derivative.

\section{Shaping Identities in Translation}

Yet the endeavour still holds possibilities, and Friel felt that the mere fact of greater accessibility for a local audience, particularly in the case of a touring company such as Field Day, offered much promise. He described his decision to translate Three Sisters as one prompted by the ability of language to shape the people who speak it:

Somehow the rhythms of these [standard English] versions do not match with the rhythms of our own speech patterns, and I think that they ought to, in some way. Even the most recent English translation again carries, of necessity, very strong English cadences and rhythms... [W]e are constantly overshadowed by the sound of the English language, as well as by the printed word. Maybe this does not inhibit us, but it forms us and shapes us in a way that is neither healthy nor valuable for us. (qtd. in Agnew 1980, 59)

Some might offer that the reverse is also true, and, for a company interested in reaching an international audience as well as a local one, dialect translations can alienate non-Irish speakers of English. Yet, as Bill Findlay has argued regarding the use of Scots on the stage, a national theatre culture "cannot function by looking over its shoulder for approbation from elsewhere ... Scottish theater has an obligation towards its own audience" (1996, 205). Of course, not only the audience benefited from such an endeavour, and Rea has argued that one of the reasons for his involvement with Field Day was his feeling that "an Irishman in English theater is very conscious of belonging to a subculture rather than a culture proper... I felt less expressed in terms of England than I did over here" (qtd. in Gillespie 1980). Speaking to Ireland in its own cadences and rhythms seems to have sufficed for Friel, and his version of the play takes only scattered liberties with the text. Rather, Friel brings his Russia to life in Irish tones in an effort to reclaim what had previously been lost for Irish audiences: a clear sense of connection with the foreign text. It is highly ironic, then, that Friel's own distance from that original culture may have inhibited this endeavour. ${ }^{10}$ 
The most politically charged, and thus the most potentially disruptive, of these early translations was Paulin's The Riot Act, a play whose change in title already draws attention away from the central heroine of the Greek original and onto the wartime situation which condemns her. Indeed even the choice of a classical play is interesting considering both the central position such drama holds in the Western canon and the affinity Translations itself expresses for the "warm Mediterranean" (49) over neighbouring Britain's colder clime; while choosing to rewrite Greek drama allows a playwright to challenge the ideals of the canon, using Greece as a reference point also allows an author trained by the British system to draw upon a model which predates British dominance. In choosing Antigone as his source, Paulin selects a play whose situation closely mirrors the situation in the North; after all, his stage directions make it clear that the war which precedes the action stems from the inability of Eteocles to share power with Polynices, just as Northern Protestant leaders have often refused such arrangements with the Catholic minority, and the course of the drama itself reiterates the theme, as Creon argues that he will not "split [the] rule" that is his "by right" with "some king else" (39-40) while the version of the play Paulin draws from uses language that is far less defensive."

Moreover, translating the play into dialect allowed Paulin to make a number of local associations that allow Greek tragedy to express his own sense of Northern Ireland. Many critics, for instance, have examined the language of Creon's first speech and pronounced it typical of a Northern politician. ${ }^{12}$ Similarly, the use of dialect influences our perception of Antigone herself, who can be viewed here as a defiant icon of the suffering Irish nation, traditionally personified as female, who stands condemned by Creon, the representative of the male British state. Such associations in the text are primarily accomplished through language alone, for The Riot Act sticks very closely to the structure of the original play, and the first production's modern costumes and draperied set hinted at, but did not clearly delineate, particular national affiliations (Richtarik 1994,216$).{ }^{13}$ Visually, the play seemed to strive for profound abstraction with its precise choreography, its dark curtains and starkly lit stage, but by manipulating the way the characters sounded, Paulin was able to suggest a number of connections that would be familiar parts of the cultural vocabulary of a local audience.

Indeed, the play foregrounds language in a way that brings Paulin's version into significant contrast with its source. While Jebb's rendering of the chorus preceding Haemon's entrance laments the tragic history of Antigone's family, Paulin's couches that history specifically in terms of language: "Ever since the day I first made this speech-it was in another time and place, and in a different language too-the grief I was speaking of then has grown and multiplied. It's got more and more" (The Riot Act, 35). 
Rather than offering a reflection on the inevitability of sorrow in a "house ... shaken from heaven [where] the curse fails nevermore" (Jebb 1978, 130), Paulin's chorus laments its own sad history, one shaped, even defined, by a change in language, and the fact that the accumulation of sorrows is connected to the loss of a language gives the play perhaps its closest identification with the situation in Ireland.

Yet, as in Translations, Paulin is not entirely willing to look to the past as a moment of glory, for even the speech delivered in "a different language" presents a record of sorrow. Moreover, Paulin's Antigone is not entirely a traditional incarnation of the feminine icon of Irish nationalism. Rather, she becomes a particularly Northern figure, a unifying idealist whose allegiance is not monopolized by the brother she buries but is given equally to both. Certainly, this vision is part of the original already: when Creon challenges Antigone's loyalty to Polynices, the traitor, she argues that "death longs for the same rites for all" (Fagles 1982, 85). Paulin's play emphasizes Antigone's belief in the equality of her brothers as she asserts that even alive Eteocles would not criticize her actions: "That he'd never do... They were full brothers./They were equal" (29). The relevance of such a figure in the context of Northern Ireland was a point which Paulin had begun to argue some years earlier in response to the cultural critic Conor Cruise O'Brien's assertion that the situation in the North was already moving "backwards ... away from the ceremonial act of non-violent disobedience, and into the fratricidal war, which precedes the action of the play," and in such circumstances "you begin to feel that Ismeme's commonsense and feeling for the living may be the more needful" response $(1973,159) .{ }^{14}$ Paulin vehemently disputed this claim in "The Making of a Loyalist," countering O'Brien's argument with the assertion that "the analogy between the play and events in the North of Ireland shows us a terrible truth-neither Ismeme, nor even Conor Cruise O'Brien, can prevent a civil war happening"' (1984, 28). The rupture, according to Paulin, already exists in the past, and the job of the present is, like his Antigone, to find a way of burying the dead together. Originally published in 1980 in the Times Literary Supplement, Paulin's response represents the ferment which helped produce The Riot $A c t$, and the essay proposes that to discredit Antigone is to side with the status quo, thereby absolving Creon/the state of any responsibility in the violence. That "The Making of a Loyalist" was republished the same year in which The Riot Act was produced, in a collection of essays dedicated to Brian Friel and Stephen Rea-the latter not only starred as Creon, but also directed the play-suggests that the production represented the fruition of Paulin's argument.

At the centre of The Riot Act stands the inevitable interconnecting of opposing sides. Even though Paulin's Creon heatedly asserts that the city is 
his by right and that he alone can rule there, the play does not allow him to remain separate from the community he strives so desperately to stand above. The staging for the first production periodically had Creon blend into the chorus (Richtarik 1994, 216), thus subsuming him into the mass of the people. Furthermore, while his first speech is precise standard English, albeit riddled with political jargon, emotion and the momentary loss of his selfpossession throw him into dialect. When the guard asks him if his account of events "sting[s his] ears or [his] conscience," Creon dismisses him with the curt, "Why-Why should it? ... You're a spieler only" (The Riot Act, 22), a shift of syntax and choice of words that indicates his connection to the same social world that produced the guard rather than preserving the strict class lines that separate them. ${ }^{15}$ In his closing speech, in the face of the loss of his family, Creon cannot muster the formal structures of the standard he employed earlier, and instead, in broken syntax, he calls himself "cackhanded ... Creon [who's] made a right blood mess" of things (62). At his lowest point, he, too, partakes in the sorrows the chorus lamented earlier, and his participation in that grief reveals itself in his means of self-expression. The use of dialect may, as Christopher Murray has argued, "flatten the play into ordinariness" at times $(1991,121)$, but in Creon's case, that very ordinariness reveals his "Northernness," his bond not only with Antigone but also with the rest of his city's population.

\section{Finding a Common Voice}

While using dialect in an attempt to reshape the English language to fit the needs of a particular national community can enable a playwright to forge a deeper connection with that community and reinvent traditional texts to reflect on local events, dialect in itself is only a partial solution, precisely because of its regional specificity. Indeed, Hiberno-English itself varies over the island of Ireland, and it is highly ironic, given Friel's goal, that in the Republic some reviewers of Three Sisters felt alienated by the production, which they claimed sounded too Northern to fit the South (Richtarik 1994, 126). What is dialectally familiar to one audience is dialectally distant from an audience whose English is not Hiberno-English (or even Derry HibernoEnglish), so that while Friel undertook the Chekhov translation to ensure that his (Northem) Irish actors would not have to make the double adjustment of becoming English to become Russian, ${ }^{16}$ by familiarizing the characters for a local audience, he forces other audiences to make the double adjustment of becoming (Northern) Irish to become Russian. Irish identity, embodied in language, then, remains fractured as dialect itself becomes ever more local.

Yet in the medium of the theatre, this obstacle is not insurmountable, for performance itself provides a means of clarifying translation. Certainly 
Translations itself uses this technique to inform George and Maire's romantic encounter, or even the play's many Greek and Latin passages, as these would be, on a literal level, incomprehensible to many, if not most, English speakers. High Time incorporates a good deal of performative translation-the youths' punk costumes, which help to rationalize Tom's antipathy for them; props like the eye-catching valentine Isabel surreptitiously sends to Val; and perhaps most vitally the mimed scenes the directors incorporated into the production - and one of Friel's more innovative additions to Chekhov's text, a dance that never quite blossoms, represents another such effective means of communicating the text's nuances. ${ }^{17}$ Similarly, the fact that The Riot Act appeared in a double bill with High Time, and that the roles of Creon/Tom and Antigone/Isabel were played by the same actors, allowed the performed texts to revise each other (Richtarik 1994, 234, 237), adding political dimensions to the latter play while offering in the conflict between Isabel and her stodgy guardian, Tom, a humorous parallel for the conflict of the Greek play. Gilbert and Tompkins propose that such doubling of actors creates metamorphic bodies which attest to the divided identity of the postcolonial subject $(1996,233)$. Yet such splitting is not always negative: if Antigone's troubles bring to mind the sorrows of the traditional nationalist embodiment of the nation as a woman, then her reappearance in the "second act" as Isabel, whose sharp mind and rejection of "feminine" restraint allow her to outwit her jailer/guardian, suggests that that same Irish nation need not necessarily succumb to a tragic fate. Revealing as the pairing of these plays is, however, neither of them succeeds quite as well alone. Individually, Paulin's, Mahon's and Friel's versions of foreign texts cannot quite bring linguistic and performative translation together for sustained effect, and thus the vision they seek to express, and the identity they seek to define, fail to materialize fully. As Paul Hadfield has proposed, Field Day is a theatre of ideas, but "the relationship between 'ideas' and the expression of these as 'theatre' was [not always] logical [or] simple" $(1993,48)$.

This is not to say that Field Day's early translations have somehow "failed" in their mission; for all its unevenness in other respects, The Riot Act offers a meaningful reflection on the formative power of language, and its pairing with High Time forces an audience to address questions which separate productions might submerge. And if Friel's Three Sisters is wordier and thus longer than necessary (Richtarik 1994, 122), the connection that its language allows an audience to make between the Prozorov family's unfulfilled yearning for Moscow and the paralysis of Joyce's Dublinersafter all, Irina does not simply have a revelation in Act One but rather "an epiphany" (Three Sisters, 16)-succeeds in bringing the Russian text into dialogue with the Irish tradition. It seems to me that these early efforts at translation have been a struggle against what finally tears the world of 
Translations apart: silence-for in the play's silences come actions which are inevitably violent, like the Donnelly twins' abduction and probable murder of George. As Gilbert and Tompkins argue, silence is what defines the postcolonial subject-both in the silence of a tongue lost and in the refusal to speak the language of the conqueror (1996, 189-90). Yet, in Translations, neither Sarah's retreat into a protective silence nor the ominous whistle that represents the Donnellys produces constructive meaning, and it is ultimately only speech, and the need to define the surrounding world through speech, that holds Baile Beag/Ballybeg together; indeed, the play's great silent moments of defiance-Doalty's assault on the soldiers' machine, his implicitly threatening act of clearing a path to the road for George and the Donnelly twins' violent attack - all happen offstage. Similarly, Field Day's early translations, in their attempt to articulate the boundaries and potentialities of Northern speech, to find a "common voice" for themselves (Kearney 1988, 124-25), have sought to put this silence aside by interpreting language itself as political. If the identity which the language of these translations seeks to shape is itself still somewhat unfocussed, that circumstance only reflects the difficulty of understanding and communicating identity in the North. Brian Friel has argued that, "We are talking to ourselves as we must" (qtd. in Agnew 1980, 60). His "we" is ambiguous-the Irish? the directors? the North? - but the verbal emphasis of the comment stresses that whoever Friel's "we" may be, they have the power, and the obligation, to turn speaking into an act of self-assertion, as opposed to the "ultimate protection of privacy" (Lojek 1994, 87) which silence represents, and to make the voice of the stage the means of perpetuating, and indeed creating, themselves.

\section{Notes}

1. Friel himself has stated that the play is not "about Irish peasants being suppressed by English sappers... The play has to do with language and only language" (qtd. in Kearney [1988], 127).

2. Michael Etherton (1989) argues that, based on the company's list of productions, "one of Field Day's commitments is to the development of Irish English," 193. In his opinion, their productions indicate that language is central "to any profound political change," 194.

3. Helen Gilbert and Joanne Tompkins (1996) offer a similar argument regarding the status of the Maori language, which, "since even many Maori do not speak [it] well ... can signify only 'history' to some audiences, and a superseded past at that," 171.

4. Steiner offers that a civilization "in which the available resources of live perception and restatement wither ... is imprisoned in a linguistic contour which no longer matches, or matches only at certain ritual, arbitrary points, the landscape of fact" (1975), 21. 
Kearney (1988), 158-60, has gathered a list of specific connections between Friel's work and George Steiner's writing. Helen Lojek (1994), 83-99, also examines the relationship between Steiner's linguistic theories and Friel's work.

5. Others, like Brian Arkins (1991), 205, do not draw distinctions between the play's varieties of English.

6. In discussing the layering of Irish identity, Zach (1988), 78, argues that "although Friel mainly attempts to sketch this divide in terms of language, he also implicitly comments on the present-day political and social situation in Northern Ireland." Edna Longley has in fact criticized Friel for this dimension of the play, stating, "No perspective discriminates between past and present, nineteenth-century Ireland and twentieth-century Northern Ireland. There is simply equation" (qtd. in Kearney [1988], 155). This assertion of "equation" is, however, problematic, and I would agree with Kearney's objections to Longley's remarks, as well as to others who criticize Friel for taking liberties with history: although the play concentrates a number of historical events into approximately two hours, as historical drama must do if it is to be "dramatic," and takes as its subject the oft-discussed topic of English colonization, in questioning myths of origin as it does, it forces the present to re-evaluate its assumptions about the past and thus to re-evaluate itself. As R.K.R. Thornton (1991), 224, has argued, "Of course the play is an attack on English influence in Ireland; but, more important, it is also a subversion of the Irish idea of the Irish."

7. See especially Loreto Todd (1989), ch. 2, 40. Also informative on characteristics of Irish-English/Hiberno-English is Liam Mac Mathúna (1990), 91-92, especially the discussion of Gaelic as a noun-centred language.

8. For a more detailed discussion of the board's reactions, see Richtarik (1994), ch. 6 . Elizabeth Butler Cullingford (1996), 228, summarizes the general attitude toward Field Day thus: "Many commentators now associate Field Day with the 'green,' or nationalist, positions it has always tried to complicate through social and economic analysis. No matter how nuanced the company's productions, pamphlets, and public statements, the anticolonial positions of its directors ... logically require a politically united Ireland: a desirable ideal, but not one to which a unionist could subscribe."

9. Rudkin rankled at the rejection, but his ties with Field Day were not completely severed. Nine years later the company performed a staged reading of his 1973 radio play Cries from Casement as His Bones Are Brought to Dublin. See Hadfield (1993), 47.

10. Brisset (1989), 22, notes that translators from French into Québécois saw themselves, interestingly, as "discovering the 'truth' of the original work," which the French "had masked."

11. Jebb (1978), 134, in his translation, has Creon ask, "Am I to rule this land by other judgment than my own?... Is not the city held to be the ruler's?".

12. See, for instance, Roche (1988), 224, Worthen (1995), 28, and Harris (1988), 258.

13. Christopher Murray (1991), 120, suggests that "the triangles, masonic symbols, [and] neo-classical architrave" which decorated the palace façade indicated to an audience that they were "in Belfast and Thebes simultaneously."

14. A number of critics have analyzed Paulin's argument with $O^{\prime} B r i e n$. See especially Roche (1988), 223-24, Murray (1991), 123, Richtarik (1994), 217-18, and Worthen (1995), 26-28. 
15. Although, as Worthen (1995), 28-29, argues, the play does distinguish between "Creon's smooth public discourse and the Guard's [more dialectally inflected] speech habits," the contrast is not so markedly maintained as this statement suggests, as Creon himself does not always make use of that "smooth public discourse."

16. Friel offered that Irish actors in traditional Chekhov productions "have to pretend, first of all that they're English and then that they're Russians. I'd like our audience to see Captains and Lieutenants who look as if they came from Finner or Tullamore" (qtd. in Richtarik [1994], 120).

17. Directors Michael Long and Emil Wolk embellished the printed text significantly for the first production; some of these additions are briefly described in Richtarik's (1994), 234-35, discussion of the play. Similarly, her discussion of Three Sisters argues that reviewers found the insertion of the would-be dance scene to be one of Friel's few "genuine addition[s]" to Chekhov's work, 123.

\section{Works Cited}

\section{Theory and Criticism}

AGNEW, Paddy. 1980. "Talking to Ourselves (Interview with Brian Friel)." Magill (Dec.): 59-61.

ARKINS, Brian. 1991. "The Role of Greek and Latin in Friel's Translations." Colby Quarterly 27 (Dec.): 202-9.

BENJAMIN, Walter. 1992. "The Task of the Translator." Trans. Harry Zohn, 71-82. In Theories of Translation: An Anthology of Essays from Dryden to Derrida, ed. Rainer Schulte and John Biguenet.

BRISSET, Annie. 1989. "In Search of a Target Language: The Politics of Theatre Translation in Quebec.” Target 1, no. 1: 9-27.

CONNOLLY, Sean. 1987. "Dreaming History: Brian Friel's Translations." Theatre Ireland 13: 42-44.

CULLINGFORD, Elizabeth Butler. 1996. "British Romans and Irish Carthaginians: Anticolonial Metaphor in Heaney, Friel, and McGuinness." PMLA 111 (Mar.): 22239.

ETHERTON, Michael. 1989. Contemporary Irish Dramatists. London: Macmillan.

FIELD DAY THEATRE COMPANY. 1985. Ireland's Field Day. London: Hutchinson.

FINDLAY, Bill. 1996. “Translating into Dialect." In Stages of Translation, ed. David Johnston, 199-217.

GILBERT, Helen, and Joanne TOMPKINS. 1996. Post-Colonial Drama: Theory, Practice, Politics. London/New York: Routledge.

GILLESPIE, Elgy. 1980. "Festival Profile: Stephen Rea." Irish Times (Oct. 10). 
GOETHE, Johann Wolfgang von. 1992. "Translations." Trans. Sharon Sloan, 60-63. In Theories of Translation: An Anthology of Essays from Dryden to Derrida, ed. Rainer Schulte and John Biguenet.

HADFIELD, Paul. 1993. "Field Day: Over But Not Out." Theatre Ireland 31 (Summer): 47-50.

HARRIS, Claudia W. 1988. "The Martyr-Wish in Contemporary Irish Dramatic Literature." In Cultural Contexts and Literary Idioms in Contemporary Irish Literature, ed. Michael Kenneally, 251-68.

JOHNSTON, David. 1996a. "Theatre Pragmatics." In Stages of Translation, ed. David Johnston, 57-66. , ed. 1996b. Stages of Translation. Bath, England: Absolute Classics.

KEARNEY, Richard. 1988. Transitions: Narratives in Modern Irish Culture. Manchester: Manchester UP.

KENNEALLY, Michael, ed. 1988. Cultural Contexts and Literary Idioms in Contemporary Irish Literature. Totowa, NJ: Barnes and Noble.

LOJEK, Helen. 1994. "Brian Friel's Plays and George Steiner's Linguistics: Translating the Irish." Contemporary Literature 35 (Spring): 83-99.

MAC MATHÚNA, Liam. 1990. "Contrastive Aspects of English and Irish." In Homage to Ireland: Aspects of Culture, Literature and Language, ed. Birgit Bramsbäck, 81-98. Stockholm: UPPSALA.

MURRAY, Christopher. 1991. "Three Irish Antigones." In Perspectives of Irish Drama and Theatre, ed. Jacqueline Genet and Richard Allen Cave, 115-29. Savage, MD: Barnes and Noble.

NANDY, Ashis. 1983. The Intimate Enemy: Loss and Recovery of Self Under Colonialism. Delhi: Oxford UP.

O'BRIEN, Conor Cruise. 1973. "Civil Rights: The Crossroads." In States of Ireland, 15286. London: Hutchinson.

PAULIN, Tom. 1984. Ireland and the English Crisis. Newcastle upon Tyne: Bloodaxe Books. 3-18.

1985a. "A New Look at the Language Question." Field Day Theatre Company,

RICHTARIK, Marilyn. 1994. Acting Between the Lines: The Field Day Theatre Company and Irish Cultural Politics, 1980-1984. Oxford: Clarendon P.

ROCHE, Anthony. 1988. "Ireland's Antigones: Tragedy North and South." In Cultural Contexts and Literary Idioms in Contemporary Irish Literature, ed. Michael Kenneally, $221-50$.

SCHULTE, Rainer, and John BIGUENET, eds. 1992. Theories of Translation: An Anthology of Essays from Dryden to Derrida. Chicago: $\mathrm{U}$ of Chicago $\mathrm{P}$.

STEINER, George. 1975. After Babel. London: Oxford UP. 
THORNTON, R.K.R. 1991. "Friel and Shaw: Dreams and Responsibilities." In Irish Writing, ed. Paul Hylard and Neil Samuels, 224-33. New York: St. Martin's P.

TODD, Loreto. 1989. The Language of Irish Literature. London: MacMillan Education.

TOOLAN, Michael. 1988. "Language and Affective Communication in Some Contemporary Irish Writers." In Cultural Contexts and Literary Idioms in Contemporary Irish Literature, ed. Michael Kenneally, 138-53.

WORTHEN, W.B. 1995. "Homeless Words: Field Day and the Politics of Translation." Modern Drama 38 (Spring): 22-41.

ZACH, Wolfgang. 1988. "Brian Friel's Translations: National and Universal Dimensions." In Medieval and Modern Ireland, ed. Richard Wall, 74-90. Gerrards Cross: Colin Smythe.

\section{Plays}

CHEKHOV, Anton. 1959. Plays. Trans. Elisaveta Fen. London: Penguin.

FAGLES, Robert, trans. 1982. Three Theban Plays. By Sophocles. New York: Penguin.

FRIEL, Brian. 1981. Translations. New York: Samuel French.

1992. Three Sisters: A Translation of the Play by Anton Chekhov. Loughcrew: The Gallery Press.

JEBB, Sir Richard Claverhouse, trans. 1978. The Complete Plays of Sophocles. 7th prt. Toronto: Bantam Books.

MAHON, Derek. 1985. High Time. Dublin: Gallery Press.

PAULIN, Tom. 1985b. The Riot Act: A Version of Sophocles' Antigone. London: Faber and Faber. 
Chapter 10

\section{THE IMPACT OF SPANISH-AMERICAN LITERATURE IN TRANSLATION ON U.S. LATINO LITERATURE}

Juliana de Zavalia

University of Massachusetts, Amherst (USA)

The presence, impact and influence of Spanish-American literature and culture in the United States are undeniable. Emily Hicks (1991) calls it "a cannibalizing pull" from America's "southern backyard." But today, this cannibalizing pull is coming from right within the U.S.-from the 27 million Puerto Ricans, Mexican Americans and Cuban Americans living there. And the Latino population in the U.S. is constantly growing with the influx of immigrants from all countries in Latin America. What happens when this somewhat culturally remote but geographically close area, labelled "exotic," "magical, "mysterious," is found to be "alive and kicking" within the geographical borders of the United States? The Americas are no longer separated by the Rio Grande, the river running between Mexico and the United States. Latino culture is now an inside phenomenon-hybrid, transculturated and more alive than ever.

Many U.S. Latino writers have been proclaiming "the increasing and inexorable latinization of the U.S.", what Gustavo Pérez Firmat refers to as a "rhythm" that sooner or later is going to get to everybody $(1994,1)$. Ilán Stavans (1995a) refers to the latinization phenomenon as the "Spanish accent" American (that is, U.S.) literature has acquired, while Chicana activist Gloria Anzaldúa proclaims the coming of "the new mestiza"-a racial, ideological, cultural and biological cross-pollination - the "raza cósmica ... at the confluence of two or more genetic streams, with chromosomes 
constantly "crossing over"' $(1987,77)$. Terms such as transculturization, cannibalization, biculturization are used to describe the cultural traffic between the U.S. and Latin America, between North and South, a traffic- no matter how imbalanced-that results whenever cultures meet and clash. Traffic is intensified when cultures share the same geographical space and boundaries become crucial in this situation. Here boundaries work in a twofold manner depending on the position of the speaker: they can be stigmatizing, homogenizing labels or empowering means of identity formation. ${ }^{1}$

Translation has played a major role in this process: witness the success of Isabel Allende's writing, films such as Like Water for Chocolate and The House of the Spirits, the proliferation of Mexican restaurants and Latin/ Caribbean music, bilingual street signs, TV stations, commercials, advertising in subways and buses, and most importantly, the Latino-and especially Latina (for women writers)--literary boom. For U.S. Latino writers, translation is a cultural phenomenon, a set of textual practices, a metaphor, an existential condition, a displacement, a traslado $^{2}$ - a site of both linguistic and topographic cultural difference. ${ }^{3}$

\section{Rethinking the Interface Between Cultures}

This paper attempts to explore the influence of contemporary SpanishAmerican literature in translation on the U.S. literary polysystem. I shall examine the ways in which the stronger host system refracts or constructs its image of Spanish America, and show how this corpus of translated literature and its U.S. refractions impinge on U.S. Latino literature. SpanishAmerican works in translation already interact among themselves in a separate literary system, but they also interact with(in) the U.S. literary polysystem in many ways. The existence within the U.S. literary polysystem of a large body of Latino writers, who, in some way or other, are related to and/or interact with Spanish-American culture (through descent roots, language, culture and traditions), makes the interface of the two polysystems problematic and complex. My approach emphasizes the importance of the Spanish-American component of U.S. Latino literature. ${ }^{4} \mathrm{I}$ will frame my analysis against the backdrop of Itamar Even-Zohar's theory of polysystems:

[O]n the one hand, a system consists of both synchrony and diachrony; on the other, each of these separately is also a system... [T] he idea of structuredness and systemicity need no longer be identified with homogeneity; a semiotic system can be conceived of as a heterogeneous, open structure. It is, therefore, very rarely a uni-system but it is necessarily a polysystem-a multiple system, a system of various systems which intersect with each other and partly overlap, using 
concurrently different options, yet functioning as one structured whole, whose members are interdependent. $(1990,11)$

Even-Zohar's theoretical framework is particularly useful for examining American literature(s) - an ambiguous term that I am deliberately using here to encompass not only Spanish-American literature and U.S. literature, but also U.S. Latino/Latina literature, a system combining the already multiple systems of both U.S. and Spanish-American literature. Even-Zohar's theory puts all the individual systems within a polysystem on an equal footing so that there is no hierarchical organization; rather, all the systems are organized around the notions of centre and periphery. ${ }^{5}$ This tenet allows for full consideration of the heterogeneous and multiple literatures of the U.S., which are sometimes abandoned in the peripheries of the stronger AngloAmerican literary system.

\section{The Spanish-American Boom}

In focussing on the Spanish-American influence on U.S. Latino literature, I shall centre my analysis on the literary boom of the 1960s and 1970s in Spanish America, which, it is important to point out, involved mainly the genre of the novel. For many novelists and critics, "la nueva novela" meant (rather pejoratively) commercial success, or bestsellerism. There resulted a plethora of definitions to describe this literary boom, and even recipes on how to write a boom novel. ${ }^{6}$ But more importantly, the Spanish-American literary boom gave rise to a translation boom and international diffusion for the writers. The fact that this literary boom generated such translation activity into various European languages was taken as a sign of the maturity of Latin American culture, a coming into its own, as it were. Thus Sara CastroKlarén and Héctor Campos (1986) wrote:

[E]ste fenómeno ha sido tomado como la prueba más eficaz de la madurez de la cultura latinoamericana. Se pensó, así, que la traducción en sí misma constituía el llamado "boom". La cultura latinoamericana habría pasado de ser una cultura de consumidores, consumidores de bienes intelectuales, a ser una cultura capaz de producir "civilización". Quiero decir que siendo leída en Europa, reseñada en L'Express o en la revista Times, había llegado a una paridad con la cultura metropolitana. (320)

[This phenomenon has been taken as the most effective proof of maturity of Latin American culture. Thus, it was thought that translation itself constituted the so-called "boom." From a consumer culture of intellectual goods, Latin American culture became a culture capable of producing "civilization." Being read in Europe and 
reviewed in L'Express and The Times meant parity with metropoli$\tan$ culture.]

In their opinion, translation into European languages, interviews of writers in metropolitan media and the new superstar status of some of the writers helped create the image of Latin American literature as a homogeneous product. They see the literary boom as a market phenomenon that involved only a few writers, and that was grossly misunderstood in the target systems into which the works were translated.

But, the Spanish-American literary boom meant more to the writers themselves. In the foreword to José Donoso's The Boom in Spanish American Literature: A Personal History, Ronald Christ writes: "During the 1960s in Latin America there appeared in different countries, and almost simultaneously, a number of novels and collections of short stories that by their virtuoso technique and style dazzled a large reading public that no one had ever guessed was there" (1977, viii). This statement stresses two very important points: the Pan-American nature of the boom, and the appearance of a large reading public unknown until then. As Christ points out, "This sudden flowering of writers like Carlos Fuentes, Julio Cortázar, and Mario Vargas Llosa won ever more attention because these same writers began, almost at once, to be translated into foreign languages, and to put Latin America on the international literary map for the first time" (viii). José Donoso himself indicated that in order to be recognized in their own countries, many Latin American writers first had to achieve success in Europe and the United States. The boom "conferred a unity where there may have been none, and a connotation more powerfully economic than esthetic" (Christ 1977, viii).

Inherent in the concept of the Spanish-American literary boom was the notion of internationalization, of movement beyond borders: geographical borders, because the boom implied movement beyond national boundaries into the rest of Latin America, Europe the U.S.; linguistic borders, because translation was a necessary and important factor in the internationalization process; narrative borders, because the new novel implied going beyond traditional narrative strategies and seeking "foster parents" outside the writers' own traditions, finally to coalesce into what Sarah Crichton calls "the hallmark of Latin American literature--'magical realism"” (1982, 27).

This movement beyond borders, made possible through the translation of Spanish-American works, effectively prepared the U.S. audience for the U.S. Latino literary boom. Literary reviews especially played a major role in this process because they create, feed and constantly reshape the U.S. construct of Spanish-American literature. ${ }^{7}$ In addition, a wide gamut of rewrites and refractions-in the form of translations, reviews, criticism, 
anthologies and films—over the last twenty years helped shorten the cultural distance between the U.S. and its geographically close, yet culturally distant, southern neighbours. As André Lefevere wrote, "the interaction of writing and rewriting is ultimately responsible, not just for the canonization of specific authors or specific works and the rejection of others, but also for the evolution of a given literature, since rewritings are often designed precisely to push a given literature in a certain direction" $(1984,219)$. So, what triggers what? What feeds what? Does a successful translation trigger more translations? Does a successful film version of his/her book boost a writer's popularity and open new markets for his/her work? Is it a good review in a prestigious newspaper that brings success to a particular author? The position of publishing houses as canon formers and important means of refractions cannot be overlooked. In fact, the manipulation of literature in such a way that only a few Spanish-American writers dominate the market has created a situation in which "the search for stars has obscured the firmament" (Tritten 1984, 36).

\section{García Márquez and Allende}

Thus, a canon of Spanish-American literature in translation started to be formed. While the boom can be considered a landmark in the history of this process, two important milestones certainly boosted it: the publication of Gabriel García Márquez's One Hundred Years of Solitude in 1970 and the awarding of the Nobel Prize for Literature to García Márquez in 1982. The universe opened up by Gregory Rabassa's excellent translation of García Márquez's novel had far-reaching consequences: it stirred interest in Latin American culture, and set the mould for this literature, so much so that writers who did not fit into the mould were excluded from commercial success. ${ }^{8}$ The popular success of García Márquez's novel fuelled interest in other Latin American writers, such as Carlos Fuentes and Mario Vargas Llosa, and promoted translation. As John Vinocur commented:

[García Márquez] has been widely regarded as a leading figure of the recent Latin American literary renaissance, which in the United States is reflected in the recent publication of books by [several Latin American writers]... But their books never approached the worldwide readership of One Hundred Years of Solitude, whose success opened publishing doors in foreign countries to many Latin American writers. $(1982, \mathrm{~A} 1)$

The status of translation in the host polysystem is crucial to an analysis of canonicity. As Even-Zohar observed:

One might of course find sporadic references to individual literary translations in various periods, but they are seldom incorporated into 
the historical account in any coherent way. As a consequence, one hardly gets an idea whatsoever of the function of translated literature for a literature as a whole or of its position within that literature. Moreover, there is no awareness of the possible existence of translated literature as a particular system. The prevailing concept is rather that of "translation" or just "translated works" treated on an individual basis. $(1990,45)$

In fact, the by-now classic One Hundred Years of Solitude illustrates EvenZohar's point. García Márquez's novel has been part of the U.S. literary polysystem for more than twenty years by now. Can we still consider it a work isolated from U.S. literature, with no imprint whatsoever on the polysystem in which it moves? Within the frame of Even-Zohar's theory, it would be reasonable to say that García Márquez's work interacts with the U.S. polysystem in various ways. But what has become canonized in the U.S. literary polysystem is his particular mode of narration, which has become the model associated with Latin American writing. In distinguishing between two different types of canonicity, "one referring to the level of texts, the other to the level of models," Even-Zohar calls the establishment of a literary model in a system "dynamic canonicity"9 $(1990,19)$. The new, revolutionary mode of narration-the model of which is embodied in García Márquez's One Hundred Years of Solitude - thus established itself as a "productive principle" in the U.S. polysystem, shaking up the dynamics of the existing system and proving to be very stimulating for the U.S. Latino novel as a genre. In the U.S., García Márquez's model has been used as the yardstick to compare and measure the work of other Spanish-American and Latino writers.

Reviews and critical articles of Spanish American writers began to appear in major U.S. magazines and newspapers. In her analysis of reviews of Latin American literature that appeared in various U.S. magazines between 1970 and 1984, Tritten reports:

the number of reviews during this period was surprising: approximately two to four reviews per year in the New York Review (each article frequently included several works); two in the New Yorker... Two to four reviews per year were published in Time. Newsweek printed the fewest with only one or two per year... $(1984,36)$

It truly was the literary "discovery" of a continent ignored until then, for these reviews undoubtedly had an impact on a large segment of the U.S. readership, since the various magazines cater to different audiences. Between 1982 and 1994, there appeared in the Book Review Digest 259 entries under the heading "Latin American Literature": 122 for the period 1982- 
$1989 ; 132$ for $1990-1994$. The year 1991 saw the most reviews. In many of the reviews, even if García Márquez is not the main subject, his style or mode of narration is evoked as a point of reference to introduce other works into the polysystem. One case in point is the review of Isabel Allende's $O f$ Love and Shadows (Kakutani, 1987, C27): "Ms Allende is not mostly imitation García Márquez. Happily, Ms Allende is no longer the novice... [She] skillfully evokes both the terrors of daily life under military rule and the subtler forms of resistance..." Allende is truly a child of the sixties/seventies boom. Fifteen years after the publication of One Hundred Years of Solitude, she made her entrance on the U.S. literary scene with The House of the Spirits, a piece in the same mould as the greatest hits of the Spanish-American literary boom, a piece that brought her stardom overnight. But, if it was anticipation of revisiting the García Márquez's model that lured readers to Allende's novel, they soon discovered her own powerful voice.

"Magical realism" became the ready-made formula used to label anything produced by America's "southern backyard": a pot of milk falling spontaneously off a table, a green-haired woman... Is this sheer misunderstanding on the part of the host culture or is it depletion of a model? Depletion effectuated not only by critics and reviewers, but also by writers themselves seeking to fit the canonized and commercially successful model. Magical realism is what publishers and readers look for in this literature; anything that strays from the model is marginalized to smaller, more academic publishing presses, and branded as not Latin American enough. García Márquez's literary production exemplifies this attitude: Of Love and Other Demons (1995) has all the ingredients readers have come to expect in a García Márquez novel..$^{10}$ Not surprisingly, the novel sold very well, as did almost all his work in translation, except The General in His Labyrinth, which, even though it revisits the same historical period (independence from Spain to early twentieth century), does not quite fit the canonized model he himself created. As Tim Padget writes: "The author's own grandness is less on display... The sensuous detail that enchants such work as Love in the Time of Cholera is too often reduced to tedious historical minutiae" $(1990,70)$.

\section{Modes of Translation}

The stronger the host polysystem, the more fluent the translations and refractions. In Lawrence Venuti's opinion, it is difficult for a translator of a cultural other within a strong monolingual polysystem to try to practice translation as a "locus of difference," in an effort to avoid "an imperialistic domestication of a cultural other" $(1992,13)$. And referring specifically to the U.S. polysystem, Carol Maier observed that there was such a preference 
among publishers for readability, that an author's style is many times sacrificed "in the name of a more appropriate version in English" (1990-1991, 20). Thomas di Giovanni's English translations of Jorge Luis Borges's work is an interesting example of how a writer's work can be sacrificed for the sake of readability and easier understanding. Matthew Howard relates the "intimate collaboration" between di Giovanni and Borges that would span over a period of four years:

Indeed di Giovanni's translations tended to proceed from one underlying principle: to make Borges's writing clearer and less ambiguous for North American readers. He therefore saw one of his main tasks as explaining obscure regional references and providing historical details that Borges had omitted in writing for Argentine readers. $(1997,72)$

He describes di Giovanni and Borges's method of translating, and suggests that Borges himself acted as censor, attempting to create "a mirror, rival 'Borges,' Borges as an English writer" (76). At work in these translations, therefore, is a domestication of the source text with the apparent consent of the author.

In Latin America "the essentially literary quality-literarity truly made manifest in certain works - ... is 'mulattoed' by other functions." And the reason for this, according to Roberto Fernández Retamar, is clear: "given the dependent, precarious nature of our historical existence, it has fallen to literature to assume functions that in the metropolises have been segregated out of it" $(1989,86) .{ }^{11}$ But, when Latin American works are moved to another polysystem, their instrumental nature, or "cultural difference," as Neil Larsen (1990) terms it, loses its immediacy and the works are decontextualized" : in the Latin American context, "local, historical circumstances ... have generated the possibility of a literature that overcomes the traditional modernism/realism duality by effectively being both modernist and realist at once" (52). The coinage of the term "real maravilloso" enabled Alejo Carpentier ${ }^{13}$ to define "América' $s$ " cultural difference at the crossroads of history and culture.

Cultural difference marks a clear, unmistakeable [sic] rift between the two worlds, whereas History, given its inherent universalizing concept, reduces difference, hence identity, to the point of disappearance... Here culture is, on the contrary, the point of entry into "a historical reality yet more real," which otherwise remains hidden from view. In proclaiming the cultural difference of "América" as the key to its historical identity, Carpentier, in effect, proclaims its modernity as both original and autonomous. (Larsen 1990, 54) 
This emphasis on culture as "a point of entry into a historical reality" is crucial to understanding the import of context - the specific social and historical bearings-when discussing the cultural production of Latin America. The social responsibility of the majority of Latin American writers is even present in the experimentation of the boom novels, and as Doris Sommer writes: "even where [Jean Franco] sees social irresponsibility, for example, in the experimental 'Boom' novels of the 1960s and 1970s, a different reading would discem the novelists' social criticism in the form of impatience with standard social-narrative projects gone sour" $(1988,113)$. Thus it can be said that the literature that lays the greatest claim to modernity is that produced by the so-called generación del boom:

Early attempts to trace the new Latin American literature to the influence of foreign models ... have, especially since the Cuban revolution, tended to be de-emphasized in a more consciously nationalist or regionalist impetus to set forth the uniquely local sources of a literature that, if it does betray the superficial traits of outside influence, transforms the foreign element into a radical original compound. It is this complex, synthetic originality that, as this general line of thinking goes, lays proper claim to a modernity that would otherwise-if allowed to retain its privileged but alien metropolitan exemplarity-fall victim to its own intolerable unmodernity as a repetition. (Larsen 1990, 50)

Larsen seems to prefers this "regionalist and autonomizing" construct because it avoids distortion by "the worst kind of mechanical, colonizing pseudoclassification" (50). In his opinion, the most systematic and critical elaboration of this issue is provided by Angel Rama's concept of transculturation, which Larsen describes as:

A category of narrative composition and analysis [which] proposes that the Latin American narrative text ... avoids the double bind in which one either settles for a direct imitation of metropolitan imports or seeks to expunge all "foreign" cultural differences. Instead, the narrative text must treat the local or regional culture itself as a species of language or code, with which to, as it were, speak or rearticulate or, in this sense, "transculturate" the exotic cultural dominant. (1991, xiii)

The "transcultural" and the "anthropophagous" are "two alternative paradigms of postcolonial oppositional culture" (xiii), which offer ways to cannibalize foreign models. Spanish-American literature is a transculturated, hybrid product, the synthetic operation of different referential codes, a contact zone for contending cultures. Thus, when moved to an alien polysystem, it is the code more familiar to the host polysystem that reviewers will 
emphasize. They will also tend to use stereotypes as the first step in learning about, and as a way of domesticating, the foreign product. ${ }^{14}$ In the case of Spanish-American literature, "magical realism" became the stereotype by which to define a "peculiar reality," one that is "magical and exotic."

To combat decontextualization, some "North American critics of Latin American literature must realize that to continue to stress the 'magical' ... is to deny the larger, broader understanding of reality that informs these texts" (Hicks 1991, xxvii). Hicks proposes a different metaphor that surpasses the binary opposition magical/real, that of "border writing": "Border writing emphasizes the differences in references codes between two or more cultures. It depicts a kind of realism that approaches the experience of border crossers, those who live in a bilingual, bicultural, biconceptual reality" (xxv). In the context of the Spanish-American literary boom, these border crossers were called "transculturators" (by Ángel Rama), writers who transformed the influence of foreign elements into a radically original compound, into a "border text," as Hicks defines it. Once Spanish-American literature is seen as having taken root in the U.S., the meaning of terms to express cultural traffic, such as transculturation and cannibalization, radically change. The questions raised are: Who cannibalizes whom? ${ }^{15}$ How is cultural traffic constructed? How is the new territory charted?

\section{The Latino Boom}

The U.S. Latino literary boom gives visibility to a social group that maintains its shifting cultural borders within a "lived reality of colonial social conditions" and unequal power relations. Groups transculturate; new elements are added, contents may change, but boundaries still exist to preserve a group from being melted into the "multicultural pot," "euphemism for the imperializing and now defunct "melting pot" (Anzaldúa qtd. in Spitta 1995, 196).

How can we trace the history of this Latino literary boom, taking into account its colonial condition?16 There are two forces at work: assimilation and resistance. And the Latino literary boom can be read in two ways: as a shift from magical realism to the reality of the barrio, the birth of "the up and coming" intellectual proclaiming the Latinization of the U.S., relishing a newly constructed Latino identity, trying to make it from the periphery to the centre of the polysystem; or as the commodification of a fashionable ethnicity, the birth of the "domesticated Latino"-a homogenized group where all Latinos are alike and interchangeable-who can provide "enlightenment without irritation, entertainment without confrontation" (Gómez Peña 1993, 51). The Latino boom bears such a striking resemblance to the Spanish-American boom in the U.S. that it could be considered a child of 
the latter. The emergence of Spanish-American writers on the U.S. scene prepared the stage for the discovery of local Latino writers. And indeed, the exotization of Spanish America reverberates in the works of U.S. Latino writers; the mainstream readership had already framed these writers within a certain stereotype and expected them to write within the boundaries of magical realism. As for translation activity, Stavans ${ }^{17}$ points out that after the Latino boom, the demand for translations of Spanish-American works diminished because the magical realism quota was now being filled by Latino writers.

Like the writers of the Spanish-American boom who sought fathers outside their own literary polysystems, U.S. Latino writers seek validation for their models outside the U.S. literary polysystem, in their Spanish-American forefathers, in their "descent roots." In Dreaming in Cuban, Cuban American writer Cristina García relates the Cuban revolution and exile through the story of the Del Pino family. In her review of the novel, Thulani Davis stated: "[i]t is perhaps [the] ordinary magic in Ms García's novel and her characters' sense of their own lyricism that make her work welcome as the latest sign that American literature has its own hybrid offspring of the Latin American school."18 Chicana writer Ana Castillo dedicates her Mixquiahuala Letters to Julio Cortázar, "the master of the game." And indeed, the multiple readings that her novel offers point back to Cortázar's Hopscotch. In How the García Girls Lost Their Accent, Julia Álvarez exploits the family saga genre to recount the story of the García family under the dictatorship of Trujillo in the Dominican Republic, and their subsequent immigration to the United States. Puerto Rican writer Rosario Ferré, writing in English, offers The House on the Lagoon, which follows the history of the island through the saga of a prominent Puerto Rican family "in the manner of Gabriel García Márquez" (front cover comment). The elements of magical realism in these works attest to the adoption of a model that is still working for U.S. Latino writers. Critics claim these texts as belonging to both American and Latin American literatures. ${ }^{19}$

But if the sixties/seventies Spanish-American literary boom was an exclusively male phenomenon, the situation today is completely different. Interest is mainly centred on Latina and Spanish-American women writers; many anthologies of their work have come to light over the last years, as has a large amount of scholarly criticism. In the introduction to a recent anthology of women writers, Susan Bassnett (1990) laments the omission of many superb writers and adds: "We console ourselves with the thought that perhaps the very scale of omissions will lead to further books, to more translations, to new editions and re-publications of neglected materials..." (7). And, this is certainly happening. The large number of anthologies of women writings over the recent years shows that the long silence is finally over. We 
are witnessing a female boom. Spanish-American and U.S. Latina-for many anthologies place both groups in the same volume, thus blurring the boundaries between them-women's voices are surpassing those of their male counterparts. The success of the sixties/seventies boom novels in the U.S. also gave rise to the emergence of other Latin American masterpieces in the U.S. polysystem, such as the work of Emesto Sábato, whose novel Sobre héroes y tumbas was not published in English translation in the U.S. until 1981 - twenty years after its publication in Spanish.

The publication of Latino works by major U.S. publishing houses such as Vintage, Harper and Alfred Knopf attests to the mainstream success of some writers, and the push toward the centre of the U.S. polysystem. Traditionally, Latino and Spanish-American writers were handled by smaller publishing houses such as Curbstone, Bilingual Press and Ediciones del Norte, or by university presses. ${ }^{20}$ The move from a small press to a major U.S. publishing house is therefore an indication of success. One case in point is Ana Castillo's first novel, The Mixquiahuala Letters, which was originally published by Bilingual Press in 1986, but which has recently been republished by Doubleday. This means more visibility and wider distribution in major bookstores, such as Barnes and Noble.

Translation becomes an important issue again when we consider that U.S. Latino writers who write in English are now being translated and published in Spanish in the United States. Moreover, classics of the boom generation are being relaunched (in Spanish) by divisions of major U.S. publishing houses, such as Harper Libros and Vintage en español, to meet the demands of a growing Spanish-speaking audience at home and south of the border. Puerto Rican writer Esmeralda Santiago wrote her first novel, When I Was Puerto Rican, in English, and later translated it herself into Spanish. Elena Poniatowska, a prestigious Mexican writer, translated Sandra Cisneros's English-language work into Spanish, in order to bring the Chicano writer into the Mexican polysystem, which has always cast a suspicious look at literature produced by Mexicans on the other side of the border. Could this trend mean an unofficial institutionalization of Spanish as the de facto second language of the United States?

Indeed, translation has become a highly significant activity and practice. But, in the case of Latino writers, the notion of translation needs radical redefinition: the rigid dichotomies target language/source language, original text/translated text seem quite inadequate in this hybridized context. In the introduction to the Spanish version of her novel When I Was Puerto Rican, Esmeralda Santiago explains:

When I write in English I have to translate from Spanish, the keeper of my memories; when I speak in Spanish, I have to translate from 
the English that defines my present. And when I write in Spanish, I find myself in the midst of three languages, the Spanish of my childhood, the English of my adulthood, and the Spanglish that constantly crosses over from one world to the other, just as we crossed from our neighborhood in Puerto Rico to the "barriadas" in Brooklyn. (xvii)

Translation is a way of life, a strategy for survival in the North. Some writers choose to write in English because it puts them in a better position to move from the periphery to the centre, and it offers access to a larger audience. In this case, Spanish becomes a touchstone, the locus of difference, the site of political and poetic imagination. Other writers have no choice in the matter: English was the language of schooling, and is therefore the language of writing; Spanish belongs to the private and more personal domain. However, sometimes the boundaries between English and Spanish no longer exist; a hybrid language is forged (as Esmeralda Santiago's "Spanglish") and attempts to use either English or Spanish exclusively create a feeling of being lost in translation.

\section{Spanish-American Versus Latino Writing}

The cultural difference between U.S. Latino and Spanish-American writings sometimes needs to be explained. Since culture is read differently by different audiences, cultural elements in these writings must be translated for certain audiences, and many Latino writers give a translation of the Spanish used in their texts, either weaving it into the fabric of the text or including a glossary. Silvia Spitta refers to this strategy as the "radical heterogeneity of those narratives," in terms of "the intercultural and transcultural dynamics of Latin American narratives" $(1995,198)$. Indeed, the stories move constantly between different cultural spaces that shape identities. There is a tension between deterritorialization and reterritorialization, and thus the risk of depoliticization of borders. But the stronghold of roots and tradition that comes across in these texts indicates that the majority of Latino writers are politically committed to their communities. In Castillo's The Mixquiahuala Letters, for example, Tere, the protagonist and writer of the letters, travels and translates back and forth between Mexico and the U.S., English and Spanish, Chicano traditions and her U.S. Latina self, as she negotiates her border identity.

At the core of many Latino writings is the tension to preserve that locus of difference- a difference that is sometimes erased in reading, depending on the audience - and thereby resist acculturation. On the other hand, there is also the need for consent, for visibility, for dialogue with the other component of their hyphenated identities - the stronger Anglo 
America-without being crushed by the imbalance of power. And, at the same time, there is the need to preserve the specificities of their own individual cultures (for Cuban culture is not the same as Chicano, Dominican is not the same as Puerto Rican). Preserving specificities is a way of avoiding depoliticization, and at the same time, it enables the writers to surpass the boundaries of stereotyping and the homogenizing labels that freeze groups into "emerging voices" or "exotic minorities," as Guillermo Gómez Peña says.

Interest in Latin America ${ }^{21}$ has manifested itself in the proliferation of Latin American Studies programs throughout the U.S., programs that also include Latina (women) studies. The large critical output from these programs is such that some critics talk about "Latinoamericanism," which Enrico M. Santi compares to "Orientalism":

Like Orientalism, then, Latinoamericanism would identify the corporate institution that frames both a systematic discipline ... and the whole network of political, economic, and imaginary interests that underlie that discipline. To focus on the status of each as discourses would actually mean to deal principally with their own internal consistencies, not with their supposed correspondence with given cultural or geographical realities. $(1992,90)$

The critical output from these programs is mainly produced in English, and in many cases does not take into account critical work produced over the years in Spanish, in Latin America. The fact that much of Latin American criticism in Spanish is only recently being translated accounts for its late incorporation into critical writing in U.S. academia. This lag allows, however, for late "discoveries," a fact that Fredric Jameson (1989) draws attention to in his foreword to the English translation of Roberto Fernández Retamar's essays.

The main goal of this paper was to discuss the cultural traffic in the Americas, and show how it affects the U.S. literary polysystem. I have been reluctant to frame this discussion within the concept of postcolonialism, which, in my opinion, mainly refers to the East-West cultural traffic. Here, in the Americas, there is rather a North-South traffic which has succeeded colonialism (by the Spanish) to a form of neocolonialism (by the U.S.), a more pervasive, yet more subtle phenomenon. The heavy cultural traffic in the Americas is constructed on a North-South/South-North plane. SpanishAmerican intellectuals, since their countries' independence from Spain (in the early nineteenth century, for the most part), have been trying to imagine and write their national states in relation-sometimes in opposition, at other times in apposition - to the northern giant, the United States. This trend can be observed not only in Domingo Sarmiento's conception of civilización y 
barbarie and José Martí's nuestra América, but also in Gloria Anzaldúa's Borderlands/La Frontera.

Translation is an important cultural vehicle in the Americas, a means of making it north along the Pan-American highway. This northbound cultural traffic is accompanied by successive waves of migration, especially from Central America and the Caribbean. These traslados opened the way for the recognition of the large Latino presence in the U.S., a force which is now expanding, within the U.S. borders, its own national borders in an attempt to rethink their "imagined communities." This cannibalization of the geographical borders of the U.S. forces us to rethink, from within these same geographical borders, the appropriation of (the concept of) America. America must be redefined so as not to reflect another appropriation from an imperial centre, but rather to consciously encompass the totality of the Americas.

\section{Notes}

1. Suzanne Oboler (1995), xvi-xvii, explores the implications of ethnic labels, which she calls "social constructions," as both "strategic and referential."

2. Translation has become a favourite metaphor among Latino intellectuals and writers. Stavans and Pérez Firmat talk about the Latino as an individual "lost in translation." The concept of translation is deployed by many writers as they search for a mode of expression to transmit their bilingual experience, so much so that the boundaries between source and target language have become highly contested ground.

3. The concepts put forward in Sherry Simon's exploration of the ways in which "translation embodies paradigms of cultural difference" (1992), 160, are extremely helpful to our exploration of the import of translation in the context of U.S. Latino literature.

4. See Stavans (1995b), 32, who raises the question "What happens when Latinos are seen as a Hispanic American branch reaching beyond the spiritual and geographical limits of a U.S. minority?"' Oboler (1995), 159, stresses the need to recognize and study the "cultural, linguistic and historical ties to various nations in Latin America," as well as to research and study the "histories, cultures and experiences that have shaped the various and multiple meanings and social values of being Latinos and Latinas in the U.S."

5. In a way, this organization can be seen as hierarchical in that the stronger system(s) are always as the centre of the polysystem, setting the boundaries of what is peripheral in relation to them.

6. See R. Avilez Fábila, "Cómo escribir una novela y convertirla en bestseller," Mundo Nuevo (Oct. 1970): 41-52.

7. Susan Tritten (1984) and Carol Maier (1990-1991) both comment on the implications of reviews of Latin American literature in the United States.

8. It seems to me that the characteristics attributed by critics to the Spanish-American literary boom-bestsellerism, homogenization, exclusion of writers-are reinforced when the works are translated and reviewed in an alien polysystem. 
9. Even-Zohar (1990), 19, refers to the establishment of a specific text in a literary canon as "static canonicity."

10. See Stavans (1995c), 149-71, for a reassessment of Gabriel García Márquez's imprint in the literary world.

11. See also Riding (1983) for a discussion of the role of Latin American intellectuals.

12. Gustavo Pellon (1992), 82, warns against socio-historical decontextualization "that is brought to bear on a literary corpus such as that of Latin America, which one could argue is consciously defined by its problematic discourse with its society and history."

13. See "De lo real maravilloso" in Carpentier (1964).

14. Partha Mitter (1987) discusses the role of stereotypes in understanding alien cultures.

15. The terms cannibalization and domestication are used to express a two-way cultural traffic. Both concepts presuppose a power relation. Whereas cannibalization is taken as a strategy of resistance, domestication implies colonization. Both terms, however, point to the same direction. The question is when and how does cannibalization become domestication, and vice versa.

16. I am reluctant to use the term postcolonial here. In an essay contextualizing the use of the term postcoloniality, Ruth Frankenberg and Lata Mani (1996), 274, propose: "the particular relation of past territorial domination and current racial composition that is discernible in Britain, and that lends a particular meaning to the term 'postcolonial' does not, we feel, obtain [in the U.S. context]." They suggest using the term " "postCivil Rights' broadly, to refer to the impact of struggles by African American, American Indian, La Raza, and Asian American communities that stretched from the mid1950 's to the 1970's," 274.

17. In a conversation at Amherst College, October 1995.

18. Gladys M. Varona-Lacey (1994), 126, in her review of the Spanish version, Soñar en cubano, writes: "En Soñar en cubano Cristina Garcia ofrece descripciones que lindan con el surrealismo y el realismo mágico" [In Soñar en cubano Cristina García offers descriptions that verge on surrealism and magical realism].

19. For example, Stavans (1995b), 19, questions: "Is Oscar Hijuelos possible without José Lezama Lima and Guillermo Cabrera Infante? Or is he only a child of Donald Barthelme and Susan Sontag?"

20. The University of Texas at Austin is very active in this field.

21. By the 1960s, U.S. interest in Latin America had become part of the Zeitgeist. If the U.S. looked upon Latin America as its "backyard," the Cuban revolution in 1959 dealt a blow to the neighbourhood. It fuelled strategies and policies to prevent the spread of Communism in America, such as international development programs (IDPs), the Peace Corps, the Alliance for Progress, military threat and/or military intervention. IDPs included financing Latin American studies which would cover a wide range of activities, including the translation and diffusion of authors from and topics on Latin America. This was reinforcement of the Cold War without being overtly political. 


\section{Works Cited}

\section{Theory and Criticism}

ANZALDÚA, Gloria. 1987. Borderlands/La Frontera: The New Mestiza. San Francisco: Aunt Lute Books.

BASSNETT, Susan. 1990. Introduction to Knives \& Angels, ed. Susan Bassnett. London: Zed Books.

CARPENTIER, Alejo. 1964. Tientos y diferencias. Mexico: U Nacional Autónoma de México.

CASTRO-KLARÉN, Sara, and Héctor CAMPOS. 1986. "Traducciones, tirajes ventas y estrellas: El boom." Ideologies and Literatures 4, no. 17: 319-38.

CHRIST, Ronald. 1977. Foreword to The Boom in Spanish American Literature: A Personal History, by José Donoso. New York: Columbia UP.

CRICHTON, Sarah. 1982. "El boom de la novela latinoamericana." Publishers Weekly (Dec. 24): 29-33.

DAVIS, Thulani. 1992. Rev. of Dreaming in Cuban, by Cristina García. The New York Times (May 17).

DONOSO, José. 1977. The Boom in Spanish American Literature: A Personal History. New York: Columbia UP.

EVEN-ZOHAR, Itamar. 1990. "Polysystem Studies." Poetics Today 11, no. 1, Special Issue.

FERNÁNDEZ RETAMAR, Roberto. 1973. Calibán. Apuntes sobre la cultura de nuestra América. Buenos Aires: Editorial La Pléyade. nesota $P$.

1989. Caliban and Other Essays. Trans. Edward Baker. Minneapolis: U of Min-

FLORES, Juan. 1996. "Puerto Rican and Latino Cultures at the Crossroads." In Latinos in New York: Communities in Transition, ed. Gabriel Haslip-Viera and Sherrie L. Bauer. Indiana: U of Notre Dame P.

FRANKENBERG, Ruth, and Lata MANI. 1996. "Crosscurrents, Crosstalk: Race, 'Postcoloniality,' and the Politics of Location." In Displacement, Diaspora, and Geographies of Identity, ed. Smadar Lavie and Ted Swedenburg, 273-93. Durham: Duke UP.

GÓMEZ PEÑA, Guillermo. 1993. Warrior for Gringostroika. Saint Paul: Graywolf Press.

HICKS, Emily. 1991. Border Writing. The Multidimensional Text. Theory and History of Literature 80. Minneapolis: $U$ of Minnesota P.

HOWARD, Matthew. 1997. "Stranger than Ficción." Linguafranca (June-July): 71-78.

JAMESON, Fredric. 1989. Foreword to Caliban and Other Essays, by Roberto Fernández Retamar, trans. Edward Baker. Minneapolis: U of Minnesota P. 
KAKUTANI, Michiko. 1987. New York Times (May 20): C27.

LARSEN, Neil. 1990. Modernism and Hegemony: A Materialist Critique of Aesthetic Agencies. Theory and History of Literature 71. Minneapolis: $\mathrm{U}$ of Minnesota P.

1991. Foreword to Border Writing: The Multidimensional Text, by Emily Hicks, xi-xx. Minneapolis: $U$ of Minnesota P.

LEFEVERE, André. 1984. "Why Waste Our Time on Rewrites? The Trouble with Interpretation and the Role of Rewriting in an Alternative Paradigm." In The Manipulation of Literature, ed. Theo Hermans, 215-43. New York: St Martin's P.

MAIER, Carol. 1990-1991. "Rewriting Latin American Literature in Translation: Time to 'Proceed to the Larger Question." Translation Review 34-35: 18-24.

MITTER, Partha. 1987. "Can We Ever Understand Alien Cultures? Some Epistemological Concerns Relating to the Perception and Understanding of the Other." Comparative Criticism 9: 7-14.

OBOLER, Suzanne. 1995. Ethnic Labels, Latino Lives: Identity and the Politics of (Re)Presentation in the United States. Minneapolis: U of Minnesota P.

PADGET, Tim. 1990. Rev. of The General in His Labyrinth, by Gabriel García Márquez. Newsweek (Oct. 8).

PELLÓN, Gustavo. 1992. "The Canon, the Boom, and Literary Theory." Latin American Literary Review 20, no. 40: 80-82.

PÉREZ FIRMAT, Gustavo. 1994. Life on the Hyphen: The Cuban-American Way. Austin: $\mathrm{U}$ of Texas $\mathrm{P}$.

RAMA, Ángel. 1982. Transculturación Narrativa en América Latina. México D.F.: Siglo XXI Editores.

RIDING, Alan. 1983. "Revolution and the Intellectual." The New York Times (Mar. 13): 6-28.

SANTI, Enrico M. 1992. "Latinamericanism and Restitution." Latin American Literary Review 20, no. 40: 89-96.

SIMON, Sherry. 1992. "The Language of Cultural Difference: Figures of Alterity in Canadian Translation." In Rethinking Translation: Discourse, Subjectivity, Ideology, ed. Lawrence Venuti, 159-76. London/New York: Routledge.

SOLLORS, Werner. 1986. Beyond Ethnicity. New York: Oxford UP.

SOMMER, Doris. 1988. "Not Just a Personal Story: Women's Testimonios and the Plural Self." In Life/Lines: Theorizing Women's Autobiography, ed. Bella Bozki and Celeste Schenk, 107-30. Ithaca: Cornell UP.

SPITTA, Silvia. 1995. Between Two Waters: Narratives of Transculturation in LatinAmerica, 159-76. Houston: Rice UP.

STAVANS, Ilán. 1993. "Lust in Translation: Notas sobre el boom narrativo hispániconorteamericano." Revista Hispánica Moderna 46, no. 2: 384-93. A31.

1995a. "American Lit Takes a Spanish Accent." Boston Sunday Globe (Jan. 8):

1995b. The Hispanic Condition: Reflections of Culture and Identity in America. New York: HarperCollins Publishers. 

149-71.

1995c. "The Master of Aracataca." Michigan Quarterly Review 24, no. 2:

TRITTEN, Susan. 1984. "Reviews of Latin American Literature in United States Magazines: Aid or Impediment to Understanding?" World Literature Today 58, no. 1: 36-39.

VARONA-LACEY, Gladys M. 1994. Rev. of Soñar en cubano, by Cristina García, trans. Marisol Palés-Castro. Hispamérica 23, no. 68: 125-26.

VENUTI, Lawrence. 1992. Introduction. Rethinking Translation: Discourse, Subjectivity, Ideology, ed. Lawrence Venuti, 1-17. London/New York: Routledge.

VINOCUR, John. 1982. "García Márquez of Colombia Wins Nobel Literature Prize." The New York Times (Oct. 22): A1, A31.

WEST, Paul. 1985. Rev. of The House of the Spirits, by Isabel Allende, trans. Magda Bogin. The Nation (July 20).

\section{Novels}

ALLENDE, Isabel. 1982. La casa de los espíritus. Barcelona: Plaza and Janes. 1985. The House of the Spirits. Trans. Magda Bogin. New York: A.A. Knopf.

1984. De amor y de sombras. Barcelona: Plaza and Janes.

Knopf.

1987. Of Love and Shadows. Trans. Margaret Sayers Peden. New York: A.A.

ÁLVAREZ, Julia. 1991. How the Garcia Girls Lost Their Accent. Chapel Hill: Algonquin Books.

CASTILLO, Ana. 1992. The Mixquiahuala Letters. New York: Anchor Books.

CISNEROS, Sandra. 1986. The House on Mango Street. Houston: Arte Público P. Books. 1994. La casa en Mango Street. Trans. Elena Poniatowska. New York: Vintage

FERRÉ, Rosario. 1996. The House on the Lagoon. New York: Plume/Penguin.

GARCÍA, Cristina. 1992. Dreaming in Cuban. New York: Ballantine Books. 1994. Soñar en cubano. Trans. Marisol Peles Matos. Madrid: Espase-Calpe.

GARCÍA MÁRQUEZ, Gabriel. 1967. Cien años de soledad. Buenos Aires: Editorial Sudamericana. \& Row. 1970. One Hundred Years of Solitude. Trans. Gregory Rabassa. New York: Harper 1989. El general en su laberinto. Buenos Aires: Editorial Sudamericana.

. 1990. The General in His Labyrinth. Trans. Edith Grossman. New York: A.A. Knopf.

1994. Del amor y otros demonios. Barcelona: Mondadori. Knopf.

1995. Of Love and Other Demons. Trans. Edith Grossman. New York: A.A. 
SÁBATO, Ernesto. 1961. Sobre héroes y tumbas. Buenos Aires: Fabril Editores. 1981. On Heroes and Tombs. Trans. Helen R. Lane. Boston: Godine.

SANTIAGO, Esmeralda. 1993. When I Was Puerto Rican. Reading, Mass.: Addison-Wesley. 1994. Cuando era puertorriqueña. New York: Vintage Books. 


\title{
FROM OTHER TONGUE TO MOTHER TONGUE IN THE DRAMA OF QUEBEC AND CANADA'
}

\author{
Louise Ladouceur \\ University of Alberta, Faculté St-Jean (Canada)
}

This article aligns itself along the postcolonial trajectory because the phenomena discussed here originate in the power struggle that exists in translation in an officially bilingual country between two languages of unequal status, the legacy of European colonial wars. It is from this angle that sense can be made of many asymmetries noted in the comparison of dramatic texts that English Canada and French Quebec have borrowed from each other by means of translation. These asymmetries can be found not only in the quantity of plays exchanged, but also in the strategies employed to translate a work which is written originally in the other official language and expected to represent this other culture in a context where the notion of bilingualism is fraught with an increasing number of problems.

A French colony ceded to Great Britain in 1763 , New France would remain part of British North America until the Constitution Act of 1867 united Upper and Lower Canada with Nova Scotia and New Brunswick to form Canada, a federation to which other provinces would gradually be added. The Canadian federation adopted a policy of institutional bilingualism that would know a lively history - too long to be recounted herecentred upon the encounter of two languages of unequal power: on one hand, a triumphant English which would become the language of the majority, a language sure of itself, destined to become a worldwide lingua 
franca; on the other, French, a minority language that had to be protected by the institution of laws and decrees, a language into which would be translated vast quantities of governmental documents first produced in English.

According to Ben-Zion Shek (1977), from the first days of British rule this diglossia would symbolize the problem between Canada and Quebec:

Les documents clés de l'histoire du Canada, tels la Proclamation royale de 1763, l'Acte de Québec, l'Acte constitutionnel, le rapport Durham, l'Acte de l'Union, l'Acte de l'Amérique du Nord britannique, le Statut de Westminster, ainsi que les textes des deux référendums sur la conscription, ont été rédigés d'abord en anglais puis traduits en français... La traduction à sens unique a reproduit les rapports réels dominants-dominés de la conjoncture militaire, en premier lieu, puis et par conséquent, politique et économique. (111)

[The key documents in Canadian history, such as the Royal Proclamation of 1763, the Quebec Act, the Constitution Act, the Durham Report, the Act of Union, the British North America Act, the Statute of Westminster, as well as the laws regulating the two referenda on conscription were originally produced in English then translated into French... This unidirectional process of translation reproduced the actual "dominant-dominated" relationship initially reflecting the situation militarily, and consequently, economically and politically as well.]

The monumental task of translation inherent to bilingualism thus embodies the clear hierarchical superiority of English vis-à-vis French - a state of affairs which would profoundly condition the translational behaviour of each group. In such a context, it is understandable that literary translation would be more actively practised among Anglophones, a group whose language remained unthreatened, and who could borrow without risking acculturation. It was quite a different story for Francophones, who were already required to translate a multitude of non-literary documents, and for whom the borrowing of a literary work was perceived "à la fois comme une menace et comme une perte d'efforts dans une entreprise marginale, du point de vue de la lutte pour la survie d'une langue et d'une culture minoritaires [both as a danger and a waste of energy in a marginal undertaking, from the point of view of the struggle for survival of a minority language and culture)" (Shek 1977, 112). In this analysis of theatre translation circulating between Canada and Quebec from the end of the 1960s up until 1994 , the study of themes or aesthetics of drama will be set aside in order to concentrate on representations of linguistic alterity proposed by each repertoire. 


\section{Unequal Exchange}

Though there were already a few plays from Quebec translated into English, it was the English production of Gratien Gélinas's Tit-Coq at Toronto's Royal Alexandra Theatre in 1951 that actually inaugurated the era of active theatrical exchange, by means of translation, between English Canada and French Quebec. Statistics compiled for my doctoral research (Ladouceur 1997b) show that, from 1951 to 1994, 101 plays from Quebec were produced or published in English translation in Canada. Ten of these plays were translated before 1970, thirty-six during the 1970s, thirty-five more during the 1980s and another twenty between 1990 and $1994 .^{2}$ As for English-Canadian plays produced or published in translation in Quebec, there was one in 1969 , six during the 1970 s, twenty during the 1980 s and twelve more between 1990 and 1994. This statistical profile indicates a 101 to 39 ratio in the respective borrowing by each repertoire, and an interval of eighteen years before Quebec reciprocated with publications or productions of translated plays. One does however note a breakthrough for English-Canadian drama in Quebec theatres beginning in 1990.

This asymmetry is due in part to the specific development of each system. In 1968, Quebec drama underwent a prodigious expansion when the theatrical institution questioned the dominant French model and promoted the use of a local vernacular on the stage, as demonstrated by Annie Brisset in her study of parodies, adaptations and translations of foreign plays in Quebec between 1968 and 1988: "Dans le secteur de la dramaturgie, c'est la langue qui va remplir la fonction distinctive nécessaire à l'émergence institutionnelle de la production québécoise [In the dramatic sector, it is language that will serve the distinctive function necessary for the institutional emergence of the Québécois production]" $(1990,273)$. In the relatively compact and socially cohesive context of French Quebec, theatre enjoyed great public favour as it displayed the specificity of the language spoken locally, a language that primarily distinguishes itself from the French model by its oral characteristics. Theatre consequently acquired a privileged status within the arts, where it permitted the affirmation of a Quebec identity freed from its ties to France and distinct in its language. This era also marked the beginning of an intense period of translation inasmuch as foreign plays would henceforth need to be presented in a local idiom, initially represented by joual, an accentuated vernacular which would later be integrated into a more varied regional language currently referred to as "Québécois."

In contrast, English Canada is spread out over a large territory and divided into regions more or less removed from one another, and often with little in common. Occupied with managing the multiple regional identities 
of what is commonly referred to as a multicultural "mosaic," English Canada was also questioning its attachment to a colonial past. In 1970, it began to seek a voice among the poor and sparsely attended alternative theatres that sprang up on the periphery of government-funded regional theatres which were more attuned to the established British and American repertoires:

Canadian plays were relegated to small, low-budget theatres that lacked the financial and technical resources available to the heavily subsidized festivals and regionals. While non-Canadian works had access to lush productions, large casts and relatively highly paid actors, Canadian plays were doomed to what George Ryga called "beggars theatre." (Wasserman 1986, 18)

With limited resources, the alternative movement dedicated itself to the promotion of an indigenous Canadian drama through the examination of Canadian history, culture and institutions, and the exploration of themes related to various Canadian realities (see Usmiani 1983 and Johnston 1991). In this instance, translation offered several advantages to the growing alternative companies, one of which was to produce a play that had already proven successful. With the dynamic state of its theatrical production, Quebec had a great deal to offer a Canadian theatre repertoire still unsure of itself.

\section{Divergent Attitudes Toward Translation}

The asymmetry in the number of plays translated on each side also underlines a divergence in the attitude taken toward translation, a divergence attributable to the unequal status of Canada's official languages. Quebec resisted borrowing literary texts from a partner from whom it was already obliged to translate volumes of documents more pragmatic in nature. Moreover, when it came to drama, the temptation if anything, was to borrow from the prestigious stages of London and New York. ${ }^{3}$ English Canada, on the other hand, armed with a hierarchically superior language spoken by the majority, did not hesitate to enlarge its own repertoire by borrowing a successful theatrical model from Quebec, which it would readily qualify as Canadian. In her study of the reception of translated Quebec theatre in Toronto up until 1988, Jane Koustas comments on the Canadian popularity of famous Quebec playwright Michel Tremblay:

Although the success of this distinctly Quebec nationalist playwright might initially suggest an openness to the "Other," reviews thus indicate that he triumphed as a Canadian, not Quebec, playwright due primarily to the universality, not québécitude, of his plays. $(1995,93)$

This divergence in attitude toward translation is highlighted by the dominant metaphors each side calls upon in the discourse pertaining to trans- 
lation. English Canada extols the meeting of the two cultures by means of an activity repeatedly referred to as a "bridge." As Kathy Mezei observed, "Since the 1950s, particularly in the context of the Quiet Revolution, the 1970 October Crisis, and the rise of the Parti québécois, English-Canadian translators have proclaimed a political mission to 'bridge' the two solitudes" $(1994,88) .{ }^{4}$ In use until the middle of the 1980s, the metaphor of the bridge joining the "two solitudes"- another emblematic representation of the relationship between Canada and Quebec - was a unifying symbol designating an activity that saw itself as neutrally friendly, motivated simply by a curiosity for the other culture.

However, in the other solitude, Quebec, the harmful effects of the abundant and obligatory translation that turned the people of Quebec into "un peuple de traducteurs" are deplored. ${ }^{5}$ According to Sherry Simon, this aversion revolves "non pas autour des sujets d'ordre culturel, mais sur des questions proprement linguistiques [not around subjects of a cultural nature, but rather on strictly linguistic questions]" $(1989,50)$. In fact, the cultural difference between "the two founding peoples" of Canada rests above all in the language (see Simon 1992, 159). A principal indicator of cultural difference, language becomes a primary symbol of identity. In such a context, translation can only be viewed with great suspicion by Francophones. This suspicion is such that when, in 1975, Jacques Brault proposed that his "langue propre," his mother tongue, could benefit from a regenerative "detour" through the language of the other, he hastened to name this positive vision of the translative process, rare in Quebec, "nontraduction" (nontranslation) (1975, 15-34). Therefore, only in denying its own action can the act of translation take on a positive value and present itself as a constructive activity. Commenting on his translation of English-Canadian poems, Brault wrote: "Une langue qui se refuse à pareille épreuve est d'ores et déjà condamnée. Morte [A language that refuses to face such a challenge is already condemned. Dead]" (15). It is, thus, an inversion of the usual argument contending that translation could be detrimental to the target language by exposing it to the influence of the source language. However, he added: “Nous n'aimons ni traduire ni être traduits. Et nous n'avons pas toujours et pas tout à fait tort. Les clefs de la traduction appartiennent aux puissants. S'il n'y a pas de langue mondiale, il y a des langues colonisatrices [We don't like to translate nor be translated. And we are not always nor completely wrong. The final word on a translation belongs to those in power. If there is no universal language, there are colonizing languages]" (16).

In Canada, inasmuch as power struggles are intimately connected to linguistic duality, translation and its accompanying discourse cannot avoid political ramifications. As Larry Shouldice notes: "Literary translation is political because language is political, and it is particularly political 
because the relationship of English to French in this part of the world is particularly political" $(1983,77)$. Still, according to Shouldice, "It is not uncommon, I think, for English Canadians to view translation as a means of fostering national unity" (75). However, the Francophone minority would see in it a dangerous political tool, "a means of penetration and possession, a necessary step in the process of becoming informed, of preparing responses, and of exerting control" (79). Thus, from Quebec's point of view, translation would represent instead "an impulse to intelligence gathering for strategic defence purposes" (75). These highly contrasted attitudes toward the function of translation would necessarily have an influence on the choice of works to be translated and the strategies employed in representing the language of the other, that "other tongue."

\section{French to English: The "Joual" Era}

At the end of the 1960s, French Quebec and English Canada were actively preoccupied with the question of identity. In Canada, the celebrations held in 1967 to mark the Centennial of the Confederation furthered the emergence of a sentiment decidedly nationalist in nature which would be fed, moreover, by the upheaval occurring in Quebec as it came to the end of the Quiet Revolution, and headed toward the affirmation and recognition of a Quebec nation. At a time of such nationalist fervour, translation responded to the desire to create a national repertoire, specifically Canadian on the one hand, and specifically Québécois on the other. The specificity of each repertoire could only rest on a notion deemed essential to the construction of a distinct national identity: difference. Though common to each linguistic group, the emphasis placed on difference gave rise to divergent approaches. As the majority defines the norm against which differences are constructed, within a Canadian context where the majority is Anglophone, it is the Francophones, not to mention various ethnic minorities, that are most likely to invest in and be invested with a sense of alterity in relation to a dominant structure of identity. However, the alterity bestowed upon them is not necessarily the one to which they lay claim.

In 1968, when Quebec theatre found a voice of its own, it was with a language deformed by the overwhelming promiscuity of English and entrusted with the responsibility of distinguishing itself from the French model, which had hitherto been viewed as the only one capable of expressing a true Francophone culture. A poor and broken sociolect ${ }^{6}$ filled with Anglicisms, joual embodied the alienation of a French language cut off from its origins, and which a constant friction with English had rendered foreign to itself. With the canonization of joual, therefore, it was two colonial traditions that were simultaneously being challenged, a fact that would hardly reassure an Anglophone public worried about the effects of Quebec nationalism. 
Whatever the case, Canada's nascent theatrical institution, hesitant yet wanting to establish a repertoire of its own, hurried to take advantage of the success of the nouveau théâtre québécois from which it would translate many plays written in joual. Among these plays, special attention was devoted to the work of Quebec playwright Michel Tremblay, who would soon become a prominent Canadian author with seventeen plays translated, produced and published in English before 1994, eleven of which appeared between 1972 and 1979. Three of these translations, moreover, would reappear in revised editions. ${ }^{7}$ John Van Burek was responsible for six of these translated versions, the tandem of John Van Burek and Bill Glassco for seven more, while the rest were tranlated by Renate Usmiani, John Stowe, Allan Van Meer and Arlette Francière.

For the most part, however, these translations were published without annotations or introductions. Except when appearing in an anthologyas was the revised translation of Les Belles-Soeurs in the 1993 edition of Modern Canadian Plays - the English version of a play was presented without any preliminary metatext explaining the difficulty involved in translating joual. Having never been exposed to the socio-historic conditions that shaped the French spoken in Quebec, Canadian English not only has difficulty in providing a linguistic equivalent to joual but it is, moreover, incapable of expressing the ideological statement made by the recourse to a colonized idiom alienated by its close contact with a dominant language.

Considering the rupture caused in Quebec theatre by Tremblay's style of writing and the challenge it poses to translation, the silence surrounding these translations, particularly in the case of the earlier publications, carries a definite, albeit discreet, message. Because it obscures the work of the translation and conveys the idea that the transcultural passage met with few obstacles-since none are mentioned-this silence places the emphasis on the final product to the detriment of the process from which it results. It creates the illusion of closeness and implies a faithfulness of the English reproduction that can only result from a total compatibility of the two cultures, a notion also at work in the assumption that translation provides a bridge on which it is easy to travel from one to the other.

What is more, as Vivian Bosley notes, Tremblay's joual is "standardized into [a] generic North American" $(1988,141)$ that retains a certain level of propriety, counterbalanced by an abundance of Gallicisms and, as in Les Belles-Sœurs, an excessive use of swearwords. Unlike the Anglicisms found in the original, the Gallicisms employed in the English version fail to reflect any actual usage inasmuch as the majority of Anglophones outside Quebec remain unexposed to the friction between the two languages and the ensuing linguistic hybridity. Indicative as they are of what Simon 
calls a "surconscience de la différence [an overawareness of the difference]" $(1994,55)$, these Gallicisms serve only to underline the origin of the source text and to highlight an alterity already expressed by the translator's choice to keep the original title in the translation, a strategy that would become the trademark of the English versions of Tremblay's plays.

With titles bereft of meaning for an English audience, such as Les Belles-Saurs (1974), Bonjour, là, bonjour (1975), En pièces détachées (1975), La Duchesse de Langeais (1976), Trois petits tours (1977), Damnée Manon, sacrée Sandra (1981) and La Maison suspendue (1991), it is suggested right from the outset that the play portrays an untranslatable reality to which an Anglophone public can hardly identify. As expressed by Bosley, commenting on the perception of Tremblay's world by an Anglophone audience and "the kind of experience we have when watching such a play in translation": "It is my contention that, instead of identifying with what is happening on stage, we become observers of an ethnological situation which strikes us as interesting and amusing and quaint" $(1988,139)$. This quaintness is made even more reassuring by the fact that, once translated and stripped of the ideological implications of the use of joual, Tremblay's plays evoke a traditional image of Quebec, picturesque and nonthreatening, a perception more akin to what could be viewed as "universal" from a Canadian point of view. If we accept, as pointed out by Linda Hutcheon, that "eternal universal Truth ... has turned out to be constructed not found-and anything but eternal and universal" (1988, viii), and that such a notion, far from being neutral and absolute, is ideologically motivated, it is possible to see how plays evoking a Quebec of the past could be perceived as more "universally" acceptable.

\section{New Markers of Identity}

By the end of the 1980s, however, joual had become a level of language, among others, within an enlarged Québécois idiom. Theatrical writing in Quebec was then thriving in the formal exploration of dramatic language through the highly stylized verbal aesthetics of such writers as René-Daniel Dubois, Normand Chaurette and Normand Canac-Marquis, who, according to Chantal Hébert (1995), developed:

a new theatrical writing involving numerous mises en abime, the mixing of genres and styles, the special use of monologues and narrative, the upsetting and telescoping of time, the fragmentation of space, discontinuity of the story-line, modification of the notion of suspense, and the questioning of the notions of character. (40-41)

Although it moved away from the preoccupation with a local vernacular, the emphasis placed upon the role of language in dramatic works remained, 
as noted by Linda Gaboriau (1995), who has translated numerous plays by Jovette Marchessault, Normand Chaurette, Michel Garneau and René-Daniel Dubois into English:

In all Quebec theatre, there is an omnipresent, invisible character and that is the Québécois language. The presence of that spoken language, whatever level the playwright has chosen, is a statement in itself, a statement of cultural survival, aspiration and communion... The underlying difficulty I find in translating Quebec theatre is dealing with this preoccupation with language, the constant awareness of the importance of speaking French. (87)

If translating joual into English presented an almost impossible task, the intensive redefining of the role and structure of dialogue in recent dramatic works from Quebec would present another kind of problem to the reception of the text within a Canadian context. When the linguistic exuberance exhibited in these plays was not toned down in the translation, the English version would be perceived as suffering from a "French verbosity" 8 incompatible with the more naturalistic codes of Canadian drama. It is as if such insistence on the function of language would prove exasperating for an English audience. Primarily unilingual and confident in their use of a language free from threat, English Canadians are ill-equipped to understand the preoccupation with the linguistic fabric, the importance given to the enunciative function and the insistence put on the very act of speaking in Quebec drama. This divergence in attitude toward the function of language could very well illustrate a critical difference between the dramatic repertoires of French Quebec and English Canada.

While this reflection of new-found verbal exuberance met with criticism, translations showed less of a tendency to insist on the origin of the borrowed text. It must be noted that in turning away from joual, Quebec theatre abandoned as well the examination of a sense of alienation and opened up to wider horizons. Gay, feminist or experimental theatre presented an enticing selection of thematic approaches from which English Canada borrowed at will without insisting, however, on the signs of a linguistic alterity specific to Quebec. In fact, there is an absence of exotic Gallicisms in recent translations of plays by Normand Chaurette, Jovette Marchessault and Michel Garneau, where specific references to the original setting or sociocultural context have been removed or Anglicized. ${ }^{9}$ It may be that the sense of alterity carried by references to a modern era is not ethnographically relevant, in the sense proposed by Simon (1994). Commenting on the approach taken by English Canada in translating Quebec literature, Simon compares the translator to an ethnographer who, unveiling a distant culture, "s'engage à en rendre toute la vérité mystérieuse et fascinante ... et à donner au texte traduit toute la densité de sa spécificité culturelle [vows to reveal all its 
mysterious and fascinating truth ... and to invest the translated text with all the density of its cultural specificity]" $(1994,52)$. The more remote this distant culture appears to be, the more it contributes to creating identity by contrast. In this search for contrast, the other culture must exhibit signs of difference that are not only irreducible but authentic. In the English translation of Quebec plays, it looks as though this authentic alterity can only belong to a bygone era, the idyllic Quebec of the past. It is, to borrow a term used by Jacques Saint-Pierre, a "fantasy" nourished by the work of Michel Tremblay-and, more recently, by that of Michel-Marc Bouchard-who brings to life and "perpétue pour les anglophones un fantasme, celui d'une certaine vision de la société québécoise des années précédant la Révolution tranquille [perpetuates for Anglophones a fantasy, that of a certain vision of Quebec society during the years prior to the Quiet Revolution]" (SaintPierre 1991, 65).

Among Quebec playwrights, Tremblay and Bouchard presently enjoy the greatest popularity in English Canada. As mentioned previously, Tremblay dominates the Quebec repertoire in English translation with seventeen plays and three revised translations published between 1972 and 1994. As for Michel-Marc Bouchard, six of his plays were translated into English between 1990 and $1996,{ }^{10}$ one of which, Lilies or the Revival of Romantic Drama, was made into a feature film directed by Torontonian John Greyson in 1996. The settling of accounts at work in Lilies takes place in 1952; the story relates events unfolding in Roberval in 1912 and portrays the narrowness of spirit and religious dogmatism of that era.

The following excerpt from Michel Tremblay's La Maison Suspendue, published in English by Talonbooks in 1991, takes place in the same era. In this account of a multigenerational family reunion involving a return to rural Quebec of 1910, Josaphat explains to his son how the legendary Chasse-Galerie ${ }^{11}$ would carry their house from Duhamel in the Laurentians right into Montreal so he could get the people of the city dancing to the tune of his violin. One can count in this excerpt no fewer than twelve Gallicisms, most of which are terms easily translatable into English-they may have been chosen for their morphological similarity to their English equivalents, which makes them more easily accessible to an Anglophone audience. These Gallicisms have been placed in italics for the purposes of this study. Within this same excerpt, it is also possible to observe a levelling out of the English in relation to the French in terms of the marks pertaining to a vernacular level of speech. Underlined in the two texts, they number twenty-nine in the original and six in the translation.

VICTOIRE. Josaphat, franchement!

JOSAPHAT. And off we all go to ma tante Blanche, or to ma tante Ozéa! The forest slides away beneath us, Duhamel is tout petit, les 
Laurentides disappear completely into the darkness... The house sways gently... Me and your mother, we just sit here on the verandah and watch the sky go by. Usually all we see from here is a big black hole where Lac Simon is, but now it's the Big Dipper, the Little Dipper, la planète Mars... The house turns on the end of the rope and we see the whole sky pass before us, like la parade on St-JeanBaptiste Day. During the whole journey, the house sways gently back and forth, back and forth... Us, we're sitting pretty. It sure is beautiful. (Silence. The three characters look around them.) When we get to our relatives', the canoe sets us down next to their place, bonsoir la compagnie, get out your accordéons, push the chairs against the wall, here we are! And then, let me tell you, the party starts in earnest! (He dances en turlutant, then stops as if at the end of a story.) And that, mon p'tit gars, is how you've been to Morial [Montreal] without even realizing! (Tremblay 1991, 34-35)

Here now is the excerpt from the original play, published in 1990 by Éditions Leméac:

VICTOIRE. Josaphat, franchement!

JOSAPHAT. On s'en va sus ma tante Blanche ou ben donc sus ma tante Ozéa! La forêt glisse en dessous de nous autres, Duhamel est tout petit, les Laurentides au grand complet disparaissent dans le noir... La maison se balance tranquillement... Moé pis ta mère on s'installe su'a galerie pis on regarde le ciel passer devant nous autres! D'habetude, c'est un grand trou noir qu'on voit là oùsqu'y'a le lac Simon, mais là c'est la Grande Ourse, pis la Petite Ourse, pis la planète Mars... La maison tourne au bout de sa corde pis on voit le ciel au grand complet passer devant nous autres comme une parade de la Saint-Jean Baptiste! Pendant tout le voyage la maison se balance un p'tit peu... Juste un p'tit peu. On est ben. C'est pas beau ordinaire! (Silence. Les trois personnages regardent autour d'eux.) Quand on arrive sus nos parents, le canot nous dépose àcôté de chez eux, bonsoir la compagnie, sortez vos accordéons, poussez les chaises

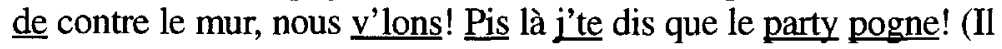
danse en turlutant, s'arrête comme à la fin d'une histoire.) C'est comme ça, mon p'tit gars, que t'as souvent été à Morial sans même t'en rendre compte! (Tremblay 1990, 43-44)

Although relatively recent, this translation reveals translative strategies that translators have been employing since 1972 to represent Tremblay's work to English Canada. 


\section{English-Canadian Plays in French}

In Quebec, however, English-Canadian playwrights of the 1970s and 1980s received little attention. The few Canadian plays then translated were those that had previously been very successful or whose themes were of particular interest to Quebec. For example, Fortune and Men's Eyes by Torontonian John Herbert was produced in New York, London and Los Angeles, and subsequently turned into a movie that was filmed in English in Quebec City, before being translated by René Dionne and produced in Quebec in 1970, 1978 and 1985. John McDonough's Charbonneau \& Le Chef recounts the events surrounding the power struggle between the Archbishop of Montreal and the Premier of Quebec during the Asbestos Strike of 1949. The translated version by Paul Hébert and Pierre Morency enjoyed phenomenal success in Quebec with extended productions in 1971, 1972, 1974 and 1986.

Of the twenty-seven English-Canadian plays translated in Quebec before 1990, I consulted twenty-four. In these translated versions, whenever the action takes place somewhere else in Canada, it is transposed into a Quebec setting. ${ }^{12}$ Most onomastic, toponymic and sociocultural references are thus naturalized and, if necessary, the text is restructured. For example, in René Dionne's adaptation of John Herbert's play Aux yeux des hommes (Éditions Leméac, 1971), the characters Rocky, Smitty and Mona keep their original names, while Queenie is renamed Alice. Place names indicating where the action occurs are modified to suggest a Quebec setting. For example, a native of the Matachewan Reservation in Ontario is relocated to "une réserve de la Côte Nord" in Quebec. Allusion to famous people not well-known in French Quebec, such as British nurse Florence Nightingale, is replaced with a French equivalent, New France's heroic nursing figure Jeanne Mance. References that have a well-known French equivalent, such as "Cinderella" or "Alice in Wonderland," are translated into French, while mention of people like famous French actress Sarah Bernhardt and silent-movie star Valentino are retained in the translation. American movie stars Bob Hope and Bette Davis, although known to Quebec's Francophone audience, are given local French equivalents, in this instance, Quebec actors Claude Blanchard and Yvette Brind'amour. These strategies, the last of which is perhaps the most eloquent, are indicative of a desire to remove from the discourse references to an English language whose powerful presence already pervades the French spoken in Quebec. It is as if resistance to its dominance requires it be denied representation whenever possible. ${ }^{13}$

In this fashion, translation followed the model of a Quebec dramatic repertoire whose specificity rested primarily on its recourse to a distinct 
idiom. While the level of Tremblay's language was raised in English translations reluctant to give voice to a vernacular that may have been perceived as too crude, Quebec translation found it necessary to dialectalize the language in borrowed plays. ${ }^{14}$ This resulted in an overall lowering of the level of language in many Quebec translations of English-Canadian plays produced before 1990. For instance, in John McDonough's Charbonneau et le Chef, the structure of the play was modified by moving, cutting or creating entire scenes in which dialogue had been radically reworked. The following excerpt chosen from among the rare sections where the translation remains faithful to the original allows one to compare the level of language at work in each version. The dialogue involves a striker, La Roche, who argues with Premier Duplessis, known as le Chef, and with the American director of the mine, who threatens to enlist the services of strikebreakers. The regionalisms and distinctive marks of the spoken language have been underlined in the original and in the translation:

LA ROCHE. Solemn. Take care, gentlemen, take care... that could have grave consequences for the town of Asbestos.

LE CHEF, Rising on his toes, his fists in the air. Is that a threat?

LA ROCHE. We are French Canadians... we will defend our homes and our jobs. They stare at each other.

LE CHEF. Suddenly, with anger in his voice. I am the Prime Minister of Quebec, I will defend the rights of the people and the laws of the people from the illegalities of your crazy strike.

LA ROCHE. Calm. Our union is holding a meeting tonight, in front of the Parish Church, Saint Aimée. He points to the Church. If you free me, I will tell the others what you have in mind.

LE CHEF. Rapidly. You are free to go. But remember He shakes his long fingers in La Roche's face remember, La Roche, I will not tolerate any violence or scom of the laws. You be sure to tell that to your comrades, you hear! Otherwise I will throw the lot of you in jail. I mean it, I mean it, I mean it. (McDonough 1968, 22-23)

Here is the translated version of the same excerpt:

LAROCHE. Moé, à vot'place, i'frais attention à mes paroles, Monsieur.

DIRECTEUR. Pourquoi?

LAROCHE. Vous parlez des scabs, hein? Ca pourrait avoir des conséquences pas mal graves pour la ville d'Asbestos. 
LE CHEF. C'est-y une menace ça, Laroche?

LAROCHE. On est des Canadiens français, on va défendre nos foyers et nos jobs... au coton...

LE CHEF, en colère. Moi, j'suis le Premier Ministre d'la province, mon gars, pis j'vas défendre les droits du peuple, j'vas défendre les lois du citoyen contre l'illégalité pis contre vos maudites grèves de fous! Vous avez une assemblée à soir?

LAROCHE. Quais, on d'vait se réunir...

LE CHEF. Avertis ta gang, sans oublier ton aumônier, que le mépris des lois, j'tolère pas ça!

LAROCHE. Mais monsieur, comment que j'vas leu dire ça? Chus arrêté.

LE CHEF. T'es libéré! Envoye! (Laroche ne bouge pas.) Envoye!

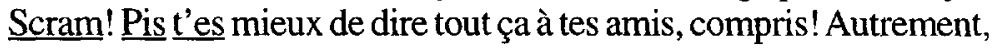
je sacre tout l'monde en prison! (McDonough 1974, 20-21)

It is impossible to ignore the emphasis placed on regionalisms and on the marks pertaining to spoken language in a decidedly vernacular Québécois translation. While present only three times in the original passage, they occur thirty times in the translation.

At the end of the 1980s, the systematic recourse to adaptation was brought into question, as was the appropriateness of routinely transposing the action of a borrowed play into a Quebec context, here expressed by translator Jean-Luc Denis: 'L'adaptation n'est pas en soi quelque chose d'illégitime; c'est lorsqu'elle est érigée en système qu'elle fait problème... Elle doit être reléguée le plus vite possible au territoire qu'elle n' aurait jamais dû quitter: celui du phénomène épisodique [Adaptation is not in itself illegitimate; it is when systematically applied that it becomes a problem... It must be relegated as quickly as possible to the territory it should have never left: that of the occasional phenomenon]" (1990, 16-17). From this point on, translations more frequently retained the original setting as well as the original names and occupations of the characters but continued to rely on an accentuated local vernacular. What is surprising in this insistence to translate into joual is that it contrasted sharply with the experimentation with language undertaken by Quebec playwrights in the 1980s. It is as if this audacity was reserved solely for writing while translation remained subject to the rule of Quebec's vernacular. Inasmuch as translation could no longer call upon the transposition authorized by adaptation, it appears as though the use of a highly accentuated idiom was a last resort in the attempt to naturalize the text to suit the receptive context. 
Since 1990, however, a new tendency can be observed in the Québécois translation of English-Canadian theatre. Of the ten English-Canadian plays produced or published in translation in Quebec between 1990 and 1993, I have consulted nine, none of which involved an adaptation. The most popular English-Canadian playwright in Quebec at the beginning of the 1990s was Albertan Brad Fraser, who had three of his plays produced in Québécois translation between 1991 and $1995 .{ }^{15}$ In these translated versions, the origin of the play is readily displayed and one translation, Poor Super Man, actually features an exact reproduction of the English title. The original settings are also retained, be it Edmonton, Calgary or, more vaguely, the West. Two of these plays, exhibiting a more or less frequent use of colloquialisms, resulted in Québécois versions bearing numerous attributes of the vernacular. However, the informal level of language, with occasional marks of orality, employed by Fraser in The Ugly Man is maintained by Maryse Warda in her 1993 translated version, L'Homme laid. Although adorned with discreet signs of orality, the language used in this translation has little in common with the accentuated vernacular that, in previous years, characterized the dramatic repertoire translated in Quebec. In this instance, translation reveals a voice without insisting on affirming a code.

\section{Conclusion}

As suggested in this study, the exchange of theatre translation between English Canada and French Quebec before 1990 shows evidence of polarization, from an emphasis placed on the untranslatable alterity of a French minority, nostalgically identified with a traditional and non-menacing past, to the attempt to resist the hegemonic and oppressive English majority in translations crafted to conceal the origin of the text while highlighting Quebec's own sense of difference. On the linguistic level, this is manifest in the English translations with their recurring recourse to calques and Gallicisms and by a raising of the level of language found in the source text, while Quebec translations tend to erase any trace of the original text and lower the level of language to promote the use of joual as the idiom of drama specific to Quebec.

At the end of the 1980s, however, this model was redefined as English-Canadian theatre enjoyed growing popularity in Quebec, while retaining marks of the original setting in translations. Although recently less accentuated, the use of a local vernacular remained prominent in Québécois versions of Canadian plays while Quebec's verbal exuberance in experimenting with language had to be toned down to fit the more naturalistic inclination of English-Canadian drama. This polarization in the methods applied to the translation of plays from one official language into the other 
reflects the power struggle at work in Canada, where English is spoken by the majority and French remains the language of a minority.

\section{Notes}

1. This study has benefited from a Social Sciences and Humanities Research Council of Canada doctoral fellowship. A shorter version was delivered in French at the Postcolonial Translations: Changing the Terms of Cultural Transmission conference held at Université de Montréal and Concordia University, May 22-25, 1997. This text was translated into English by Richard Lebeau.

2. Although periodization according to decades for statistical purposes is arbitrary, it permits readily accessible reference on the time axis. It must be noted, however, that 1970 and 1980 are pivotal years in the context of relations between Canada and Quebec. During the 1970 October Crisis, the federal government responded to violent acts perpetrated by the Front de libération du Québec by proclaiming the War Measures Act, thus temporarily suspending civil liberties in Quebec. In the 1980 Quebec Referendum, sixty percent of the voters refused to give the Parti Québécois government the mandate to negotiate sovereignty-association with the Canadian Confederation (The Canadian Encyclopedia [Edmonton: Hurtig, 1985], 1311, 1555).

3. Brisset's (1990) statistical study shows that sixty-nine percent of the foreign plays translated by seven Quebec theatre companies between 1968 and 1988 were originally written in English.

4. In this article, Kathy Mezei comments on the use of the bridge metaphor in a number of works: Louis Dudek and Michael Gnarowski's foreword to The Making of Modern Poetry in Canada (1970); John Glassco's foreword to his anthology The Poetry of French Canada in Translation (1970); G.V. Downes in When We Lie Together: Poems from Quebec and Poems, by G.V. Downes (1973); Jean Delisle in his book Au cour du trialogue canadien: Bureau des traductions, 1934-1984/Bridging the Language Solitudes: Translation Bureau, 1934-84 (1984). This metaphor also appears in Philip Stratford's article "Literary Translation: A Bridge Between Two Solitudes" (1983) and in Kathy Mezei's article "A Bridge of Sorts: The Translation of Quebec Literature into English" (1985).

5. "Que nous le voulions ou non, nous sommes un peuple de traducteurs" [Whether or not we want it, we are a people of translators]" (Léon Lorrain, qtd. in Daviault [1971], 716).

5. A dialect associated with a specific social group or class. For example, joual was more closely identified with Montreal's illiterate working class.

7. These plays are: Les Belles-Saurs, trans. Bill Glassco and John Van Burek (Vancouver: Talonbooks, 1974), rev. ed. (Vancouver: Talonbooks, 1992); Bonjour, là, bonjour, trans. Bill Glassco and John Van Burek (Vancouver: Talonbooks, 1975), rev. ed. (Vancouver: Talonbooks, 1988); Hosanna, trans. Bill Glassco and John Van Burek (Vancouver: Talonbooks, 1974), rev. ed. (Vancouver: Talonbooks, 1991).

8. For example, criticizing the English translation of The Edge of Earth Is Too Near, Violette Leduc, by Jovette Marchessault, Ray Conlogue wrote in The Globe and Mail: 
"Part of the problem is a French lyrical verbosity that does not work in English-at least, not in Suzanne [sic] de Lotbinière-Harwood's overwrought translation" (qtd. in Wallace [1990], 225). Conlogue's comments on the English translation of Michel Garneau's Warriors reads: “The difficulty is that Gilles' exuberant language and his passion for ideas are distinctly Gallic. An anglophone adman might well have Gilles' talent and encounter his moral dilemma, but there is no way he would talk about it in this fashion" (1990), C9. See also the title of the review of Normand Chaurette's Le Passage de l'Indiana: "Fuelled by Long Monologues, Play's Verbosity Is Its Engine," Conlogue (1996), C15.

9. For example, in Warriors (Linda Gaboriau's translation of Michel Garneau's Les Guerriers), reference to a book published by the French publishing house "les éditions de minuit" is replaced in the translated version by a "penguin paperback," and the advertising campaign directed toward a "jeune québécois raisonnable" is aimed in the translation at "reasonable young people." In Jovette Marchessault's The Edge of Earth Is Too Near, Violette Leduc (translated by Susanne de Lotbinière-Harwood), titles of books written by Violette Leduc (e.g., L'Asphyxie and L'Affamée) or passages referring to other contemporary writers close to Leduc have been removed.

10. These plays are: Lilies or the Revival of a Romantic Drama [Les Feluettes ou la Répétition d'un drame romantique], trans. Linda Gaboriau (Toronto: Coach House, 1990), produced at Theatre Passe Muraille, Toronto, 1991, Touchstone Theatre, Vancouver, 1994; The Tale of Teeka [L'Histoire de l'oie], trans. Linda Gaboriau (Toronto: Dundurn, 1998), produced at the World Stage Festival, Toronto, 1992; The Vancouver East Cultural Centre/Les Deux Mondes, Vancouver, 1995; The Orphan Muses [Les Muses orphelines], trans. Linda Gaboriau (Winnipeg: Scirocco Drama, 1995), produced by Touchstone Theatre, Vancouver, 1996; The Coronation Voyage [Le Voyage du couronnement], trans. Linda Gaboriau, reading by the Centre des auteurs dramatiques/Factory Theatre, Toronto, 1996; Desire [Désir], trans. Linda Gaboriau, performed by Playwrights' Workshop Montreal/Theatre Lac Brome, 1996; Heat Wave [Les Grandes chaleurs], trans. Bill Glassco (Winnipeg: Scirocco Drama, 1996). For more Quebec plays in translation, see Gaboriau and Gauthier (1998).

11. "French Canadian variant of the Wild Hunt, a legend [in which] one or several persons together are able, with the help of the Devil, to travel in a canoe through the air at tremendous speed" (Smith [1985], 320).

12. For a detailed analysis of the transpositions in Quebec translations of English-Canadian plays, see Ladouceur (1997b).

13. This diverges from Brisset's (1990), 112, interpretation of similar strategies observed in Quebec translations of foreign plays, where she contends that such an approach is destined to "réduire au silence la voix de l'Étranger" $(1990,112)$. As demonstrated here, it is not so much reference to any foreign culture that is the object of suspicion but, more precisely, cultural items pertaining to the dominant linguistic code, English.

14. This phenomenon had been previously observed by Brisset (1988), 16: "la représentation théâtrale de la québécité qui se projette sur le texte étranger exige un abaissement social des protagonistes pour justifier qu'on les fasse parler suivant un mode d'expression distinct du franco-français [the theatrical representation of québécité projected on the foreign text demands that the social status of the characters be lowered to justify their use of a language distinct from the French of France]."

15. They are: Des restes humains non identifiés et de la véritable nature de l'amour [Unidentified Human Remains and the True Nature of Love], trans. André Brassard 
(Montreal: Boréal, 1993), produced at Théâtre de Quat'Sous, Montreal, 1991; L'Homme laid [The Ugly Man], trans. Maryse Warda (Montreal: Boréal, 1993), produced at Théâtre de Quat'Sous, Montreal, 1993; Poor Super Man [Poor Super Man], trans. Robert Vézina (Unpublished $\mathrm{ms}$. available at the National Theatre School of Canada, Montreal, 1995), produced at Théâtre de Quat'Sous, Montreal, 1995.

\section{Works Cited}

\section{Theory and Criticism}

BOSLEY, Vivian. 1988. "Diluting the Mixture: Translating Michel Tremblay's Les BellesSoeurs." TTR 1, no. 1: 139-45.

BRAULT, Jacques. 1975. Poèmes des quatre côtés. Saint-Lambert: Noroît.

BRISSET, Annie. 1988. "Le public et son traducteur: Profil idéologique de la traduction théâtrale au Québec." TTR 1, no. 2: 11-18.

1990. Sociocritique de la traduction: Théâtre et altérité au Québec (1968-1988). Longueuil: Préambule.

CONLOGUE, Ray. 1990. "Warriors Succumbs to Faulty Adaptation." Rev. of Warriors, by Michel Garneau. The Globe and Mail (Feb. 28): C9.

1993. "Quebec's Surprising New Wave." The Globe and Mail (Jan. 26) : A12.

1996. "Fuelled by Long Monologues, Play's Verbosity Is Its Engine." Rev. of Le Passage de l'Indiana, by Normand Chaurette. The Globe and Mail (Nov. 9): C15.

DAVIAULT, Pierre. 1971. "Une culture d'emprunt." In Le Choc des langues au Québec (1760-1960), ed. Guy Bouthiller and Jean Meynaud, 715-18. Montreal: Les Presses de l'Université de Montréal.

DELISLE, Jean. 1984. Au cour du trialogue canadien: Bureau des traductions, 19341984/Bridging the Language Solitudes: Translation Bureau, 1934-1984. Ottawa: Ministre des approvisionnements et services Canada.

DENIS, Jean-Luc. 1990. "Traduire le théâtre en contexte québécois: Essai de caractérisation d'une pratique." Jeu 56: 9-17.

DOWNES, G.V. 1973. When We Lie Together: Poems from Quebec and Poems by G.V. Downes. Vancouver: Klanak.

GABORIAU, Linda. 1995. "The Cultures of Theatre." In Culture in Transit: Translating the Literature of Quebec, ed. Sherry Simon, 83-90. Montreal: Véhicule Press.

GABORIAU, Linda, and Daniel GAUTHIER, eds. 1998. Quebec Plays in Translation. Montreal: Centre des auteurs dramatiques.

GLASSCO, John. 1970. The Poetry of French Canada in Translation. Toronto: Oxford UP.

HÉBERT, Chantal. 1995. "The Theatre: Sounding Board for the Appeals and Dreams of the Québécois Collectivity." In Essays on Modern Quebec Theatre, ed. Joseph I. Donohue Jr. and Jonathan M. Weiss, 27-46. East Lansing: Michigan State UP. 
HUTCHEON, Linda. 1988. The Canadian Postmodern: A Study of Contemporary English-Canadian Fiction. Toronto: Oxford UP.

JOHNSTON, Denis W. 1991. Up the Mainstream: The Rise of Toronto's Alternative Theatres, 1968-1975. Toronto: U of Toronto P.

KOUSTAS, Jane. 1995. 'From 'Homespun' to 'Awesome': Translated Quebec Theatre in Toronto." In Essays on Modern Quebec Theatre, ed. Joseph I. Donohue Jr. and Jonathan M. Weiss, 81-107. East Lansing: Michigan State UP.

LADOUCEUR, Louise. 1997a. "Du spéculaire au spectaculaire: Le théâtre anglo-canadien traduit au Québec au début des années 90." In Nouveaux regards sur le théâtre québécois, ed. Betty Bednarski and Irene Oore, 185-94. Halifax/Montreal: Dalhousie French Studies/XYZ éditeurs.

1997b. "Separate Stages: La traduction du thêatre dans le contexte Canada/ Québec." Ph.D. diss., U of British Columbia.

MEZEI, Kathy. 1985. "A Bridge of Sorts: The Translation of Quebec Literature into English." The Yearbook of English Studies: Anglo-American Literary Relations, 15, Special Issue: $202-26$. 102 .

1994. "Translation as Metonomy: Bridges and Bilingualism." Ellipse 51: 85-

SAINT-PIERRE, Jacques. 1991. "Michel Tremblay, dramaturge québécois et canadien: Bilan de la réception d'une pièce et sa traduction." In Littérature québécoise: La recherche en émergence, 57-69. Proceedings of the Deuxième colloque interuniversitaire des jeunes chercheur(e)s en littérature québécoise, Centre de recherche en littérature québécoise, Université Laval, June 1990. Quebec City: Nuit Blanche.

SHEK, Ben-Zion. 1977. "Quelques réflexions sur la traduction dans le contexte socioculturel canado-québécois." Ellipse 21: 111-16.

SHOULDICE, Larry. 1983. "On the Politics of Literary Translation in Canada." In Translation in Canadian Literature: Symposium 1982, ed. Camille La Bossière, 73-82. Ottawa: U of Ottawa P.

SIMON, Sherry. 1989. L'inscription sociale de la traduction au Québec. Quebec: Office de la langue française.

1992. "The Language of Cultural Difference: Figures of Alterity in Canadian Translation." In Rethinking Translation: Discourse, Subjectivity, Ideology, ed. Lawrence Venuti. London/New York: Routledge.

1994. Le trafic des langues: Traduction et culture dans la littérature québécoise. Montreal: Boréal.

SMITH, Nancy. 1985. "Chasse-Galerie." The Canadian Encyclopedia, vol. 1, 320. Edmonton: Hurtig.

STRATFORD, Philip. 1983. "Literary Translation: A Bridge Between Two Solitudes." Language and Society 11: 8-13.

USMIANI, Renate. 1983. Second Stage: The Alternative Theatre Movement in Canada. Vancouver: U of British Columbia P. 
WALLACE, Robert. 1990. Producing Marginality: Theatre and Criticism in Canada. Saskatoon: Fifth House.

WASSERMAN, Jerry, ed. 1986. Modern Canadian Plays. Rev. ed. Vancouver: Talonbooks. , ed. 1993. Modern Canadian Plays. 3rd ed. 2 vols. Vancouver: Talonbooks.

\section{Plays}

BOUCHARD, Michel Marc. 1987. Les Feluettes ou la Répétition d'un drame romantique. Montreal: Leméac.

1990. Lilies or the Revival of a Romantic Drama. Trans. Linda Gaboriau. Toronto: Coach House.

FRASER, Brad. 1993a. The Ugly Man. Edmonton: NeWest. . 1993b. L'Homme laid. Trans. Maryse Warda. Montreal: Boréal. 1995a. Poor Super Man. Edmonton: NeWest.

1995b. Poor Super Man. Trans. Robert Vézina. Unpublished ms. available at the National Theatre School of Canada, Montreal.

GARNEAU, Michel. 1989. Les Guerriers. Montreal: VLB. 1990. Warriors. Trans. Linda Gaboriau. Vancouver: Talonbooks.

HERBERT, John. 1971. Aux yeux des hommes. Trans. and adapt. René Dionne. Montreal: Leméac.

1986. "Fortune and Men's Eyes."In Modern Canadian Plays, ed. Jerry Wasserman, 57-81. Rev. ed. Vancouver: Talonbooks.

MARCHESSAULT, Jovette. 1982. La Terre est trop courte, Violette Leduc. Montreal: Pleine Lune.

1985. The Edge of Earth Is Too Near, Violette Leduc. Trans. Susanne de LotbinièreHarwood. Unpublished ms. available at the National Theatre School of Canada, Montreal.

McDONOUGH, John Thomas. 1968. Charbonneau \& Le Chef. Toronto: McClelland and Stewart.

1974. Charbonneau et le Chef. Trans. and adapt. Paul Hébert and Pierre Morency. Montreal: Leméac.

TREMBLAY, Michel. 1990. La Maison suspendue. Montreal: Leméac.

1991. La Maison Suspendue. Trans. Bill Glassco and John Van Burek. Vancouver: Talonbooks. 


\title{
Chapter 12
}

\section{THE CHANGING FACE OF TRANSLATION IN INDIAN LITERATURE}

\author{
Anita Mannur \\ University of Massachusetts, Amherst (USA)
}

\begin{abstract}
A traditional brass lamp has several wicks jutting out to be lit. The more numerous the wicks, the brighter the light. The lamp is the same, the oil is the same but it is the wicks that determine the brightness of the light. The lights from the various wicks merge imperceptibly and produce a brightness which is the totality of many lights. Just as many wicks produce one light, India's many languages produce one literature.
\end{abstract}

K.M. George $(1984, x)$

While K.M. George's analogy between the brass lamp and literature provides an undoubtedly poetic conceptualization of Indian literature, it begs a central question. If each wick produces light of equal brightness, why is it that over the course of time, one wick in particular has tended to attract greater attention than all the others combined? Why has Indian writing in English gained a more prominent status than Indian literature in the various regional languages? Why don't Indian writers writing in regional languages enjoy the same level of international prestige and fame as those who write in English? ${ }^{1}$

The following comment from Gowri Ramnarayan addresses a pivotal issue that has preoccupied Indian literary studies for the past few decades: 
In a national quiz for university students, Vaikom Mohammed Bashir, doyen of Malayalam writing, was identified as a leader of the Muslim League. That is not however surprising. To an educated Indian, Indian literature is confined to writings in his or her own region and language; more often it means Indian writing in English. He knows R.K. Narayan, Salman Rushdie and Vikram Seth. But ask him about Adiga, Akilon or Jibanada Das and you may get blank stares.

The facts speak for themselves. The regional writer remains invisible on the national scene. The media largely ignore him or her unless he or she gets involved in politics or embroiled in controversy. Awards from apex literary bodies are no more than news flashes of the day and writings in Indian languages hardly cross state borders. $(1996,73)$

Ramnarayan addresses the common misconception that the only "serious" literature emerging from India comes from the "Indo-Anglian" tradition. ${ }^{2}$ Even in India, scholars face the problem of knowing how to promote an understanding of Indian literature written in the various regional languages of India. ${ }^{3}$ Thus, although Ramnarayan accurately identifies a crucial problem in the field of Indian literary studies, the basic premise of her argument is not entirely correct. While she rightly asserts that little is known about Indian-language writers, she incorrectly attributes the phenomenon to a lack of regional literatures in translation. In fact, regional-language literatures have been translated into English for decades, as the statistical account of the volume of literary works translated into English from the various regional languages shows.

Jatindra Mohanty's bibliography is a comprehensive study of regional-language literatures (excluding Sanskrit, Prakrit and other ancient languages) in the form of anthologies, biographies and autobiographies, chronicles, criticisms, diaries, dramas, essays, hymns, letters, memoirs, novels, poetry, sayings, songs, stories and tales and travelogues. Although Mohanty does not define the exact temporal span covered by the bibliography, he states that "attention has not been confined only to recent times, but has frequently gone back to the rich past of Indian literature" $(1984, \mathrm{xi})$. His study covers early works such as Tirukkural, Adi Grantha, Silappadikaaram, through pre-twentieth-century writings by Tulsidas, Vidyapati, Kabir and Ghalib, up to works published in 1984 . The bibliography provides approximate figures for the volume of regional-language literature translated into English. For ease of comparison, I have collated these statistics in Table 1 below.

These figures suggest that the level of translation activity is not as high as one would hope (or expect), but they show that translation from Indian regional languages into English is, and has been for many years, 
Table 1

Summary of Literary Translations from

Regional Languages to English (up to 1984) ${ }^{4}$

\begin{tabular}{lclc}
\hline $\begin{array}{l}\text { Source } \\
\text { Language }\end{array}$ & $\begin{array}{l}\text { Number of } \\
\text { Translations }\end{array}$ & $\begin{array}{l}\text { Source } \\
\text { Language }\end{array}$ & $\begin{array}{l}\text { Number of } \\
\text { Translations }\end{array}$ \\
\hline Assamese & 6 & Malayalam & 50 \\
Bengali & 368 & Marathi & 61 \\
Gujarati & 31 & Oriya & 41 \\
Hindi & 152 & Punjabi & 61 \\
Kannada & 51 & Sindhi & 6 \\
Kashmiri & 8 & Tamil & 115 \\
Konkani & 8 & Telugu & 42 \\
Maithili & 5 & Urdu & 69 \\
\hline TOTAL & & & 1,074 \\
\hline
\end{tabular}

steadily taking place in India. Not surprisingly, a greater volume of translated works is from languages such as Bengali, Hindi and Tamil, which have a large corpus of native speakers; whereas the volume of translation from the comparatively "minor" literary languages, such as Maithili and Konkani, is markedly smaller. What is surprising is that until 1986, "major" literary languages that have well-established literary traditions on the subcontinent, such as Urdu and Kannada, appeared infrequently in translation. In this context, Ramnarayan's statement that the regional-language writer remains invisible on the national scene is partially true. Her conclusions illumine an issue that directly pertains to the state of literary affairs in India today. Despite the "abundance" of literature translated from regional languages, why is knowledge of Indian writers centred on those of the IndoAnglian tradition?

In this paper I will explore some of the problems that have characterized Indian literature for a significant portion of modern Indian literary history. Why is it difficult for knowledge of Indian writers to transcend state boundaries despite the fact that translation is taking place? To address this question, I will examine how both ideological concerns, pertaining to the choice of a "representative" target or link language, and concrete issues inform the current practice of translation in India.

In order to integrate the various regional literatures into the larger framework of Indian literature, the existence of institutions or forums that promote literary exchange acquires a definite urgency. Certain forums in 
India aim specifically to facilitate the interchange of regional literatures. Mohanty notes that despite resistance to accepting the unity of Indian literature, "institutions like Sahitya Akademi and the Central Institute of Languages are ... helping in this process of unification of consciousness" (1984, vii). This suggests that both of these institutions are trying to help eliminate barriers between regional-language literatures by creating a space for scholars in the various regional literatures to assemble and share ideas and knowledge.

Sahitya Akademi, a major governing literary body in India, publishes Indian Literature, a bimonthly journal, which is intended to promote the idea that the various regional literatures can be considered as a comprehensive whole under the rubric "Indian literature." But this "ideal" of a unified Indian literature is undercut in reality by Indian Literature's tendency to group the literatures along regional lines: each volume is devoted a specific region. Table 2 below is a diachronic survey of the titles of some recent volumes of Indian Literature.

\section{Table 2}

Focus of Selected Issues of Indian Literature (1993-1997)

\begin{tabular}{lll}
\hline Volume & Date of Publication & Focus of Volume \\
\hline 153 & Jan.-Feb. 1993 & Accent on Hindi Poetry \\
154 & Mar.-Apr. 1993 & Accent on Hindi Fiction \\
155 & May-June 1993 & Accent on Malayalam Fiction \\
159 & Jan.-Feb. 1994 & Gujarati Dalit Literature \\
161 & May-June 1994 & Tamil Writing Today \\
163 & Sept.-Oct. 1994 & 8 Malayalam Poets \\
164 & Nov.-Dec. 1994 & 25 Indian Poets in English \\
165 & Jan.-Feb. 1995 & 5 Bengali Short Stories \\
166 & Mar.-Apr. 1995 & Telugu Writing Today \\
167 & May-June 1995 & 10 Bengali Poets \\
168 & July-Aug. 1995 & Kannada Short Story Today \\
170 & Nov.-Dec. 1995 & Urdu Writing Today \\
172 & Mar-Apr. 1996 & Accent on Oriya Writing Today \\
173 & May-June 1996 & Accent on Gujarati Writing \\
174 & July-Aug. 1996 & Accent on Gujarati Short Story \\
175 & Sept.-Oct. 1996 & Accent on Women Writing in English \\
176 & Nov.-Dec. 1996 & Accent on Marathi Short Story \\
177 & Jan.-Feb. 1997 & Accent on Assamese Poetry \\
178 & Mar.-Apr. 1997 & Accent on Kashmiri Fiction \\
179 & May-June 1997 & Accent on Manipuri Poetry \\
\hline
\end{tabular}


Thus, while Indian Literature attempts to integrate Indian literary pursuits, the result is the exact opposite, for by placing the different regional-language literatures in separate volumes, it effectively separates them and highlights their differences. This segregation of the regional-language literatures contributes to the impression that there is a logical separation between them, that they cannot be put together in a comparative national framework, and thereby compartmentalizes the various regional literatures.

One of the main obstacles preventing the scholar of Indian literature from conceptualizing Indian literature as a unified whole is language. Faced with a corpus of at least seventeen state languages, each possessing its own distinctive literary tradition, how can scholars, who, if Indian, are not likely to be versed in more than five regional languages (if that many), let alone their literatures, study Indian regional literatures comparatively? While Indian Literature, intended to be the forum for Indian regional-language literatures, has sought to solve this problem by publishing in English-all the articles, essays and case studies in Indian Literature are in English-this poses additional problems. In some cases, citations from a text will appear in the source (regional) language only, but in most cases, citations are accompanied by an English translation for readers who do not know the particular regional language. This practice reinforces the idea that a "link language" is needed to ensure communication across the nation. The link language in this instance is English.

Undoubtedly, this is where translation becomes an important issue. Some propose that all regional literatures should be studied in translation. But, this gives rise to another problem: the choice of a suitable target language. Although the main focus of literary scholarship traditionally centres on translation from regional languages into English, this issue has been hotly contested. ${ }^{5}$ On the one hand, there are those who believe the link language in India should be English, and on the other hand, there are those who argue in favour of Hindi. The Hindi/English target-language debate carries serious ideological implications. If English is the chosen target language, one must keep in mind the historical, social and political circumstances that enabled English to "take root" in India. But the question that arises is, Why is there the need for a link language in India? Should Indians blindly attempt to integrate regional-language literatures from the various states of India merely because the former colonial regime decided that all the states should be integrated into one nation called "India"? In the name of promoting a more integrated study of literature that transcends state boundaries, should Indians use English as the link language to "unite" the literary efforts of a "nation" that has only existed as a single national unit for fifty years, thereby engaging in an act of double-hegemony?6 
As Indian Literature demonstrates, translation is the key to studying Indian literature as a comprehensive whole since it is simply impossible for anyone to know every regional language of India. Thus, without overtly stating it, Sahitya Akademi favours the use of English as the link language for furthering knowledge of the various regional-language literatures in India. This particular problem is not restricted to India. As Ngũgĩ wa Thiong'o notes, observing on the role of indigenous and colonial languages used in African literature:

English, like French and Portuguese, was assumed to be the natural language of literary and even political mediation between African people in the same nation and between nations in Africa and other continents. In some instances these European languages were seen as having a capacity to unite African peoples against divisive tendencies inherent in the multiplicity of African languages within the same geographical state. $(1986,6)$

The question of whether to translate "native" or "regional" languages into English (or French or Portuguese) acquires a marked urgency in postcolonial spaces and times. Historically, and even today, many nations-including India, Kenya and Nigeria-face the problem of fostering a national identity in a multilingual state. The advancement of literary studies in these nations therefore often centres on agreeing on a suitable link language. In India, the question requires advancing one step beyond merely finding a literary voice that represents the experiences and history of the Indian populace. It literally translates into a language that will enable writers, scholars, critics and the ordinary Indian reader access to the various regional-language literatures. They rely on translations to compare and make connections between the different language-literatures.

In contrast to Indian Literature's policy of using English as a link language, V.K. Gokak in his seminal work The Concept of Indian Literature $^{7}$ proposes that Hindi is the most appropriate link language into which to translate Indian regional literatures. The use of Hindi may overcome some of the ideological obstacles (as suggested by Ngũgĩs statement) of using English as the link language in India. Gokak argues:

[T] he fact that the entire people in the area from Madhya Pradesh to Himachal Pradesh speak Hindi (or dialects of it), apart from the Pun$\mathrm{jab}$ and East India, gives Hindi a tremendous advantage even as a regional and national language. Its resources are far greater for the purposes of translation and the production of scientific and technical literature than those of any other Indian language. $(1978,16)$

This statement implies that Hindi is a more appropriate link language than English because it has historical and geographical roots in India. Gokak 
suggests that the choice of link language for Indian regional literatures should be based on linguistic similarities, and Hindi is the modern language closest to other Indian languages (17). In addition, the themes and images in the regional literatures will translate "better" into Hindi than English, because many of the meanings in the source languages also exist in Hindi (unlike English), thereby rendering it a better target or link language (17). Other arguments in favour of Hindi as a link language in India allude to the fact that Hindi is not only a national language of India, but as the language of the "Bollywood"8 films, which have a huge national following, it is virtually the "second" language of the general population in urban (and some rural) areas throughout India. As Aijaz Ahmad observes, "Hindi now commands far greater space in the electronic media and popular culture (clearly in the North but, through cinema and television, in the South as well)" $(1992,76)$.

Gokak's view encouraging the use of Hindi sounds reasonable in theory, but there are practical obstacles to his proposal. Although Hindi has the advantage of being a language rooted in India, and of being structurally and thematically close to Indian regional languages, it is somewhat naïve to suggest that everyone, including regional-language writers, will readily welcome the use of Hindi as the link language into which their writings will be translated. In fact, the very cultural proximity of Hindi to the other national or regional languages gives rise to problems. Hindi is presently (and has been for much of the last two decades) under attack from various nonHindi-speaking states (particularly the South Indian states Karnataka, Tamil Nadu, Andhra Pradesh and Kerala, which use Kannada, Tamil, Telugu and Malayalam), which strongly oppose the looming threat of cultural hegemony posed by Hindi.

Moreover, various arms of India's central government have also played their part in this particular debate about the role of Hindi on the subcontinent. In 1997, for example, a government-proposed project sparked an uproar, in the form of resistance to Hindi, among South Asian scholars in the United States. An article in India Abroad (May 9, 1997) addressed the controversy surrounding the "Indian Council of Cultural Relations' desire to compile [and publish] a directory of Hindi professors, scholars and writers living overseas ... in Hindi" (22). The project, conceived to mark India's fiftieth anniversary of independence, was intended to facilitate communication among South Asian scholars worldwide. However, it was perceived as emblematic of the "linguistic chauvinism" of the central government; the complaint being that the government of India was covertly stating that "one language group, namely Hindi, is more equal than the others" (22). In defence, a spokesperson for the government asserted that Hindi "has a very special status as the official national language of the country," and that such 
an attitude was "quite damaging to the very notion that India is a nation concerned for the united operation of its linguistic, cultural and literary groups" (22). Indeed, it is political pressure from the central government to make Hindi the primary language in India (as opposed to recognizing both English and Hindi as official languages), and the cultural hegemony of Hindi as the language of popular culture, that have fostered a strong anti-Hindi sentiment among speakers of other languages.

Discussing the complex web that entangles the relationship between the various regional languages, Sisir Kumar Das noted that not only do Kashmiri speakers feel that Urdu has usurped the place of their language, but that "Bengali hegemony was a constant irritant in Orissa and Assam, Konkani felt humiliated and desperate as it was denied all possibilities of development, [and] Telugu speakers also had strong feelings about the domination of Tamil" $(1995,39)$. In the Indian context, using Hindi in lieu of English as the link language poses practical and ideological problems for the literary arena, precisely because Hindi "threatens" to usurp the "strength" of the regional languages. While some people may simply not be able to read literature in Hindi, others may resist reading regional literature in Hindi translation because they consider it a threat to the other regional languages, including their own. ${ }^{9}$ On the other side of the floor are people like G.N. Devy, who suggests that English is the language most suitable for linking the various Indian literatures because, unlike Hindi, "ILET ${ }^{10}$ has the advantage of being able to circulate internationally by virtue of its being in English, as well as the cultural 'merit' of being fully representative of the country and culture of its origin" $(1993,119)$. Though English is not native to India, it is the lingua franca most considerably widespread among middleand upper-class Indians, who are likely to be the target audience for literature in general, and Indian regional literature in particular. In addition, English is preferred by many because it is not perceived as a direct threat to the regional languages. In Devy's framework, translation is more than a mere force to dismantle state borders in India; it is also a way to augment the readership of Indian regional-language literatures worldwide. This advantage is afforded exclusively to English translations, for a Hindi translation is certainly not likely to unlock the door to the international literary market as easily as its English counterpart.

How do current translation practices figure in this matrix? K. Ayyappa Paniker, who writes and translates various literary works in Malayalam, observed that translation in India does not usually take place directly between regional languages. Rather, he explains, "English serves as the main link for inter-Indian literary translations, as well as for Indian-non Indian translation" $(1994,136) .11$ The translation process can therefore be schematized as follows: 


\section{$\mathrm{RL} 1 \rightarrow$ ENGLISH $\rightarrow \mathrm{RL} 2$}

where RL1 is the source regional language; and RL2 is the target regional language.

This model poses an interesting challenge to the use of any Indian regional Indian language as a target language, precisely because it still has to be filtered through English. The role of English as a "filter" language between regional languages certainly explains why English is more typically the target language for literary translations, since it must be the first target language of any RL1 to RL2 translation. Therefore, on a practical level, translation into Hindi will not necessary eliminate the presence and role of English, but rather emphasize the need for English as a neutral filter.

Although demand for regional-language literature is high in India, literature in English is in even higher demand because it is accessible to readers across the country and overseas. This alone makes translation of regional literatures into English necessary. As Devy observes:

There has been an emergence of a substantial class of Indians who speak an Indian language but cannot read it well. English has been the socially privileging language in India for over a century; and the importance of English in trade and technology makes it the most attractive choice as the medium of school education. Invariably therefore, the children sent to these schools need to be given Indian myths, epics and literatures in English translation. Translation has come to be the bridge between literature of the past and present generation. It has also become the bridge between the new writings in Indian languages and the new readership that is gradually losing these languages. $(1993,117)$

Moreover, the "efficacy of the English language in the dissemination of information about Indian literature at a professional level," the use of English as an instrument of mediation that has "brought Indian literatures closer mainly through translations, creating a store-house of information about different language-literatures" (Das 1995, 59) and the fact that English is the accepted language of critical enquiry worldwide reinforce the importance of English for scholarly pursuits. The choice of a target language in which to translate Indian regional literatures therefore is not and has not been entirely based on ideals. On the contrary, practical concerns, such as the nature of the critical field and scholarship, the requirements of the educational system, trade, industry, access to foreign markets and the desire to preserve the regional languages in the various states, work together to determine the link language between regional literatures.

But even in the unlikely scenario that a consensus could be reached vis-à-vis the choice of a link language, the current status of ILET $^{12}$ within 
academic circles poses an additional challenge. At present, regional literatures in translation are uncommon in university syllabi, not because none exists or because no translation activity is taking place, but rather primarily because translated works have traditionally not been accorded a high status. Devy $(1993,3)$ suggests that this is merely in line with the hierarchical structure of literary studies in India:

A number of critics have endeavoured to establish a hierarchy in terms of artistic range and abundance in literatures written in English. The descending order of terms in this hierarchy is:

(i) British literature;

(ii) American literature;

(iii) Anglo-Irish literature;

(iv) Australian literature;

(v) Canadian literature;

(vi) other writings in English, such as Caribbean, African, Indian.

The basic structural principle behind this argument is usually that mono-lingual cultures rank higher than multi-lingual cultures. ${ }^{13}$

Given the low position of Indo-Anglian writing on this hierarchical scale, it is even more difficult for ILET to establish itself as "serious" literature worthy of study in academic circles, for the very reason that it is rung below IndoAnglian writing - a literature that already lies at the bottom of the hierarchy. ILET lacks the "cultural power" (Even-Zohar 1990, 66) needed to make it prestigious, for in India, regional literatures in translation simply do not possess the level of prestige and cult power of British or American literature. This prejudice toward translated literature within academia means that these works are generally not included in college syllabi. And herein lies the paradox: scholars are unwilling to study/teach translated literature because of its low status, but it is their very reluctance to teach/promote the study of translated literature that makes it difficult for this work to enter the literary canon, and thereby gravitate upward to higher rungs on the hierarchical scale.

While it is easy to blame academia for creating this problem, one should also keep in mind that syllabus content in India is restricted by the availability and affordability of books. The low status of translated works has meant that publishing houses, uncertain of the saleability of these works, have been hesitant to undertake systematic translation projects, until recently. Among the large publishing houses in India, Jaico, Dialogue, India Book House, Pearl, Sterling, Vikas, Bharatiya Vidya Bhavan, M.C. Sarkar and Co., and Rupa have sporadically published translations. The Calcutta Writers Workshop and United Writers (based in Calcutta) have published the most translations to date, which may be one reason why more translations of Bengali literature have been published than other regional-language 
literatures. It is worth noting that eighty-three of the works translated from Bengali were written by Rabindranath Tagore, who had also translated many of them into English himself. This particular detail sheds light on an important issue: regional literatures are often translated because of a supported interest in the source literature in question. According to Mohanty's bibliography, eight pieces of Konkani literature - all written by R. Pandit-have been translated and published by Thomas Gay. Since no other Konkani writer has been translated into English, one might suppose that Gay has a personal interest in Pandit's work. Certain university presses, such as Punjab University Press and the University of Trivandrum Press, have their own regional-language publications and also publish translations from Punjabi and Malayalam, respectively. But these tend to be sporadic. By far, the majority of translated works are published by small independent presses that never systematically publish translations from any specific regional language into English. Traditionally, translated literature, when available, is expensive and, more often than not, reprints are not issued: once the last copy is sold, the book disappears from bookstore shelves "forever," rendering it difficult for educators to include these works in their syllabi, even if they genuinely want to study them. ${ }^{14}$

Hence, market forces have adversely affected the availability of translated literary works on the Indian market. However, this situation has undergone rapid changes over the last few years. Ramnarayan notes:

It is only in the last six to seven years that literary organisations, publishers and academics have taken translations seriously. This year [1996], a translation programme of some significance and magnitude ( 55 books in 11 languages) has been launched by Macmillan as a literary exercise as well as an educational project. $(1996,73)$

This is the first time that a comprehensive translation project covering so many languages has been launched by a private agency. In the past, it was Sahitya Akademi, in affiliation with the national government, which undertook most of the translation of regional literatures, which, as Ramnarayan remarked, was of "uneven quality and poorly distributed" $(1996,73)$. Although Macmillan India has published only eleven novels 15 thus far, it is promising to think that four times this number remain to be published. ${ }^{16}$ Macmillan's outlay in this venture bears witness to the vital role that economic and financial forces play in the translation process. Considering the prominent Indo-Anglian writers, we would have to admit that their literary fame is not exclusively derived from the literary merits of their respective works. The financial backing and support, as well as the strategic marketing of their work by large international publishing houses such as Penguin, Pantheon, Oxford, Chicago and Viking, have given these writers prominent visibility on the world scene. 
While it is true that the Macmillan translation project was launched for educational and literary purposes, it is also true that Macmillan was only willing to get involved if sufficient sponsors could be found (Ramnarayan 1996, 73). And in fact, it was a large private contribution "to the tune of Rs 14 lakhs [1.4 million rupees, or approximately US $\$ 47,000]$ from the M.R.A.R. Education Trust ${ }^{17}$ [that] enabled this project to be launched" (74). The project was inspired by a desire to make the classics in regional languages available to wider audiences both in India and abroad. In addition to publishing translations of previously untranslated work, Macmillan is also helping to establish a clientele for existing regional-language literatures in translation. R. Narayanaswami, director of sales for Macmillan, stated that college libraries and university syllabi are the primary targets, as these are the main institutions that can help to create and maintain a following for these works. This is a particularly important move in view of the fact that, in the past, translated works remained obscure partly because of their relative absence from college syllabi. By targeting this market, Macmillan is focussing on a crucial element that will surely enable regional literatures in translation to become a visible and ultimately integral part of the Indian literary establishment.

Traditionally, economic concerns have played an important part in maintaining the obscurity of literary works in translation. Literature in translation was undertaken sporadically by commercial publishers such as major international publishers, including Allen and Unwin, Longman, Viking, Penguin, Heinemann, Doubleday and Macmillan, and often in conjunction with projects established by international organizations such as UNESCO. In the late nineteenth and early twentieth century, Scottish Mission Industries functioned as the main translating body in India, focussing on theological texts. Foreign university presses, such as Oxford, Chicago, California, Harvard and Indiana, have also published translations of Indian literature. But, as previously mentioned, the bulk of the translations was undertaken by Sahitya Akademi, United Writers, Calcutta Writers Workshop and smaller Indian publishing houses. These smaller presses do not have the financial resources to launch wide-scale publishing campaigns and promote sales of translated works on potential markets.

Prior to the ambitious Macmillan translation project, the cost of literature in general tended to be fairly high, thereby reducing the viability and visibility of the works. In fact, this had a sort of domino effect: the high prices hindered consumption, which led publishing houses not to reprint translated works, which augmented the relative "obscurity" of the works and the writers both on the literary market and in academic arenas. However, the price of the Macmillan novels is relatively low: ranging from Rs 45 to Rs $140 .{ }^{18}$ Ramnarayan remarked that these prices would certainly 
make them affordable to "serious middle-class readers." In the past (and even today) the high prices of literary works have made them less attainable, and thus limited their circulation. The affordability of the Macmillan novels becomes evident when compared to the sale price of some prominent Indo-Anglian fiction that occupy an important position within the Indian literary system (see Table 3 below). It is not surprising therefore that the Macmillan editions have generated higher sales, overall, of regionallanguage literatures in translation. ${ }^{19}$

Table 3

Prices of Selected Works of Indo-Anglian Literature (1998) ${ }^{20}$

\begin{tabular}{lllr}
\hline Title & Author & Publisher & Price (Rs) \\
\hline $\begin{array}{l}\text { The God of } \\
\text { Small Things }\end{array}$ & Arundhati Roy & India Ink & 395 \\
$\begin{array}{l}\text { A Fine Balance } \\
\text { The Moor's }\end{array}$ & Rohinton Mistry & Faber and Faber & 604 \\
$\begin{array}{l}\text { Last Sigh } \\
\text { The Revised }\end{array}$ & Salman Rushdie & Vintage & 225 \\
Kama Sutra & Richard Crasta & Penguin & 125 \\
$\begin{array}{l}\text { Beach Boy } \\
\text { The Inscrutable }\end{array}$ & Ardarshir Vakil & Penguin & \\
Americans & Anurag Mathur & Rupa & 200 \\
The Macmillan & Various regional & Macmillan & 80 \\
Novels (Translations) & & & $45-$ \\
\hline
\end{tabular}

In a country that has several regional languages, translation is the only way to bridge the ever-widening chasm between each of the distinctive literary traditions, and to keep the various regional-language literatures from fading into obscurity. Of course, in this context, it would be ideal if regional literature could attract the same following as Indo-Anglian literature in the original language, without being translated. But this is not really possible in a multilingual society such as India. It would also be ideal if a readership for regional literatures in their original languages could be created without recourse to a link language, be it English or Hindi. But reality suggests that translation is an absolute necessity. And the dictates of the educational system, trade, technology, the nature of the translation process and, perhaps the most important factor, the investment and financial support of multinational publishing houses, necessitate the use of English. English is the language that has clout in the modern world, and perhaps it is better to work with that fact, rather than against it. As Mukherjee writes: 
English has made it possible for an Indian text to be read or "discovered" in translation more widely than it could be in any other language earlier. Hence, though English may not be the most suitable language for translating Indian literary texts, it offers the widest area of discovery through and in translation. $(1981, \mathrm{x})$

Thus, isolated projects to translate regional-language literatures will not effect wide-scale changes or help to better the status of translated literature in the long term, even if they produce startling results in the short term. What is perhaps needed is a systematic regional literature translation policy.

On the threshold of the new millennium, what changes are in store for the future of regional Indian literature? Macmillan's large-scale translation project, Sahitya Akademi's more active role in the literary translation process and Ravi Dayal's publication of Nirmal Verma's and K. Shivaram Karanth's work in translation are a few examples of steps in the right direction (Rai 1998, 80). In the long term, merely publishing translations of classics and writers who are well-established in their particular regional literary canon will not suffice. Rather, sustained efforts to translate new works by emerging young writers on the regional literary scene need to be undertaken by several organizations and publishing houses in order to effect longterm changes in the status of translated works in India. Das reminds us that publishers who began to wield greater power in the twentieth century have used that power to contribute "significantly towards the popularization of classics, the growth of readership, the widening of the market for modern literature and also towards the financial stability of young writers" $(1995,27)$.

Writers and translators must therefore begin to forge closer links with publishing houses in the next century, taking advantage of their financial resources and power to keep regional-language literature strong. In addition, established writers and critics of regional-language literature need to work closely with new writers, perhaps by facilitating the translation of their works, so as to sustain a tradition of regional literature in translation. The international diffusion of U.R. Anantha Murthy's works was certainly aided by the fact that it was the well-known A.K. Ramanujan who had translated his novel Samskara into English. Likewise, Sadat Hasan Manto, a well-known figure in Urdu literature, is certainly likely to attract even more attention among non-Urdu readers (particularly outside the Indian context) in the near future, since his work has been included in Mirrorwork, Salman Rushdie's anthology of Indian writing. Thus, by taking lesser-known writers under their wing, established writers can potentially effect significant and positive changes in the status of regional-language literature in translation - a move that stands to be beneficial both to themselves and to the new writers. 
Governing literary bodies, such as Sahitya Akademi, are also in a position to effect considerable changes by remaining committed to publishing regional literatures in translation. Already, by providing incentives to translators, such as the Translation Prize, Sahitya Akademi has helped to make translation a more prestigious activity in India. Moreover, with figures such as U.R. Anantha Murthy-a well-known regional-language writer who vociferously addresses the merits of reading regional-language literature in public forums-at the helm of Sahitya Akademi, the status of regional literary works is certainly likely to improve considerably. In the long term, such moves will not only help to enrich Indian literature, but will encourage and reward literary production in the regional languages. An impetus to translate regional literatures will not silence the voice of regionallanguage writers, but rather, translation through a link language will enable the reading public not versed in the various regional languages to hear and appreciate, and therefore give strength to, the many voices of regional-language literature in India.

\section{Notes}

1. See "Commonwealth Literature Does Not Exist" in Rushdie (1991) for details on the history, nuances and problematics of this particular issue. The discussion on p. 69 is particularly relevant to my argument.

2. "Indo-Anglian literature," which refers to literature written in English by Indian authors, has had an interesting, and at times controversial, history. See "An Essay in Definition" in Mukherjee (1981).

3. The idea that "Indian literature" can be used to describe all of the literatures produced in the various languages of India, as well as in English, has been debated at length by many scholars. In the preface to Comparative Indian Literature (1984), K.M. George, for example, asks the question, "How can fifteen or more languages produce one literature?" See this preface for further comments on this particular question. Jatindra Mohanty's (1984) preface to Indian Literature in English Translation also provides a useful bibliography of other works that address this question.

4. According to the UNESCO publication Index Translationum, an additional twentyfive translations were published in 1985 and 1986, including seven from Bengali, seven from Hindi, three from Tamil, two from Oriya, one each from Gujarati, Kannada, Malayalam, Punjabi and Telugu and one in several languages.

5. For an excellent discussion of the role of a link language in India, see "A Link Literature for India" in Mukherjee (1981).

6. See George (1984), ix-xi, for further discussion of this point.

7. Published in 1978, this work provides a history of and a paradigm for the study of Indian literature. Though dated, it nevertheless enables one to historically contextualize the debate regarding a "suitable" language to link regional literatures in India.

8. The popular name for the Indian film industry, based in Mumbai. 
9. See Rushdie (1991), 65-70, for additional comments.

10. The acronym for "Indian literature in English translation."

11. See Das (1995), 54-60, for his discussion on European-Indian literary interactions for a more exhaustive treatment of this subject.

12. A distinction must be made between Indian literature written in English, which Mukherjee calls "Indo-Anglian literature," and Indian literature in English translation (ILET), which Mukherjee (1981), 3-4, calls "Indo-English literature."

13. Devy does not place each literature on a separate line. I have done this to emphasize the hierarchy at work in this framework.

14. I wish to thank Professor S.K. Aithal, professor of English at the Indian Institute of Technology in Kanpur, for providing me with this information.

15. See N. Kamala's paper in this volume for the titles of these novels.

16. I should emphasize that for the purposes of this paper, I am not directly addressing the quality of the translations per se. I am more interested in statistics and the volume of work translated in India.

17. Named for the Madrasi businessman M.R. Arunachalam.

18. Approximately US $\$ 1.30$ to US $\$ 4$. Currency conversions are not always good indicators; comparisons based on purchasing power within a given society are usually more appropriate: the Indian publications India Today and Frontline (comparable to Time or Newsweek), cost approximately Rs 15 , that is, US\$0.50.

19. According to Ramnarayan, Macmillan reportedly sold the first 3,000 copies immediately, and long-term sales, reprints and a world market are anticipated.

20. These figures were obtained from Crossword Bookstore, Mumbai and Athree Book Centre, Mangalore, in January 1998.

\section{Works Cited}

AHMAD, Ajjaz. 1992. In Theory: Classes, Nations, Literatures. London: Verso.

AITHAL, S.K. 1996. Personal Interview (Oct. 8).

DAS, Sisir Kumar. 1995. A History of Indian Literature, 1911-1956. Struggle for Freedom: Triumph and Tragedy. New Delhi: Sahitya Akademi.

DATTA, Amaresh, ed. 1987. Encyclopaedia of Indian Literature, vol. 1. New Delhi: Sahitya Akademi.

DEVY, G.N. 1993. In Another Tongue: Essays on Indian English Literature, ed. Wolfgang Zach. Frankfurt: Peter Lang.

EVEN-ZOHAR, Itamar. 1990. "Polysystem Studies.” Poetics Today 11, no. 1, Special Issue.

GEORGE, K.M. 1984. Comparative Indian Literature. 6 vols. Trichur: Kerala Sahitya Akademi/Macmillan India.

GOKAK, V.K. 1978. The Concept of Indian Literature. New Delhi: Munshiram Manoharlal.

HANIFFA, Aziz. 1997. "Embassy Embroiled in a Language Controversy." India Abroad (May 9): 22. 
Index Translationum. 1991, 1992. Paris: UNESCO.

Indian Literature. New Delhi: Sahitya Akademi.

MOHANTY, Jatindra Mohan. 1984. Indian Literature in English Translation: A Bibliography. Mysore: Central Institute of Languages.

MUKHERJEE, Sujit. 1981. Translation as Discovery and Other Essays on Indian Literature in English Translation. New Delhi: Allied Publishers.

NGŨGI wa Thiong'o. 1986. Decolonising the Mind: The Politics of Language in African Literatures. London: James Currey.

PANIKER, K. Ayyappa. 1994. "The Anxieties of Authenticity: Reflections on Literary Translation." Indian Literature 162: 128-38.

RAI, Alok. 1998. "Glimpses of a Vanished Life." India Today (Jan. 12); 80.

RAMNARAYAN, Gowri. 1996. "Indian Offerings." Frontline (Aug. 9): 73-74.

RUSHDIE, Salman. 1991. Imaginary Homelands. New York: Penguin. 
This page intentionally left blank 


\title{
Chapter 13
}

\section{GATEWAY OF INDIA: REPRESENTING THE NATION IN ENGLISH TRANSLATION}

\author{
N. Kamala \\ Jawaharlal Nehru University (India)
}

English translations of Indian literary texts published in India may not at first sight seem comparable to the Gateway of India, the monumental memento of the British Raj on Indian shores. The Gateway of India, as people familiar with India are aware, was built on the shores of Bombay-now translated, or rather back-translated, to Mumbai-to welcome British royalty. A symbol of conquest and colonization, the Gateway served to allow entry and access not just to the islands of Bombay, but more importantly to the jewel in the crown, India. Through the Gateway, the imperial traveller could perceive in his mind's eye the vision of a subject-nation, a nation constructed and processed in and for his gaze. As Tejaswini Niranjana points out, one of the professed aims of English education was to give the colonized, "along with the English language, models of national culture" (1992, 107), the stated objective being to "give a liberal English education to the middle and upper classes, in order that we may furnish them with both the materials and models for the formation of a national literature" (Trevelyan 1838,175 ). While various notions of India-indeed, various Indias-may have pre-existed British colonization, this one monolithic nation, India, was constructed only in English translation.

The Gateway of India looked outward, welcoming the colonizer, a symbol and facilitator of appropriation, but it also looked inward, bringing a people together (and driving them apart) as they dutifully defined their nation in the curiously perceived neutrality of the English language. As 
Sujit Mukherjee points out in his foundational work Translation as Discovery, translation of literary texts from various Indian languages into English "offers the widest area of discovery" (1994, viii), promising that there may be an Indian literature after all, rather than various regional ones.

Aijaz Ahmad puts forward a similar argument when he admits that he "cannot confidently speak of an 'Indian' literature as a theoretically coherent category" $(1995,243)$. A united, theoretically coherent, national "Indian" literature cannot be posited through essentially discrete histories of Indian language-literatures: a "'national' literature has to be more than a sum of its regional constituent parts" (243-44). Though at some level, every literary work written by an Indian national can be considered part of "Indian literature," Ahmad believes that institutions that could produce a coherent and unified knowledge of the various language-literature clusters in India, within any theoretical framework, have been largely absent. There has been no encouragement for access to the various Indian language-literatures through translation into other Indian languages. This has resulted in a situation whereby "it is in English more than any other language that the largest archive of translations has been assembled so far, [and soon] English will become, in effect, the language in which the knowledge of 'Indian' literature is produced" (250). And this despite the fact that English is "the language least suited for this role ... because it is, among all Indian languages, the most removed, in its structure and ambience, from all the other Indian languages, hence least able to bridge the cultural gap between the original and the translated text" (250).

However, it seems that more and more educated Indians are able to read and write only in one language other than their mother tongue, and that language is English. What is even more worrisome is that the proportion of Indians living in metropolises who are competent only in English is growing steadily. Thus, Sujit Mukherjee's comment, first voiced almost a decade ago, seems relevant even today: "The literary compartments in which we live in India-with windows wide open to non-Indian literatures, but doors closed to the work of neighbouring Indians-tend to grow rather than diminish" $(1994,15)$ despite various organizational attempts to bring together literary practitioners in the different Indian languages. The problem within India is that it is far easier to access developments and achievements in languages of contiguous regions, than to access those in languages of more distant regions. For example, a Tamil may be aware of, and up-to-date on, the latest trends in Kannada or Malayalam or Telugu literature, but have little or no idea of what is going on on the Gujarati or Punjabi literary scene. This awareness is not based on the existence or availability of translations, but merely on physical proximity and immediate cultural and political relevance. Hence it is that these factors, either together or individually, must 
be in place for the literature of any specific region to have an impact on the public of another region of the subcontinent. As in the case of all news, literary achievement is processed and transmitted through the popular media; a recent case in point is the Bangladeshi-not Indian-writer Tasleema Nasreen's novel Lajja. Accessing Indian literary works through translation into another Indian language is still a distant dream. In fact, even translations between adjacent regional languages are few and far between. Currently in India, the only way for a large number of readers across the subcontinent to have access to other regional language-literatures is through English translation. Knowing this, many writers seek to have their work translated into English.

This is not seen as a satisfactory situation by everybody. In a recent review of a collection of poems translated from Oriya into Bangla, Meenakshi Mukherjee laments that " $[\mathrm{m}] \mathrm{uch}$ of the seminaring and workshopping on literary translation in recent years begin from the assumption that translation of literary texts in India necessarily means translation into English, ignoring the much richer and wider possibilities of intra-language transfers where the so called 'problems' turn into pleasure and profit" $(1997,45)$. Nonetheless, Mukherjee recognizes that intralanguage translation in India is far easier between contiguous language-regions: "There is so much cultural overlap between two geographically adjacent languages in India that the concept that each language has its own ethos - an idea that translation theorists thrive on-has to be revised in our situation" (45). Indeed, most Indian translators would agree with this point, for it is very often their aim, as well as that of various organizations and translation projects, to show the oneness of the Indian nation, even if this is possible only through English.

The focus of this paper is Macmillan India's new series "Modern Indian Novels in English Translation," the first of which were published in 1996. This series can be considered a modern-day gateway to India. As N.S. Jagannathan remarked in a seminar on translation, which focussed on the same series, "we are probably translating [into English] because we are in a situation within India, in which in order to [make available] a Tamil novel to somebody in Assam or Bengal or Punjab, the only way to do it today is to situate it in English" (Mar. 1997, 19). He considers this situation an "agony," but an inevitable one at the moment. He remarked that while he could have read Bengali novels in Tamil translation in the 1930s and 1940s, today translation into Tamil is taboo in India. Translation into English has become, to borrow a phrase from Sujit Mukherjee, "a patriotic activity" $(1994,125)$. On the one hand, this may carry the same "ambassadorial considerations" as translations of French Quebec literature into English in Canada (Bednardski 1995, 122), in that English translation makes the literature of a region and a culture known to other regions of the country, 
and serves to establish a certain credibility and a relationship of mutual regard as well. However, English is one of Canada's two official languages; it is an inherent language there. In India, such ambassadorial considerations could be just as readily and successfully fulfilled by translation into and among the various Indian languages, rather than into English. On the other hand, translation into English does, at the moment, help to establish or construct the oneness, the nationness of India. With regard to the English translation of Quebec literature in Canada, Kathy Mezei remarks, "What and how certain texts are translated, what is omitted, what is altered, and what is foregrounded can give us a biased and modified impression of Quebec culture. Quebec becomes not what it is, but what we wish it to be" $(1995,142)$. A similar process is set in motion in translating Indian literary texts into English in India, but in this case, not to present a particular region as we wish it to be - that is, different - but to make the entire nation what we wish it to be - that is, unified.

In an essay dealing with anthologies of Indian English poetry, Suman Gupta argues that the real danger with "Indianness" is that the grammar of singularity is so pervasive,

that it seems almost natural that anthologists should try to find an adequate Indian experience in the selected texts, should identify with centrist definitions of Indianness at the expense of local realities, should think of the various literatures in Indian languages as $a$ continuous Indian literature, should think of living and experiencing India as one continuous experience, and provide all this with the sonority of an assumed voice of the nation. $(1996,112)$

Local realities from which the various Indian language-literatures ariseand to which they return-will, in anthologies of Indian literature, be "constantly made corollary to a larger homogenous Indian reality" (112). In Gupta's opinion, this situation is almost inevitable because while there may be various Indian language-literatures, there is no Indian literature in Indian languages. What there may be is "a Bengali literature of India, a Tamil literature of India, a Marathi literature of India, and so on-i.e., indigenous literatures which acknowledge perspectives of the nation-people that are conditional upon their local realities" (111). Gupta does acknowledge the possibility of nationalist literatures in various Indian languages under certain political conditions, and constructed against the grain of local realities. But these are unique and discontinuous moments.

Meenakshi Mukherjee, in her review entitled "A Feast Cooked in Clarified Butter," of Macmillan India's new series, remarks that the project editor, Mini Krishnan, "surprises us ... by the unexpected solemnity of her homogenising rhetoric in the introductory note where she projects our 'In- 
dian tradition' as 'one of humankind's most enduring attempts to create an order of existence that would make life both tolerable and meaningful" $(1996,15)$. Indeed, in the main Introduction, which is published in all the novels of the series, Krishnan remarks that "all Indians know that they have a complex, stable system of values, beliefs and practices which-though forged long ago-has never really been interrupted." The aim of the new Macmillan series is to explore this "stable system of values, beliefs and practices" that underlies the surface differences that seem to exist in India. Krishnan hopes that "these novels will express most of the ideas, customs, unquestioned assumptions and the persistent doubts that have characterised Indian life for at least a thousand years."

This admirably patriotic sentiment raises as many doubts about the credibility of the venture as it seeks to answer, because the series brings together in English translation, as stated in the Introduction, "selections from the corpus of fiction Indians have created after their Independence (1947)." It seems therefore that the basic assumption is that there is an India which has existed continuously for at least a thousand years, and this India can be excavated, explored and expressed through the English translation of contemporary novels originally written in modern Indian languages. It must be assumed that this premise governed the choice of texts to be translated, and that novels which do not express this continuity of the Indian condition were rejected.

Mini Krishnan could not be unaware of her assumption or the choices it dictates. On the contrary, she is fully conscious of her politics. At the aforementioned translation seminar, which focussed on the series, Krishnan prefaced her intervention with the seemingly off-the-cuff, throw away remark that she "thought that Delhi was a foreign country to us southerners. Nothing we ever did for fourteen years [there] ever caught up here" (1997, 3 ), later adding that "there are lots of people who have yet to know something about the south, [and] southerners who know very little about the north... There is definitely a great ignorance within India itself" (3). Krishnan's agenda as editor of the Macmillan series project, then, is to map an India where the North-South divide is shown to be superficial-the result of a layer of amnesia coupled with hegemonic tendencies of the Hindi belt, and resistant aspirations of the south-and which can be dusted away through translation into the neutral English language to reveal the fundamental and continuing unity underneath. This agenda parallels political developments in India - the south having contributed two prime ministers in the recent past - as well as developments in the powerful popular culture domain of the cinema.

Among the major film releases from the south, which have taken the rest of India by storm in the last few years, is Tamil director Mani Ratnam's 
patriotic film Roja. Roja deals with Kashmiri militancy-a subject that had not been tackled until then by Indian filmmakers. It argues and plays upon patriotic sentiments for a united India, stressing the continuities across the nation. The film's importance lies in the fact that it is a Tamil film, from a region which saw and defined itself - and perhaps still does - in the realm of politics as different from the rest of India, a region which sought autonomy as a first step toward the redemption of Tamil honour. Sisir Kumar Das points to the growth of Dravidian chauvinism as an example of the rising sense of regionalism which "at its best, is rooted in certain cultural specifics lending literary creations concreteness, and at its worst, a false sense of superiority offending the other and eventually demeaning the self' $(1995,387)$. Tamil regionalism expressed in the "glorification of the Tamil language and culture was intensified by a continuous repudiation of Sanskrit culture, 'the Aryans' and 'north India"' (387). Language became a new instrument of power politics and this linguistic patriotism is, in Das's view, "a threat to the idea of nation constructed by the Indian elite" (389). Roja attacks such fissiparous tendencies and makes an emotional statement for unity among the people. It is important for Tamils to assert themselves as both Tamil and Indian, but this comes with an equally important political agenda: it is the Tamils who wish to define or restate Indianness. The Macmillan translation project that gave birth to the new series reflects this newly effervescent South Indian leadership in Indian politics and popular culture, and the South Indian's desire to imagine an India in which she/he would have a crucial role to play.

Shobhana Bhattacharjee compares the Macmillan "Modern Indian Novels in English Translation" series to the Indian folktales series that became widely available in the first decade after Indian Independence. The folktales were published as the Lok Kathayen of various states: "The states were new, the stories were ancient, but by linking stories to states, these units of the new nation were given a legitimacy of tradition. More than that, we became aware of the states, and since the books' covers were nearly identical, we slotted them away in our minds as parts of a whole" $(1997,4)$. Thus while giving traditional sanction to differences, the folktales also helped to reinforce the unity of the newly born nation: "that's how they were bought for us - with pride in this new-born creature called Independent India, a unity constituted of different elements" (4). Bhattacharjee remembers liking the folktales series, and makes the following comment about the new Macmillan novel series: "my first old-fashioned reason for liking the Macmillan translations is that visually and physically the books are a unity, and whether it is intentional or not, this reminder of that early nation-building effort pleases me" (4). And she pointed out that novels originally written in Indian languages make available through English translation an India vastly different from that of contemporary Indian English novels, or more 
specifically, Stephanian English novels. Usually the characters in Stephanian novels are cushioned by wealth and privilege, whereas the lives of the characters in the Macmillan novels "are decided for them by the poverty and systems of belief and law and justice that hedge them in" (4).

Indeed the Macmillan novels portray an India different from that of the urban, upper-middle-class, westernized Indian. The crucial difference between the post-Independence folktales and the Macmillan novel series is that the folktales were published in Hindi, while the novels are in English translation. The Hindi (northern Indian) vision and appropriation of Indian literary culture is replaced by a contemporary novel production staking a claim to pan-Indianism in English - a language that is not inherent to any hegemonic region in India. The choice of language was deemed necessary not just because Macmillan is an English-language publisher, but because English is the language that South India uses to counter Hindi hegemony when attempting to address the whole of India. English is used as the vehicle of unity.

N.S. Jagannathan agrees with, and welcomes, the assertion of unity underlying the Macmillan series, calling it "the civilisational unity we have had in spite of everything else" (Apr. 1997, 5). He includes in his concept of unity the protest movements Manu and Ambedkar, which are part of Indian tradition. But he identifies another level of unity, one imposed by the "two hundred years' British rule in which we as colonials and post-colonials have shared a pan-Indian experience" (5), including the unification of the nation-state and the commonality imposed by English education. Jagannathan agrees that there must be a certain politics involved in choosing the novels, and offers some selection guidelines: the writers should be the best or, at least, near-best in their region; they should have a certain allIndia visibility; the quality of the story should be high; and there should be a balance in approach and treatment. Jagannathan would like to see some comic fiction included, but fails to see that the guidelines he suggests will devalue differences and lead to the selection only of work which deals with what can be universalized as Indian. Paradoxically, he argues for the inclusion of a "quintessentially" Bengali novel, and for more women writers, because "we live in a society in which the male gets away with so much" (5). Jagannathan leaves us in some confusion as to what he means by "the best" or "all-India visibility," and how they square up with quintessentially regional novels and those written by women.

That these are problems the editors working on the Macmillan novel series faced is apparent when one peruses the final list, which helps to illustrate some of the points made in this paper so far. Eleven novels were selected to be translated: five are in South Indian languages - two in Tamil, two in Malayalam, one in Kannada; three novels are in East Indian 
languages - two from the often-neglected Oriya, one in Bengali; and of the remaining three novels, one is in Gujarati from the West, the other two from North India - one in Punjabi, the other in Hindi. While it is true that this series is only the first in an ambitious translation project, its biases are worth noting: there are five novels from South India; there are only two novels by women writers, and both are in Tamil. Women are fairly well represented in the whole project: the project editor, Mini Krishnan, is a woman from South India; of the language editors, who must have had some influence on the choice of novels to be translated, two are women-Nabaneeta Dev Sen for Bengali and C.T. Indira for Tamil; and interestingly, but not surprisingly, most of the translators are women.

With regard to the novels: the Tamil novels, Lamps in the Whirlpool by Rajam Krishnan and Yamini by Chudamani Raghavan - the only novels by women writers in the series-are Brahminical in setting and question traditional Hindu values and beliefs, especially as they circumscribe the lives of women; the Malayalam novels, Pandavapuram by Sethu and Outcaste by Matampu Kunjukuttan, address the question of women's sexuality and societal morality, respectively; the Kannada novel, Bharathipura by U.R. Ananta Murthy, centres on a foreign-educated Indian man who returns to his hometown, Bharathipura. It explores and interrogates various ideas and beliefs, from the traditional hierarchical and religious to the modern romantic and liberal. The Song of the Loom (Hindi) by Abdul Bismillah, which describes the lives of Benares weavers, was "widely acclaimed [in the original version] for its densely textured portrayal of a localized community from a discernibly progressive perspective" (Joshi 1996, 16). As Maya Joshi writes, this book also asserts "the need to interrogate the notion of an uncomplicated continuity as something to be particularly proud of" (16). Face of the Morning (Oriya) by Ganeswar Mishra is written from a child's point of view, and is set in the temple town of Puri; The Survivor (Oriya) by Gopinath Mohanty is not set in a particularly characteristic geographic location, but, as has been noted, contextualization of Oriya life and culture compensates for its setting's lack of specific character. The other novels are fairly specific as to their geographic and cultural locations.

In the main Introduction, as previously noted, project editor Mini Krishnan states that these novels express and explore "a complex stable system of values and practices which - though forged long ago - has never really been interrupted." Indeed, all the novels are written from within specific traditional Hindu societies, and all question various facets of these societies, the hierarchies and hegemonies that have always existed. But the India this series of novels actually maps is quite different from the India one would expect to encounter based on the project editor's Introduction. 
Examining how the project attempted to level out the local rootedness of each novel to form a unified corpus of modern Indian novels, I discovered that this was done through the introduction to each novel, which largely treats it as an individual free-floating text dealing with various Indian themes. There seems to be a certain haphazardness about the introductions, as if the decision to write one for each novel was a last-minute decision: five introductions are by the language editors, and the Hindi novel also has a preface by the translator; two introductions are written by the individual translators; and four were written by critics. Of these eleven introductions, only three attempt to place the novels concerned in their specific literary context, by highlighting their position in their regional literary histories; four introductions (including two which mention literary histories) discuss the authors' other works; and all the introductions, except for the one accompanying the Hindi novel, offer a reading of the novel, often in terms of background, plot, characterization and style. The Hindi novel has an expressionist introduction by the language editor, who calls it the Prologue.

Most importantly, while the series consists of modern Indian novels in English translation, there are no annotations by the translators in any of the novels, even though at least one translator, Rana Nayar, claims having provided translator's notes, but that it was the publishers' decision not to incorporate them. In Nayar's opinion, the translator's notes would have been informative, and since the language editors make no mention of translation problems encountered by the translators, they should have been included in the final publication of the novels $(1997,8)$. Indeed, none of the language editors addresses the issue of translation problems, except in very general terms. Manoj Das's introduction to the Oriya novel Face of the Morning, which was translated by Prafulla Mohanty and Jo Westbrook, mentions that "[c]ertain elements in this work, its lyrical and often colloquial narrative quality besides, cannot survive translation" (ix). Das cites the example of an Oriya simile in the original, whereby someone's "cheeks are found to have swelled like Chitau Pitha" (ix). To fully appreciate the appropriateness of the simile in the text, one has to know what Chitau Pitha is, and to know that, one has to have direct knowledge of the culture. He also deemed it necessary to highlight the cultural importance of, and reverence for, the cow in Indian society. Das concludes that if despite such demands on the translation process, the novel has turned out well in English, it is because the novel displays such love and understanding of the characters that it can inspire empathy in readers from a different milieu. Even in the introduction to the Malayalam novel Outcaste, which is written by the translator, Vasanthi Shankaranarayanan, who mentions specific translation problems, the particular problems, as well as the strategies used to solve them, are stated in very general terms. In a paragraph on the language used in the novel-a mixture of Sanskritized Malayalam, and the colloquial 
conversational dialect peculiar to the Namboodri community-and the particular features of the writer's style, Shankaranarayanan merely mentions that "in order to overcome the difficulties presented by a combination of these factors, I have used approximations wherever possible and have changed the construction of the sentences so that they made sense in English" (xv). She also uses detailed footnotes in the translation, as do all of the other translators, and includes a name index at the end, an editorial strategy unique to her translation. An awareness of the cultural moorings of each novel comes through in this series, but there seems to be a reluctance to spell it out or even mention it in terms that would problematize the project's agenda - the recovery of a united India.

Consequently, the "free-floating" texts are not free-floating after all, but are treated as such to fit in the agenda established by the project editor. This seems somewhat paradoxical, given the editorial practice of detailed footnotes generalized throughout the series. In her Introduction to the series, Krishnan explains that the footnotes in the texts are not intended for the Indian reader and are not intended to explain regional specificities, but rather to explicate Indian expressions and Indian cultural practices to the foreign English-language reader: "Some of the footnotes may seem excessive but they have been prepared with non-Indian readers in mind" (v). That she had non-Indian readers in mind is apparent from her parenthetic glossing of the year of India's independence from the British, a date all Indians are expected to know, and the curious use of the possessive in the same sentence in her Introduction: "The method we have adopted is to translate selections from the corpus of fiction Indians have created after their independence (1947)" (my emphasis). And those Indians have strange pilgrim towns, like Rishikesh ${ }^{1}$ and Badri, ${ }^{2}$ and many tiny waterways, like the Alakananda, ${ }^{3}$ which the project editor felt were necessary to explain in footnotes for their readers. Thus, three footnotes appear on the very first page of Chudamani Raghavan's Yamini:

1. A pilgrimage town on the river Ganga in the Himalayan foothills.

2. Shrine of Lord Badrinath (Vishnu) in the Himalayas, the tallest mountain range in the world, sacred to the Hindus, who believe that the gods live there.

3. A tributary of the Ganga, it meets the Bhagirathi and both together form the Ganga.

In fact, there are so many footnotes in the translations that Meenakshi Mukherjee reacted thus: "[T] he inane footnotes first irritated and then infuriated me so much that with a masochistic compulsion I kept looking at the bottom before reading the page" $(1996,15)$. Mukherjee fails to understand why terms like sari, dhoti and Brahmin need to be explained or defined in a 
footnote or how the footnote imparts new knowledge to the reader, for sari is described as "a five-metre length of material which Indian women wrap around themselves"; dhoti is defined as "a sarong-like piece of cloth" (shouldn't "sarong" be explained as well?); and a Brahmin is "the highest caste among Hindus." Even more interesting is the need for a footnoteand the footnote itself-accompanying the word "coconut," which is described as "a fruit like the breadfruit." Mukherjee castigates the project editor for "justifying their presence in the name of some mythical non-Indian reader, presumably retarded" (15).

In defence of the need for footnotes, Mini Krishnan stated, at the translation seminar in New Delhi in 1997, that she saw these novels as textbooks to be used in various universities across India itself, and that she considered the notes necessary for Indian students also, as there is such a great divide within the country: "There is definitely a great ignorance within India itself" (1997, 3). She claimed that the footnotes were prepared keeping in mind the Indian teachers who "need a lot of help," but also the foreign reader who is not at all mythical: she knew for a fact that many tourists and other foreigners had read the novels and had greatly appreciated the footnotes. Krishnan's defence of her decisions is quite significant in what it reveals: on the one hand, the project wishes to project the image of a unified India, an India of unbroken continuities, to Indian readers-in which case, there should be no need for these kinds of footnotes; and on the other hand, the project wishes to export this India overseas, even if at the moment it caters only to tourists and foreigners in India. Thus, the footnotes, which, to all intents and purposes, are for the benefit of the foreign reader, actually camouflage the project editor's belief that the Indian reader also needs footnotes, and contradict her assertion of "unbroken continuities" or a homogeneous Indian culture despite the many regional languages and traditions. Krishnan admits that there is a "schizophrenic impulse" behind her having these novels published for two very different markets: the Indian textbook market and the English-speaking world market. This schizophrenia also seems to influence her ambivalence between homogeneity and difference among the various regions and language-cultures in India.

I think the problem lies in that Krishnan and the Macmillan series team sought to kill too many birds with one stone. At the seminar, she claimed that the terminological footnotes were necessary because "I definitely want people who don't know our language to understand them ... they haven't had our language for two hundred years, the way we have had theirs" (1997, 3 ). (Note her use of "language" in the singular-a slip of the tongue perhaps, but a revealing one.) For, she says, it is easier for Indians "to slip between East and West than it is for [foreigners] to open the gate and get into our diverse culture" (4). (Note her use of "culture," again in the singu- 
lar.) The project's agenda is thus made clear: to construct a culture that accommodates diversity in one chosen language-English.

This attempt to drown out differences could not succeed in any case, for even apart from the problems a foreigner would have understanding local cultural details, as well as the religious and caste configurations that exist in India, how would a translator deal with a novel like Abdul Bismillah's The Song of the Loom, which is heavily footnoted in the Hindi original itself, because of "the almost ghettoized specificity of the novel, and the author's avowedly documentary intentions" (Mukherjee 1996, 16). This novel believes in the difference of the people it portrays, a different community, a different world from that of other Hindi speakers in India. Such an authorial intent to explore a world that is so different from the mainstream regional language-culture characterizes many other contemporary Indian novels, including those in this series. According to translator Rana Nayar, the major problem encountered in translating Gurdial Singh's Night of the Half Moon was that it isn't in standard Punjabi, but rather in the Malwayee dialect $(1997,8)$. In fact, Punjabi words are often in quotation marks to emphasize the difference between the Punjabi reader's and the Malwayee character's worlds. Such nuances and intentions in the originals have been flattened out in the English translation of most of the novels. It is obvious that the Macmillan translation project was not concerned with maintaining or highlighting differences or discussing translation problems. This is probably due to the notion that translating into English is considered an almost "natural" activity in India, and any difficulties encountered in transposing meaning from an Indian language into English are simply seen as inherent to all translation activity.

However, upon closer examination, this is not the case. Not only is there an asymmetrical power relationship between English and Indian languages in terms of global politics, but there is also an asymmetrical power relationship between English and Indian languages within India itselfEnglish being the language of the urban elite. For this reason, Shobhana Bhattacharjee has a problem with the Benarsi weaver (in The Song of the Loom) swearing in English (e.g., "arsehole"), for it brings to mind urban Westernized youths, and not Benarsi weavers at all; the weaver in question would sound more authentic to her if the equivalent in his Hindi dialect was used in the English translation (1997). Awareness of this power relationship also prompted Tamil writer C.S. Lakshmi (Ambai) to comment that "being translated into English was a kind of promotion" $(1997,23)$. She says that it was only after her work had been translated into English that she was invited to various forums, "because when you write in Tamizh [Tamil] only, they assume that you don't have anything to state." More interestingly, however, she warned that translation into English could start a trend whereby 
writers write to be translated, and exoticize their realities for an audience in translation: "there is this danger of looking at your own culture in a much exaggerated self-conscious way and detailing realities the way you have never done before, because you feel these details will be important for somebody else" (23).

Many writers will participate willy-nilly in an unarticulated agenda to provide foreign readership with an ethnic third-world India, to such an extent that while, as Harish Trivedi puts it, the numerous footnotes that translators of these books see fit to include indicate "a desire to act as native informants for these texts," they end up constituting a sort of "colonial cringe," more like "falling-at-the-feet notes" $(1997,27)$. But the question is, Whose feet are they falling at? British royalty no longer lands at the Gateway of India, nor does the American plutocracy drop anchor there. Today the Gateway of India stands as a firm reminder of British colonialism in the cosmopolitan city of Mumbai, which the British called Bombay. It attracts Indian tourists from other parts of the subcontinent, who take ferry rides to and from the monument. It is now Indian tourists who leave and enter the Gateway, who contemplate an India keen to reassert its regional identities. This is the audience that English translations in India should address first and foremost: an Indian English-speaking audience whose vision of the world is seen through the Gateway of India, but whose vision of India as a unified nation is also seen through this same Gateway. Sujit Mukherjee opines that it is this audience that publishers of English translations in India should be targeting, before even thinking about the unknown international market. Indo-English literature (as Mukherjee calls Indian language-literature in English translation) commands "a national market" consisting of Indians "who read books for pleasure," who "do not read any Indian writing, either because they receive greater satisfaction from reading foreign authors, or because they cannot read any Indian language well enough to be able to respond to literature composed in that language" $(1994,132)$.

The most appropriate audience for Indo-English literature in India is therefore the general Indian reading public who read in English for the pleasure of rediscovering their cultural heritage or to place a particular work in the context of other Indian language-literatures. Thus English as the Gateway of India at the turn of the millennium should serve and address, mainly and squarely, an Indian public. The Indian reading public constitutes a large and important market for Indian language-literatures in English translation. Future translation projects should focus on that public, and assume that foreigners entering the Gateway have sufficient knowledge of Indian culture(s) to navigate through Indo-English literary waters. It is perhaps time for India to take a leaf from Canada's book and refocus its literary translation activity as an "intra-national," rather than an "inter-national" 
affair, thereby providing Indian translators with a precise target-audience, with a "precise collective destination" (Simon 1995, 8).

\section{Works Cited}

\section{Theory and Criticism}

AHMAD, Aijaz. 1995. In Theory: Classes, Nations, Literatures. First published 1992. New Delhi: Oxford UP.

BEDNARDSKI, Betty. 1995. "From Ouèredéare to Soçaurez: Translating the English of Jacques Ferron." In Culture in Transit: Translating the Literature of Quebec, ed. Sherry Simon, 110-32.

BHATTACHARJEE, Shobhana. 1997. The Book Review (Apr.). New Delhi.

DAS, Sisir Kumar. 1995. A History of Indian Literature, 1911-1956. Struggle for Freedom: Triumph and Tragedy. New Delhi: Sahitya Akademi.

GUPTA, Suman. 1996. "Reinscribing Nation-People in Anthologies of Indian English Poetry." Journal of Commonwealth Literature 32, no. 2.

JAGANNATHAN, N.S. 1997. The Book Review (Mar., Apr.). New Delhi.

JOSHI, Maya. 1996. The Book Review (Sept.). New Delhi.

KRISHNAN, Mini. 1997. The Book Review (Apr.). New Delhi.

LAKSHMI, C.S. 1997. The Book Review (Apr.). New Delhi.

MEZEI, Kathy. 1995. "Speaking White: Literary Translation as a Vehicle of Assimilation in Quebec." In Culture in Transit: Translating the Literature of Quebec, ed. Sherry Simon, 133-48.

MUKHERJEE, Meenakshi. 1996. "A Feast Cooked in Clarified Butter." The Book Review (Sept.). New Delhi.

1997. The Book Review (Jan.-Feb.). New Delhi.

MUKHERJEE, Sujit. 1994. Translation as Discovery and Other Essays on Indian Literature in English Translation. 1981. Reprint. Hyderabad: Orient Longman.

NAYAR, Rana. 1997. The Book Review (Apr.). New Delhi.

NIRANJANA, Tejaswini. 1992. Siting Translation: History, Post-Structuralism and the Colonial Context. Berkeley: U of California P.

SIMON, Sherry, ed. 1995. Culture in Transit: Translating the Literature of Quebec. Montreal: Vehicule Press.

TREVELYAN, Charles. 1838. On the Education of the People of India. London: Longman, Orme, Brown, Green and Longmans.

TRIVEDI, Harish. 1997. The Book Review (Mar.). New Delhi. 


\section{Novels}

ANANTHA MURTHY, U.R. 1996. Bharathipura. Trans. P. Sreenivasa Rao. Madras: Macmillan.

BISMILLAH, Abdul. 1996. The Song of the Loom. Trans. Rashmi Govind. Madras: Macmillan.

DAVE, Harindra. 1996. Henceforth. Trans. Bharathi Dave. Madras: Macmillan.

KRISHNAN, Rajam. 1996. Lamps in the Whirlpool. Trans. Uma Narayanan and Prema Seetharam. Madras: Macmillan.

KUNJUKUTTAN, Matampu. 1996. Outcaste. Trans. Vasanthi Shankaranarayanan. Madras: Macmillan.

MISHRA, Ganeswar. 1996. Face of the Morning. Trans. Prafulla C. Mohanty and Jo Westbrook. Madras: Macmillan.

MOHANTY, Gopinath. 1996. The Survivor. Trans. Bikram K. Das. Madras: Macmillan.

MUKHOPADHYAY, Shirshendu. 1996. Woodworm. Trans. Shampa Banerjee. Madras: Macmillan.

RAGHAVAN, Chudamani. 1996. Yamini. Trans. Vasantha Surya. Madras: Macmillan.

SETHU. 1996. Pandavapuram. Trans. Prema Jayakumar. Madras: Macmillan.

SINGH, Gurdial. 1996. Night of the Half Moon. Trans. Pushpinder Syal and Rana Nayar. Madras: Macmillan. 
This page intentionally left blank 


\title{
Chapter 14
}

\section{TRANSLATING (INTO) THE LANGUAGE OF THE COLONIZER ${ }^{1}$}

\author{
Paul St-Pierre \\ Université de Montréal (Canada)
}

The difficulties which immediately arise when terms such as colonialism or postcolonialism are used are by now well-known, ${ }^{2}$ and so too are the critical discourses that they nevertheless make possible and which account, at least in part, for their continued use. My aim here will not be to justify or to criticize the use of such terms; rather, I wish to examine the way in which certain themes they point to are played out in Chha Mana Atha Guntha (literally Six Acres and Thirty-Two Decimals) —an Indian novel published at the turn of the century, at a time when the British Raj was actively consolidating its power and position in India-as well as the transformation these themes undergo in the three English translations of the novel which have appeared since Indian Independence. It will become clear that although all three translations are postcolonial, in more than a merely chronological sense, they differ greatly in the choices made by the translators and in the way they situate themselves in relation to colonial rule. The tension between the generalization necessarily involved when terms such as colonialism and postcolonialism are used, on the one hand, and the specification of particular texts and contexts, on the other, informs my approach here.

More specifically, this paper will look at the way in which two important and related instruments of British colonial rule-law and languagefigure in the novel, and how they are dealt with in the translations. Bernard S. Cohn has demonstrated that law and language within India ${ }^{3}$ under colonial rule were part of a larger series of "orderings" imposed on Indian 
society by the colonizers. Often through the use of translation and the equivalences it provided, British categories of thought were substituted for native Indian ones. Of the educated Englishmen who arrived in India in the late eighteenth and early nineteenth centuries, Cohn writes:

In coming to India, they unknowingly and unwittingly conquered not only a territory but an epistemological space as well. The "facts" of this space did not exactly correspond to those of the invaders. Nevertheless, the British believed they could explore and conquer this space through translation: establishing correspondence could make the unknown and the strange knowable. $(1996,4)$

Conquest of India was to take place through the translation of one space into the other, both literally and figuratively, a translation which involved a hierarchical ordering, with one space-the native or Indian space- marked as inferior and in need of translation. This conquest took various forms, and Cohn has defined different modalities of appropriation whose purpose was to give the colonizers control by transforming the Indian space in terms of their own familiar categories and prior expectations (5-11). Among these were observation and travel, mapping and surveys, census-taking, the collection of artifacts and the production of historiography. As Cohn remarks, the "conquest of India was a conquest of knowledge" (16).

Many of these modalities arose out of very pragmatic concerns. One of the principal aims of the production of historiography, for example, was to determine "how revenue was assessed and collected" (5). As Sunil Khilnani has pointed out, the notion of the state the British brought to India was fundamentally different from that existing there; they defined "power in political terms and locat[ed] it in a sovereign, central state," one of whose principal duties was "to siphon off commercial and economic benefits more efficiently" (1997, 21-22). The same economic concern was at the heart of the codification and "clarification" of the Indian legal system, its ultimate transformation in terms of British modes of thought and functioning based on the interpretation of precedent, which were alien to the modes of legal functioning native to India. ${ }^{4}$ The main purpose of such clarification was to ensure regular revenues to the state through the assessment of taxes on property. For such revenue to be collected, the ownership of property needed to be clearly established. Thus Sir William Jones (1746-1794), one of the major figures of British colonial rule in India, set out with the purpose of codifying the aspects of civil law which would determine "those rights, public and private, that affected the ownership and transmission of property" (Cohn 1996, 71). As will be seen in the discussion of Chha Mana Atha Guntha, the effects of such reform on Indian society were profound and often disastrous. $^{5}$ 
Yet another purpose of codification was the desire to avoid reliance on native interpreters of the law, as their honesty, competence and disinterest were deemed suspect. Jones distrusted "Indian scholars' interpretations of their own legal traditions" and "wanted to provide the British courts in India, the Crown, and the East India Company with a sure basis on which to render decisions consonant with a true or pure version of Hindu law" (69). As such, the codification of law was intimately tied to translation into the English language, as the law was to be administered by British judges and courts, with the result that during the first part of the nineteenth century it was "the chain of interpretations of precedents by English judges that became enshrined as Hindu law" (emphasis added) (75). Significantly, what had begun as an attempt to provide India with "a true or pure version of Hindu law" ended with its replacement by law made in India by British judges.

The learning and codification of Indian languages through the production of grammars and dictionaries, as well as the production of translations into English, was also one of the modalities of colonial control (see, in particular,"The Command of Language, and the Language of Command" in Cohn 1996, 16-56). English was introduced as the language of administration, law and higher education, which had the effect of limiting access to positions of power and influence to Indians who developed a vested interest in ensuring the continuation of colonial rule. Proximity to the colonizers, whether geographical or linguistic, or both, as in the case of the Bengali "babus" (see note 10 infra) in the nineteenth century, created new elites, which became increasingly distanced from their own society and culture. Identification with the colonizers seemed to provide an opportunity to escape the inferior position in which these very colonizers had placed them, and one form this identification took was the adoption of English at the expense of their native Indian language.

The use of English in India, which has continued and even increased since Independence, is certainly one of the more enduring legacies of British rule, although the importance English retains should now be seen more in a global perspective than as a purely colonial heritage. In a country where only a tiny educated minority have access to English, it remains the language of the courts and of higher education, and retains its function as a source of position and privilege. Chha Mana Atha Guntha draws attention to the ambiguity surrounding the use of English, to the creation within India of a heterogeneous English space in contradiction with local and regional traditions and history. The novel represents, but also problematizes, the hierarchy of languages and cultures established during the colonial period, resisting the dominance of foreign linguistic spaces, whether English or, as in the case of Bengali, the language of the intermediary spaces between the colonized and the colonizer. Examples of the latter are the language of 
middle-level administrators (the babus) acting as go-betweens in the two spaces and whose interest lies in maintaining the separation, and the language of lawyers, also positioned between the two spaces and able to manipulate the legal system to their own advantage.

It is largely because the novel is written in an Indian vernacular that this dual space, with its hierarchies, impositions and renunciations, can be so effectively evoked. What happens then when the novel is translated into English, the language of the colonizers? As Vicente Rafael has rightly argued, all translation activity necessarily involves the creation of hierarchies; it is the particular nature of the shift from one set of hierarchies to another, through the process of translation, that this paper will attempt to describe.

\section{Chha Mana Atha Guntha}

Chha Mana Atha Guntha, by Fakir Mohan Senapati, was serialized in the monthly publication Utkal Sahitya between 1897 and 1899, and published in novel form in 1902. It is considered a founding text of modern Oriya literature, ${ }^{6}$ and the first Indian social-realist novel. Despite being held in high esteem, it nevertheless remains at a temporal, cultural and linguistic remove from its readers. This distance is both one of tone and of language, the duality inherent in the narrative voice serving to create an ironic distance between text and reader, while yet another form of distance is created through the use of non-Sanskritized, colloquial Oriya rather than the more "elevated" forms usual in literature. Somewhat paradoxically, the decision to use language closer to that of everyday use has resulted in the novel containing words and expressions which have disappeared from modern Oriya and which require explanation and footnotes for today's Oriya reader. Indeed, the difficulty which the original poses for such readers will very likely lead many to have access to the text solely through its English translation. ${ }^{7}$

Chha Mana Atha Guntha recounts the rapacious greed of the main character, Ramachandra Mangaraj, and his mistress, Champa, their lust for a small plot of land - the six acres and thirty-two decimals referred to in the title - and their ultimate downfall: she is murdered by a fellow thief and Mangaraj is dispossessed at the hands of an unscrupulous lawyer. The manipulation of the legal system is a major theme of the novel and a moving force behind the unfolding of events. Of as much interest as the bare storyline, however, is the manner in which the story is told, especially its satirical tone, which creates a relationship between the narrator and his tale such that as the narrator tells the story, his comments lead us to hear another, contradictory, voice calling into question much of what he affirms and indeed all forms of authority, and creating a critical distance informing the novel as a 
whole. An illustration of this can be found at the very beginning of the novel, where the narrator discusses the suggestion that Mangaraj is perhaps not as pious as he might seem, that he does not fast as he pretends to do on holy days: ${ }^{8}$

Just the other afternoon, though, Mangaraj's barber, Jaga, let it slip that on the evenings of ekadasi a large pot of milk, some bananas, and a small quantity of khai and nabata are placed in the master's bedroom. Very early the next morning, Jaga removes the empty pot and washes it. Hearing this, some people exchanged knowing looks and chuckled. One blurted out, "Not even the father of Lord Mahadeba can catch a clever fellow stealing a drink when he dips under the water." We're not absolutely sure what was meant by this, but our guess is that these men were slandering Mangaraj. Ignoring their intentions for the moment, we would like to plead his case as follows: Let the eye-witness who has seen Mangaraj emptying the pot come forward, for like judges in a court of law we are absolutely unwilling to accept hearsay and conjecture as evidence. All the more so since science textbooks state unequivocally that liquids evaporate. Is milk not a liquid? Why should milk in a zamindar's household defy the laws of science? Besides, there were moles, rats, and bugs in his bedroom. And in whose house can mosquitoes and flies not be found? Like all base creatures of appetite, these are always on the lookout for food; such creatures are not spiritually minded like Mangaraj, who had the benefit of listening to the holy scriptures. It would be a great sin, then, to doubt Mangaraj's piety or sincere devotion. Such is our firm belief.

In this passage, the mere accumulation and juxtaposition of arguments, supposedly in Mangaraj's favour, serve to discredit him; in the end, readers are led to associate him with the moles, rats, bugs, mosquitoes and flies with which he shares his bedroom. The satirical tone of the passage, targeting not only Mangaraj but the judges in the law courts and legal proceedings, where lies can become truth and truth can be ignored, and even the texts of science and holy scripture, is a constant feature of the novel, which takes aim at all forms of authority and most especially those whose power oppresses the weak. ${ }^{9}$

The novel presents the theme of loss, in its many forms, but more specifically - and this is what ties the novel to the colonial context-loss as a direct result of the manipulation of the legal system. Mangaraj manages to gain control of Ali Mian's land by loaning him money (revenues he obtained from Ali Mian's own zamindari, in fact), knowing full well that Ali Mian will default on repayment; he tricks Bhagia and Saria into forfeiting their six acres and thirty-two decimals by exploiting their naïveté and lack 
of experience with legal documents; and finally, Mangaraj himself loses everything when he is condemned for stealing Bhagia and Saria's cow, and is reduced to signing over all his possessions to his lawyer, Ram Ram Lala, in the vain hope that in this way he might be able to conserve them. What is particularly significant in all these instances is the way in which land changes hands, involving very often the (mis)application of the law. As John V. Boulton points out in his work on Fakir Mohan, the use of the legal system to determine ownership and facilitate the transmission of property was something new in nineteenth-century India and a direct result of British colonization. Land had always been the principal source of power in Oriya society, but previously it had not been exchanged. As a result, "before the coming of the British ... the mercantile classes had been gaining increasing social importance, but had, up to then, failed to secure any real power. By a change in the tenancy laws the British enabled the mercantile classes to invest their fortunes in land" $(1993,393)$. The accumulation of land by Mangaraj, as well as its subsequent loss, should thus be seen as a specific and, for the narrator, distinctly negative result of colonial occupation. This is made clear through the contrast between Mangaraj and the Baghasinghs, traditional zamindars now living on the edge of poverty, but still retaining their autocratic and feudal ways. Mangaraj's success in destroying what remains of their property and power, through Champa's trickery, only serves to further accentuate the evils the author associates with modem, that is, colonial, times.

Yet another form of dispossession presented in the novel relates to language and culture. Contact with the British is considered to have had negative effects upon education and social practices in Orissa. To quote from Boulton again: "the exposure of Hinduism to the challenge of Christianity and Western scepticism weakened the respect of the young for their parents, caste councils and religious faith; morality declined among the Western-educated; and in towns alien vices were indulged" (497). This theme of degeneration is reiterated throughout the novel especially through the references to the "babus," a term mixing both respect and contempt, and enabling the narrator to maintain his ironic distance. ${ }^{10}$ Thus the following passage from the novel:

As for us, it is not that we do not know how to describe the beauty of a heroine. Consider how ridiculously easy it is. According to classical literary techniques, all one has to do is find parallels between specific attributes of our heroine Champa and different fruits, such as bananas, jack-fruits, or mangoes, and common trees, leaves, and flowers. But such old-fashioned methods are no longer suitable; for our English-educated babus we now have to adopt an English style. Indian poets usually compare the gait of a beautiful woman to that of 
an elephant. The babus frown on such a comparison; they would rather the heroine "galloped like a horse." The way English culture is rushing in like the first floods of the river Mahanadi, we suspect that our newly educated and civilized babus will soon appoint whipcracking trainers to teach their gentle female companions to gallop.

These same babus, the narrator tells us, "are educated; they have studied and have mastered profundities." But, he continues, "Ask a new babu his grandfather's father's name and he will hem and haw, but the names of the ancestors of England's Charles the Third will readily roll off his tongue. To be considered a scholar, it is necessary to have read about the English and the French; there is no point in learning about oneself or one's neighbour." These westernized, English-learning, English-educated, modern (all adjectives used in the text) babus have divorced themselves from their own history and culture. They identify completely with the colonizers in an attempt at assimilation, itself a form of dispossession, which the narrator satirizes by ironically adding his own voice to theirs, thereby underscoring the extent to which the babus have lost touch with their own identity and see themselves only through the eyes of the other. The narrator notes:

Today, in our nineteenth century, the sciences enjoy great prestige, for they form the basis of all progress. See, the British are whiteskinned whereas Oriyas are dark in complexion. This is because the former have studied the sciences, whereas the latter have no knowledge of these.

None of the three published translations of the novel reproduce these sentences, as if such a claim, in an English version of the novel, might possibly be taken at face value, and the narrator perceived as identifying with the colonizers and espousing their position as his own. Here, the narrator uses a claim about the effects of science to make mockery of other equally outrageous beliefs at the very heart of the colonial project. In the published English translations, however, the narrator's irony disappears, along with the critique.

\section{The Translations}

The three published translations of Chha Mana Atha Guntha differ radically from one another. Their additions, simplifications and deletions reflect the different purposes the translators set for themselves, their different "translation projects" (see Berman 1995, 76-79), which find expression in the accompanying notes, prefaces and comments, as well as in the translations themselves. The differences between the three translations, published 
under similar conditions - within three years of each other, in India, and by Indian publishers - should caution us against concluding too quickly, from individual cases, about the ways representations of colonialism are transformed through translation in the postcolonial period. Indeed, the translations demonstrate that colonial values and hierarchies continue to produce effects in the postcolonial period in various, and even contradictory, ways.

\section{Six Acres and a Half (1967)}

In their one-page translators' note to the "English edition" of the novel, the Senapatis express their hope that "this great novel should reach a wider circle of readers among people not acquainted with the Oriya language" (8). Clarifying their purpose in producing the translation, a purpose which they define less in literary than in social and political terms, they continue:

We have made the English translation as true to the original as practicable. We hope this will facilitate, among the reading public of this vast sub-continent of India, a closer understanding of life in Orissa in the last century; in so doing it may promote that unified view of Indian life which is unmistakable in spite of the rich diversity of our country.

The projected readership for whom the translation is produced is explicitly identified as Indian, and the translators' aim is to demonstrate the unity which lies behind regional differences of language, culture and religion. From this respect, it is significant that the translation appeared as a "National Book Trust Book" under the imprint of the Publications Division of the Ministry of Information and Broadcasting, Government of India. The National Book Trust, founded in 1957, was established with the explicit mandate to promote national integration and unity through its different collections, often through translation (see St-Pierre 1998). That the cause of Indian national unity was to be furthered through translation into English, a language accessible to only a small minority of the population, may seem paradoxical, but this paradox reflects the ambiguous role English has in post-Independence India. Precisely because of its use by the educated elites, English was considered the language in which literary works could, in 1967, reach the widest audience within India itself. For although Hindi had been identified as the sole national language-English being accorded associatelanguage status - the geographical and even religious tensions surrounding the use of Hindi were still very strong at the time, and indeed had led to the delay in the implementation of constitutional provisions regarding its exclusive use as national language. ${ }^{11}$ English was in a certain sense the more acceptable, the more "neutral" of the two languages. ${ }^{12}$ In addition, English had, and still retains, the function of a link language in India. The sheer number of languages in the country (1,652 according to the 1961 census) 
requires that certain languages-most notably English and Hindi-be given a de facto privileged position and be used to compensate for the lack of translators for other languages, including the eighteen languages officially recognized in Schedule VIII of the Indian Constitution. Translation from one of these languages into English makes texts available for translation into other Indian languages.

But, in reality, the Senapatis' translation of Chha Mana Atha Guntha is not aimed only at "the reading public of the vast sub-continent of India," as stated by the translators, since publications by the Publications Division of the Government of India receive wide distribution outside India. The promotion of a certain vision of India and of Indian life was thus not purely for internal consumption; rather, the translation was also to have a representative function, to serve as an example of the true nature of India for foreigners. This double-intended readership is reflected in the terms contained in the glossary, which includes not only "[t]erms and expressions which are local or bear the stamp of local atmosphere" (8), but also those which would be familiar to the majority of Indian readers, but require explanation for foreign readers, for example, the names of the months of the Hindu calendar (Aswina, Bhadra, Chaitra, etc.), days of religious observance (ekadasi, jamastami), forms of address (Saant, Saantani) and so forth. The translation is given the purpose of bridging the gap between the local and the national, as well as of demonstrating the possibility of attaining unity at the national level through the use of English, making evident India's status as a separate, independent and cohesive state. The "unified view of Indian life" that the translation is to promote is intended for readers both inside and outside the country, the double imprint of the translation underscoring the Janus-like function it is to fulfill.

In addition to the glossary and their "Note," the translators supply two footnotes in the text. The first comes at the very beginning of the novel: "Ramchandra Mangaraj was a mofussil* Zamindar." The gloss on "mofussil" reads as follows: "That is to say, living in the countryside, unlike many big (absentee) landlords who lived in the metropolis, Calcutta, or at least in big towns like Cuttack." The gloss not only provides a precise meaning for "mofussil" ("living in the countryside..."), but also underscores the implied contrast between country and city, between centre and periphery. Two types of zamindars are evoked: those who live on their lands in the countryside, and the absentees who live in the cities, more specifically, in the administrative areas of the colony: Calcutta (Bengal)-the seat of British power-and Cuttack (Orissa) - the administrative centre for the region.

Allusion is being made here to the fundamental shift in Indian society already referred to, brought about by the British through their modification of the legal system, and more specifically, of the ownership of property. 
independent newspapers were being published in several variants of Malay in the larger polyglot coastal cities. These papers were owned and operated by peranakan (semi-assimilated ethnic Chinese), Eurasians and Dutch private citizens. Their straightforward reporting brought new possibilities for the kinds of stories that could be told in Malay: for example, a story could be brought down out of the fantastic world and made to operate in the here and now. While literacy was still uncommon, those who could read had access to factual narrative, as well as serialized stories in the independent press. Thus began the leap in development from the oral mode and the ideal, semi-religious setting of wayang and some forms of hikayat, to the realism of modern Indonesian written literature.

As literacy increased, the independent press began publishing books in various variants of Malay, for the language was native to at least three populations: the Batavians (i.e., Jakartans), peranakan and certain groups on Sumatra, which is close to Malaysia. Book prices were low; publishers expected that books would be read aloud to an audience. Two main types of books were published: prose translations of great Chinese verse classics, whose audience was the peranakan, who were interested in Chinese culture, but who did not read Chinese; and thrillers written in Malay, which were just as improbable perhaps as the older epics and legends, but set in present-day cities and liberally sprinkled with sex and violence. The thrillers were intended for an audience seeking distraction; the violence was usually quite graphic, characters were oversimplified, the supernatural figured prominently in the plots and coincidence was rampant. The plot of Seitang-Koening, a thriller written by Raden Mas Tirto Adhi Soerjo, a journalist whose title suggests that he was a member of one of the princely families of Java, is summarized by C.W. Watson (1971): a njai (native wife or mistress of a Dutchman) is blackmailed into sleeping with an Arab to whom she is in debt. At the critical moment, however, they are interrupted by the Dutchman bearing a rifle, who in turn extorts a large sum of money from the Arab. Hilarity ensues. The language and independent nature of these productions made them antithetical to the colonial government of the time, and spurred the foundation of Balai Pustaka as a corrective measure.

In their role as colonizer, the Dutch saw themselves as different from the larger European powers. As C. van Eerde (1914) explained in "Omgang me inlander":

When history calls upon small nations to engage with energy and intelligence in the demanding work of empire, a little country such as Holland provides better guarantees than larger nations to implement the appropriate policies. Bigger European countries have a proclivity to use brute force in colonial administration-a blunt vio- 
remains, it will be impossible for Orissa to progress"13 (in Boulton 1993, 71). Thus, in Orissa, the perceived threat came less directly from the colonizers per se than from other Indians-the absentee landlords, Calcutta, as well as administrative centres such as Cuttack-those who, because of their proximity to the centres of power, were able to position themselves between the colonizers and their subjects, and reap the benefits. ${ }^{14}$

\section{The Stubble Under the Cloven Hoof (1967)}

A second translation of Chha Mana Atha Guntha, by C.V. Narasimha Das, also appeared in 1967 , accompanied by a variety of prefatory texts, including a dedication, a "Publisher's Note," a text-“"The Author to the Reader"written by the translator, an "Acknowledgement" and a nineteen-page "Introduction." The dedication clearly states the purpose of the translation: "Dedicated to All the ill-paid Indian teachers of English who smile sceptically at Research in English studies in India, but believe passionately in harnessing the English language to deliver the national goods of which Research usually knows nothing." Translation into English is presented here as fulfilling the true role allotted to English in India, that of going beyond the boundaries erected by the foundation of Indian states along linguistic lines, and of delivering "the national goods" (emphasis added). Once again the opposition between regional and national is alluded to, mirroring that between the Indian vernaculars and the English language.

The translation is presented as a rewriting of the original work-a sort of "old wine in new bottles"- -as a recasting in terms of modern consciousness (iii), and is almost three times as long as the other published versions. Dr. Johnson's remarks on Pope's translation of The lliad are quoted in support of the undertaking to continue the creative process, to recreate in English rather than to merely translate. ${ }^{15}$ As the translator himself notes in "The Author to the Reader": "Fakir Mohan himself, I fancy, would have written something vitally like this book if he had come to write in English today. He would have poured his genius, which chiefly means his hilarity, into such an English mould as this; and a star would then have risen in the firmament of Indo-Anglian fiction" (i). Through the translation, Fakir Mohan loses his regional and vernacular ties and becomes an Indian author writing directly in English, a transformation which is not unproblematic given his marking in the novel of separate linguistic and cultural spaces. Signing as the author, the translator considers his work an illustration of his "faith that English literature can enrich an Indian vernacular tale by teaching him who retells it in English the art of rechristening its thought and imagery and giving it an Indo-Anglian domicile in the commonwealth of letters" (iii). As a result his translation and rewriting of the original work "symbolically 
amounts to the cultivation of a literary habit which the role of the English language in New India seems to call for" (iii). In post-Independence India, English is to be less an object of academic study than a tool which can be used to create links beyond the particularisms of the vernaculars, making possible a certain unity at the national level.

In his "Introduction" to the novel, Das emphasizes the importance of the colonial heritage, and specifically "the dignity and nobility of the British Indian jurisprudence which we, the citizens of Independent India of today, have received as an invaluable heritage from the British rule" (iii). This is not the sole heritage of colonial times, however, for just as socialist thinkers in India wish to appropriate English-held property as national property, so too the translator wants to call national "the bridge named the English language" (vi).

Through a quotation added by the translator on the inside title page: "I am a fond father to every child of my fancy," the novel is placed under the auspices of Charles Dickens; and a passage, also added by the translator, from Shakespeare's The Merchant of Venice, begins the first chapter of the novel and serves to make explicit the moral of the tale. The lesson to be learned is in fact amply clear in the novel itself and the decision to quote Shakespeare has symbolic rather than semantic importance, coming as it does from a professor of English Studies in India. As Harish Trivedi has written, the reaction to Shakespeare's texts in India is a litmus test for the colonial and postcolonial relations between Britain and India. ${ }^{16}$ Through the addition of quotations heading the chapters, the novel in Das's translation comes to serve as an illustration of passages from the most important authors of the Western canon of English literature: Dickens, Shakespeare, Dryden, Spenser, Swift and so forth. By supplementing Fakir Mohan's work with such quotations, the translator is attempting to ensure its literary worth. At the same time, however, through such references, the old hierarchies between the merely regional or national, on the one hand-of which IndoAnglian literature and Indian literature in English translation are but two examples-and that which can claim universal appeal, on the other, are maintained.

In the opening passage of Das's version of the novel, cultural difference is handled in a number of ways: it is explained-"there are twentyfour Ekadsai [sic] days"; adapted_- "over eight long miles around," where "miles" translates kos, an Indian measure of distance; elided - the term mofussil has no equivalent in the translation; or defined-"the Tulasi leaf, (that is, the Indian basil)." And while certain of the additions made by the translator are references to specifically Indian realities, they are no sooner used than explained or defined: "the Samant (we mean Mangaraj himself 
by this title of gentility)" or "every Dwadasi day, that is, the day following the Ekadasi." Allusions which might not be understood by non-Hindu readers-for example, "One blurted out, "Even the father of Lord Mahadeba can't catch a clever fellow stealing a drink of water after dipping into it"'are amplified in the translation:

One of them, an accomplished wag, was even heard to say that if you dive under water for a holy ablution ostensibly to inaugurate an Ekadasi fast and then choose to quaff perfidiously under cover of water, even Lord Mahadev who, with his all-surveying eye, is believed to be infallibly omniscient will never be able to know and punish your sub-aquatic profanity.

Here, one line of story grows to five lines of explanation. Also, as the opening chapter of the novel progresses, references are added to, among other things, English Common Law, Section 60 of the "Indian Evidence Act," Oliver Twist, Dr. Johnson, the Gospel of Saint John and Wordsworth's "Michael." None of these appear in the original text.

Who is Das writing for? At first it would seem that the translation has been produced for British readers, considering the references to the literature of Great Britain, added by the translator, and the explanations of Hindu customs and practices incorporated into the body of the translation. Working against such a hypothesis, however, are a certain number of indices pointing to a primarily Indian readership. First among these is the nature of the translation itself, with its additions and amplifications. Its transformation of the original text sets it squarely within the Indian tradition of "transcreation."17 In addition, the decision to publish the translation in Cuttack makes it unlikely that it would be read elsewhere than in Orissa, or even there, since locally published works tend to quickly disappear, as has this translation, which is now unobtainable. Two conflicting sets of indications, then, reflect both the colonial origins of the use of English in India and its status within Independent India. The translation is dedicated to "All the ill-paid Indian teachers of English," and like them, the translation combines elements from two traditions while belonging entirely to neither.

\section{A Plot of Land (1969)}

The third translation, by Nuri Misra, was published in 1969 by a local publisher in Orissa. In his brief "Preface" Misra insists on the importance of the original work and its author, while at the same time situating his translation within the Indian tradition of "transcreation":

"A Plot of Land" has been rewritten from the original Oriya social novel "Chha Mana Atha Guntha" by Fakir Mohan Senapati. 
Considered by most to be the greatest storyteller and grand old poet of Orissa, Fakir Mohan was also a prince of novel writing in the Oriya language. He published the novel in the year 1902, when it took the literary world by storm. (Emphasis added)

He places emphasis on the social nature of the novel and its "realistic picture of the contemporary society" with its "greedy landlords," "corrupt policemen" and "unscrupulous lawyers" as well as on the moral implications of the tale: "how greed can bring about a man's ultimate downfall."

The translator describes his work as "an easy reader," produced for those "for whom English is a second language," and given the publisher of the translation, the readers referred to can be presumed to be Indian. For English-as-a-second-language readers then, the translator places in italics and includes in the glossary accompanying the translation "terms which are local and very much associated with the spirit of the novel." But in the case of this translation, too, doubt arises as to the intended readership, since the glossary includes definitions of such pan-Indian terms as Brahmin, lathi, pan, puja and tulsi, in addition to various weights, measures and units of currency, some specific to Orissa (guntha, mana) others not (krosa, maund, seer). The inclusion in the glossary of the English word mile makes it even more difficult to determine the intended readership, since it is unlikely that many would require an explanation of such a common word. In the end, what characterizes this translation is less a well-defined readership than a certain level of mastery of the English language that the readers are expected to possess.

These different "translation projects," and the translations themselves, result both from the way in which the translators defined their potential readerships, and from their relation to the English language. The translation by the Senapatis is aimed at both a national and an international audience, and its purpose is to provide an example of what it means to be "Indian." The one by C.V. Narasimha Das attempts to make the novel Indo-Anglian, considering this denial of its regional and vernacular origins a homage to its greatness. By making the translation into an Indian novel in English, integrable into the larger context of English (i.e., British) literature, the translator hopes to ensure its recognition. Finally, the translation by Nuri Misra is attributed an essentially pedagogical function; it is hoped that by reading an Indian vernacular novel in English translation, readers will be able to improve their command of English. The main function of this translation then is not to make the novel available to readers unable to read Oriya, but rather to make the English language itself available to them. 
All three translations raise the question of the relation of Indian vernaculars to English, and the status of English both as a quasi-indigenous language of India and as a foreign, international language. While ensuring that the novel will be read by a wider audience, the translations also raise the question of the cost of such wider availability. If it is likely that educated readers, even those whose mother tongue is Oriya, will read Chha Mana Atha Guntha in English translation, what effect does translation into English have on the use and survival of Indian languages as such? Does the confusion which seems to exist with regard to the potential readers for the translations reflect another confusion which English introduces-being both an Indian and a foreign language- - between the regional, the national and the international, where the diversity of the regional is denied in the attempt to construct a nation, and where one of the important tools in the construction of an independent nation is an instrument of domination? These questions relating to the functions and hierarchies of languages are given prominence through the process of translation itself; they are also directly addressed in Chha Mana Atha Guntha, which is why translation into English becomes in this case particularly significant.

\section{Language(s)}

Retuming now to Chha Mana Atha Guntha, let us examine the passage describing the rise in fortune of Ali Mian, from whom Mangaraj was to fraudulently obtain the zamindari, the source of his subsequent wealth. Here the fortunes of both individuals, as well as the languages referred to-Sanskrit, Persian, English - are tied directly to colonialism. Ali Mian's situation, for example, improved significantly after the local British administrator bought a horse from him; because he was pleased with his purchase, he appointed Mian police inspector. His rapid ascent in the world is described thus in the translation by Rabi Shankar Mishra et. al.:

(A) In the past, the Persian language had been held in high favor; it was the language of the court. With a sharp and pitiless pen God has inscribed a strange fate for India: yesterday, the language of the court was Persian, today it is English. Only He knows which language will follow tomorrow. Whichever it may be, we know for certain that Sanskrit lies crushed beneath a rock for ever. English pundits say, "Sanskrit is a dead language." We would go even further, "Sanskrit is the language of the half-dead." Anyhow, our Mian got a job through the Sahib's mercy; he was now a thana daroga. He survived in this job for thirty years without much trouble, and during that time amassed considerable property. During these years he acquired four zamindaris and built himself a big house; he owned farms and 
gardens and a large number of household goods. In those days, the zamindaris of Orissa were auctioned off in Calcutta.

In this passage, the influence and presence of the colonial powers within India are foregrounded. The reference to Persian as the language of the court, its replacement by English, the fate of Sanskrit-as determined by English pundits, Mian's obtaining a position through the mercy of the Sahib and, finally, the auctioning off of zamindaris in Calcutta, all point to the occupation of India by colonial powers. What happens to these references in the three published translations of the novel will concern us here. Indeed, these references receive different treatment in each translation: from the accentuation of the colonial context in Das's version to its erasure, to a greater or lesser degree, in the other two.

Here then is the same passage in Das's translation, where the temporal frame is specified and situated specifically in terms of the British presence in India: "In the past," at the beginning of passage (A) above, is rendered as "In the dawn of the British rule in our country"; "In those days," toward the end of the passage, is rewritten as "In the early days of the British Indian Empire." At the same time, anachronistically, but in keeping with the translator's identification with the author, the temporal frame is extended into the present through the reference to the "Republic of India":

(B) In the dawn of the British rule in our country Persian was the queen of languages, because it was the language of the old royalty and of the ruling classes; and so it was chosen for official use in the new British Indian courts of law. How capricious are the fortunes of languages, like those of nations and civilizations! It is the will of the Arbiter of the Destiny of this land of Bharat that Persian should have been the language of the rulers the day before yesterday, that English should have succeeded to that honour yesterday and that Hindi should aspire for the very same honour today in the Republic of India. Heaven only knows what other languages are now waiting in the queue for their turn. But we can confidently say that Sanskrit can never hope to go anywhere near that glorious queue; nor has it ever any business to hope to. Has it not been cast aside as a "dead-language" by learned and wise people in India? Some learned Englishmen themselves have rightly taught our slow Indian thinkers that Sanskrit is a "dead language". We humbly wish to express this profound discovery a little more decisively and vividly by saying that Sanskrit is the language of feckless, feeble and emasculated people. Whatever it is, let it alone and let us come back to our story.

Under the gracious patronage of the District Sahib of Midnapore the horse-trader, Ali Mian, got a job in the Police Force of Bengal as a 
Sub Inspector. After a long and distinguished service for thirty years during which he had been placed in charge of several Police Stations as Officer-in-charge, he acquired considerable fortune and material assets of various kinds. In addition to a great number of buildings, grounds and gardens, and costly and fine furniture, his acquisitions included a big zamindary which comprised of four taluks, each taluk being a bunch of villages and the domains thereof. In the early days of the British Indian Empire, the zamindary estates of Orissa used to be sold by public auction in Calcutta under the orders of the courts of law for default of payment of peishkush, the insolvent zamindars being considered in law as "judgement debtors."

Typical of this "imaginative recast" of the novel is the fact that this passage is more than twice as long as passage (A) previously cited, and four times as long as the same passage in the other two published versions. Additions have been made, and passages have been expanded; together they account for the greater length. The most notable additions, at least for our purposes, since they link the evolution of India to the history of colonial occupation, are the allusion to the use of Persian in the "new British Indian courts of law," the reference to Hindi and the Republic of India and the explanation as to why the zamindaris were being auctioned off in Calcutta. Colonial hierarchies are emphasized: Persian, "the language of the court," is described in the first case as "the language of the old royalty and of the ruling classes," and in the second, as "the language of the rulers," thereby highlighting the change in political structures which came about in the colonial era. The adverb "rightly" and the adjective "slow" in the rendering of "English pundits say" as "Some learned Englishmen themselves have rightly taught our slow Indian thinkers," serve both to reproduce the discourse of the colonizers and to ironically undermine it.

Whereas additions and elaborations characterize Das's translation, the other two tend to reduce the novel to its bare narrative, dispensing for a large part with comments considered irrelevant or, perhaps more to the point, no longer relevant to the central matter of the novel. Here are the translations of the same passage by the Senapatis (C) and by Nuri Misra (D):

(C) In those days, Persian was the favoured language and it was also the court language. Through the patronage of the European officer, Ali Mian got an appointment as a Police Daroga. During his tenure of service, he worked fairly well; he had, at times, to face many difficulties but he acquired a sizeable property in the 30 years of his service. Besides his residential house, garden and furniture, he acquired four Zamindari estates.

Those were the days when the Zamindari estates of Orissa were being put to auction at Calcutta. 
(D) Persian was a popular language in India. Persian was also the court language. But then English replaced it. However, Alimian was given a post of police Daroga by the grace of the Saheb. Alimian then became Miansaheb. Miansaheb served continuously for thirty years and earned a considerable amount of property. Besides his houses, gardens and household materials, he had four Zamindari estates. In olden days, Orissa Zamindari estates were put to auction sale at Calcutta.

Table 1

References to Language(s)

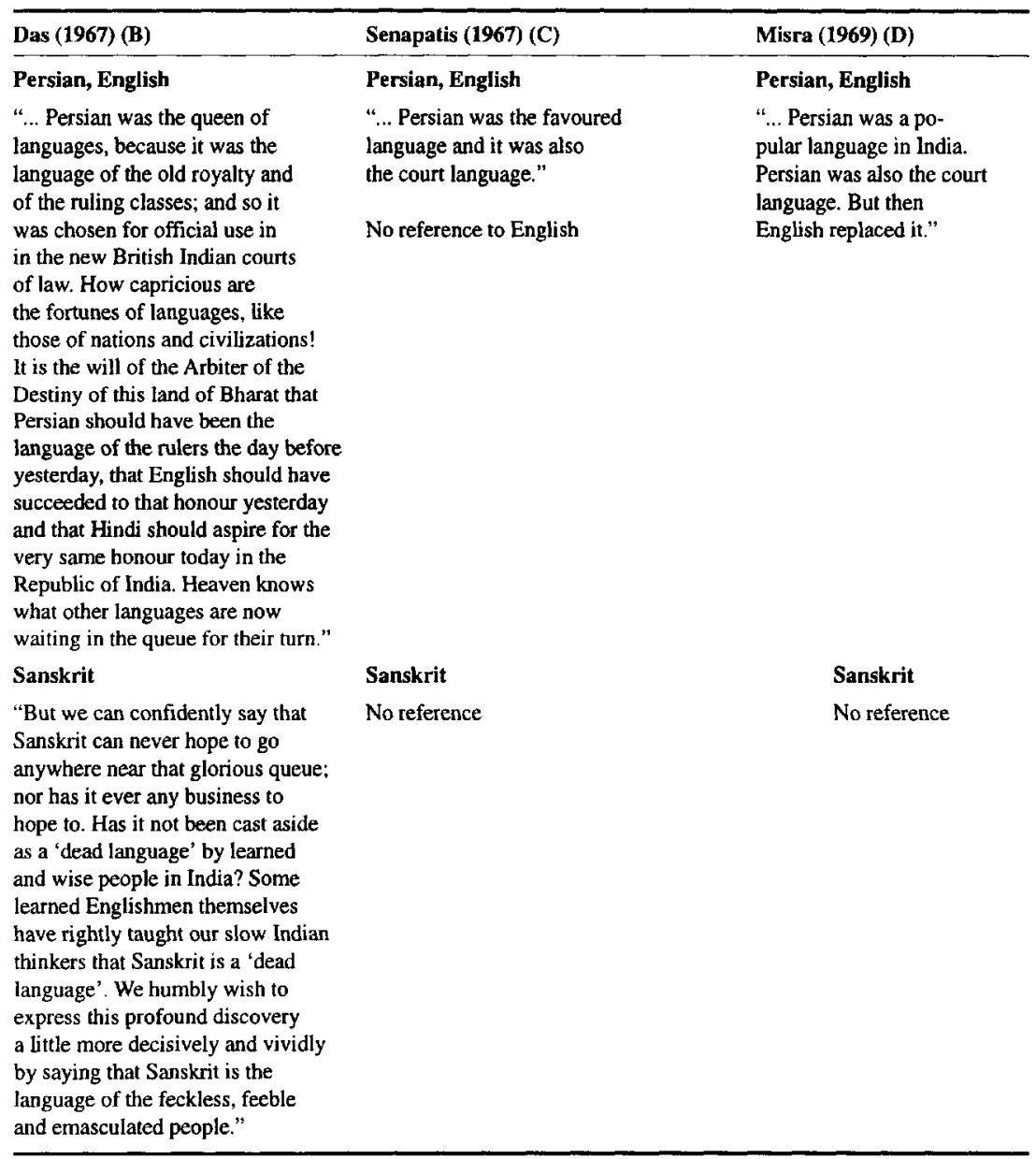

A comparison of the three published translations shows that the deletions and/or additions in the passage centre primarily on the question of 
language(s). Das specifies and embroiders on their role within India, and their identification with the centres of power. The other translators, however, reduce references to language to a bare minimum, even eliminating all reference to Sanskrit. Table 1 above shows the differences between the three translations in this respect.

The translation by the Senapatis omits all reference to English and Sanskrit, as well as to the succession of languages, and the possibility that the dominance of English is merely temporary. Misra's translation also does not mention the status of Sanskrit, and neutrally notes that English has replaced Persian, without conjecturing on the future. On the other hand, Das's translation, as we have seen, not only stresses the replacement of one language by another in the past, it brings us to the present where, indeed, English has a rival in Hindi, and suggests that Hindi is simply one more in this chain of languages, likely also to be replaced at some future point in time. Das is the sole translator, in the case of the published versions, to include remarks on Sanskrit, which take aim both at the Orientalist English scholars proclaiming Sanskrit a dead language, and at the Brahmins, characterized here as weak and feeble.

\section{Table 2}

Narrator's Presence

\begin{tabular}{lll}
\hline Das (1967) (B) & Senapatis (1967) (C) & Misra (1969) (D) \\
\hline $\begin{array}{l}\text { Narrator's presence } \\
\text { - "How capricious are the fortunes of languages, like }\end{array}$ & $\begin{array}{l}\text { Narrator's presence } \\
\text { Omitted }\end{array}$ & $\begin{array}{l}\text { Narrator's presence } \\
\text { those of nations and civilizations!" }\end{array}$ \\
- "Heaven only knows what other languages are now \\
waiting in the queue for their turn. But we can confidently \\
say..." \\
- "Some learned Englishmen themselves have rightly \\
taught our slow Indian thinkers that..." \\
- "We humbly wish to express this profound discovery..." \\
- "Whatever it is, let it alone and let us come back to \\
our story."
\end{tabular}

Another type of modification brought about in the passage by the Senapatis and by Misra should also be noted here, since it has important consequences for the tone of the narrative and the ironic distance the narrator maintains from his tale. The self-conscious references the narrator makes to himself and to his story are lessened in both of these translations, thereby eliminating the layering of narrative voices, and weakening the critical and satirical tone of the novel. As Table 2 above indicates, the narrator's presence is completely eliminated in their translations of the passage under examination. 


\section{The Language of the Law}

Finally, let us turn to a passage of the novel which sets the scene for Mangaraj's trial for the murder of Saria, and at which in the end he is condemned for the theft of a cow:

The Sessions Court in Cuttack was very crowded. People from all over-government offices, the bazaar, the weekly market - had come to witness the trial. Just as an audience gathers for a badi pala hours before the singers are ready, a crowd filled up the courtroom long before the trial was to begin. It was a large crowd, and there was a lot of noise. Two chaprassis were shouting, "Quiet! Quiet!" adding to the confusion. A powerful rural zamindar was being tried for murder. The magistrate had referred the case to the Sessions Court. The hearing had been going on for five days now, and today was to be the last. It had not yet started. Tomorrow was Wednesday, the day on which mail for England was dispatched. The judge Sahib was hurriedly writing a letter, which began, "My dear Lady." Whenever a criminal case was scheduled to be heard, the Sahib would open an English newspaper and read it, or leisurely write a letter, leaving everything else to the peshkar. All he did was sign the documents recording the depositions of the witnesses and pronounce the judgement. But today the Sahib was doing everything himself, because today's main witness [the civil surgeon for the district] was an Englishman; he would also have to write out the judgement in English. It was as if everything in the court today was Englished. But we are Oriyas, and so are our readers, and the printing presses here have only Oriya type. Thus, we have translated everything into Oriya.

In this passage, reference is made to what at first seem two distinct, and very clearly opposed, geographical spaces, each characterized by its own language. The first space is that of England and English, a space which in terms of the action of the novel is at once foreign and domestic. The colonizers introduced into India not only their legal and medical systems (represented here by the judge and the civil surgeon), but also imposed their language. In this passage the reference to the English language is a sign of the foreign space which empowers those in some way connected to itthrough their very Englishness-and which confirms the inferior status of those who are not. This is the sense of the judge sahib's habitual behaviour whenever a criminal case is to be heard: he "opens an English newspaper and reads it, or leisurely writes a letter." Despite these activities divorcing him from the reality of the case under trial, he nevertheless carries out his functions as the representative of the colonial power, signing the depositions of the witnesses and pronouncing the judgment in English. In this 
depiction, the British system of law and the domestic situation to which the law is applied are kept clearly separated, the second being handed over to the native subordinate (the "peshkar") and the first remaining firmly within the control of the British official (the "judge"). And it becomes clear from what takes place on this particular occasion, with the "Englishing" of "everything in the court," that the separation of functions and languages also implies the superiority of the foreign over the domestic.

The presence of one English witness is sufficient for the proceedings to take place in English, and for the judge to feel that he should take an active role in the trial. This witness, the Civil Surgeon for the district of Cuttack, introduced as Dr. A.B.C.D. Douglas, son of E.F.G.H. Douglas, is, like the judge, a colonial official, and this simple fact should be confirmation enough of his qualifications and the reliability of his testimony. Reacting somewhat testily at one point during the interrogation, Dr. Douglas blurts out, in defense of the accuracy and truth of his deposition: "We have been a Civil Surgeon for over ten years now. Before then we were in the military department. We studied medicine at a London college and obtained our degree from there." Because he is a British official, Douglas feels that his word should not be questioned by a mere Indian prosecutor or lawyer. The priority of the English space over the Oriya (Indian) space is thus established clearly, at least in the minds of the colonial officials, for, in fact, this priority is undermined by the ironic distance the narrator maintains from the proceedings.

The second space is that of India, more specifically Orissa, and Oriya. While the last two sentences of the passage make this very explicit, the presence of this space can be felt throughout, beginning with the location of the Sessions Court in Cuttack. Allusion to the badi pala, and lexical items such as chaprassis, zamindar, sahib and peshkar are all indices of this space, one which is systematically devalorized. The markers of "Oriyaness" are also markers of inferiority: the chaprassis, by shouting "Quiet! Quiet!" comically produce the opposite effect from that desired, and at the same time mirror an English court clerk's "Oyez, Oyez" calling the court to order; the trial itself is compared to a trivial musical performance, which the crowd attends purely for entertainment; it is the peshkar, an Oriya, who replaces his superior, the British judge sahib, in trials which involve only natives.

But this hierarchy of spaces and languages is not one espoused by the narrator, and this is the significance of the last two lines of the passage: "But we are Oriyas, and so are our readers, and the printing presses here have only Oriya type. Thus we have translated everything into Oriya." This act of translation by the narrator mirrors the "Englishing" of everything in the court on this occasion, and like it is a reflection of the power language 
can have within a particular context. Just as everything in the court is Englished, so too everything in the novel is translated into Oriya. And what justifies such an act of translation? The fact that "we are Oriyas." In other words, it is this particular geographical space, precisely in its difference and distance from Britain, which requires that everything be translated into Oriya, the language of the people. The textualization of the trial scene in the original novel is thus itself already a translation-from English into Oriya-a translation made necessary by the dominant British colonial presence in Orissa, and which marks this presence as foreign, a translation carried out to preserve a certain commonality of experience and community (hence, "we are Oriyas") in the face of and against this presence. It is this act of translation into Oriya which enables the narrator's voice to be heard above and through the clash of different languages.

In this translation of Chha Mana Atha Guntha into English, however, everything, or almost everything - and here the degree to which contextual markers have been effaced is important- has been back-translated, so to speak, so that now the narrator is saying, in English, that everything has been translated into Oriya. In this paradox, there is a reversal in the recounting of what takes place in the courtroom when the English witness is to be heard, since in the translation, English becomes, or at the very least represents, Oriya, the language of the original, the language into which the author had already translated everything. And in this translation back into the English of the Oriya, which is already a translation from the English, hierarchies shift in a fundamental way. What comes through in these acts of translation is a certain reciprocity between languages, a potential for equality, an abolition of the hierarchies. It is precisely the possibility of translating - the taking on of the power and the privilege which can accompany the act of translation (for not all translation is a sign of inferiority) - which is figured here by the narrator's act of translation for the members of his community, an individual act that gives power to a community connected through language, an anticolonial act undermining the colonizers' refusal to translate certain texts, contexts and situations into native languages, and contradicting the colonizers' use of translation as a modality of appropriation when it suits them.

How do these different spaces and languages and their interaction fare when the novel is translated into English? Without exception, the three published translations eliminate all reference to the "Englishing" of everything in the court that day, and to the subsequent necessity of translating everything into Oriya for diffusion to the community. This is perhaps not too surprising in the case of the translations by the Senapatis and by Misrasince omission and compression seem to be the basic translation strategies of these two versions; it is more surprising, however, in the case of Das's 
translation, which usually-and the treatment of this passage is no exception - expands on the original, almost beyond recognizable bounds. In Das's translation, the sentence "Two chaprassis were shouting 'Quiet! Quiet!' adding to the commotion" begins with a description of the two "liveried orderlies," as he calls them, and goes on to describe the vendors and lawyers doing business outside the courtroom, under the banyan tree. Thus, ten words in a quite literal translation somehow grow to more than 300 in Das's version. Nonetheless, despite this rewriting and amplification of the original, his translation contains no reference to the "Englishness" of the court proceedings, nor to the need to translate these into Oriya, the language of the original text.

In fact, what is problematic for the translators of the three published versions is the reference, in the last few lines of the passage, to translation itself and to the Oriya and English languages in their roles as target and source. For, foregrounding as they do the very process of translation in this scene, and more specifically its implications in terms of power and community, the passage and these sentences in particular-coming at the end of the courtroom scene, and underscoring as it were the foreignness of the proceedings - become untranslatable. The information contained in these sentences renders translation visible as "translation," and situates it within a larger process of "practices of displacement" (Clifford 1997, 3), ${ }^{18}$ of transactions between cultures, transactions permeated with inequality, but transactions nonetheless, not determined once and for all by the colonial, or postcolonial, situation as such. The agency the narrator has here is specifically that of translator, whose voice is heard through the very act of translating for readers, who like him are Oriyas. Insofar as such translation enters into contradiction with colonial hierarchies and priorities, particularly those which have survived India's Independence, its very visibility becomes problematic.

\section{Conclusion}

At the very heart of Chha Mana Atha Guntha lies the colonial system and the changes it brought to Indian society, notably in terms of the legal system and in the relations between the Indian vernaculars, as well as in the relations between these vernaculars and the language of the colonizers. As we have seen, language and law were two of the principal modalities of appropriation used by the British in their conquest of India. These same modalities figure prominently in the novel. It is through the manipulation of the legal system and property ownership—both British-established and imposed systems - that Mangaraj's rise becomes possible; the same legal system, however, brings about his ruin when he is condemned not for the murder of 
Saria (for which he was being tried), nor for trickery and deceit used in obtaining the six acres and thirty-two decimals referred to in the title of the novel, but for being in possession of Saria and Bhagia's prize possession, their cow. In terms of natural law and justice, Managaraj's end is richly deserved, but at the same time it makes a mockery of the legal system instituted by the British.

Intertwined with the law is the question of language, and of the alienation a foreign tongue can create within a culture, especially when this language is associated with domination and exclusion. Such is the case here; the English language is identified with a loss of identity, and with hierarchies marking and maintaining the colonized as inferior. And this is not the case for English only, but also for any language - such as Bengaliassociated with the centre of colonial power.

The three translations of Chha Mana Atha Guntha result from quite different strategies on the part of the translators. Published within two years of each other-between 1967 and 1969-all three by Oriyas and all published in India, the translations, by their differences, point to the complexity of postcolonial situations, and in particular that of India. The colonial legacy "lives on," albeit profoundly modified, in diverse ways in postcolonial times. This is perhaps most obvious, in India, with regard to English itself and the conflicting attitudes to which it gives rise. The three published translations demonstrate the possibility of quite different, even contradictory, effects produced in what could be considered, at least from a certain distance, as the same context. For example, it is Das's translation which most clearly focusses on the colonial experience, and more specifically the negative aspects of this experience. Other indications, however, would lead us to situate this translation most squarely within the colonial tradition itself, considering the addition of epigraphs in the form of quotations from English classics at the head of each chapter, the inclusion in the body of the translation of references to English literature which are absent from the original text and, finally, the frame of reference in the translator's "Introduction" for discussion of the novel. Here is how Das discusses his choice of a title for his translation, abolishing all distinctions and the very hierarchies which the novel itself explores:

I wonder sometimes why I did not choose to call my book "Man of Property" after John Galsworthy. That title would have been quite appropriate - as appropriate, I believe, as the one that my book actually bears now. So far as their passionate attachment to property is concerned, what is the difference between Soames Forsyte [sic] (that unhappy husband of Irene) and Ramachandra Mangaraj? I could similarly call my book by the alternative name of "A Book of Rascals” after Thackeray's “A Book of Snobs." (xiii) 
But the co-existence within the novel of contradictory voices and strategies needs to be maintained in translation, as does the variety of colonial experiences presented here-both those which are classically considered as such in India (i.e., the Moghul and the British empires), and those which are so by association (e.g., the relations with Bengal, but also the relation to Brahminical power). Whereas the other two published translations quite systematically flatten the irony and defuse the satire, Das's heightens them and makes them explicit, undercutting the references to British literature and culture which he himself has added. Neither solution is completely satisfactory insofar as the first erases and the second exaggerates the different voices, both strategies having the effect of simplifying complexities and reducing ambiguities. The great achievement of Fakir Mohan is precisely his ability to demonstrate, with subtlety and nuance, the effects of the use and abuse of power. If, as the narrator of Chha Mana Atha Guntha claims, lawyers are able to make black white and white black, then what the narrator wishes to show is the world, and more specifically Orissa under British colonial rule, in its shades of grey.

\section{Notes}

1. I would like to thank the Social Sciences and Humanities Research Council, Canada, for its support, which has made research on this topic possible.

2. See St-Pierre (1997). Most general studies on colonialism and postcolonialism comment extensively on their use; see, for example, Loomba (1998), xi-xv and ch. 1.

3. The notion of "India" during the colonial period is highly problematic, projecting upon an amalgam of princely states, territories under British "protection," and areas under the direct nule of the colonizers, a unity which was not to exist until after 1947.

4. See Masani (1987), 20:

Many Indians believe that truth was the first casualty in the adversarial system of justice which British rules of evidence introduced, with the litigants like rivals in a boxing-ring and the judge as referee. They argue that a more inquisitorial system, with an active, investigating magistrate, might have been better suited to Indian conditions. British justice, with its rigid and impersonal procedures, was certainly alien to a people accustomed to the informal and more intimate disputations of traditional panchayats (village tribunals) or to the role of humble supplicants at princely durbars.

5. Sitakanta Mahapatra (1993), 31, describes the theme of the novel as follows:

Chha Mana Atha Guntha reveals the changes in the land tenure system when land rights slowly passed on to absentee landlords inside the State and sometimes from outside the State. The distant and absentec landlord, devoid of any direct contact with the peasants, the decline of the village artisan and craftsman class and the emergence of a new class of social exploiters in the growing towns, Chha Mana Atha Guntha is a brilliant portrayal of the social transformation in the later half of 19th Century Orissa, the ruthless exploitation of a poor village couple by the rapacious Zamindars. 
6. Oriya is one of the eighteen official languages which figure in Schedule VIII of the Indian Constitution. It is spoken primarily in the eastern coastal state of Orissa, and has a long written literary tradition dating back to the tenth century.

7. The phenomenon alluded to here-reading the literature of one's mother tongue in English translation-is on the rise in India. The education of Oriyas in English-language schools, with the prestige and material advantages which come from such an education, is increasingly having the effect of alienating students from their own language. This is the case in other parts of India as well.

8. Unless otherwise indicated, all quotations from the novel are taken from the translation by Rabi Shankar Mishra et al., presently being prepared for publication.

9. Consider, for example, the following passage from chapter twelve, which describes Asura Pond and the wildlife using it:

Some sixteen to twenty cranes, white and brown, chum the mud like lowly farmhands, from morning till night... A pair of kingfishers suddenly arrive out of nowhere, dive into the water a couple of times, stuff themselves with food, and swiftly fly away. Sitting on the bank, a lone kingfisher suns itself, wings spread like the gown of a memsahib. O stupid Hindu cranes, look at these English kingfishers, who arrive out of nowhere with empty pockets, fill themselves with all manner of fish from the pond, and then fly away. You, you nest in the banyan tree near the pond, but after churning the mud and water all day long, all you get are a few miserable small fish. You are living in critical times now: more and more kingfishers will swoop down on the pond and carry off the best fish.

Immediately after this admonition, the object of the narrator's satire switches to the Brahmins:

The kite is smart and clever; it perches quietly on a branch, like a Brahmin guru, and from there swoops down into the pond to snatch a big fish. That lasts it for the whole day. Brahmin gurus perch on their verandahs, descending on their disciples once a year, like the kite.

10. Yule and Burnell (1990), 44, give the following definition for "baboo":

Properly a term of respect attached to a name, like Master or $M r$, and formerly in some parts of Hindustan applied to certain persons of distinction. Its application as a term of respect is now almost or altogether confined to Lower Bengal... In Bengal and elsewhere, among Anglo-Indians, it is often used with a slight savour of disparagement, as characterizing a superficially cultivated, but too often effeminate, Bengali. And from the extensive employment of the class, to which the term was applied as a title, in the capacity of clerks in English offices, the word has come often to signify 'a native clerk who writes English.'

11. The Constitution originally provided that in 1965 Hindi would replace English. The transitional period was, however, extended due to opposition to what was seen as the imposition at the national level of what was in essence a regional, north-Indian language.

12. This is reflected in its choice as official state language in areas where no one major Indian language is predominant (Manipur, Meghalaya, Nagaland, Tripura, as well as most of the Union Territories).

13. This contempt for Oriya finds an echo in Chha Mana Atha Guntha in the following description of the Muslim police sub-inspector for Cuttack: "Sheikh Inayat Hosein was a top-class Daroga of Cuttack district. He had a command of Persian. In his view Oriya was the language of idiots; thus he did not write in Oriya and chose to sign 
Government papers in Persian only." This passage is edulcorated in the translations by the Senapatis and by Nuri Misra to: "He could not write Oriya as he did not know it" and "He considered Oriya to be a useless language," respectively.

Of the published translations of the novel, only that by C.V. Narasimha Das gives a clear sense of the contempt administrative officials had for native Oriyas:

Of all the Police Sub-Inspectors in the district of Cuttack, Sheik Inayat Hossain was the doyen and was generally esteemed by all competent critics as the pearl of his tribe. His erudition in Persian was profound. It was quite evident to him that Oriya was a paltry language meant for poltroons. It was no better than the drivel of empty-pated Simple Simons. So he would not slight his proud pen by writing it nor would he contaminate the purity of that pen by giving it a taste of that base language. His signature on all official papers therefore flaunted itself invariably in noble Persian characters.

14. The second of the two footnotes in this translation links the development of the legal system to the colonial context. After Mangaraj is convicted of stealing Saria and Bhagia's cow, his lawyer tells him: "I shall get you acquitted by appealing to the Supreme Court*" (99). The gloss explains: "The East India Company had at first established the Sadar Dewani Court at Calcutta. Later on it was converted into the Supreme Court, which was again converted into the High Court subsequently."

15. The translator (Das [1967], i) writes: "There is, however, much in my work which, by design, corresponds to Dr. Johnson's verdict on Alexander Pope's English translation of Homer's Iliad, 'Homer doubtless owes to his translator many Ovidian graces not exactly suitable to his character; but to have added can be no great crime, if nothing be taken away. Elegance is surely to be desired, if it be not acquired at the expense of dignity.",

16. According to Trivedi (1993), 33-34:

Shakespeare's status, popularity and dissemination in the post-colonial India of today, nearly half a century after independence, is determined to a large extent by a non-literary factor, just as it was in colonial India. Then it was the Empire; now it is ELT, or the hegemony of English as the pre-eminent international language. English is not only the world language which the whole of the non-English speaking world is under increasing economic and cultural pressure to learn; in India, it is also, because of a post-colonial realisation of the value of our colonially derived advantage in this respect, one of the two [sic] official languages of India, together with Hindi. About $40 \%$ of the population knows Hindi and only $2 \%$ knows English, but it is this tiny minority which is the privileged, prosperous, decision-making new ruling caste of the country.

17. The term transcreation occurs frequently in the discussion of translation in India, despite no strict definition of what it actually consists in. Paternity of the term is usually attributed to P. Lal, but has recently been claimed by P.K. Saha.

18. In his recent work Routes: Travel and Translation in the Late Twentieth Century (1997), James Clifford views "Practices of displacement ... as constitutive of cultural meanings rather than as their simple transfer or extension," 3.

\section{Works Cited}

\section{Theory and Criticism}

BERMAN, Antoine. 1995. Pour une critique des traductions: John Donne. Paris: Gallimard. 
BOULTON, John V. 1993. Phakirmohan Senapati: His Life and Prose Fiction. Bhubaneswar: Sahitya Akademi.

CLIFFORD, James. 1997. Routes: Travel and Translation in the Late Twentieth Century. Cambridge, MA: Harvard UP.

COHN, Bernard S. 1996. Colonialism and Its Forms of Knowledge: The British in India. Princeton: Princeton UP.

KHILNANI, Sunil. 1997. The Idea of India. New York: Farrar Strauss Giroux.

LAL, P. 1972. Transcreation: Two Essays. Calcutta: A Writer's Workshop Publication.

LOOMBA, Ania. 1998. Colonialism/Postcolonialism. London/New York: Routledge.

MAHAPATRA, Sitakanta. 1993. Discovering the Inscape. Essays on Literature. Delhi: B.R. Publishing Corporation.

MASANI, Zareer. 1987. Indian Tales of the Raj. Berkeley: U of California P.

RAFAEL, Vicente. 1993. Contracting Colonialism. Durham/London: Duke UP.

SAHA, P.K. 1995. “Translating Indian Literary Texts into English.” In Literary India: Comparative Studies in Aesthetics, Colonialism and Culture, ed. P.C. Hogan and L. Pandit. Albany: State U of New York P.

SAMAL, J.K. 1989. History of Modern Orissa. Calcutta: Firma KLM Private Ltd.

ST-PIERRE, Paul. 1997. "Multiple Meanings and Contexts: The Diversity of the PostColonial." TTR 10, no. 1: 9-17.

. 1998. "Theory and Practice: Translation in India." In Unity in Diversity? Current Trends in Translation Studies, ed. Lynne Bowker, Michael Cronin, Dorothy Kenny and Jennifer Pearson, 47-56. Manchester: St. Jerome Publishing.

TRIVEDI, Harish. 1993. Colonial Transactions: English Literature and India. Calcutta: Papyrus.

YULE, Col. Henry, and A.C. BURNELL. 1990. Hobson-Jobson: A Glossary of Indian Words and Phrases, and of Kindred Terms, Etymological, Historical, Geographical and Discursive. 1886. New edition. Ed. William Crooke. Calcutta: Rupa and Co.

\section{Translations of Chha Mana Atha Guntha}

DAS, C.V. Narasimha, trans. 1967. The Stubble Under the Cloven Hoof. Cuttack: Sahitya Samsad.

MISHRA, Rabi Shankar, S.P. MOHANTY, Jatindra K. NAYAK and Paul ST-PIERRE, trans. Forthcoming. Six Acres and a Third. Berkeley and London: University of California Press.

MISRA, Nuri, trans. 1969. A Plot of Land. Cuttack: Cuttack Student's Store.

SENAPATI, B.M., and A.M. SENAPATI, trans. 1967. Six Acres and a Half. New Delhi: Publications Division of the Ministry of Information and Broadcasting. 
Chapter 15

\title{
THE POST-MISSIONARY CONDITION: TOWARD PERCEPTUAL RECIPROCITY ${ }^{1}$
}

\author{
Probal Dasgupta \\ University of Hyderabad (India)
}

\section{Cognitive Accountability and Courage}

The postwar world has managed to build a postcolonial system. At the very least, this is a system of states that does not officially endorse the desire that groups with a temporary geomilitary advantage have to wear proudly all the chauvinisms that come naturally to them, with no awareness of the obvious laziness and cowardice involved in such an exhibition. It has taken a lot of courage to build even this. We now need to learn how to live here and keep building the kind of world this logically leads to. And that effort is going to take as much courage as we can muster. For modernity itselfwhich I construe postcoloniality to be a specific instantiation of - crucially involves the exercise of courage in the pursuit of knowledge. A culture is modern to the extent that its thinking does business with a question of epistemic courage that can be stated as:

\section{(1) Popper's Question}

As you work to develop and understand the place of your proposal in the body of knowledge, are you fearlessly exposing it to critical scrutiny from as many sources as you possibly can?

It takes courage to want to live a life that takes this question seriously in the practice of science. For a society to imagine a collective life that accepts 
such living as its core commitment, which is the Enlightenment proposal characteristic of modernity, takes even more courage, of a special kind: the courage of accountability. Justice must not only be done, but also be seen to be done. Science, also in the Science Writ Large routinely proposed in all versions of the modernity project, must grapple with this seeing, and with the "spectators" to whom this statement must apply in any real implementation.

If in fact every serious society must invite universal participation in seriously seeing that justice is done and accounts settled, then it follows that societies striving for modernity or even claiming to be modern must be brave enough to begin to make themselves cognitively accountable. There is perhaps a beginning of this courage in science at its best. But the "muscle tone" of the courage of the community of scientists seems to be way below the levels one would have hoped for on the basis of the Galilean inheritance. Such a matter is too important to be left to the scientists. The community of thinking men and women as a whole must find a way to take over the task of working toward greater cognitive accountability. This may involve inventing either some new form of interdisciplinary and socially responsible labour that brings cultural studies people and scientists together, or other hitherto unimagined ways of breaching barriers.

I shall argue here that cognitive accountability requires that modernity constitutively needs to invite translation of the discourses that claim to present knowledge; that knowledge is usefully characterized in terms of creative continuations of action types; that this characterization leads to models that make the power-knowledge nexus optional and contingent; that pursuit of these themes can help us out of the missionary predicament we are trapped in; and that the missionary and industrial readings of our cognitive predicament are mutually convertible.

\section{Serious Respecification}

For cognitive accountability, it is necessary to ensure that what is said in initiating cultures does not remain fossilized in the first telling of the story. Stories have to be retold in new and different cultures, and the retelling has to seriously respecify the terms of the stories. Only then can the real content of the stories, as opposed to contingent features locking them into the initial context, become available for the record - and for one's delectation. Serious respecification becomes an especially interesting activity, deserving rigorous attention, if the stories being retold crucially use conceptual terms, and if their retooling calls for actually reimagining the ideas in cultures radically different from the original context. I am especially interested in the retelling of scientific stories. 
To flesh this out, consider the following example: the French terms cytogénétique and cytologie are defined in Le Petit Robert as follows:

CYTOGÉNÉTIQUE. n.f. (1855; de cyto-, et génétique). Biol. Partie de la génétique appliquée à l'observation microscopique de la cellule et notamment des chromosomes.

CYTOLOGIE. n.f. (1890; de cyto-, et -logie). Partie de la biologie générale qui étudie la cellule vivante, sous tous ses aspects (structure, propriétés, activité, évolution).

Now, here is a bureaucratic way to "do" these terms in the Eastern Indic language Bangla: kosh is the standard equivalent for cellule, and the tacking on of normal suffixes yields the words koshjanonbiggean and koshtatto for cytogénétique and cytologie, respectively. Of course, if terminological retooling involved only this, then the activity should only be discussed in the privacy of terminology creation cells of Third World monasteries under the tutelage of a mindless developmental mission, and neither scientists, nor the informed segments of the general public in industrialized societies should reasonably wish to pay any attention thereto. It becomes more interesting if scientists and sensitive craftspersons of words, working together, attend to the service that the Greek terminological inheritance continues to perform in the metropolitan languages, and how or why one proposes to respecify concepts taken from these sectors when moving into what I call Less Equipped Languages (LELs) to prefigure discussions of where the formalization of such Equipment might intersect with other types of formalization.

Under such promising conditions, it becomes possible to keep in mind the relationship between cytologie and another use of -logie, in ethnologie, for example, which Le Petit Robert tells us is the "Étude des faits et documents recueillis par l'ethnographie (couvrant le domaine de l'anthropologie culturelle et sociale)," in contrast to ethnographie, which is defined as: " $V x$. Classement des peuples d'après leurs langues. Mod. Étude descriptive des divers groupes humains (ethnies), de leurs caractères anthropologiques, sociaux, etc." It is reasonable for a consistent terminology in Bangla to propose tatto to render -logie, even if the real life of the First World's anthropology and biology departments discourages or prevents direct or virtual contact between the users of these two sets of words. ${ }^{2}$ Now, if we render -graphie as -biddaa, and decide to maintain ethno- as is-a decision that carries over, in principle, to any other term which might strike users of non-metropolitan languages as for some reason not requiring reconceptualization, as it is unclear if it represents, in its present form, more than a dressing up of some opaque object or some unexamined preconception about realities - this yields the Bangla terms ethnobiddaa and ethnotatto for ethnographie and ethnologie, respectively. 
Once such respecifications of conceptual terms across radical cultural gaps take place in non-bureaucratic (i.e., non-missionary, non-industrial) ways, on the basis of increasingly symmetric conversations, it will become possible to identify what comes out as invariant or universal, on defensible grounds, across cultural gaps. Then one can evaluate the familiar Western-industrial claim - the OECD claim, to give it an opaque designation that does not invite reconceptualization, but rather describes local realities - that the content of the hard sciences is "universal" and robust under cultural transmission. Only if such an experiment is performed will we indeed find out which elements of the sciences, if any, survive cultural transplanting carried out with seriousness on both sides.

The picture emerging from these considerations forces me to conclude that a scientific translation enterprise which takes serious respecification as part of its core program must form an obligatory constituent of a society that wishes to build a culture around the pursuit of science and other forms of rational discourse and practice. If scientists are not going to check or respond to this conclusion themselves, it becomes the responsibility of the general public in their societies to do it for them, instead of spending their time applauding the rationality of the sciences. But let me scrutinize the status of the inquiry I seem to have embarked upon: does this material perhaps not enter into the core considerations of how to pursue scientific work in the modern world? Is such a discussion entirely a matter of the optional, local concerns of culture specialists? Scientists are certainly convinced it is. They have inherited an abridged version of the Enlightenment in which they have sealed off their compartment from the general space of public discussion, convinced that the public culture as a whole is optional. Scientists believe that they are already working hard and successfully to ensure that the knowledge they are accumulating is a rational construction; they believe that certain objective factors have helped them to succeed in doing this: one is the quantitative revolution that helps them to keep tabs on numerical and other formal devices in their writings. The wide use of formal devices in exposition and reasoning brings about a greater comparability of results and proposals across researchers and disciplines, making it possible to try to work across barriers within science. The second is the procedure of repeatedly checking experiments against external reality in laboratory after laboratory to ensure continuity with the outside world. A third factor is the custom of going through the due process of critical scrutiny formalized as refereeing and post-publication criticism of scientific contributions. Do these factors in fact ensure only a self-congratulatory appearance of success? ${ }^{3}$

To provide one possible approach to these issues, I would like to argue that a culture can sustainably claim to be modern to the extent that it remains in touch with Popper's Question. A modern culture must consist- 
ently take risks and encourage criticism from as wide a range of participants as possible. If potential scrutiny of a proposal is available across language barriers, then one must, as a fearless seeker of criticism, actively cross those barriers and go halfway to find it. It thus follows from these principles that a civilization seeking to implement the scientific program will pursue the possibilities of cognition into every language. This involves actively encouraging locally rooted and accountable scientific activities in all communities in their own languages. This argument makes translatability a constitutive factor of modernity. For a culture to sustain the claim that it is modern, it must be relocatable in some completely different set of practices. This is tantamount to saying that if an experiment exemplifies a real effect, it must be replicable in some other laboratory.

Therefore (here I will put forward some arguments that may require further reflection and stimulate controversy):

(2) A complete network of scientific idea production and exchange must, for science-internal reasons, include arrangements to ensure not only (A) that work done in each language is translated into other languages - an old imperative that has been allowed to lapse after the take-over by English, a hijack that the scientific community has welcomed with unexamined glee; but also (B) that scientific work is indeed done, and in fact flourishes, independently, in many languages.

(3) A complete network in the sense of (2) above must also work on the details of the actual translation done under (2A). In particular, (X) one needs to keep monitoring the cultural health of the way in which specific concepts from a Source Language (SL), in which a given piece of research is done, are respecified in the Target Language (TL); and (Y), task (X) is inseparable from that of monitoring the independent health of scientific inquiry traditions in the local context of the TL communities.

(4) These considerations are--apart from being motivated by issues in cultural studies, a point that need not be laboured here-also science-internal. For one thing, $(\mathrm{P})$ a scientific community that keeps in touch with its Popper's Question will need to do these things to maximize its criticism-inviting function. For another-and this accountability issue forms part of the question of courage- $(Q)$ the mathematical care that led to a great leap forward in the sciences urgently needs to be followed up by replicating that care for the verbal, non-quantitative parts of the written and spoken messages whereby scientists practise their disciplines. Call that replication (Q), the Qualitative Revolution, which is yet to come; working for $(\mathrm{Q})$ is a matter of accountability in the sciences. (R) We have learnt that we 
need to work in healthier laboratories, industries and societies for physico-chemical reasons. We will learn that we also need to work in culturally healthy communities, whose conversations are run on local energies, and are not drugged on long-distance imports for all matters. The moment we let ourselves learn this is the moment we pay rigorous attention to issues of cultural health. Sick cultures produce sick research.

I would like to hypothesize, in continuation of the arguments just proposed, that the key conceptual terms in which the rough and ready initial formulations of scientific conjectures and their theoretical neighbourhoods are packaged in the contexts that inaugurate particular fields and subfields of inquiry need to be respecified in the conceptual contexts of other cultures. And I say need, not in the sense that the Third World wants such aid for its own existence - this may or may not correspond to verifiably felt desires-but in the sense that, to meet the obviously unmet epistemological conditions on the validity of the scientific enterprise in the metropolitan or industrialized world, it is necessary to perform this cross-cultural task.

One way to look at this metropolitan or science-internal need is to ask if we have any direct grasp of the conceptual content of particular bits of formal or verbal machinery in scientific research writings. In particular, do we know what they mean, apart from the set of interchangeable equivalents in the metropolitan languages in which scientific writings are taken seriously as primary productions? We do not. All that we have is glossaries in the metropolitan languages, but these languages are culturally very close to each other; they use similar or identical metaphoric systems. Serious respecification obliges scientists to rethink what they thought they understood. ${ }^{4}$ Then they wonder if they were right when they claimed something was "understood" in the sense that they had obtained firm results that were tightly connected with the rest of the fabric of inquiry. Out of this wondering on the part of scientists might come a revitalization of the sense of wonder that one had always associated with one's identity as a scientist. Why should the revitalization of scientists' sense of wonder be a matter of more than vicarious concern for the cultural studies researcher, to reverse the direction of the question that occupied us earlier on?

\section{From Conceptual Politics to Perceptualist Strategy}

If anything is important in the postcolonial space of discussion, it is the question of the power-knowledge nexus. Centralization is more problematic than most other things. One issue, then, is how not to throw the knowledge-baby out with the power-bathwater. My response to this goes 
through the standard Foucauldian equation: Power = Action/Action, which means that power is exercised to the extent that the actions performed produce effects on other actions rather than on entities. Assuming this characterization of power as a starting point, I propose that one way to delink knowledge from power first in theory, and later in practice, is to visualize knowledge in terms of the equation:

(5) Knowledge $=$ Action $\rightarrow$ Action $\rightarrow$

A prose rendering of this equation might run: knowledge is the creative continuation of an action series. Whenever Plato's Socrates wanted to exemplify knowledge, he considered cobblers. Let us therefore consider the transmission of knowledge in the cobbler's trade: Master Cobbler makes master shoe; Apprentice watches; Apprentice makes trial shoe; gets rebuked; responds by moving closer to model; performs creative modification; Master accepts tribute from creative Disciple - or appreciative customers do, if Master too perverse. ${ }^{5}$ This leads to a politics of the industrial, for it should be possible to centrally standardize a state of the art for the entire trade, and a sufficiently generalized market, with optimal information flowing through all satellites, would ensure at any given moment that customers can force all producers to either perform at that moment's state of the art or go out of business. To pursue this scenario, cobblers and their mediators (who sponsor production or distribution of the ideal shoe) are of course quite frightened of the chaos that such a market mechanism might unleash, forcing them to keep responding to unpredictable vicissitudes. They therefore try to save the labour of having to keep paying Attention. To do this, they set up a system based on a Code, whose principle is Memory rather than Attention. The move is to create a bureaucracy that aggregates all shoe producers, or all shoe sellers, or all cobbler trainers, into a single system working on the basis of Concepts. These moves, made by producers of all types, and seen as optimally parallel, lead to a Politics that makes Concepts the standard way to standardize. Thus the threat from truly open exchanges is obviated, and no one has the trouble of paying Attention. In other words, the Code with its Concepts is a machine that saves Perceptual labour.

To put it differently: in and as the Code, the Emperor tries to speak with supreme intelligence, built for Him by state of the art satellites and those who compute for them. If the Emperor can centrally speak with full accuracy, nobody has to take the local trouble of listening. Whatever can be listened to is already one of the utterances that the Emperor can utter and for which he therefore has a structured representation. One will never have to improvise on the basis of listening. In the same way, the Chef already knows how to cook any dish that any local simpleton might come up with, for all the Subchefs have agreed to hand over their surplus knowledge to the Chef. ${ }^{6}$ 
The decision by the producers of knowledge to let hijackers appropriate their product is quite visible in the sciences, whence my worry about revitalizing scientists' sense of wonder. Ever since particle physics became fundamental, it has been clear that cottage-industry thinkers sitting in their little privacies cannot be particle physicists. They have to wangle Emperor-funded research projects to even begin to get training, and learn how to ask intelligent questions in the field, let alone find and defend answers to them. So they correspondingly sell their answers to the Emperor as well. At no point do they face the public in this business; they regard the public discussion space, and culture, and accountability, and the pursuit of criticism as optional. If this is how they are structurally obliged to visualize even their fellow citizens of the industrialized societies, imagine how much more marginal the proletariat of the Third World must seem to them. Now, perhaps, it is becoming clearer why the moribund state and possible revitalization of the sense of wonder in the circles of science becomes an issue for cultural studies. The basic question is how to retrieve the Cognitive from its hijack by the Industrial. Science is a special case of the codified centralization of knowledge, handing over all knowledge to machines that save perceptual labour; scientists are bound to fall for such a labour-saving device as if it were a form of rationality, trained as they have been to regard formalization as a device that beneficently helps them to escape from... words!

One might wish to argue that scientists should be persuaded to revisit mathematically the non-mathematic expository devices in their texts, namely, words; and to work for a qualitative revolution that would make them aware of the potentials of these devices and how they interact with the fruits of the quantitative one. I am deliberately not making that argument, which if made would in my opinion reinforce the bureaucratic codification of cognition into inappropriately industrial forms. Language does indeed have something to do with the retrieval of the cognitive from its hijack by the industrial. But this cause is not best served by asking scientists to add some linguistics to their basic mathematical training. The problem lies deeper. The scientization of knowledge as a whole has encouraged and intensified the process of robbing cognition of its local action lines, striving to derive them without residue from potentially global forms of force. Call this process the Politics of the Conceptual. We have seen why the process of Codesetting inevitably produces the political as an effect, as a device for saving local perceptual labour.

As in other cases of inappropriate, premature and excessive industrialization, the natural response is to devolve some energies to locations where their application is needed, and thus to deindustrialize. In other words, one tries not to save perceptual labour by ceasing to teach the supremely 
intelligent Chef how to cook everything for every place, by pausing to notice that women and other nurturing agents ubiquitously, but differently, produce locally needed nourishment locally anyway. In listening to and responding to what is heard, one's actions change, and the Emperor refrains from some of the mega-speaking he would do to keep proving that he is globally cleverer than any local proletariat can be locally clever. This means that some of the Emperor's centrally controlled global speaking - the Politics of the Conceptual-must be replaced by what I shall call the Strategy of the Perceptual, which involves a method of listening to local realities without insisting that what all the sensitive listeners hear add up, without insisting that all small-time listeners hand over their surplus listening to some supremely intelligent big-time ear. It is this transition that we are struggling to find enough courage to negotiate, in our difficult times.

\section{The Post-Missionary Condition ${ }^{7}$}

We are living at a time when it is possible to put forward the following arguments, and expect most of our readers to agree:

(6) Translation was born under the mark of the Missionary moment, in the sense that that type of translation has become the kind that codifies and organizes other kinds. Users agree that missionary translations are grossly infelicitous.

(7) Semantically based accounts of translation, that is, translation theories, arise under the aegis of second-wave missions that are corrected by the apparatus of knowledge, and can be called secular. Users agree that translation theories grossly overspecify semantics.

One way to characterize the time when these are nearly default opinions, is to call this collective state of mind the Postmissionary condition. Missionaries proper, representing classical scriptures that they believe must be transmitted to everybody before real history can begin, often failed in their mission because they worked for a bureaucracy that was directing their actions. Their naïve fundamentalism has given way to today's sophisticated foundationism in the mainstream agendas of development. The foundationists sponsor translation theories with knowledge of, and sometimes in response to, the failures of the first-wave translation enterprise. If these theories seem to overspecify certain details and thus fail at the level of characterizing the task-despite some acknowledged successes in the translation itself - then we cannot treat this failure as identical to that of fundamentalism. Foundationism has been trying to get too much "right," too systematically. Systematization of this kind inevitably leads to bureaucracy, which was what was wrong with the missionaries in the first place. More 
specifically, the problem with this second wave of systematic translation is that translators are encouraged to be very careful with their tools, with the authorial intentions they do or do not wish to respect, and with other items. Being very careful involves trying to be technical with respect to some technique. The work of ensuring that that body of technique is maximallyand increasingly — excellent is centralized in some team of academics and potential translator trainers. Consequently, it turns out that what translators are giving their audiences, even when it appears to be in ordinary language and thus not to be technical, is mediated through the precision-ensuring external authority of a bureaucracy of technique managers. The translator's use of language thus becomes indirect in the way that technicalese does: it creates a care-induced distance, somewhat akin to communicators speaking loudly to overcome the barrier of physical distance. It is these specific effects that concern me here.

Some have been scapegoating linguists for the failures of the second wave of translation, and trying to steer translation studies away from linguistics-using paths. Sophisticated versions of critiques of the second wave will no doubt identify its failure in terms of bureaucracy and system-building. We all, linguists included, would like to deal with the problems of the second wave; but to do this, we need at least a viable diagnosis and some alternative proposals to try out. The diagnosis that I am offering says in more detail that the missionary methods are conceptual in principle: they assume that there is some teachable, right way to do things that can be made to work for "other cases" in advance, without having to negotiate them with the perceptions of new populations. This politics of mobilization (of translation trainees) and of concepts (that provide the content imparted to these victims) is shared by both the developmental second wave and the fundamentalist first wave. It is convenient to visualize all the believers in this politics as being missionaries, old and new.

The package of alternative proposals that I wish to offer focusses on the idea that translators are trying to serve the cause of Reperception. Given the foregoing, we cannot afford to prepackage any systematic recipes for the work of translators; the alternatives must explore other useful avenues: how to help translators cross barriers without falling into a centralizing trap? Translators have to find ways to listen carefully to what the SL text is saying to its audiences listen again to how various TL texts work with their audiences and gently - keeping in touch with the way they have been finding their own place in both societies (never a completed task)-make room for the translation as a text that audiences can Perceive. Translators want their audiences to Perceive the original Perceiving also, or the range of earlier Perceivings of the SL text. This is what I mean by Reperception. Translators' labour is thus interlocal. The issue is not whether translators should be 
encouraged to write a text that is verbally different from what some current school of translatology would encourage them to produce as an appropriate translation, but how to help them further this Reperceptual mode, and avoid the Conceptual one. I am not arguing in favour of translations differing from what any ideal recipe would cook up; I am more concerned with the question of the choice of focus for a translation enterprise. A lot of energy and theoretical effort is expended on translation from LELs into MELs. My argument, if on the right track, proposes a need to bring about some balance of trade for other than commercial reasons. The translators' craft needs not to be retooled, but detooled so that translators rely less on recipes, and more on taste or sense. They need to mediate between the two listenings-to the SL text and to the TL text-and not between the SL Emperor's speech as they think the first elite would have it and the TL Emperor's speech as they think the second elite would have it. A conceptual politics of mobilization is an utterance, a directive of some sort; the translators' task is to be perceptual, they must be preconception-fighting listeners who are constantly discovering preconceptions to fight.

The basic cultural act of living as a member of a community is also the one that enables us a space elsewhere, across relevant barriers: it is the act of explicit reciprocal guesthood, where each of us gives space to the other in a transaction, and adjusts to the way the other gives space to us. This continuous adjustment depends crucially on reciprocal perception, which must include Reperception in its constitutive movements, and which can be called Reciprocal Attention. In attending to each other's needs and wishes, we stop regarding some elements of what we hear as crucial and others as simply irrelevant, for listening works on several planes of relevance and finds ways to treat everything we hear as relevant on some plane or other. This causes a displacement out of a rationality that idealizes, that is impatient about interruptions or distractions, into a different reasonableness. The moment this basic cultural act fails, we lapse from understanding into gestures that lead toward bureaucracy. For activities constituting the cultural to stay alive as they cross barriers, a practice of undistractable attention is needed. Bureaucracy is a Memory system, it is a labour-saving device that enables one to avoid having to pay Attention!

Reperception is a useful notion for the operation that needs to be performed in the traffic between metaphoric systems that make perception possible within the space of a text's key terms. This labour is best carried out in the public domain that concerns all communities, but belongs to no specific culture. Such a public domain exists at least because the ethic of science presumes that everybody is trying to pool their percepts, as empirical and conceptual material, for a universal cognitive project. ${ }^{8}$ The labour of Reperception is best carried out in the negotiative discourse of the public 
wearing the hat of Universal Public, not in the nationalist moment of pledging allegiance to a particular cultural flag, coded under some specified or specifiable bureaucratic system of concepts. In fact, codes, in the relevant sense, tend toward the patriarchal, hierarchical form that all bureaucratic institutions are patterned on. They presume that the relevant concepts in a given, specific domain will be just that, sitting next to each other in conceptual space, uninterrupted. This picture resembles the usual idealization of a specific labour as a set of connected activities that add up, uninterrupted, to the ends for which the means are being rationally and specifically deployed; any distractions that would get in the way are excluded from the idealization. And the usual idealizations, and the idea of rationality they rest on, are patriarchal. This mode of seeing sees only the connected labour that rational producers put in, and ignores the necessary interruptions associated with the daily and other routines of nurture, domesticity, leisure and sleep, and of having people (typically women) outside a given work process clean up and tie loose ends to "help," to Supplement producers, who are conceptually construed as men, even if they now empirically include a large number of women. Any alternative to codes has to take a clear look at this pattern of seeing and work a way out of this "common" sense toward a different sense equally rooted in the common practices of our living. The term Supplement signals a place where the uncommon sense of certain theoreticians can usefully intersect with this task.

A politics of Reperception has to work at the level of discourse, a flow of spoken and written activity where the performers are explicitly each other's guests, taking and giving space and aware that this is the fundamental act of culture. Once all the interruptions and the essential reasons for them are put back in the image of productive labour, it becomes possible to see that the ongoing task of looking after the labour, normally left to the hierarchy of institutions, can only sustain itself as a Discourse, not as a mere practice subordinated to an extra-practical Code that tells those under the Code what productive acts to perform. If the public space is a Discourse in this sense, which resists the Code and does not accept the proffered role of merely Supplementing it, and if the idea that it is a public space can hook up with the public-constituting function of science as a generalized knowledge-discourse claiming to have the neutral means to cut across irrelevant cultural barriers, then the problem of how to characterize translators' labour of Reperception performed in this public space to cross barriers can be placed in our more general exploration of the role of courage in the construction of a postcolonial living space.

At this point it becomes useful to revisit our diagnosis of what is wrong with the missionary mindset and put these considerations in touch with the problematic of accountability: 
(8) The prototypical Missionary condition is a case of non-accountability, the kind that traps itself in a web of recipes.

The first-wave failure of practice stems from a bureaucracy's inability to perceive and cope with detail. The second-wave failure of theoretically careful systematicity reflects a knowledge-system's excessive effort to get it right. This effort leads to overprecise technicalizations, which, I shall argue, are loud. My argument is part of an attempt to address these two failures of accountability, both of which are still active in our theoretical inheritance. This attempt can usefully begin with the question of why the field of translation studies continues to pursue pedagogical theories that codify such practices. My provisional answer is that a plurality of sectoral practices in today's traffic gives rise to a plurality of theories. For example, life keeps throwing up charismatic figures whose texts must, for their adoration industries, be scripturally rendered into the world's languages. Hence the survival of fundamentalist methodologies asking how the charisma can be maintained or otherwise made available for foreign worshippers. In another sector, the boy scouts of industrial development still believe in a foundational exactitude needing to be fed by the myth of accurate translatability. This is why some semantically oriented translation theories keep asking what the author would want done if he/she could read the TL texts to check how scrupulously the translations respect his/her intentions. These sectors of practice nourish these types of theory as codifications.

Notice that this discussion uses the terms Practice and Codification, which presume that the form of labour is centrally controlled by a codified theory and a pedagogy that specifies it for the practitioners. Only a practice that is organized in a way that lacks self-sufficient relay systems needs such a set-up. The idea of a technicalization is that you and I do not have enough in common to be able to get across to each other, so we hand over part of our talking time to the voice of authority emanating from some expert segment of the community. We let the experts tell us on what basis, and with what words, we should address each other. When we do this, throwing technical terms at each other like practised wielders of weapons, we announce to each other, and to eavesdroppers, that you are so distant from me, and I from you, that we have to SHOUT. It is in this sense that technical terms are loud. Loudness is a thread that runs through both phases of the world's missionary history, from the preachers who had to project their voices, right down to the development preachers who have machines and verbal Equipment do it for them. As a counterpoint to this, we are here getting ready to learn how to be quiet and slow enough. Only if we are mutually hospitable across cultural barriers will real and sustainable perception be possible. Bureaucracies do not have guests because they cannot be guests; they can only provide asylum, and asylums are intrinsically hierarchical institutions, 
bound by the rules of loudness. A discussion of how not to get trapped there would use the alternative terms Praxis and Discourse. A Praxis is a way of acting that has the courage to set its own rules as it goes along and does not systematically leave to some external expert subcommunity the task of holding the rules for this practice. A Discourse is a Praxis which, to ensure accountability, self-consciously and bravely includes its own talking about itself—not leaving "irrelevant" things out, not editing its "civilian" deshabillé into some "official, mobilized, military" costume embodying somebody's norms of correctness. Only the discursive accountability imperative, if taken seriously, will help us out of the bureaucratic trap that all methodologies tend to push us into.

We who wish to outgrow the missionary mindset must part company with the standard assumptions surrounding scientific activity as currently visualized. For scientific work takes mobilization for granted; it assumes that rationality must take a mobilized form. Certain dissidents have of course found Understanding, which they sometimes call Verstehen even in English, to be incompatible with the assumption that rationality must mobilize. These dissidents argue that the pursuit of Verstehen must do business with the business of civility that precedes and surrounds the scientific component of civilization. ${ }^{9}$ The problem with science as standardly visualized-though its practice often tacitly improves on these visualizations-is that it is committed to centralizations that leave the makers and users of the verbal Equipment that is supposed to deal with local realities completely undistracted and undisturbed, consequently unaccountable to the local populations, which, through their daily residency in the relevant locations, have knowledge that would make them excellent interactive critics of such Equipment if it were not insulated from their discourses. This problem spills over into language planning and terminology standardization activities which are designed to give LELs a share in the precision available to MELs. ${ }^{10}$

It is very hard for an industry to keep trying to be brave or accountable: one tends to surrender one's courage to the superior officers in the army, and let them worry about whether the armed forces as a whole are being brave about anything at all. The question I wish to raise is whether scientists, in the real conditions under which they work today, can afford to even imagine being accountable, and whether, given the answer to that question, they can continue to see themselves as fearlessly, criticism-facingly trying to find true, sustainable answers to hard questions. My query also addresses the rest of us, other members of industrial societies and their satellites, to the extent that our patterns of explicit or implicit cheering lock the scientist-athletes who perform on our behalf into demonstrably inquiry-destroying mindsets. 
What I am suggesting is that the appropriate response to the post-missionary condition is working a way out of the missionary mindset by striving for greater accountability. We can begin by requiring accountability from ourselves in dialogue with our friends and colleagues who, in complicity with the military-industrial complex that holds inquiry hostage, have been taking part in actions that reduce or destroy the possibility of courageous mental labour in the pursuit of the types of knowledge, including especially science, that seem to interest users across cultural boundaries - and thus to intersect with the enterprise of translation. This leads, on reflection, to a certain danger: if I work my way out of memory-laden systems of recipes and become free-floating, do I end up trying to catch the Attention of some public in the mode of advertising? Does my escape from the ancien régime's Archive leave me in some equally courage-undermining modern Arcade? As an advertiser of wares one is indeed initially caught in the Arcade mode, and needs to square this with the earlier self-image as an Author of a Text whose web of Concepts is intended-for eternity-for an Archive embodying the social Memory. Nothing quite cancels that self-image. A Perceptual overlay shapes the way any of this can function; it is only when some imagined merely Perceptual level of our work is exaggerated that we lapse into ephemerally quotidian copywriting. If we resist that, we can see the Perceptual as the material richness that it is, as the situated reality of our conceptual intervention as a translator. How then can our Perceptually conscious Arcade generations spontaneously resisting bureaucracy ${ }^{11}$ retrieve and reachieve the standards of the Conceptually visualized Archive? How, in other words, can a strategy of reperception make its problematic-initially given as a here and now grappling with a particular dyad of texts - more general? Is it possible for interlocal labour to generalize? Is there a way that generalization does not turn one into yet another bureaucrat who grows impatient with distractions or interruptions that are contingent matters of any situation? Can we avoid imagining that contingent cases are inappropriately tempting us to take their local problems too seriously? And can we also manage to work freely with our locations, without lapsing into the Arcade mode, servile to the mercenary exigencies of the moment? ${ }^{12}$ To put the question more concretely: is there some rigorously interlocal way to reinvent a figure like the ancient Indian materialist Caarvaak, who affirmed perception and denied even inference? As an Indian who would like to claim that inheritance, it seems to me that there is, if we can learn-and work with parts of the public that are brave enough to try to learn-how to perceive conclusions in premises, instead of performing bureaucratically computed steps to formally arrive at deductions that the problem solver cannot personally see.

The considerations outlined above are best read as a succession of images with captions designed to present, in a journalistic mode, the 
possibility that patriarchal code-like arrangements in prevalent institutions may be impeding the cross-cultural traffic whose universality continues to be posited in the rhetoric associated with science and its industrial concomitants. I would like to suggest that the biggest enemy of universal cognitive traffic, and of the local cultivation of cognition presupposed by the image of such traffic, is industriality itself, the principle of centralization and the bureaucratic rationality that conceptually organizes groups of relevant entities to the exclusion of the irrelevant interruptions that supposedly distract our attention from them. My point is that these well-founded interruptions form an essential part of that which a reasonable perceiver would wish to perceive, with full local detail; that a sustainable rationality would look very different from this; and that patterns of real and potential attention should be on the agenda of translation studies, as translators have the job of modifying the objects and patterns of people's attention.

\section{Notes}

1. I wish to thank the Shastri Indo-Canadian Institute for providing me with a fellowship, which helped make this article possible.

2. But there is no reason to confine one's notion of real life to the occurrence of such social contacts. That both disciplines are using the same Greek resource in the same way-following paths which seemed separate during what may look to the future like a temporarily overspecialized and tool-oblivious phase of the history of scientific pursuits-is also a reality of the discursive life of metropolitan scientific inquiry today, even if its participants choose irrationally to ignore this reality.

3. That such a question cannot be discussed with scientists in the context of scientific research itself seems an irrelevant sociological fact, one that has no bearing on the issues themselves, which are important enough that thinking men and women in general should focus on them even if scientists do not wish to.

4. Such rethinking of scientific representations is unfortunately not brought about by the routine teaching of More Equipped Languages (MELs) to LEL speakers who become scientists.

5. Notice that (5) allows local action lines to continue independently of centralized modes of aggregating local knowledges into Codes; however, it is understood that that option exists. When it comes into play, (5) works with the Foucauldian equation and becomes Power/Knowledge, oversimplifying somewhat. In that scenario-which really invites a Platonic essentialization of the cobbler's trade for all cobblers of every time and place-the Concept of the Cobbler is produced.

6. This formulation I owe to a discussion with Rajendra Singh, professor at the Université de Montréal.

7. This section need not be read as completely dependent on the foregoing. My argument here is based on what I believe to be independently confirmable feelings shared by many of us in the house of translation. However, this section may also be considered a core, and the preceding material a theoretical preamble. De gustibus non disputandum est. 
8. At this point, it becomes important that scientific explorers discover that their universal inquiry cannot sustain itself, but needs a surrounding universal culture whose assumptions and practices make sustainable inquiry possible.

9. Some aficionados of dissident traditions, who may be reading these words, will develop pragmatic characterizations of technicality and mobilization to improve their own understanding of matters brought up here. When they do, I look forward to seeing the results, which I cannot arrive at unaided.

10. The terms Less Equipped Languages (LELs) and More Equipped Languages (MELs) enable me to place on the agenda the task of examining the equipment standardly assumed to be valuable. This standard assumption reflects the unexamined industrial ways of science.

11. Recall that (6) and (7) unpack a tacit consensus characteristic of the entire post-missionary generation.

12. There is the risk that a certain type of shift away from the Memory-Archive may tend to lead to some equally centralizing, market-driven Attention-Arcade. Do we know how not to move into that third-wave bureaucracy? Can the cultural turn in translation studies, which would glibly like to give up on linguistics, resist that slide? 
This page intentionally left blank 


\section{UNIVERSITY OF OTTAWA PRESS}

\section{Perspectives on Translation Series \\ Edited by Jean Delisle}

The Perspectives on Translation series consists of works that analyze translation from a theoretical or practical point of view. In addition to the history, methodology and theory of translation, the series covers lexicology, terminology, interpretation. Textbooks for students as well as for professional translators and interpreters can be found in the Didactics of Translation series. Both series welcome manuscripts written in either English or French.

Advisory committee:

Jean Delisle, Series Director, University of Ottawa

Marie-Christine Aubin, Collège universitaire de Saint-Boniface

Annie Brisset, University of Ottawa

Monique C. Cormier, Université de Montréal

Luise von Flotow, University of Ottawa

Daniel Simeoni, McMaster University

Lawrence Venuti, Temple University (Philadelphia)

Agnès Whitfield, York University

In the same series:

Jean Delisle and Judith Woodsworth, Les Traducteurs dans l'histoire, 1995.

Clara Foz, Le Traducteur, l'Église et le Roi, 1998.

Francesca Gaiba, The Origins of Simultaneous Interpretation: The Nuremberg Trial, 1998.

Jean Delisle and Hannelore Lee-Jahnke (eds.), Enseignement de la traduction et traduction dans l'enseignement, 1998.

Ruth A. Roland, Interpreters as Diplomats: A Diplomatic History of the Role of Interpreters in World Politics, 1999.

\section{In the Didactics of Translation series:}

Jean Delisle, La Traduction raisonnée. Manuel d'initiation à la traduction professionnelle de l'anglais vers le français, 1993.

Jean Delisle, La Traduction raisonnée. Livre du maître, 1993.

Allison Beeby Lonsdale, Teaching Translation from Spanish to English, 1996. 
@

Le papier utilisé pour cette publication satisfait aux exigences minimales contenues dans la norme American National Standard for Information Sciences Permanence of Paper for Printed Library Materials, ANSI Z39.48-1992.

\author{
C) Aamv Marquis \\ MEMBRE DU GROUPE SCABRINI \\ Québec, Canada \\ 2000
}

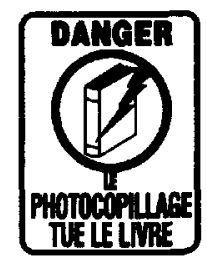

